Universidade de São Paulo

Faculdade de Filosofia, Ciências e Letras de Ribeirão Preto

Departamento de Química

Programa de Pós-Graduação em Química

\title{
Síntese e Caracterização de pentafluorofenil-piridil-porfirinas substituídas com complexos de rutênio.
}

\author{
Emmanuel Zimmermann Moreira \\ Dissertação que será apresentada à Faculdade de \\ Filosofia, Ciências e Letras de Ribeirão Preto da \\ USP, como parte das exigências para a obtenção do \\ título de Mestre em Ciências, Área: Química.
}

Ribeirão Preto -SP 
Universidade de São Paulo

Faculdade de Filosofia, Ciências e Letras de Ribeirão Preto

Departamento de Química

Programa de Pós-Graduação em Química

\title{
Síntese e Caracterização de pentafluorofenil-piridil-porfirinas substituídas com complexos de rutênio.
}

\author{
Emmanuel Zimmermann Moreira
}

Dissertação que será apresentada à Faculdade de Filosofia, Ciências e Letras de Ribeirão Preto da USP, como parte das exigências para a obtenção do título de Mestre em Ciências, Área: Química.

Orientadora: Profa. Dra. Yassuko Iamamoto

Ribeirão Preto -SP 


\section{FICHA CATALOGRÁFICA}

Moreira, Emmanuel Zimmermann

Síntese e Caracterização de pentafluorofenil-piridil-porfirinas substituídas com complexos de rutênio. Ribeirão Preto, 2007. $114 \mathrm{p}$.

Dissertação de Mestrado, apresentada à Faculdade de Filosofia de Ribeirão Preto/USP - Área de concentração: Química.

Orientadora: Ribeiro, Iamamoto, Yassuko.

1. Porfirina. 2. Complexo de Rutênio. 3. Eletroquímica. 4. Luminescência. 
"A imaginação é mais importante que o Conhecimento."

(Albert Einsten) 


\section{Dedico}

Aos meus pais

Vocês foram às pessoas mais importantes em todo esse grande percurso. Sem vocês eu já teria desistido faz tempo. Obrigado por vocês me mostrarem o maravilhoso caminho dos estudos. Agradeço pelo suor por vocês derramado, pela luta e pela confiança em mim depositada, para que um dia eu pudesse me tornar uma pessoa com um pouco mais de conhecimento.

Amo vocês Tininha e Luizinho.

A minha irmã

Obrigada pelos ótimos momentos vividos e pelo seu incentivo nos momentos em que eu estava desanimado e sem rumo na vida. Agradeço por você agüentar meu mau humor nas horas em que eu me encontrava angustiado. Agora minha querida irmãzinha, mas uma etapa do ciclo da vida chega ao fim. É muito bom poder acordar e ver que nós e nossos pais formamos uma linda família, e espero que esta família continue assim pela eternidade.

Amo você Dandan. 


\begin{abstract}
A minha namorada Tatiana
"A distância não é ruim, ela apenas nos mostra o quanto é bom estarmos juntos." Adoro poder estar junto a ti, e são nesses momentos que eu consigo relaxar e ter calma para tomar as decisões mais corretas, porque eu penso em como aquela decisão vai afetar a nossa vida como um casal. Obrigada pela sua calma, paciência e por sempre estar disposta a me ajudar mesmo entendendo pouco daquilo que eu pesquiso.

Amo você, é muito bom realizar qualquer tarefa ao seu lado.
\end{abstract}

Obrigado por você ter aparecido em minha vida. 
Agradecimentos

À Professora Yassuko pelas discussões e pela liberdade de trabalho durante todos esses anos.

À Professora Sofia Nikolaou pelas discussões e por colaborar intensivamente na realização deste trabalho.

Ao Professor Serra pela sua disposição em sempre querer ajudar.

Aos Professores prof Luiz Alberto Beraldo de Moraes, Marcos Nogueira Eberlin e Norberto Peporine Lopes pelos espectros de massa.

À Professora Zenis e ao professor Roberto Santana pelo auxílio na eletroquímica.

Ao meu amigo Fábio Vinhado (Cozido) pela sua grande paciência, por ter me apresentado ao mundo porfirínico e pelas boas risadas.

Às minhas amigas Tatiana e Mariana que sempre se mostraram muito prestativas, amorosas e estiveram ao meu lado em toda a graduação e em todo esse mestrado.

Aos meus amigos Paulão, Ana Cecília, Ana Paula, Nathália e todos aqueles que pertencem a 38ª Turma de Química da USP-RP.

À minha amiga Christiane pelas discussões, pelas risadas nas aulas de espanhol, pela ajuda no inglês do abstract e por me mostrar outra forma de enxergar o mundo.

Ao meu amigo Rômulo por me mostrar que um químico precisa ter uma vida social.

Aos colegas de Laboratório Bioinorgânica e Terras Raras: Alba Denise, Ana Masson, Aninha, Anderson, Carla, Caco, Cinara, Cláudio, Fernanda, Heide, Janaína, Lívia, Luciana, Luciano, Looser, Maria Sílvia, Marquinhos, Paulinha, Priscilla, Rebeca, Patrícia, Pitião, Simone e Vinícius.

Aos funcionários e alunos da Farmácia e da Química que de alguma forma contribuíram para a realização deste trabalho.

À FAPESP pela bolsa concedida. 


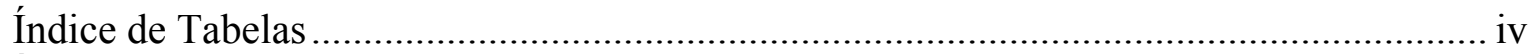

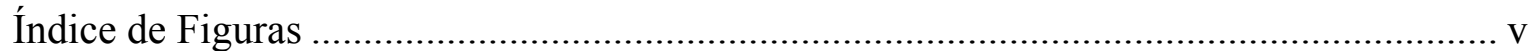

Abreviaturas e Símbolos...........................................................................................

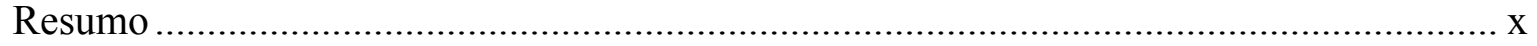

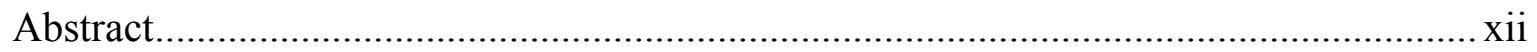

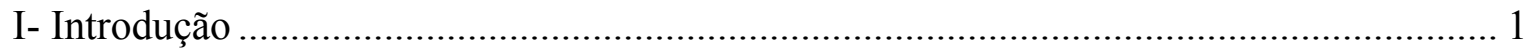

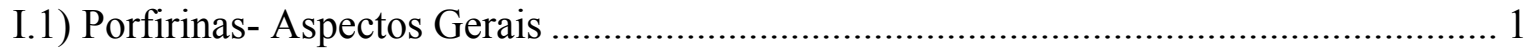

I.2) Síntese de Porfirinas .......................................................................................... 3

I.3) Espectros Eletrônicos de Absorção...…………………………………………….... 6

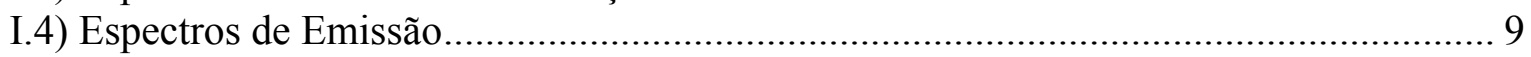

I.5) Sistemas mistos - combinação de porfirinas com cluster trinuclear de rutênio

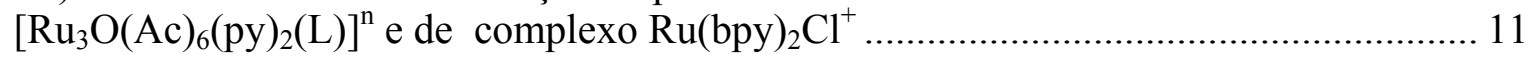

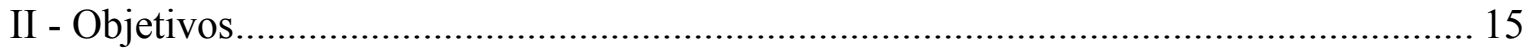

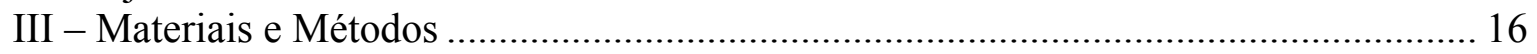

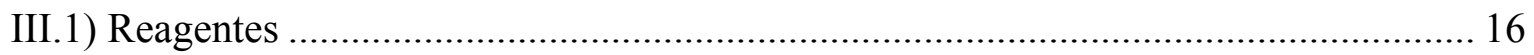

III.2) Síntese dos Complexos Metálicos...................................................................... 17

III.2.1) Síntese do cluster assimétrico $\left[\mathrm{Ru}_{3} \mathrm{O}(\mathrm{Ac})_{6}(\mathrm{py})_{2}\left(\mathrm{CH}_{3} \mathrm{OH}\right)\right] \mathrm{PF}_{6} \ldots \ldots \ldots \ldots \ldots \ldots \ldots \ldots \ldots . . \ldots 17$

III.2.1.1) Síntese do cluster mãe $\left[\mathrm{Ru}_{3} \mathrm{O}(\mathrm{Ac})_{6}\left(\mathrm{CH}_{3} \mathrm{OH}\right)_{3}\right] \mathrm{CH}_{3} \mathrm{COO} \ldots \ldots \ldots \ldots \ldots \ldots \ldots \ldots \ldots . . . . . . . . . . . . .17$

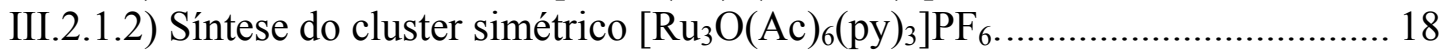

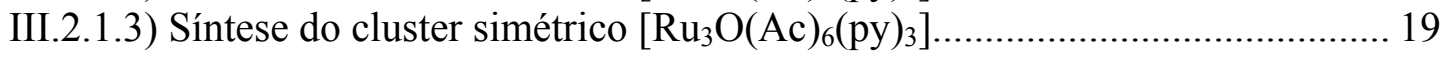



III.2.1.5) Síntese do cluster assimétrico $\left[\mathrm{Ru}_{3} \mathrm{O}(\mathrm{Ac})_{6}(\mathrm{py})_{2}\left(\mathrm{CH}_{3} \mathrm{OH}\right)\right] \mathrm{PF}_{6} \ldots \ldots \ldots \ldots \ldots \ldots . . .20$



III.3) Síntese de porfirinas 4-N-piridil e pentafluorofenil substituídas............................. 22

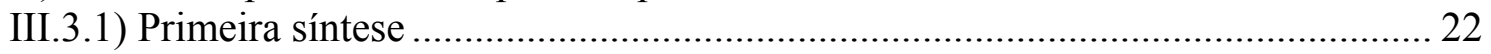

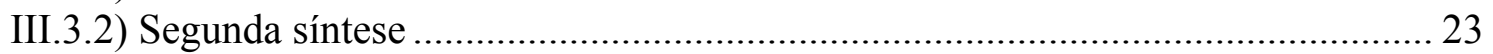

III.4) Pré-purificação, separação e purificação das porfirinas 4-N-piridil e pentafluorofenil substituídas por cromatografia em coluna .................................................................... 24

III.4.1) Tentativa de pré-purificação dos produtos da primeira síntese das porfirinas... 24

III.4.2) Separação das porfirinas 4-N-piridil e pentafluorofenil substituídas obtidas na primeira síntese, por cromatografia em coluna de sílica gel. ....................................... 24

III.4.3) Purificação das porfirinas base livre pentafluorofenil e 4-N-piridil substituídas

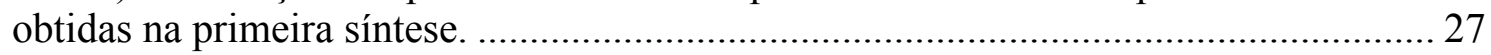

III.4.4) Pré-purificação dos produtos da segunda síntese das porfirinas......................... 29

III.4.5) Separação das porfirinas 4-N-piridil e pentafluorofenil substituídas obtidas na seguna síntese, por cromatografia em coluna de sílica gel.......................................... 29

III.4.6) Purificação das porfirinas base livre pentafluorofenil e 4-N-piridil substituídas

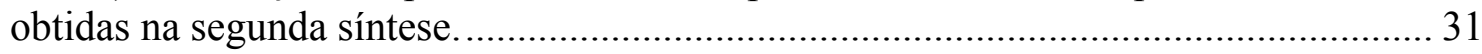

III.5) Síntese e purificação de supermoléculas ................................................................ 32

III.5.1) Síntese e purificação da díade [M(4-N-Py)TFPPH $\left.{ }_{2}\left\{\mathrm{Ru}_{3} \mathrm{O}(\mathrm{Ac})_{6}(\mathrm{py})_{2}\right\}\right] \mathrm{PF}_{6}$

(Supermolécula 1, Figura 21)............................................................................... 32

III.5.2) Síntese e purificação da díade $\left[\mathrm{M}(4-\mathrm{N}-\mathrm{Py}) \mathrm{TFPPH}_{2}\left\{\mathrm{Ru}(\mathrm{bpy})_{2} \mathrm{Cl}\right\}\right] \mathrm{PF}_{6}$

(Supermolécula 2, Figura 21) pelo método direto........................................................... 34

III.5.3) Síntese e purificação da díade $\left[\mathrm{M}(4-\mathrm{N}-\mathrm{Py}) \mathrm{TFPPH}_{2}\left\{\mathrm{Ru}(\mathrm{bpy})_{2} \mathrm{Cl}\right\}\right] \mathrm{PF}_{6}$

(Supermolécula 2, Figura 21) através da formação do aqua complexo

$\left[\mathrm{Ru}(\mathrm{bpy})_{2} \mathrm{Cl}\left(\mathrm{H}_{2} \mathrm{O}\right)\right]^{+}$..... 
III.5.4) Síntese e purificação da díade trans-[B(4-N-Py)BFFPH $\left.\mathrm{H}_{2}\left\{\mathrm{Ru}_{3} \mathrm{O}(\mathrm{Ac})_{6}(\mathrm{py})_{2}\right\}\right] \mathrm{PF}_{6}$ (Supermolécula 3, Figura 21). 36

III.5.5) Síntese e purificação da díade cis-[B(4-N-Py)BFFPH $\left.{ }_{2}\left\{\mathrm{Ru}_{3} \mathrm{O}(\mathrm{Ac})_{6}(\mathrm{py})_{2}\right\}\right] \mathrm{PF}_{6}$

(Supermolécula 4, Figura 21). 36

III.5.6) Síntese e purificação da tríade trans-[B(4-N-Py)BFFPH ${ }_{2}$

$\left.\left\{\mathrm{Ru}_{3} \mathrm{O}(\mathrm{Ac})_{6}(\mathrm{py})_{2}\right\}\left\{\mathrm{Ru}(\mathrm{bpy})_{2} \mathrm{Cl}\right\}\right]\left(\mathrm{PF}_{6}\right)_{2}($ Supermolécula 5, Figura 21) através da formação do aqua complexo $\left[\mathrm{Ru}(\mathrm{bpy})_{2} \mathrm{Cl}\left(\mathrm{H}_{2} \mathrm{O}\right)\right]^{+}$. 37

III.5.7) Síntese e purificação da tríade trans-[B(4-N-Py)BFFPH $\mathrm{H}_{2}\left\{\mathrm{Ru}_{3} \mathrm{O}(\mathrm{Ac})_{6}(\mathrm{py})_{2}\right\}$

$\left.\left\{\mathrm{Ru}(\mathrm{bpy})_{2} \mathrm{Cl}\right\}\right]\left(\mathrm{PF}_{6}\right)_{2}$ (Supermolécula 5, Figura 21) pelo método direto........................ 38

III.5.8) Síntese e purificação da tríade cis-[B(4-N-Py)BFFPH ${ }_{2}\left\{\mathrm{Ru}_{3} \mathrm{O}(\mathrm{Ac})_{6}(\mathrm{py})_{2}\right\}$

$\left.\left\{\mathrm{Ru}(\text { bpy })_{2} \mathrm{Cl}\right\}\right]\left(\mathrm{PF}_{6}\right)_{2}($ Supermolécula 6, Figura 21) pelo método direto......................... 39

III.6) Tratamento de Resíduo..................................................................................... 40

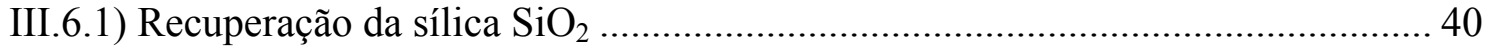

III.6.2) Recuperação de solventes (acetona, diclorometano)......................................... 40

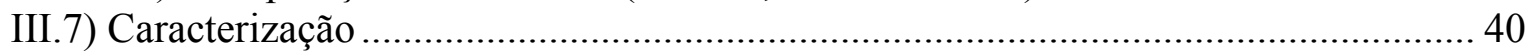

III.7.1) Espectroscopia Eletrônica .............................................................................. 41

III.7.2) Ressonância Magnética Nuclear ${ }^{1} \mathrm{H} \mathrm{e}^{19} \mathrm{~F}$....................................................... 41

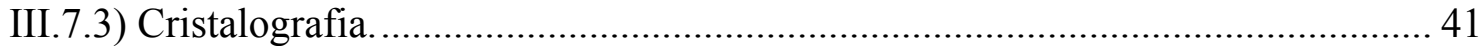

III.7.4) Voltametria Cíclica e Voltametria por Pulso Diferencial ................................... 42



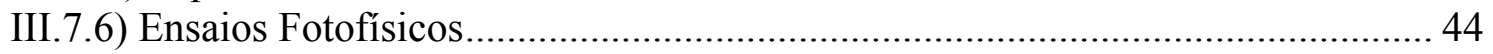

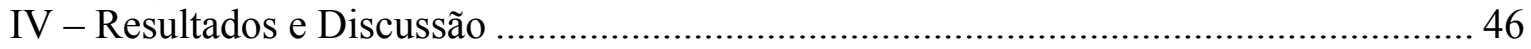

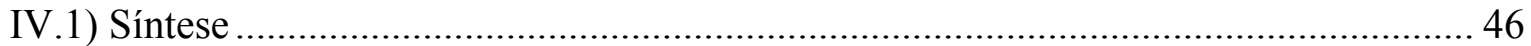

IV.1.1) Síntese de porfirinas base livre 4-N-piridil substituídas e pentafluorofenil....... 46

IV.1.2) Síntese da díade $\left[\mathrm{M}(4-\mathrm{N}-\mathrm{Py}) \mathrm{TFFPH}_{2}\left\{\mathrm{Ru}_{3} \mathrm{O}(\mathrm{Ac})_{6}(\mathrm{py})_{2}\right\}\right] \mathrm{PF}_{6}$ (Supermolécula 1,

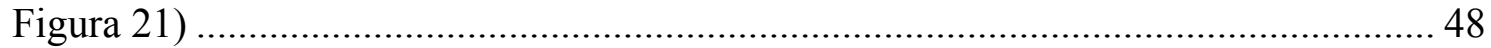

IV.1.3) Síntese da díade $\left[\mathrm{M}(4-\mathrm{N}-\mathrm{Py}) \mathrm{TFFPH}_{2}\left\{\mathrm{Ru}(\mathrm{bpy})_{2} \mathrm{Cl}\right\}\right] \mathrm{PF}_{6}$ (Supermolécula 2,

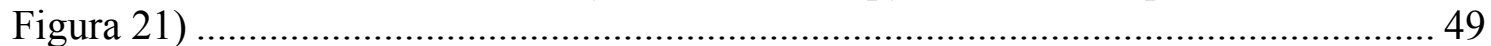

IV.1.4) Síntese das díades trans- e cis-[B(4-N-Py)BFFPH $\left.{ }_{2}\left\{\mathrm{Ru}_{3} \mathrm{O}(\mathrm{Ac})_{6}(\mathrm{py})_{2}\right\}\right] \mathrm{PF}_{6}$

(Supermoléculas 3 e 4 , Figura 21) .......................................................................... 50

IV.1.5) Síntese das tríades trans- e cis-[B(4-N-Py)BFFPH ${ }_{2}\left\{\mathrm{Ru}_{3} \mathrm{O}(\mathrm{Ac})_{6}(\mathrm{py})_{2}\right\}$

$\left.\left\{\mathrm{Ru}(\mathrm{bpy})_{2} \mathrm{Cl}\right\}\right]\left(\mathrm{PF}_{6}\right)_{2 \cdot 2}$ (Supermoléculas 5 e 6, Figura 21) ........................................ 51

IV.2) Espectroscopia Eletrônica .................................................................................. 52

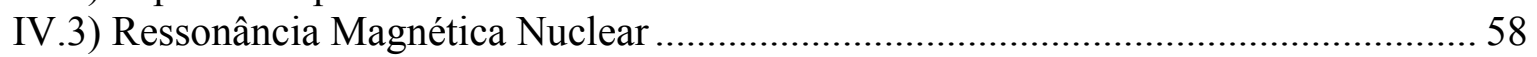

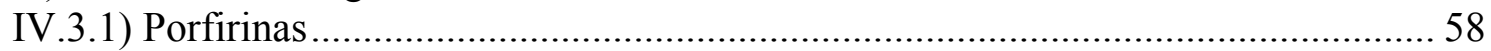

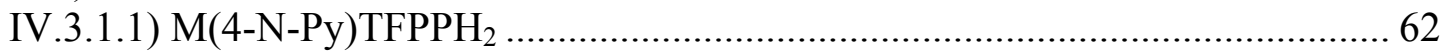

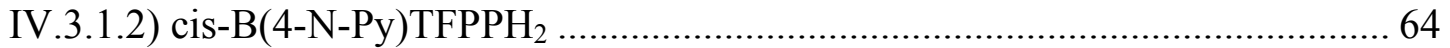

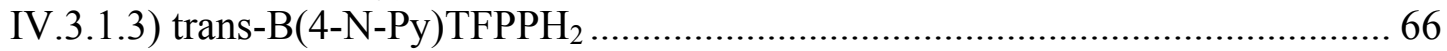

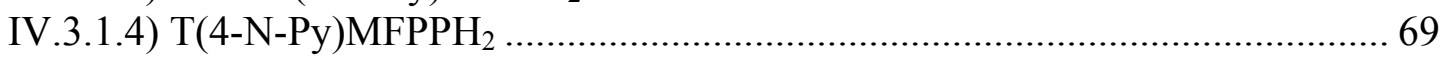

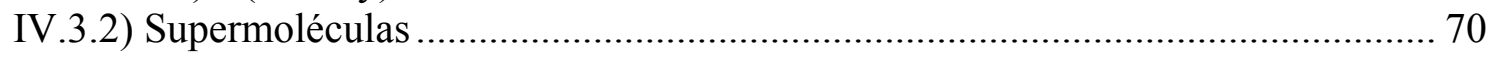

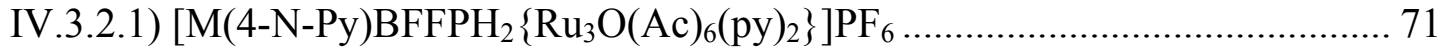

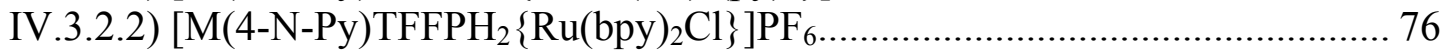

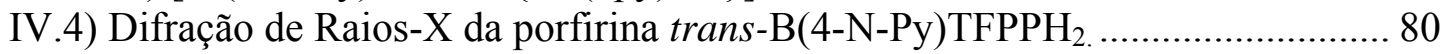

IV.5) Análise Estrutural por Espectrometria de Massa ………………………................. 85

IV.6) Voltametria Cíclica e Voltametria de Pulso Diferencial........................................... 95

IV .6.1.) Porfirinas: Voltametria de Pulso Diferencial .................................................. 95






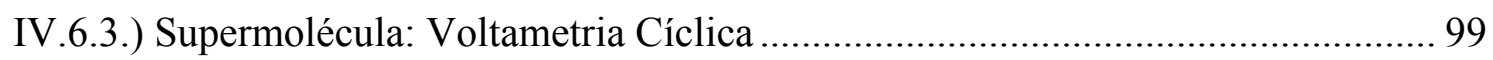

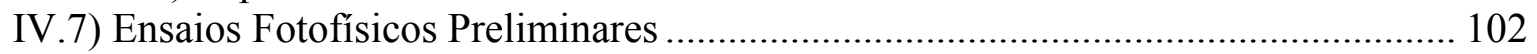

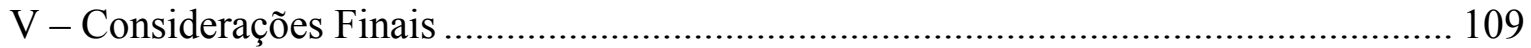

VI - Referências........................................................................................... 110 


\section{Índice de Tabelas}

Tabela 1: Procedência dos reagentes utilizados ........................................................... 16

Tabela 2: $\mathrm{R}_{\mathrm{f}}$ das diferentes porfirinas obtidas na síntese .......................................... 26

Tabela 3: Purificação das porfirinas M(4-N-Py)TFPPH ${ }_{2}$, trans-B(4-N-Py)BFPPH ${ }_{2}$ e cis-

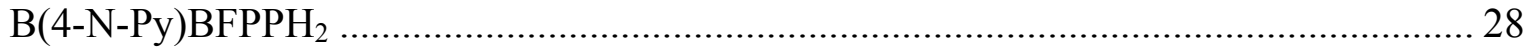

Tabela 4: Purificação das porfirinas trans-B(4-N-Py)BFPPH ${ }_{2}$, cis-B(4-N-Py)BFPPH ${ }_{2}$, $\mathrm{T}(4-\mathrm{N}-\mathrm{Py}) \mathrm{MFPPH}_{2}, \mathrm{~T}(4-\mathrm{N}-\mathrm{Py}) \mathrm{PH}_{2}$

Tabela 5: Comprimento de onda e logaritmo das absortividades molares $(\log \varepsilon)$ das bandas das moléculas sintetizadas

Tabela 6: Atribuição tentativa dos espectros de RMN ${ }^{1} \mathrm{H}$ das porfirinas sintetizadas ....... 60

Tabela 7: Atribuição tentativa dos espectros de $\mathrm{RMN}{ }^{19} \mathrm{~F}$ das porfirinas sintetizadas....... 60

Tabela 8: Atribuição tentativa dos espectros de $\mathrm{RMN}{ }^{1} \mathrm{H}$ da díade $\left[\mathrm{M}(4-\mathrm{N}-\mathrm{Py}) \mathrm{BFFPH}_{2}\right.$

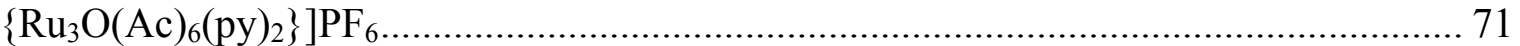

Tabela 9: Atribuições tentativas dos espectros de $\mathrm{RMN}$ de ${ }^{1} \mathrm{H}$ da díade [M(4-N-

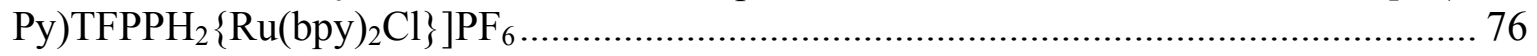

Tabela 10: Dados cristalinos e refinamento da estrutura trans-B(4-N-Py)TFPPH $2 \ldots \ldots \ldots . . .82$

Tabela 11: Coordenadas atômicas $\left(\times 10^{4}\right)$ e parâmetro de deslocamento isotrópico $\left(\AA^{2} \mathrm{X}\right.$ $10^{3}$ ) para a trans-B(4-N-Py)TFPPH $\mathrm{H}_{2}$, U(eq) é definido como um terço do traço do

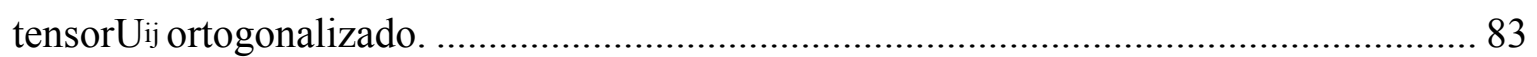

Tabela 12: Comprimento de ligação[Å] e ângulos $\left[^{\circ}\right]$ para a trans-B(4-N-Py) $\mathrm{TFPPH}_{2} \ldots . .84$ Tabela 13: Potenciais de meia onda da série meso- pentafluorofenil-piridil-porfirina, em DMF, a = pico anódico .98

Tabela 14: Potenciais de meia onda da porfirina e supermoléculas em ACN, a = pico

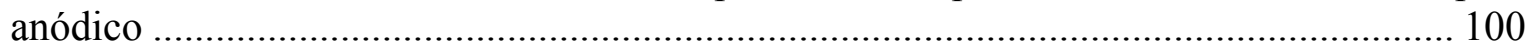

Tabela 15: Comprimento de onda e rendimento quântico das moléculas estudadas........ 104 


\section{Índice de Figuras}

Figura 1: Esquema da estrutura de meso-arilporfirinas...................................................... 1

Figura 2: Síntese da $\mathrm{TPPH}_{2}$ pela condensação entre pirrol e benzaldeído............................ 3

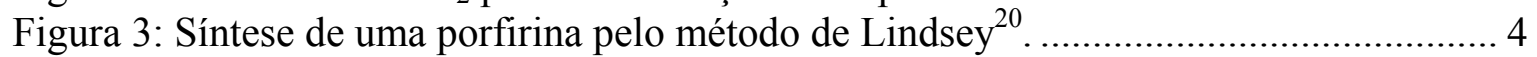

Figura 4: Síntese de uma porfirina simétrica do tipo $\mathrm{A}_{2} \mathrm{~B}_{2}$ pela condensação de ................ 5

Figura 5: Espectro UV-Visível de uma porfirina base livre............................................... 6

Figura 6: Transições eletrônicas no modelo dos quatro orbitais de fronteira ${ }^{33}$..................... 8

Figura 7: Transições eletronicas no modelo de quatro orbitais proposto por Goutermann a) quatro transições permitidas $b$ ) as transições $\mathrm{HOMO}-\mathrm{e}_{\mathrm{g}}$ que dão origem as bandas $\mathrm{B}$ e Q.8 Figura 8: Representação esquemática das possíveis transições eletrônicas. ....................... 10 Figura 9:Voltametria cíclica de $\left[\mathrm{Ru}_{3} \mathrm{O}(\mathrm{Ac})_{6}(\mathrm{pz})_{3}\right]$ ilustrando o comportamento. eletroquímico típico de clusters trinucleares de acetato de rutênio ${ }^{41}$................................. 12

Figura 10: Voltametria cíclica da TPP ilustrando o comportamento típico das porfirinas. 13 Figura 11: Representação esquemática das reações de transferência de elétrons fotoinduzidas em sistemas mistos. .......................................................................... 14

Figura 12: Estrutura do cluster mãe $\left[\mathrm{Ru}_{3} \mathrm{O}(\mathrm{Ac})_{6}\left(\mathrm{CH}_{3} \mathrm{OH}\right)_{3}\right] \mathrm{CH}_{3} \mathrm{COO}$......................... 17

Figura 13: Estrutura do cluster simétrico $\left[\mathrm{Ru}_{3} \mathrm{O}(\mathrm{Ac})_{6}(\mathrm{py})_{3}\right] \mathrm{PF}_{6}$................................... 18

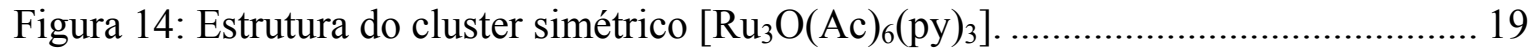



Figura 16: Estrutura do cluster assimétrico $\left[\mathrm{Ru}_{3} \mathrm{O}(\mathrm{Ac})_{6}(\mathrm{py})_{2}\left(\mathrm{CH}_{3} \mathrm{OH}\right)\right] \mathrm{PF}_{6} \ldots \ldots \ldots \ldots \ldots \ldots \ldots . . . . . . . . .20$

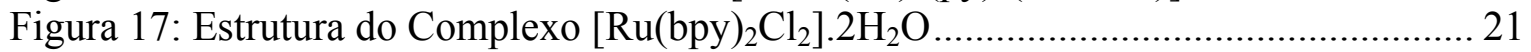

Figura 18: Porfirinas base livre obtidas nas sínteses...................................................... 22

Figura 19: Fluxograma de separação da primeira síntese das porfirinas............................. 26

Figura 20: Fluxograma de separação da segunda síntese das porfirinas............................. 30

Figura 21: Representação da estrutura das novas supermoléculas...................................... 33

Figura 22: Síntese de porfirinas 4-N-piridil e pentafluorofenil substituídas pelo método

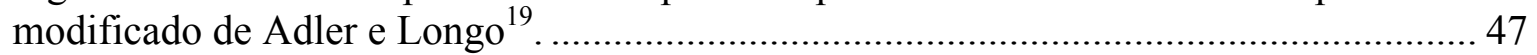

Figura 23: Espectro UV-Visível em DCM do meio reacional de porfirinas 4-N-piridil e pentafluorofenil substituídas (final da síntese).............................................................. 47

Figura 24: Espectro de UV-Vísivel de uma solução da porfirina M(4-N-Py)TFPPH ${ }_{2}$...... 53

Figura 25: Espectro de UV-Vísivel da série de porfirinas. ................................................ 53

Figura 26: Espectros de porfirina base livre dos tipos etio e phyllo................................... 54

Figura 27: Espectro de UV-Vísivel da díade $\left[\mathrm{M}(4-\mathrm{N}-\mathrm{Py}) \mathrm{TFPPH}_{2}\left\{\mathrm{Ru}(\mathrm{bpy})_{2} \mathrm{Cl}\right\}\right] \mathrm{PF}_{6}$ em

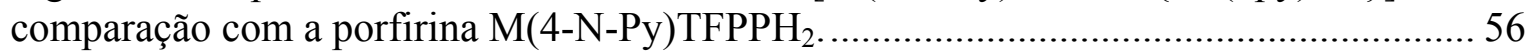
Figura 28: Espectro de UV-Vísivel da díade $\left[\mathrm{M}(4-\mathrm{N}-\mathrm{Py}) \mathrm{TFPPH}_{2}\left\{\mathrm{Ru}_{3} \mathrm{O}(\mathrm{Ac})_{6}(\mathrm{py})_{2}\right\}\right] \mathrm{PF}_{6}$ em comparação com a porfirina M(4-N-Py) $\mathrm{TFPPH}_{2}$..................................................... 57 Figura 29: Espectro de UV-Vísivel das díades substituídas com o cluster

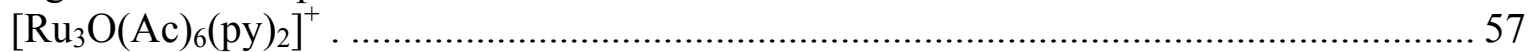

Figura 30: Espectro de UV-Vísivel comparativo das diferentes tríades obtidas com as

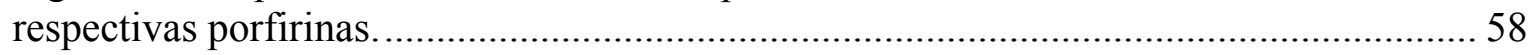

Figura 31: Esquema de numeração dos prótons das porfirinas.......................................... 59

Figura 32: Padrões básicos para o espectro de $\mathrm{RMN}{ }^{1} \mathrm{H}$ de prótons $\mathrm{H} \beta$-pirrólicos. ........... 61

Figura 33: Comparação do RMN ${ }^{1} \mathrm{H}$ das série meso-pentafluorofenil-piridil-porfirina. ... 61

Figura 34: Espectro de $\mathrm{RMN}$ de ${ }^{1} \mathrm{H}$ da porfirina $\mathrm{M}(4-\mathrm{N}-\mathrm{Py}) \mathrm{TFFPH}_{2}$ em $\mathrm{CDCl}_{3}$.............. 63

Figura 35: Espectro de $\mathrm{RMN}$ de ${ }^{19} \mathrm{~F}$ da porfirina $\mathrm{M}(4-\mathrm{N}-\mathrm{Py}) \mathrm{TFFPH}_{2} \mathrm{em} \mathrm{CDCl}_{3}$............. 63 


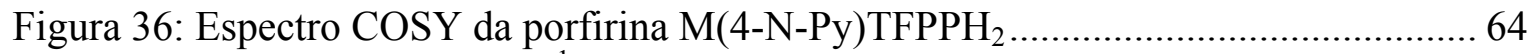

Figura 37: Espectro de $\mathrm{RMN}$ de ${ }^{1} \mathrm{H}$ da cis-B(4-N-Py)TFPPH $\mathrm{e}_{2}$ em $\mathrm{CDCl}_{3}$. ...................... 65

Figura 38: Espectro de RMN de ${ }^{19} \mathrm{~F}$ da porfirina cis-B(4-N-Py) $\mathrm{BFFPH}_{2}$ em $\mathrm{CDCl}_{3} \ldots \ldots . . .66$

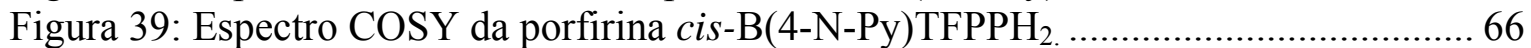

Figura 40: Espectro de $\mathrm{RMN} \mathrm{de}{ }^{1} \mathrm{H}$ da trans-B(4-N-Py)TFPPH ${ }_{2}$ em $\mathrm{CDCl}_{3} \ldots \ldots \ldots \ldots \ldots \ldots \ldots . .68$

Figura 41: Espectro de $\mathrm{RMN}$ de ${ }^{19} \mathrm{~F}$ da porfirina trans-B(4-N-Py)BFFPH ${ }_{2}$ em $\mathrm{CDCl}_{3} \ldots 68$

Figura 42: Espectro COSY da porfirina trans-B(4-N-Py)TFPPH 2 ................................. 69

Figura 43: Espectro de $\mathrm{RMN}$ de ${ }^{1} \mathrm{H}$ da porfirina $\mathrm{T}(4-\mathrm{N}-\mathrm{Py}) \mathrm{MFFPH}_{2}$ em $\mathrm{CDCl}_{3}$............. 70

Figura 44: Representação da estrutura da díade. [M(4-N-



Figura 45: Espectro de RMN de ${ }^{1} \mathrm{H}$ da díade $\left[\mathrm{M}(4-\mathrm{N}-\mathrm{Py}) \mathrm{TFFPH}_{2}\left\{\mathrm{Ru}_{3} \mathrm{O}(\mathrm{Ac})_{6}(\mathrm{py})_{2}\right\}\right] \mathrm{PF}_{6}$ em $\mathrm{CDCl}_{3}$; A) Ampliação na região de 9,0 a 7,0 ppm; B) Ampliação na região de 7,0 a 4,8 ppm; C) Ampliação na região de 1,5 a $-0,3$ ppm; D) ampliação na região de $-2,2$ a $-3,5$ ppm. (os números na figura correspondem ao valor da integral para cada sinal). ............. 74 Figura 46: Espectro de $\mathrm{RMN}$ de ${ }^{19} \mathrm{~F}$ da díade $\left[\mathrm{M}(4-\mathrm{N}-\mathrm{Py}) \mathrm{TFFPH}_{2}\left\{\mathrm{Ru}_{3} \mathrm{O}(\mathrm{Ac})_{6}(\mathrm{py})_{2}\right\}\right] \mathrm{PF}_{6}$

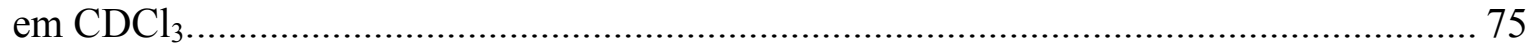

Figura 47: Espectro COSY da díade [M (4-N-Py)TFPPH $\left.\mathrm{H}_{2}\left\{\mathrm{Ru}_{3} \mathrm{O}(\mathrm{Ac})_{6}(\mathrm{py})_{2}\right\}\right] \mathrm{PF}_{6} \ldots \ldots \ldots . .75$

Figura 48: Estrutura da díade $\left[\mathrm{M}(4-\mathrm{N}-\mathrm{Py}) \mathrm{TFPPH}_{2}\left\{\mathrm{Ru}(\mathrm{bpy})_{2} \mathrm{Cl}_{3}\right\} \mathrm{PF}_{6}\right.$.......................... 76 Figura 49: Espectro de $\mathrm{RMN}$ de ${ }^{1} \mathrm{H}$ da díade $\left[\mathrm{M}(4-\mathrm{N}-\mathrm{Py}) \mathrm{TFFPH}_{2}\left\{\mathrm{Ru}(\mathrm{bpy})_{2} \mathrm{Cl}\right\}\right] \mathrm{PF}_{6}$ em $\mathrm{CDCl}_{3}$, A) ampliação na região de 10,3 a 7,0 ppm; B) ampliação na região de 0,2 a $-3,2$ ppm ( os números na figura correspondem ao valor da integral para cada sinal). ............. 79 Figura 50: Espectro de RMN de ${ }^{19} \mathrm{~F}$ da díade $\left[\mathrm{M}(4-\mathrm{N}-\mathrm{Py}) \mathrm{TFFPH}_{2}\left\{\mathrm{Ru}(\mathrm{bpy}){ }_{2} \mathrm{Cl}\right\}\right] \mathrm{PF}_{6} \mathrm{em}$

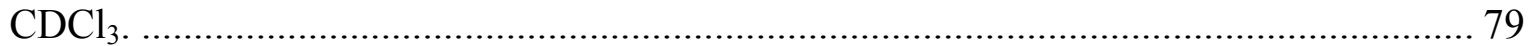

Figura 51: Espectro COSY da díade [M (4-N-Py)TFPPH $\left.\mathrm{H}_{2}\left\{\mathrm{Ru}(\mathrm{bpy})_{2} \mathrm{Cl}\right\}\right] \mathrm{PF}_{6} \ldots \ldots \ldots \ldots \ldots . . . .80$

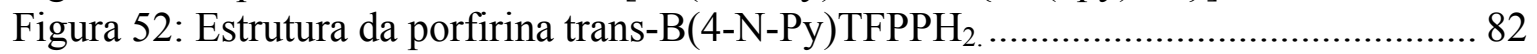

Figura 53: Diagrama da cela unitária da porfirina trans-B(4-N-Py) $\mathrm{TFPPH}_{2}$................... 82

Figura 54: Interação das nuvens $\pi$ entre moléculas da porfirina trans-B(4-N-Py)TFPPH ${ }_{2}$.

Figura 55: Espectro ESI MS da porfirina cis-B(4-N-Py)BFFPH ${ }_{2} \ldots \ldots \ldots$

Figura 56: Espectro ESI MSMS do íon m/z 797 da porfirina cis-B(4-N-Py)BFFPH ${ }_{2} \ldots \ldots . . .87$

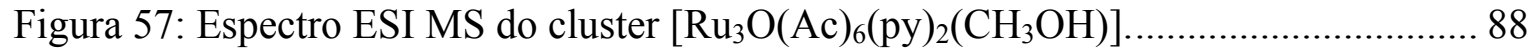

Figura 58: Espectro ESI MS da díade cis-[B(4-N-Py) $\left.\mathrm{BFFPH}_{2}\left\{\mathrm{Ru}_{3} \mathrm{O}(\mathrm{Ac})_{6}(\mathrm{py})_{2}\right\}\right] \mathrm{PF}_{6} \ldots . .89$ Figura 59: Espectro ESI MSMS do íon m/z 1629 da díade cis-[B(4-N-

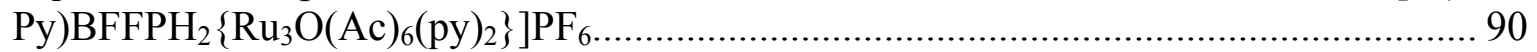

Figura 60: Espectro ESI MSMS do íon $\mathrm{m} / \mathrm{z} 815$ da díade cis-[B(4-N-



Figura 61: Espectro ESI MS da tríade cis-[B(4-N-

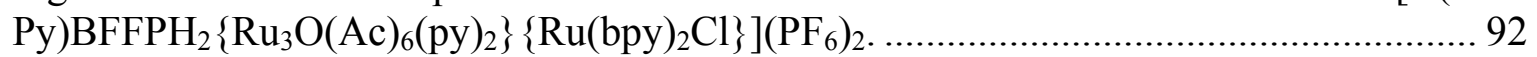
Figura 62: Espectro ESI MSMS do íon $\mathrm{m} / \mathrm{z} \quad 1039$ da tríade cis-[B(4-N-

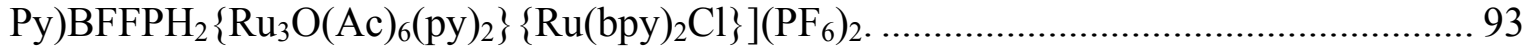

Figura 63: Espectro ESI MS da díade [M (4-N-Py)TFFPH $\left.\mathrm{H}_{2}\left\{\mathrm{Ru}_{3} \mathrm{O}(\mathrm{Ac})_{6}(\mathrm{py})_{2}\right\}\right] \mathrm{PF}_{6} \ldots \ldots . . .94$ Figura 64: Espectro ESI MS da díade $\left[\mathrm{M}(4-\mathrm{N}-\mathrm{Py}) \mathrm{TFFPH}_{2}\left\{\mathrm{Ru}(\mathrm{bpy})_{2} \mathrm{Cl}\right\}\right] \mathrm{PF}_{6} \ldots \ldots \ldots \ldots \ldots . . . . .95$ Figura 65: Voltametria de pulso diferencial na região catódica das soluções de porfirina com concentração de aproximadamente $1,0 \times 10^{-4} \mathrm{~mol} . \mathrm{L}^{-1}$ em DMF. Eletrólito 0,10 mol. $\mathrm{L}^{-1}$ de $\mathrm{TBAPF}_{6}$ em ACN. Velocidade de varredura $10 \mathrm{mV} / \mathrm{s}$. 97 
Figura 66: Voltametria de pulso diferencial na região anódica das soluções de porfirina com concentração de aproximadamente $1,0 \times 10^{-4} \mathrm{~mol} . \mathrm{L}^{-1}$ em DMF. Eletrólito 0,10 mol.L $\mathrm{L}^{-1}$ de $\mathrm{TBAPF}_{6}$ em ACN. Velocidade de varredura $10 \mathrm{mV} / \mathrm{s}$. 97

Figura 67: Comparação dos potenciais de redução das porfirinas. 98 Figura 68: Voltamogramas cíclicos de uma solução $1.10 \times 10^{-3} \mathrm{~mol}^{-1} \mathrm{~L}^{-1}$ da porfirina $\mathrm{M}(4-$ N-Py)TFPPH ${ }_{2}$ em ACN. Eletrólito 0,10 mol.L ${ }^{-1}$ de TBAPF 6 em ACN. Figura 69: Voltamogramas cíclicos de uma solução $1.10 \times 10^{-3}$ mol.L ${ }^{-1}$ da díade $[\mathrm{M}(4-\mathrm{N}-$ Py)TFFPH $\left.\mathrm{H}_{2}\left\{\mathrm{Ru}_{3} \mathrm{O}(\mathrm{Ac})_{6}(\text { py })_{2}\right\}\right] \mathrm{PF}_{6}$ em ACN. Eletrólito $0,10 \mathrm{~mol}^{-1}$ de TBAPF 6 em ACN. 101

Figura 70: Voltamogramas cíclicos de uma solução $1.10 \times 10^{-3}$ mol.L $\mathrm{L}^{-1}$ da díade $[\mathrm{M}(4-\mathrm{N}-$ Py)TFFPH $\left._{2}\left\{\mathrm{Ru}(\mathrm{bpy})_{2} \mathrm{Cl}\right\}\right] \mathrm{PF}_{6}$ em acetonitrila. Eletrólito $0,10 \mathrm{~mol}^{-L^{-1}}$ de $\mathrm{TBAPF}_{6}$ em acetonitrila. 102

Figura 71: Espectro de excitação de uma solução com concentração de aproximadamente $1,0 \times 10^{-6}$ mol. $\mathrm{L}^{-1}$ de porfirinas em DCM. 103

Figura 72: Espectro de emissão de uma solução com concentração de aproximadamente $1,0 \times 10^{-6}$ mol. $L^{-1}$ de porfirinas em DCM...... 103 Figura 73: Espectro de excitação das soluções das díades com concentração de aproximadamente $1,0 \times 10^{-6} \mathrm{~mol} . \mathrm{L}^{-1} \mathrm{em}$ DCM. ......................................................... 107 Figura 74: Espectro de emissão das soluções das díades com concentração de aproximadamente $1,0 \times 10^{-6} \mathrm{~mol} . \mathrm{L}^{-1}$ em DCM. 107 Figura 75: Espectro de excitação das soluções das tríades com concentração de aproximadamente $1,0 \times 10^{-6} \mathrm{~mol} . \mathrm{L}^{-1} \mathrm{em}$ DCM. ............................................................. 108 Figura 76: Espectro de emissão das das soluções das tríades com concentração de aproximadamente $1,0 \times 10^{-6} \mathrm{~mol} . \mathrm{L}^{-1} \mathrm{em}$ DCM. 108 


\section{Abreviaturas e Símbolos}

1D

2D

$\lambda$

$\varepsilon$

Ac

$\mathrm{ACN}$

ACT

CCD

$\mathrm{Cp}_{2} \mathrm{Fe}$

COSY

DCM

DMF

$\mathrm{E}_{\mathrm{pa}}$

$\mathrm{E}_{\mathrm{pc}}$

$\mathrm{EPH}$

$\mathrm{E}_{(1 / 2)}$

$\mathrm{EtOH}$

HOMO

IC

$\mathrm{I}_{\mathrm{pa}}$

$\mathrm{I}_{\mathrm{pc}}$

LUMO

MM

$\mathrm{MeOH}$

MLCT

$\mathrm{RMN}{ }^{1} \mathrm{H}$

$\mathrm{RMN}{ }^{19} \mathrm{~F}$

TBAPF $_{6}$

UV-Vis
Experimento de $\mathrm{RMN}{ }^{1} \mathrm{H}$ unidimensional

Experimento de $\mathrm{RMN}{ }^{1} \mathrm{H}-{ }^{1} \mathrm{H}$ bidimensional

Comprimento de onda

Coeficiente de absortividade molar

Acetato

Acetonitrila

Acetona

Cromatografia em camada delgada

Ferroceno

Correlated spectroscopy

Diclorometano

N,N'- Dimetilformamida

Potencial de pico anódico

Potencial de pico catódico

Eletrodo padrão de hidrogênio

Potencial eletroquímico de meia onda

Etanol

Orbital molecular ocupado de maior energia

Transições internas da unidade $\left[\mathrm{Ru}_{3} \mathrm{O}\right]$

Corrente de pico anódico

Corrente de pico catódico

Orbital molecular não ocupado de menor energia

Massa molar

Metanol

Transição de transferência de carga metal $\rightarrow$ ligante

Ressonância Magnética Nuclear de Próton

Ressonância Magnética Nuclear de Flúor

Hexafluorofosfato de tetrabutilamônio

Espectroscopia de absorção na região do ultravioleta e visível 
$\mathrm{TFPPH}_{2}$

$\mathrm{M}(4-\mathrm{N}-\mathrm{Py}) \mathrm{TFPPH}_{2}$

trans-B(4-N-Py)BFPPH cis-B(4-N-Py)BFPPH T(4-N-Py)MFPPH $\mathrm{T}(4-\mathrm{N}-\mathrm{Py}) \mathrm{PH}_{2}$

$\mathrm{TPPH}_{2}$ 5,10,15,20-tetrapentafluorofenilporfirina

5,10,15-tris(pentafluorofenil)-20-mono-(4-N-piridil)porfirina

5,15-bis(pentafluorofenil)-10,20-bis(4-N-piridil)porfirina 5,10-bis(pentafluorofenil)-15,20-bis(4-N-piridil)porfirina 5-mono(pentafluorofenil)-10,15,20-tris-(4-N-piridil)porfirina 5,10,15,20-tetra(4-N-piridil)porfirina 5,10,15,20-tetrafenilporfirina 


\section{Resumo}

Esta dissertação apresenta a síntese, a caracterização de pentafluorofenilpiridilporfirinas base livre e substituídas com complexos de rutênio. Foi feita a investigação de como a inserção de grupos pentafluorofenil (grupos retiradores de elétrons) interfere nas propriedades eletroquímicas, espectroscópicas e fotofísicas das porfirinas.

A partir da coordenação do complexo $\left[\mathrm{Ru}(\mathrm{bpy})_{2} \mathrm{Cl}\right]^{+}$e do cluster trinuclear de rutênio $\left[\mathrm{Ru}_{3} \mathrm{O}(\mathrm{Ac})_{6}(\mathrm{py})_{2}\right]^{+}$à porfirina $\mathrm{M}(4-\mathrm{N}-\mathrm{Py}) \mathrm{TFPPH}_{2}$ foram construídas as díades modelo [M(4-N-Py)TFFPH $\left.{ }_{2}\left\{\mathrm{Ru}_{3} \mathrm{O}(\mathrm{Ac})_{6}(\mathrm{py})_{2}\right\}\right] \mathrm{PF}_{6}$ e $\left[\mathrm{M}(4-\mathrm{N}-\mathrm{Py}) \mathrm{TFFPH}_{2}\left\{\mathrm{Ru}(\mathrm{bpy})_{2} \mathrm{Cl}\right\}\right]$ $\mathrm{PF}_{6}$, que foram caracterizadas pelas mesmas técnicas que as porfirinas. Também foram sintetizadas as tríades assimétricas cis- e trans-[B(4-N-Py) $\mathrm{BFFPH}_{2}\left\{\mathrm{Ru}_{3} \mathrm{O}(\mathrm{Ac})_{6}(\mathrm{py})_{2}\right\}$ $\left.\left\{\mathrm{Ru}(\mathrm{bpy})_{2} \mathrm{Cl}\right\}\right]\left(\mathrm{PF}_{6}\right)_{2}$, onde há a coordenação do complexo $\left[\mathrm{Ru}(\mathrm{bpy})_{2} \mathrm{Cl}\right]^{+}$e do cluster trinuclear de rutênio $\left[\mathrm{Ru}_{3} \mathrm{O}(\mathrm{Ac})_{6}(\mathrm{py})_{2}\right]^{+}$aos isômeros das porfirinas cis- e trans- $\mathrm{B}(4-\mathrm{N}-$ Py) $\mathrm{BFFPH}_{2}$. Estas moléculas foram caracterizadas por análise de massa ESI MS e ESI MSMS e por espectroscopia UV-Vísivel. Pelos espectros UV-Vísivel pode-se notar que os espectros são apenas uma somatória do perfil espectral dos componentes, sugerindo ausência de comunicação eletrônica. No entanto estudos eletroquímicos das díades [M(4-NPy)TFFPH $\left.{ }_{2}\left\{\mathrm{Ru}_{3} \mathrm{O}(\mathrm{Ac})_{6}(\mathrm{py})_{2}\right\}\right] \mathrm{PF}_{6}$ e $\left[\mathrm{M}(4-\mathrm{N}-\mathrm{Py}) \mathrm{TFFPH}_{2}\left\{\mathrm{Ru}(\mathrm{bpy})_{2} \mathrm{Cl}\right\}\right] \mathrm{PF}_{6}$ indicam que esta comunicação existe, embora pequena, não é negligenciável.

Os estudos por análise de massa ESI MS e ESI MSMS foram realizados com as porfirinas, com o complexos $\left[\mathrm{Ru}(\mathrm{bpy})_{2} \mathrm{Cl}\right]^{+}$, com o cluster trinuclear de rutênio $\left[\mathrm{Ru}_{3} \mathrm{O}(\mathrm{Ac})_{6}(\mathrm{py})_{2}\right]^{+}$, com as díades modelos $\left[\mathrm{M}(4-\mathrm{N}-\mathrm{Py}) \mathrm{TFFPH}_{2}\left\{\mathrm{Ru}_{3} \mathrm{O}(\mathrm{Ac})_{6}(\mathrm{py})_{2}\right\}\right] \mathrm{PF}_{6} \mathrm{e}$ $\left[\mathrm{M}(4-\mathrm{N}-\mathrm{Py}) \mathrm{TFFPH}_{2}\left\{\mathrm{Ru}(\mathrm{bpy})_{2} \mathrm{Cl}\right\}\right] \mathrm{PF}_{6}$ e com as tríades assimétricas cis- e trans-[B(4-NPy) $\left.\mathrm{BFFPH}_{2}\left\{\mathrm{Ru}_{3} \mathrm{O}(\mathrm{Ac})_{6}(\mathrm{py})_{2}\right\}\left\{\mathrm{Ru}(\mathrm{bpy})_{2} \mathrm{Cl}\right\}\right]\left(\mathrm{PF}_{6}\right)_{2}$. As estruturas dos compostos foram confirmados por ESI MS. Para as tríades cis- e trans-[B(4-N-Py) $\mathrm{BFFPH}_{2}$ $\left.\left\{\mathrm{Ru}_{3} \mathrm{O}(\mathrm{Ac})_{6}(\mathrm{py})_{2}\right\}\left\{\mathrm{Ru}(\mathrm{bpy})_{2} \mathrm{Cl}\right\}\right]\left(\mathrm{PF}_{6}\right)_{2}$ os experimentos ESI MSMS permitiram verificar que a fragmentação dos compostos, levam às unidades monossubstituidas [B(4-N$\left.\mathrm{Py} \mathrm{BFFPH}_{2}\left\{\mathrm{Ru}_{3} \mathrm{O}(\mathrm{Ac})_{6}(\mathrm{py})_{2}\right\}\right]^{+}$e $\left[\mathrm{B}(4-\mathrm{N}-\mathrm{Py}) \mathrm{BPFPH}_{2}\left\{\mathrm{Ru}(\mathrm{bpy})_{2} \mathrm{Cl}\right\}\right]^{+}$e os fragmentos substituintes $\left[\mathrm{Ru}(\mathrm{bpy})_{2} \mathrm{Cl}\right]^{+}$e $\left[\mathrm{Ru}_{3} \mathrm{O}(\mathrm{Ac})_{6}(\mathrm{py})_{2}\right]^{+}$. Não foi possível verificar nenhuma diferença na fragmentação dos isômeros cis- e trans- das supermoléculas. 
Os ensaios de luminescência mostraram que a introdução de grupos modificadores $\left[\mathrm{Ru}(\mathrm{bpy})_{2} \mathrm{Cl}\right]^{+}$e $\left[\mathrm{Ru}_{3} \mathrm{O}(\mathrm{Ac})_{6}(\mathrm{py})_{2}\right]^{+}$suprimem a emissão da porfirina. Os dados fotofísicos preliminares mostram que as duas unidades ligadas às porfirinas $\mathrm{M}(4-\mathrm{N}-\mathrm{Py}) \mathrm{TFPPH}_{2}$, cise trans- $\mathrm{B}(4-\mathrm{N}-\mathrm{Py}) \mathrm{BFPPH}_{2}$ estão atuando como aceptor final de carga. 


\section{Abstract}

This work reports the synthesis and characterization of free base pentafluorophenylpyridilporphyrins as well as the synthesis and characterization of these compounds coordinated with ruthenium complexes. We have investigated how the insertion of pentafluorophenyl groups (electronwithdrawing groups) interferes with the eletrochemical, spectroscopic and photophysical properties of the compounds.

The dyads models $\left[\mathrm{M}(4-\mathrm{N}-\mathrm{Py}) \mathrm{TFFPH}_{2}\left\{\mathrm{Ru}_{3} \mathrm{O}(\mathrm{Ac})_{6}(\mathrm{py})_{2}\right\}\right] \mathrm{PF}_{6} \quad$ and $\left[\mathrm{M}(4-\mathrm{N}-\mathrm{Py}) \mathrm{TFFPH}_{2}\left\{\mathrm{Ru}(\mathrm{bpy})_{2} \mathrm{Cl}\right\}\right] \quad \mathrm{PF}_{6}$ were constructed using the $\left[\mathrm{Ru}(\mathrm{bpy})_{2} \mathrm{Cl}\right]^{+}$ complex, the trinuclear ruthenium cluster $\left[\mathrm{Ru}_{3} \mathrm{O}(\mathrm{Ac})_{6}(\mathrm{py})_{2}\right]^{+}$, and the free base porphyrin $\mathrm{M}(4-\mathrm{N}-\mathrm{Py}) \mathrm{TFPPH}_{2}$. These dyads were characterized by the same techniques used to characterize the isolated porphyrins. The assimetric triads cis- and trans-[B(4-NPy)BFFPH $\left.{ }_{2}\left\{\mathrm{Ru}_{3} \mathrm{O}(\mathrm{Ac})_{6}(\mathrm{py})_{2}\right\} \quad\left\{\mathrm{Ru}(\mathrm{bpy})_{2} \mathrm{Cl}\right\}\right]\left(\mathrm{PF}_{6}\right)_{2}$ were also synthesized, through coordination of the $\left[\mathrm{Ru}(\mathrm{bpy})_{2} \mathrm{Cl}\right]^{+}$complex with the $\left[\mathrm{Ru}_{3} \mathrm{O}(\mathrm{Ac})_{6}(\mathrm{py})_{2}\right]^{+}$trinuclear ruthenium complex and the cis- and trans isomers of the $\mathrm{B}(4-\mathrm{N}-\mathrm{Py}) \mathrm{BFFPH}_{2}$ porphyrin. These molecules were characterized by ESI MS and ESI MSMS mass analyses and UVVisible spectroscopy. The UV-Visible spectra were a sum of the spectral profile of the isolated components, suggesting a lack of eletronic communication between the units. However, electrochemical studies of the $\left[\mathrm{M}(4-\mathrm{N}-\mathrm{Py}) \mathrm{TFFPH}_{2}\left\{\mathrm{Ru}_{3} \mathrm{O}(\mathrm{Ac})_{6}(\mathrm{py})_{2}\right\}\right] \mathrm{PF}_{6}$ and $\left[\mathrm{M}(4-\mathrm{N}-\mathrm{Py}) \mathrm{TFFPH}_{2}\left\{\mathrm{Ru}(\mathrm{bpy})_{2} \mathrm{Cl}\right\}\right] \mathrm{PF}_{6}$ dyads denoted this communication exists. So, despite being low, it must not be disregarded.

ESI MS and ESI MSMS mass analyses of the porphyrins, the complex $\left[\mathrm{Ru}(\mathrm{bpy})_{2} \mathrm{Cl}\right]^{+}$, the trinuclear ruthenium cluster $\left[\mathrm{Ru}_{3} \mathrm{O}(\mathrm{Ac})_{6}(\mathrm{py})_{2}\right]^{+}$, the dyads model $[\mathrm{M}(4-$ $\left.\mathrm{N}-\mathrm{Py}) \mathrm{TFFPH}_{2}\left\{\mathrm{Ru}_{3} \mathrm{O}(\mathrm{Ac})_{6}(\mathrm{py})_{2}\right\}\right] \mathrm{PF}_{6}$, and $\left[\mathrm{M}(4-\mathrm{N}-\mathrm{Py}) \mathrm{TFFPH}_{2}\left\{\mathrm{Ru}(\mathrm{bpy})_{2} \mathrm{Cl}\right\}\right] \mathrm{PF}_{6}$ and the assimetric triads cis- and trans-[B(4-N-Py)BFFPH $\left.{ }_{2}\left\{\mathrm{Ru}_{3} \mathrm{O}(\mathrm{Ac})_{6}(\mathrm{py})_{2}\right\}\left\{\mathrm{Ru}(\mathrm{bpy})_{2} \mathrm{Cl}\right\}\right]\left(\mathrm{PF}_{6}\right)_{2}$ were carried out. The structures of the compounds were confirmed by ESI MS. The ESI MSMS experiments for the cis- and trans-[B(4-N-Py)BFFPH${ }_{2}\left\{\mathrm{Ru}_{3} \mathrm{O}(\mathrm{Ac})_{6}(\mathrm{py})_{2}\right\}$ $\left.\left\{\mathrm{Ru}(\mathrm{bpy})_{2} \mathrm{Cl}\right\}\right]\left(\mathrm{PF}_{6}\right)_{2}$ triads allow us to verify that the fragmentation of the compounds results in the monosubstituted units $\left[\mathrm{B}(4-\mathrm{N}-\mathrm{Py}) \mathrm{BFFPH}_{2}\left\{\mathrm{Ru}_{3} \mathrm{O}(\mathrm{Ac})_{6}(\mathrm{py})_{2}\right\}\right]^{+}$and $[\mathrm{B}(4-\mathrm{N}-$ Py)BPFPH$\left.{ }_{2}\left\{\mathrm{Ru}(\mathrm{bpy})_{2} \mathrm{Cl}\right\}\right]^{+}$, and the substituents units $\left[\mathrm{Ru}(\mathrm{bpy})_{2} \mathrm{Cl}\right]^{+}$and 
$\left[\mathrm{Ru}_{3} \mathrm{O}(\mathrm{Ac})_{6}(\mathrm{py})_{2}\right]^{+}$. No difference in the fragmentation of the cis- and trans-isomers of the supermolecules was detected.

The luminescence experiments showed that the porphyrin emission is almost totally quenched because of the binding of the groups $\left[\mathrm{Ru}(\mathrm{bpy})_{2} \mathrm{Cl}\right]^{+}$and $\left[\mathrm{Ru}_{3} \mathrm{O}(\mathrm{Ac})_{6}(\mathrm{py})_{2}\right]^{+}$. Photophysics results shows that these two units bounded to porhyrins $\mathrm{M}(4-\mathrm{N}-\mathrm{Py}) \mathrm{TFPPH}_{2}$, cis- and trans- $\mathrm{B}(4-\mathrm{N}-\mathrm{Py}) \mathrm{BFPPH}_{2}$ act as charge receptors. 


\section{I- Introdução}

\section{I.1) Porfirinas- Aspectos Gerais}

Porfirinas são muito interessantes devido às possibilidades diversas de suas aplicacões, algumas das características que as porfirinas apresentam são: versatilidade sintética, estabilidade térmica, amplo sistema eletrônico $\pi$ e propriedades fotofísicas interessantes ${ }^{1}$.

Um sistema altamente conjugado de onze duplas ligações alternadas está presente nas porfirinas $^{2}$ (Figura 1). Muitos de seus derivados metálicos estão presentes em várias proteínas. Suas aplicações podem ser em fios moleculares ${ }^{3}$, na construção de dispositivos para o armazenamento de informação ${ }^{4}$, em materiais óticos não-lineares ${ }^{5,6,7}$ e na catálise $^{8,9,10,11,12}$. Algumas destas aplicações são correlacionadas com sua propriedade de fluorescência, isto é, pela sua forte fluorescência no vermelho.

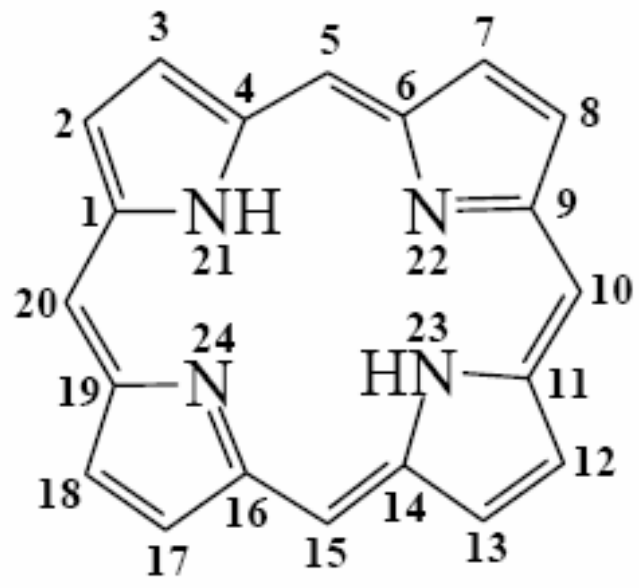

Figura 1: Esquema da estrutura de meso-arilporfirinas

As porfirinas são compostos de geometria quadrada planar que apresentam um macrociclo central contendo 20 átomos de carbono e 4 átomos de nitrogênio, denominado porfina, e grupos substituintes ao redor deste anel. A nomenclatura utilizada para nomear as porfirinas foi estabelecida por $\operatorname{Smith}^{13}$ e Falk na qual as posições metínicas do anel porfirínico são denominadas de meso ou ainda 5,10,15,20. As posições 2, 3; 7, 8; 12, 13 e 17, 18 que correspondem aos carbonos pirrólicos e são também denominadas de posições $\beta$. As porfirinas que apresentam átomos de hidrogênio ligados aos nitrogênios 21 e 23 são 
chamadas de "bases livres"; e quando há substituição destes hidrogênios por um metal coordenado pelos quatro nitrogênios é denominada metaloporfirina. A incorporação de prótons aos nitrogênios 22 e 24 origina a forma diácida, e a remoção dos hidrogênios 21 e 23 origina a forma dibásica (Figura 1).

As porfïrinas naturais são substituídas, geralmente, por resíduos metil, etil, vinil, acetil e propionil, ligados nas posições 2, 3, 7, 8, 12, 13, 17 e 18. Nos seres vivos as porfirinas geralmente são encontradas na forma de metalocomplexos, sendo o íon $\mathrm{Fe}^{3+} \mathrm{o}$ centro metálico mais comum. Por se tratarem de porfirinas assimétricas, as rotas sintéticas para obtenção destes derivados naturais são extremamente complicadas, restando a alternativa de extração de material biológico, o que implica em diversas etapas de purificação.

Porfirinas com substituintes do tipo alifáticos no anel são denominadas alquilporfirinas, e arilporfirinas se os substituintes são aromáticos. O prefixo "tetrakis" é utilizado para porfirinas com quatro substituintes iguais nas posições meso do anel $(5,10$, 15 e 20). Se tais grupos forem anéis aromáticos, eles podem possuir heteroátomos como substituintes nas posições orto, meta e/ou para de um anel benzênico. A introdução de substituintes periféricos leva a diferentes propriedades físico-químicas, como solubilidade, estabilidade química e fotoquímica, coeficiente de extinção molar, etc. ${ }^{14}$.

Dentre suas aplicações na medicina, uma das mais importantes é a Terapia Fotodinâmica (TFD) no tratamento de câncer, apresentando resultados promissores. A combinação droga (derivados porfirínicos) mais luz forma a base da TFD ${ }^{15}$. Em diversos processos biológicos, as porfirinas podem existir na forma monomérica ou na forma agregada. Entretanto, a agregação de porfirinas reduz sua eficiência nas aplicações em TFD devido à redução dos tempos de vida e rendimentos quânticos de produção dos estados excitados singleto e tripleto e levando, conseqüentemente, à redução na produção de oxigênio singleto. 


\section{I.2) Síntese de Porfirinas}

Porfirinas mesotetrasubstituídas foram preparadas pela primeira vez em 1936 por Rothemund $^{16}$ que aqueceu pirrol, benzaldeído e piridina num tubo vedado a $150^{\circ} \mathrm{C}$ por 24 horas.

Os rendimentos na síntese de porfirinas a partir desta reação eram inferiores a 3\% e o produto obtido encontrava-se contaminado pela clorina, que corresponde à porfirina reduzida nas posições 17 e 18 (17,18-diidroporfirina). Ball e colaboradores ${ }^{17}$ obtiveram melhores resultados adicionando acetato de zinco à mistura reacional, uma modificação que posteriormente foi utilizada por Badger e colaboradores ${ }^{18}$ para a síntese de diversas tetrafenilporfirinas ortossubstituídas.

Um grande avanço nestas sínteses foi obtido por Adler, Longo e colaboradores ${ }^{19}$ quando eles mostraram que os rendimentos de porfirinas poderiam ser aumentados realizando-se a reação em meio ácido e sistema aberto. Em refluxo com ácido propiônico, esta condensação levou a rendimentos maiores que $20 \%$ e permitiu o uso de uma maior variedade de benzaldeídos substituídos, além de ser possível a obtenção do produto cristalizado após resfriamento, facilitando assim o processo de purificação. A $\mathrm{TPPH}_{2}$ passou a ser sintetizada por este método (Figura 2).

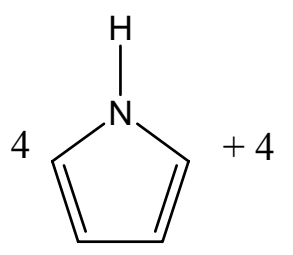<smiles>O=Cc1ccccc1</smiles>
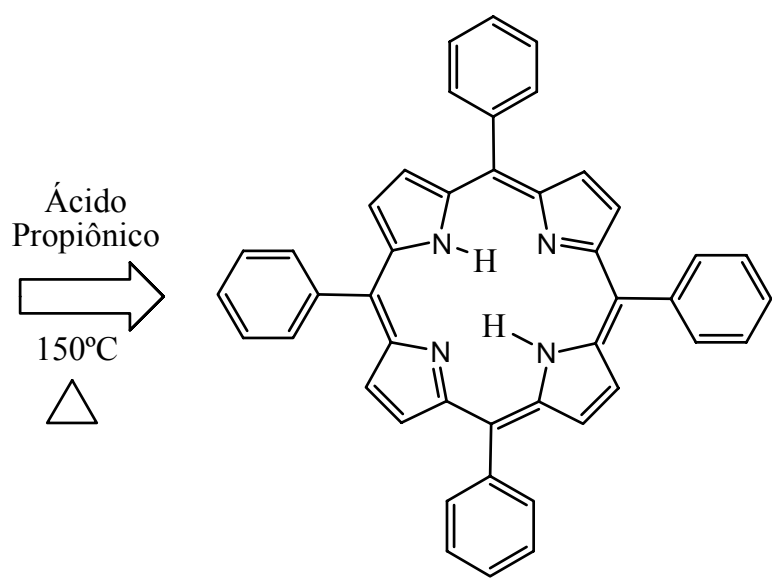

Figura 2: Síntese da $\mathrm{TPPH}_{2}$ pela condensação entre pirrol e benzaldeído.

Lindsey e colaboradores ${ }^{20}$ desenvolveram um outro método sintético geral para mesotetrafenilporfirinas. Este método pressupõe que, sob condição de equilíbrio e na 
presença de um catalisador ácido, a condensação ocorre via formação de porfírinogênio. O método de Lindsey é um processo que ocorre em duas etapas:

i) Pirrol e aldeído são condensados inicialmente, na presença de um catalisador ácido e em condições anaeróbicas para a produção do porfirinogênio;

ii) Em seguida, o porfirinogênio é oxidado à porfirina pela adição de agentes oxidantes como: p-cloranil (tetra cloro-1,4-benzoquinona) ou DDQ (2,3-DCM-5,6-diciano-1,4-benzoquinona).

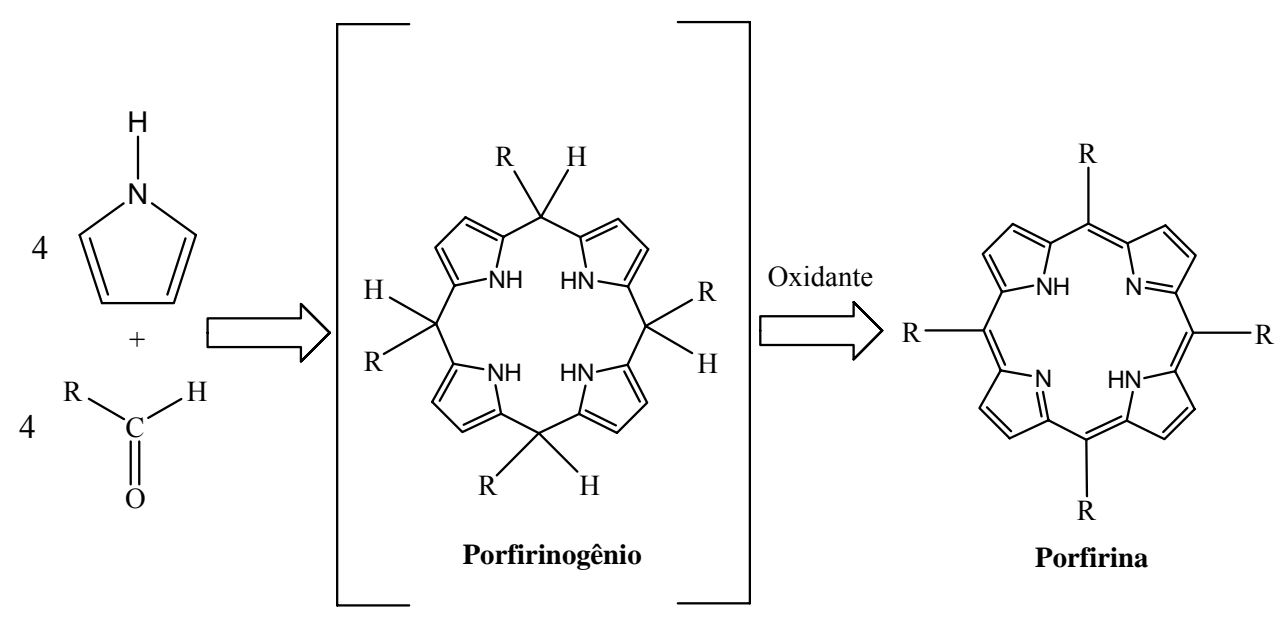

Figura 3: Síntese de uma porfirina pelo método de Lindsey.

Esta reação é realizada em solventes clorados (DCM, clorofórmio) e à temperatura ambiente. O rendimento de várias porfirinas aumentou até aproximadamente $50 \%$ com a utilização do método proposto por Lindsey.

Os métodos de Rothemund, Adler-Longo e Lindsey têm sido utilizados nas sínteses de meso-tetraarilporfirinas contendo uma variedade de substituintes nos grupos fenis. É possível ainda preparar uma porfirina contendo diferentes grupos nas posições meso, utilizando-se aldeídos diferentes na condensação com pirrol. Contudo, isto resulta na formação de mistura de espécies, as quais devem ser separadas por cromatografia a fim de se obter as porfirinas desejadas ${ }^{21}$.

Recentemente, através da utilização da condensação de dipirrometanos e aldeídos, foi obtido um avanço significativo na obtenção de porfirinas do tipo $\mathrm{A}_{2} \mathrm{~B}_{2}$, onde as posições 5,15 e 10,20 apresentam substituíntes diferentes ${ }^{22}$ (Figura 4). 


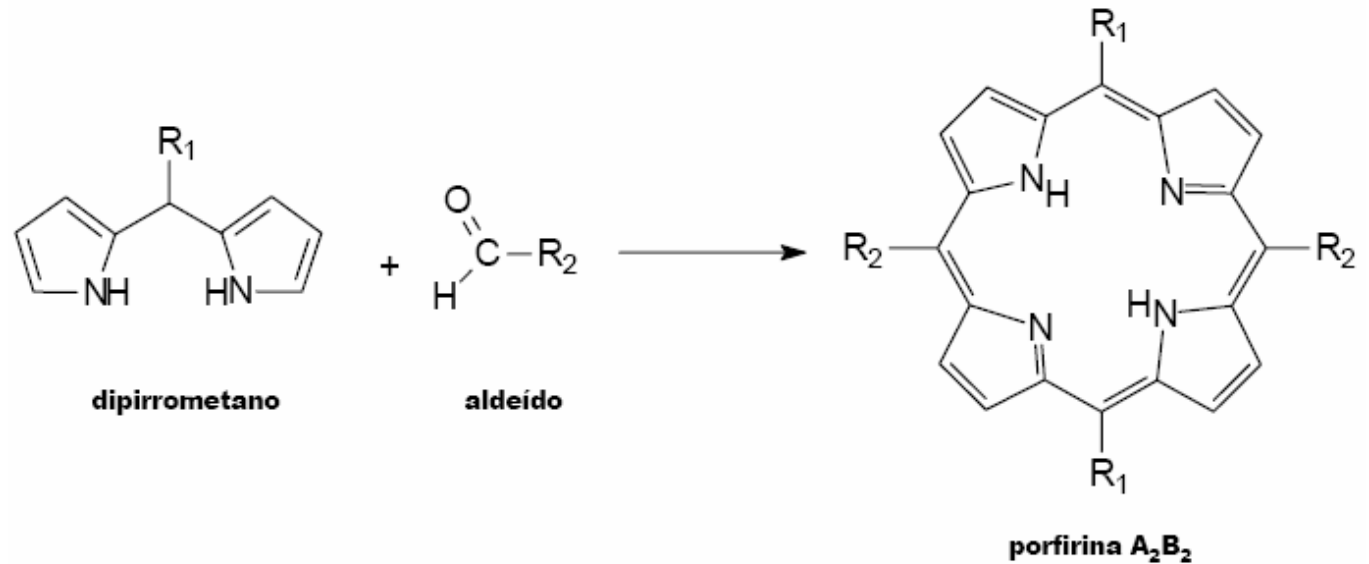

Figura 4: Síntese de uma porfirina simétrica do tipo $\mathrm{A}_{2} \mathrm{~B}_{2}$ pela condensação de dipirrometanos e aldeídos.

As porfirinas têm a propriedade de formar complexos com a maioria dos íons metálicos, constituindo dessa forma uma importante classe de pigmentos cíclicos. As metaloporfirinas, como por exemplo, os complexos ferroporfirnícos, constituem o grupo prostético de uma importante classe de proteínas e enzimas conhecidas como hemeproteínas. Nos seres vivos diversos processos bioquímicos são realizados por proteínas associadas a porfirinas: transporte de $\mathrm{O}_{2}$ (hemoglobina) ${ }^{23}$, armazenamento de $\mathrm{O}_{2}$ (mioglobina), respiração celular, cadeia de transporte de elétrons (citocromo C), catálise de reações de hidroxilações e epoxidações (citocromo P-450) ${ }^{14,24,25,}$ decomposição de peróxidos (catalase).

O método mais utilizado para a síntese de metaloporfirinas é o descrito por Adler $^{26}$, onde é usado a DMF e um sal solúvel neste solvente, por exemplo, $\mathrm{FeCl}_{2}$. Outros métodos foram descritos por Buchler ${ }^{27}$, tais como o método do acetato, no qual uma porfirina reage com um sal metálico em meio ácido.

Um dos muitos usos das porfirinas se refere à sua ação catalítica ${ }^{8,9,10,11,12}$ e dentre seus usos pode se destacar a oxigenação de compostos orgânicos como o (Z) cicloocteno. O uso de metaloporfirinas como catalisadores tem sido explorado e essa reação apresenta um alto rendimento na formação do respectivo epóxido ${ }^{28,29}$. Diversas aplicações de metaloporfirinas têm sido relatadas como modelos biomiméticos do citocromo $\mathrm{P} 450^{30}$, por exemplo no estudo de metabolismo de fármacos como o praziquantel um anti-helmíntico ${ }^{31}$ ou na oxidação da atrazina, um herbicida ${ }^{32}$. 


\section{I.3) Espectros Eletrônicos de Absorção}

Devido à conjugação as porfirinas apresentam uma intensa absorção de energia na região UV (Figura 5) ${ }^{33}$. A energia relativa destas bandas é alterada devido à perturbação dos níveis de energia eletrônicos, causada pela presença de substituintes no anel porfirínico. O espectro eletrônico das porfirinas base livre apresenta, usualmente, cinco bandas características. A mais intensa, a banda Soret ou banda $\mathrm{B}(0,0)$, possui máximo de absorção entre 410 e $450 \mathrm{~nm}$. No caso das porfirinas piridil substituídas apresentam absortividades molares $(\varepsilon)$ na ordem de $2 \times 10^{5} \mathrm{~cm}^{-1} \mathrm{~mol}^{-1} \mathrm{~L}$. As demais bandas apresentam máximos de absorção na região entre 500 e $650 \mathrm{~nm}$ e absortividades cerca de dez vezes menores que a da banda Soret. Essas bandas são denominadas de bandas Q e são, na ordem decrescente de energia, $\mathrm{Qy}_{(1,0)}, \mathrm{Qy}_{(0,0)}, \mathrm{Qx}_{(1,0)}, \mathrm{Qx}_{(0,0)}$.

As cinco bandas têm origem na transição $\pi^{*} \leftarrow \pi$, para as porfirinas bases livres $\mathrm{D}_{2 \mathrm{~h}}$. As metaloporfirinas e porfirinas diprotonadas possuem uma maior simetria $\left(\mathrm{D}_{4 \mathrm{~h}}\right)$, e apresentam somente duas bandas $\mathrm{Q}: \mathrm{Q}_{(1,0)}$ e $\mathrm{Q}_{(0,0)}$, na ordem decrescente de energia.

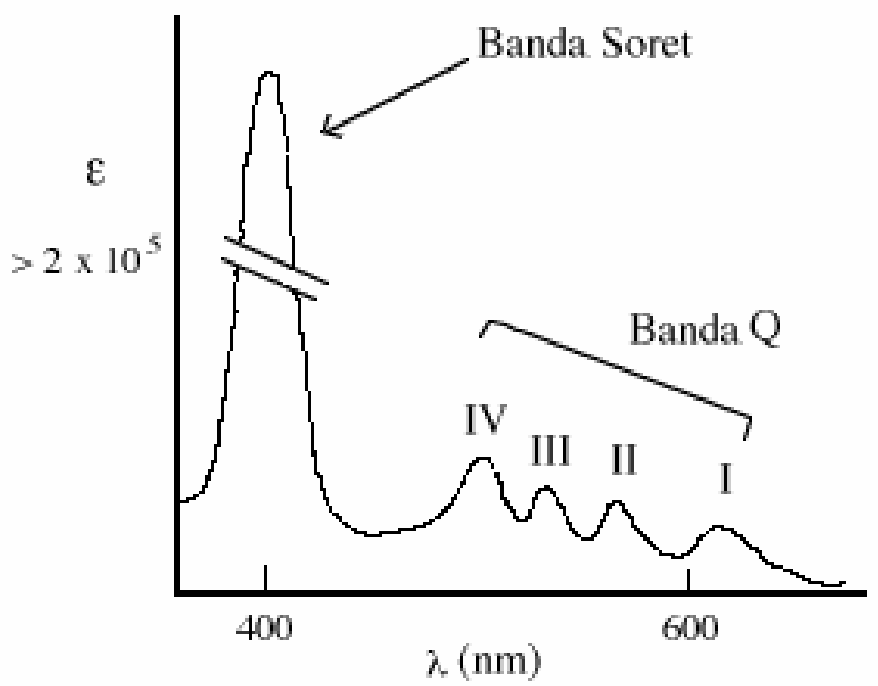

Figura 5: Espectro UV-Visível de uma porfirina base livre ${ }^{34}$.

O estudo dos espectros eletrônicos das porfirinas, metaloporfirinas e compostos macrocíclicos correlatos, foi realizado por Gouterman e colaboradores. Segundo o modelo dos quatro orbitais de fronteira, os orbitais $\mathrm{a}_{1 \mathrm{u}}(\pi)$ e $\mathrm{a}_{2 \mathrm{u}}(\pi)$ (HOMO's) encontram-se 
completamente preenchidos e o orbital vazio de menor energia possui simetria $\mathrm{e}_{\mathrm{g}}(\pi)$ (LUMO's). Os dois orbitais preenchidos $\mathrm{a}_{1 \mathrm{u}}(\pi)$ e $\mathrm{a}_{2 \mathrm{u}}(\pi)$ possuem energias muito próximas (Figura 6 e Figura 7a) podendo haver inversão da posição relativa desses orbitais, dependendo do metal central coordenado ao anel porfírínico. Os estados excitados de menor energia resultam da promoção de um elétron daqueles orbitais para o orbital $\mathrm{e}_{\mathrm{g}}$, gerando dois estados de simetria $E_{u}$, com energias próximas (Figura 6). Contudo, a interação entre estes dois estados excitados provoca o desdobramento dos mesmos. Na Figura 6 estão representados os diagramas de orbitais moleculares para complexos com simetria $\mathrm{D}_{4 \mathrm{~h}}$ (metaloporfirinas) e complexos com simetria $\mathrm{D}_{2 \mathrm{~h}}$ (porfirinas base livre), para as metaloporfirinas se observa uma transição intensa na região de $400 \mathrm{~nm}$ (banda Soret ou B) e duas transições na região de 500 a $600 \mathrm{~nm}$ (bandas $\mathrm{Q}_{0-0}$ e $\mathrm{Q}_{1-0}$ ).

Segundo o modelo de Gouterman ${ }^{33,35}$ a grande intensidade da banda Soret (banda B) é resultante da somatória dos momentos de transição de dipolo elétrico das duas transições que levam ao estado $\mathrm{E}_{\mathrm{u}}$, enquanto que a intensidade da banda $\mathrm{Q}_{0-0}$ é definida pela diferença entre aqueles momentos de transição. Assim, caso os orbitais $a_{1 u}$ e $a_{2 u}$ sejam degenerados esta banda praticamente desaparece, como no caso da Co-TPP ${ }^{36}$.

No caso das porfirinas base-livre, a diminuição da simetria para $\mathrm{D}_{2 \mathrm{~h}}$ provoca a quebra da degenerescência do estado $\mathrm{E}_{\mathrm{u}}$ em $\mathrm{B}_{2 \mathrm{u}}$ e $\mathrm{B}_{3 \mathrm{u}}$ (Figura 6), desdobrando-o nas suas componentes nas direções x e y. Isso leva ao aparecimento de quatro bandas na região do visível. As bandas na região do visível pode ser numeradas de 1 a 4 (Figura 5). O tipo de espectro em que as bandas apresentam intensidade IV $>$ III $>$ II $>$ I são denominados do tipo etio como é o caso da tetrafenilporfirina $\left(\mathrm{TPPH}_{2}\right)$. $\mathrm{O}$ espectro em que as bandas apresentam intensidade IV $>$ II $>$ III $>$ I são denominados do tipo phyllo. 


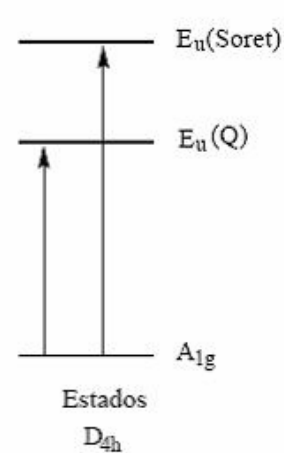

$\mathrm{D}_{4 \mathrm{~h}}$
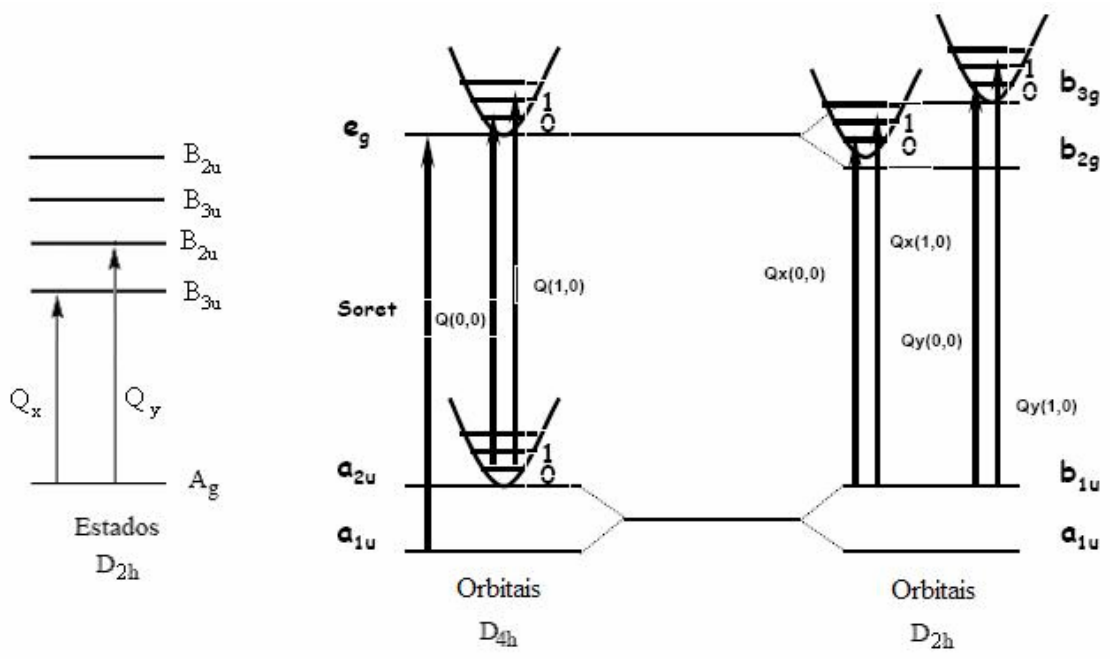

Figura 6: Transições eletrônicas no modelo dos quatro orbitais de fronteira.

Tetrafenilporfirinas que contém substituintes halogenados $(\mathrm{F}, \mathrm{Cl}, \mathrm{Br})$ nas posições orto dos grupos fenis, como é o caso da $\mathrm{TFPPH}_{2}$, apresentam uma redução significativa na intensidade das bandas III e I, ficando estas bandas praticamente suprimidas. Isto pode ser atribuído à restrição na rotação dos grupos fenis devido à interação estérica entre os ortosubstituintes e os hidrogênios $\beta$-pirrólicos. Assim, a TFPPH $\mathrm{H}_{2}$, devido a presença dos átomos de flúor, possui rotação limitada e um espectro no qual as bandas III (536 nm) e I (636nm) são suprimidas .

(a)

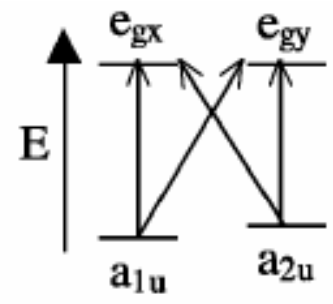

(b)

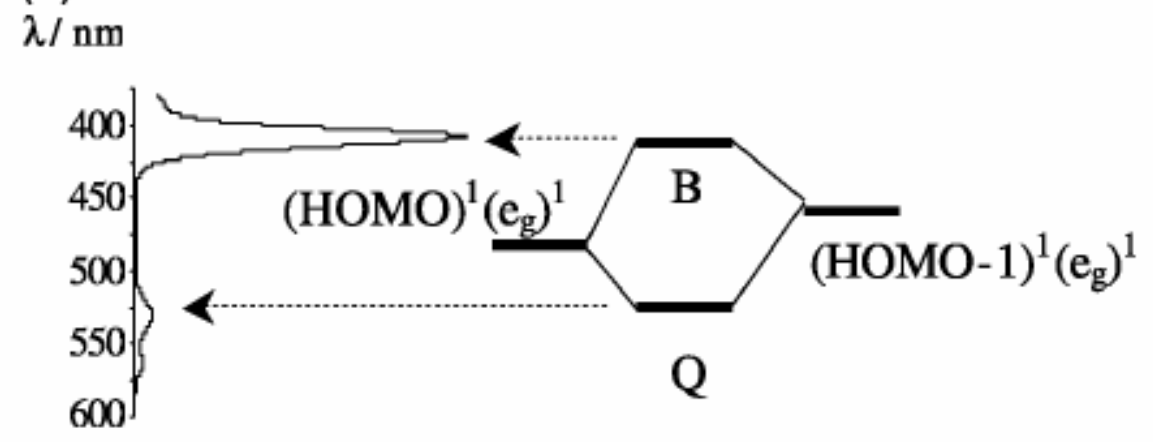

Figura 7: Transições eletronicas no modelo de quatro orbitais proposto por Goutermann a) quatro transições permitidas b) as transições $\mathrm{HOMO}-\mathrm{e}_{\mathrm{g}}$ que dão origem as bandas $\mathrm{B}$ e Q. 


\section{I.4) Espectros de Emissão}

Alguns compostos orgânicos sob luz ultravioleta podem apresentar um rendimento quântico de fluorescência elevado, podendo ser detectado mesmo em pequenas concentrações. Pode-se monitorar a mudança da concentração dos compostos usando fluorescência, e com isso a cinética da reação química pode ser investigada. Também por técnicas de fluorescência podem-se monitorar as mudanças de agregação das macromoléculas.

Após a absorção de luz, o estado excitado formado pode ser desativado, por diversos caminhos, formando o composto mais estável e de menor energia. Os processos de decaimento energético podem ser classificados em radiativos, com emissão de luz, e não radiativos, havendo apenas liberação de calor ${ }^{37}$.

Os elétrons se encontram preferencialmente no estado vibracional mais baixo do estado fundamental singlete $\left(\mathrm{S}_{0}\right)$ a temperatura ambiente. Com a absorção de energia (Processo 1, Figura 8) ocorrem transições para níveis vibracionais mais altos $(1,2, \ldots, n)$ dos estados excitados singlete $\left(\mathrm{S}_{1}, \mathrm{~S}_{2}, \ldots, \mathrm{S}_{\mathrm{n}}\right)$. Em seguida, a energia térmica é dissipada (Processo 2, Figura 8), atingindo-se o nível vibracional mais baixo do estado excitado $\mathrm{S}_{1}$, (processo não radiativo). Nesse momento, várias etapas podem ocorrer simultaneamente. A desativação do estado excitado acontece em duas vias: uma transição térmica (não radiativa) $\mathrm{S}_{1} \rightarrow \mathrm{S}_{0}$ (Processo 4 , Figura 8 ) e uma transição radiativa com emissão de luz $\mathrm{S}_{1} \rightarrow \mathrm{S}_{0}$, chamada fluorescência (Processo 3, Figura 8). Essa transição pode ocorrer para um nível vibracional do estado fundamental diferente de zero, originando diferentes bandas no espectro de emissão.

Existe ainda a possibilidade de ocorrer uma transição proibida, uma transição entre estados de multiplicidade diferentes, ou seja, uma transição singlete-triplete, geralmente $\mathrm{S}_{1} \rightarrow \mathrm{T}_{1}{ }^{38}$ (Processo 5, Figura 8). Essa etapa é denominada de cruzamento inter sistemas. O estado $T_{1}$ também pode ser despopulado pela via não radiativa (Processo 7, Figura 8) ou num processo com emissão de luz, chamado fosforescência (Processo 6, Figura 8). Esses processos são ilustrados pelo diagrama de Jablonski simplificado apresentado na Figura 8. 


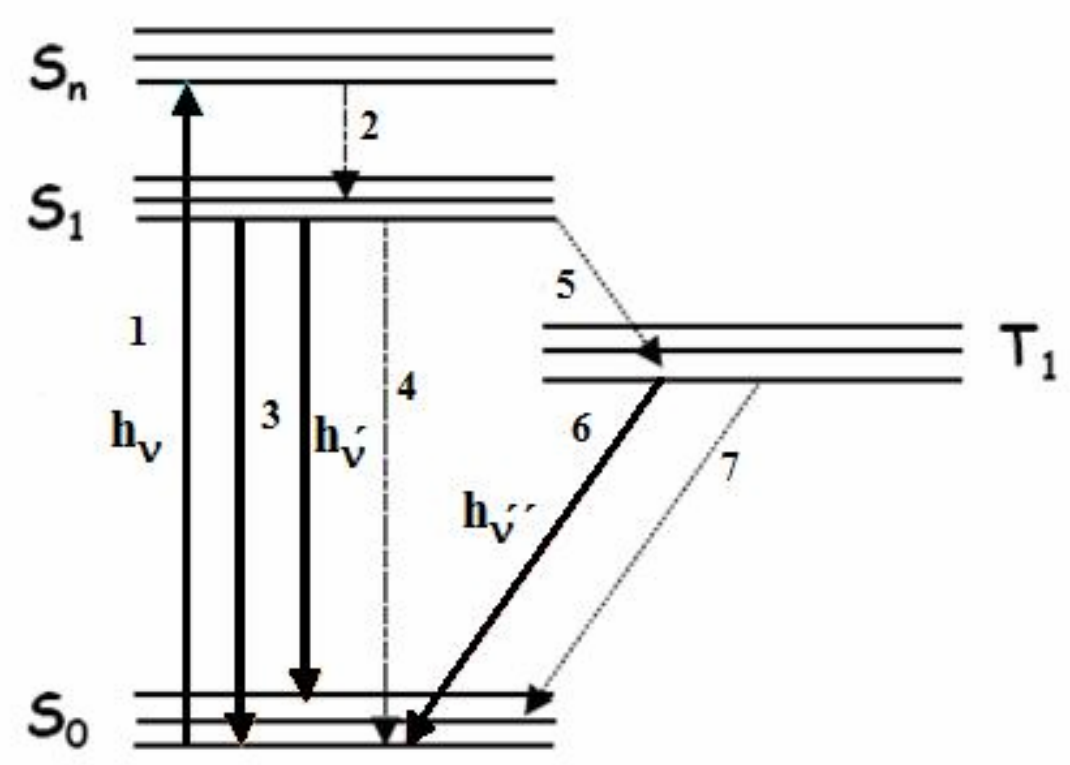

Figura 8: Representação esquemática das possíveis transições eletrônicas ${ }^{39}$.

A caracterização desses processos se dá pela determinação das constantes de velocidade dos processos radiativos e não radiativos e dos rendimentos quânticos de fluorescência $\left(\Phi_{\mathrm{F}}\right)$, de fosforescência $\left(\Phi_{\mathrm{P}}\right)$ e de formação do estado triplete $\left(\Phi_{\mathrm{T}}\right)$, ou seja, a razão entre os fótons emitidos em cada um desses processos pelos fótons absorvidos na excitação da espécie.

$\mathrm{Na}$ caracterização dos processos que conduzem à formação e desativação dos estados excitados devem-se considerar as constantes de velocidade e os rendimentos quânticos. A magnitude destes dois parâmetros determina as propriedades fotoquímicas intrínsecas da molécula. Um ponto importante que deve ser comentado antes da descrição das propriedades luminescentes dos compostos porfirínicos é denominado efeito do átomo pesado (heavy atom effect), esse efeito altera consideravelmente alguns processos de desativação do estado excitado. Pela regra da seleção somente transições entre dois estados de mesma multiplicidade são permitidas, sendo assim transições entre estados singlete e triplete são "proibidas". Contudo, a transição entre estados singlete e triplete é possível desde que uma perturbação interna ou externa origine uma mistura dos estados envolvidos gerando estados singletes e tripletes impuros. Estas misturas são originadas de interações magnéticas entre o momento orbital do elétron e o momento magnético do spin, sendo este fenômeno denominado de acoplamento spin-órbita. Estas perturbações são 
originadas pelo campo magnético gerado próximo ao núcleo e a magnitude deste campo é diretamente proporcional à massa nuclear, sendo assim estas perturbações são chamadas de efeito de átomo pesado uma vez que átomos leves originam pequenas misturas.

A maioria das bases livres e um grande número de metaloporfirinas são luminescentes, as porfirinas podem ser classificadas como fluorescentes ou fosforescentes.

As porfirinas fluorescentes apresentam rendimentos quânticos de fluorescência $\left(\varnothing_{\mathrm{f}}\right)$ entre 0,2 e $10^{-3}$ e as porfirinas fosforescentes apresentam rendimentos quânticos de fosforescência $\left(\varnothing_{\mathrm{p}}\right)$ entre 0,2 e $10^{-4}$. As porfirinas bases livres e metaloporfirinas com metais de camada cheia são fluorescentes. A fluorescência desses derivados é observada à temperatura ambiente, enquanto que a fosforescência só é verificada a baixas temperaturas $^{40}$ e em meio congelado, diminuindo-se a conversão interna $T_{1} \rightarrow S_{0}$.

Metaloporfirinas dos elementos de transição não apresentam fluorescência devido à formação de novos estados gerados pelos orbitais $\mathrm{d}$, permitindo novas vias de decaimento não-radiativo.

Metaloporfirinas contendo íons metálicos diamagnéticos com orbitais $\mathrm{d}$ semipreenchidos são preferencialmente fosforescentes, sendo que os complexos de $\operatorname{Pd}(\mathrm{II})$ e Pt(II) apresentam alto rendimento quântico de fosforescência na ausência de $\mathrm{O}_{2}$, mesmo em temperatura ambiente.

Os complexos metálicos paramagnéticos geralmente não são luminescentes, as exceções, como no caso de algumas $\mathrm{Cu}(\mathrm{II})$-porfirinas, apresentam baixo rendimento quântico de emissão, emissão esta que não é necessariamente atribuída à fluorescência ou fosforescência, visto que os estados moleculares não são classificados como singletes ou tripletes, devido à interação entre estados de transferência de carga e o sistema $\pi$ do macrociclo.

\section{I.5) Sistemas mistos - combinação de porfirinas com cluster trinuclear de rutênio $\left[\mathrm{Ru}_{3} \mathrm{O}(\mathrm{Ac})_{6}(\mathrm{py})_{2}(\mathrm{~L})\right]^{\mathrm{n}}$ e de complexo $\mathrm{Ru}(\mathrm{bpy})_{2} \mathrm{Cl}^{+}$}

Há um extenso artigo de revisão que mostra uma visão bastante ampla da química de clusters ${ }^{41}$, complexos trinucleares de rutênio de fórmula geral $\left[\mathrm{Ru}_{3} \mathrm{O}(\mathrm{Ac})_{6}(\mathrm{py})_{2}(\mathrm{~L})\right]^{\mathrm{n}}$. No entanto, clusters do tipo $\left[\mathrm{Ru}_{3} \mathrm{O}(\mathrm{Ac})_{6}(\mathrm{py})_{2}(\mathrm{~L})\right]^{\mathrm{n}}$, com porfirinas, têm sido pouco 
explorados como unidades de montagem de supermoléculas ${ }^{42,43,44}$. Há também na literatura alguns trabalhos com a coordenação do complexo $\mathrm{Ru}(\mathrm{bpy})_{2} \mathrm{Cl}^{+}$com a porfirina $^{45,46,47,48,49,50}$, mas não há relatos em que ocorra a coordenação do cluster $\left[\mathrm{Ru}_{3} \mathrm{O}(\mathrm{Ac})_{6}(\mathrm{py})_{2}(\mathrm{~L})\right]^{\mathrm{n}}$ e o complexo $\mathrm{Ru}(\mathrm{bpy})_{2} \mathrm{Cl}^{+}$à uma mesma porfirina.

$\mathrm{O}$ interesse no cluster trinuclear de rutênio $\left[\mathrm{Ru}_{3} \mathrm{O}(\mathrm{Ac})_{6}(\mathrm{py})_{2}(\mathrm{~L})\right]^{\mathrm{n}}$ baseia-se em suas propriedades eletrônicas e eletroquímicas, resultantes da forte comunicação eletrônica entre os íons metálicos, ligados em ponte pelo átomo de oxigênio central. Esses clusters apresentam-se como opções versáteis para a elaboração de estruturas capazes de protagonizar reações redox multieletrônicas, em função de seu comportamento eletroquímico. Um exemplo de comportamento eletroquímico típico é apresentado pelo cluster $\left[\mathrm{Ru}_{3} \mathrm{O}(\mathrm{Ac})_{6}(\mathrm{pz})_{3}\right]$ que apresenta cinco pares de ondas monoeletrônicas reversíveis em uma faixa de potencial que vai de $-2,0 \mathrm{~V}$ até $+2,0 \mathrm{~V}$ vs $\mathrm{EPH}$ (eletrodo padrão de hidrogênio) (Figura 9).

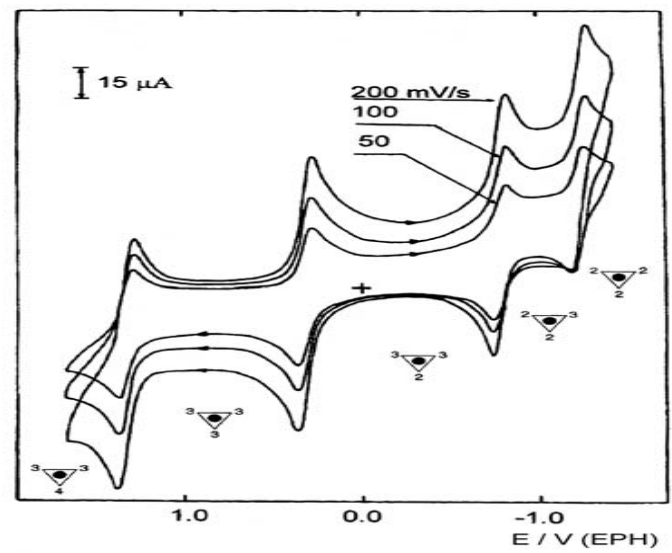

Figura 9:Voltametria cíclica de $\left[\mathrm{Ru}_{3} \mathrm{O}(\mathrm{Ac})_{6}(\mathrm{pz})_{3}\right]$ ilustrando o comportamento. eletroquímico típico de clusters trinucleares de acetato de rutênio.

Uma porfirina base livre sem muitas alterações estruturais, tal como a tetrafenilporfirina TPP, apresenta quatro processos redox centrados no macrociclo, sendo duas oxidações (1,16 V e 1,56 V vs. EPH) e duas reduções (-1,04 V e -1,34 V vs. EPH). 




Figura 10: Voltametria cíclica da TPP ilustrando o comportamento típico das porfirinas.

Já o complexo $\mathrm{Ru}(\mathrm{bpy}){ }_{2} \mathrm{Cl}^{+}$apresenta somente um processo eletroquímico em 1,04 $\mathrm{V}$ vs EPH, onde o rutênio sofre um processo oxidativo $\mathrm{Ru}(\mathrm{II}) \rightarrow \mathrm{Ru}(\mathrm{III})$.

Na medida em que o macrocíclo é modificado pela adição de novos substituintes, pela posição destes no anel porfirínico, ou pela metalação, os potenciais de redução e oxidação das moléculas são alteradas ${ }^{51,52}$, a caracterização eletroquímica é importante. Permite dessa forma, observar como o metal interfere no macrocíclo, e como o macrocíclo consegue modular as características dos substituintes ou dos íons metálicos ${ }^{53,54,55,56 .}$

Em particular, têm-se obtido resultados bastante interessantes através da combinação dos clusters com tetrapiridil-porfirinas ${ }^{42,43,44}$. Para mencionar um exemplo, obteve-se um catalisador para a redução tetraeletrônica de $\mathrm{O}_{2}$ baseado em eletrodos modificados com a supermolécula CoTCP (cobalto porfirina tetracluster trinuclear de rutênio). Por outro lado, não existe na literatura um estudo sistemático da supressão da luminescência de porfirinas (base livre ou $\mathrm{Zn}$ ) por clusters trinucleares ${ }^{42,57,58,59}$.

Sistemas que apresentam reações de transferência de energia e/ou de elétrons são a base para o desenvolvimento de dispositivos fotoquímicos; tais dispositivos devem ser capazes de funcionar como chaveadores moleculares, apresentar o chamado efeito antena ou ainda sofrer processos de separação de carga mediados por luz ${ }^{60}$. Conhecendo-se a capacidade dos clusters trinucleares de rutênio de suprimir a luminescência do núcleo porfirínico, planejou-se uma estrutura na qual, pela ligação química entre uma unidade doadora $\mathrm{D}$ (complexo $\mathrm{Ru}(\mathrm{bpy})_{2} \mathrm{Cl}^{+}$), um cromóforo emissor $\mathrm{E}$ (porfirina) e um aceptor 
final A (cluster), pudesse ser concluido que reações de transferência de energia e elétrons sucessivas e conseqüente separação de carga (Figura 11) ocorreria.

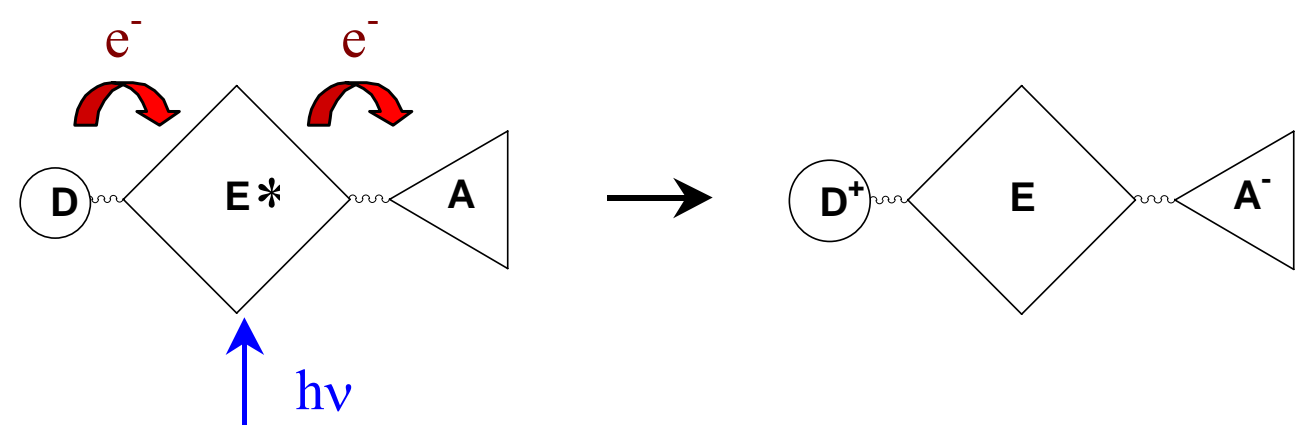

Figura 11: Representação esquemática das reações de transferência de elétrons fotoinduzidas em sistemas mistos. 


\section{II - Objetivos}

- Construir uma estrutura com diferentes cromóforos coordenados a porfirinas, onde o cluster trinuclear de rutênio $\left[\mathrm{Ru}_{3} \mathrm{O}(\mathrm{Ac})_{6}(\mathrm{py})_{2}(\mathrm{MeOH})\right] \mathrm{PF}_{6}$ funcionaria como receptor final de carga e o complexo $\left[\mathrm{Ru}(\mathrm{bpy})_{2}(\mathrm{~L})_{2}\right]$ funcionaria como um doador inicial de carga, de modo a promover reações fotoinduzidas de transferência intramolecular de energia e ou de elétrons (Figura 11).

Tendo como meta o objetivo geral acima, foram objetivos específicos:

- Sintetizar e caracterizar as porfirinas M(4-N-Py)TFPPH ${ }_{2}$, cis-B(4-N-Py)BFPPH trans-B(4-N-Py)BFPPH $\mathrm{H}_{2}, \mathrm{~T}(4-\mathrm{N}-\mathrm{Py}) \mathrm{MFPPH}_{2}$ e investigar como a introdução do grupo pentafluorofenil nas porfirinas afeta o comportamento eletroquímico, espectroscópico e das propriedades fotofísicas das porfirinas em questão, sempre utilizando como padrão as porfirinas comerciais tetrafenilporfirina $\mathrm{TPPH}_{2}$, tetrapiridilporfirina $\mathrm{T}(4-\mathrm{N}-\mathrm{Py}) \mathrm{PH}_{2}$ e a tetrapentafluorofenilporfirina $\mathrm{TFPPH}_{2}$.

- Sintetizar e caracterizar as díades modelo [M(4-N-Py)TFPPH $\left.{ }_{2}\left\{\mathrm{Ru}_{3} \mathrm{O}(\mathrm{Ac})_{6}(\mathrm{py})_{2}\right\}\right]$ $\mathrm{PF}_{6}$ e $\left[\mathrm{M}(4-\mathrm{N}-\mathrm{Py}) \mathrm{TFPPH}_{2}\left\{\mathrm{Ru}(\mathrm{bpy})_{2} \mathrm{Cl}\right\}\right] \mathrm{PF}_{6}$ utilizando a porfirina M(4-N-Py)TFPPH 2 , o complexo $\mathrm{Ru}(\mathrm{bpy})_{2} \mathrm{Cl}_{2}$ e o cluster trinuclear de rutênio $\left[\mathrm{Ru}_{3} \mathrm{O}(\mathrm{Ac})_{6}(\mathrm{py})_{2}(\mathrm{MeOH})\right] \mathrm{PF}_{6}$. Verificar como as coordenações dos grupos modificadores alteram o comportamento eletroquímico, espectroscópico e propriedades fotofísicas da porfirina M(4-N-Py)TFPPH ${ }_{2}$. A idéia da utilização do complexo $\mathrm{Ru}(\mathrm{bpy})_{2} \mathrm{Cl}_{2}$ e do cluster trinuclear de rutênio $\left[\mathrm{Ru}_{3} \mathrm{O}(\mathrm{Ac})_{6}(\mathrm{py})_{2}(\mathrm{MeOH})\right] \mathrm{PF}_{6}$ e porfirinas é compreender se ocorre comunicação eletrônica entre as unidades combinando estudos das propriedades espectroscópicas, eletroquímicas e fotoquímicas.

- Sintetizar e caracterizar as tríades assimétricas utilizando os isômeros cis- e trans-B(4-N-Py)BFPPH $\mathrm{B}_{2}$, o complexo $\mathrm{Ru}(\mathrm{bpy})_{2} \mathrm{Cl}_{2}$ e o cluster trinuclear de rutênio $\left[\mathrm{Ru}_{3} \mathrm{O}(\mathrm{Ac})_{6}(\mathrm{py})_{2}(\mathrm{MeOH})\right] \mathrm{PF}_{6}$ para as construção das moléculas cis- e trans-[B(4-NPy)BFPPH $\left.{ }_{2}\left\{\mathrm{Ru}_{3} \mathrm{O}(\mathrm{Ac})_{6}(\mathrm{py})_{2}\right\} \quad\left\{\mathrm{Ru}(\mathrm{bpy})_{2} \mathrm{Cl}\right\}\right] \mathrm{PF}_{6}$, Verificar como a coordenação de dois grupos modificadores altera o comportamento eletroquímico, espectroscópico e das propriedades fotofísicas das porfirinas cis- e trans-B(4-N-Py) $\mathrm{BFPPH}_{2}$ e investigar as diferenças das estruturas das formas cis- e trans- das porfirinas. 


\section{III - Materiais e Métodos}

\section{III.1) Reagentes}

Os reagentes, todos de grau analítico com exceção de alguns solventes, foram obtidos comercialmente e utilizados sem purificação prévia. As procedências dos mesmos estão mostradas na Tabela 1.

Tabela 1: Procedência dos reagentes utilizados

\begin{tabular}{|c|c|}
\hline Reagente & Procedência \\
\hline \multicolumn{2}{|c|}{ Solventes } \\
\hline $\begin{array}{c}\text { ACT } \\
\text { Acetonitrila } \\
\text { Acetonitrila deuterada } \\
\text { Benzeno } \\
\text { Clorofórmio } \\
\text { Ciclohexano } \\
\text { Clorofórmio deuterado } \\
\text { Dimetilformamida } \\
\text { DCM } \\
\text { Etanol } \\
\text { Éter etílico } \\
\text { MeOH } \\
\end{array}$ & $\begin{array}{c}\text { Synth } \\
\text { Synth, Merck } \\
\text { Aldrich } \\
\text { Cinética Química } \\
\text { Synth } \\
\text { Synth } \\
\text { Aldrich } \\
\text { Synth } \\
\text { Synth, Merck } \\
\text { Synth } \\
\text { Merck } \\
\text { Synth, Merck } \\
\end{array}$ \\
\hline \multicolumn{2}{|c|}{ Outros } \\
\hline $\begin{array}{c}\text { Ácido Acético Glacial } \\
\text { Acetato de Sódio Anidro } \\
\text { Ácido fórmico } 88 \% \\
\text { Ácido sulfúrico concentrado } \\
\text { Alumina neutra } 90 \\
\mathrm{AgNO}_{3} \\
\mathrm{Bromo} \\
\mathrm{NH}_{4} \mathrm{PF}_{6} \\
\mathrm{Piridina} \\
\mathrm{RuCl}_{3} \cdot \mathrm{nH}_{2} \mathrm{O} \\
\text { Sílica } 230-400 \text { mesh } \\
\mathrm{TBAPF}_{6}\end{array}$ & $\begin{array}{l}\text { EM Science } \\
\text { Synth } \\
\text { Química Fina } \\
\text { EM Science } \\
\text { Merck } \\
\text { Cennobrás } \\
\text { Aldrich } \\
\text { Acros } \\
\text { Vetec } \\
\text { Aldrich } \\
\text { Macherey-Nagel } \\
\text { Aldrich }\end{array}$ \\
\hline
\end{tabular}




\section{III.2) Síntese dos Complexos Metálicos}

\section{III.2.1) Síntese do cluster assimétrico $\left[\mathrm{Ru}_{3} \mathrm{O}(\mathrm{Ac})_{6}(\mathrm{py})_{2}\left(\mathrm{CH}_{3} \mathrm{OH}\right)\right] \mathrm{PF}_{6}$.}

As sínteses descritas neste item foram realizadas segundo o procedimento descrito por Meyer e colaboradores ${ }^{61}$.

\section{III.2.1.1) Síntese do cluster mãe $\left[\mathrm{Ru}_{3} \mathrm{O}(\mathrm{Ac})_{6}\left(\mathrm{CH}_{3} \mathrm{OH}\right)_{3}\right] \mathrm{CH}_{3} \mathrm{COO}$.}



Figura 12: Estrutura do cluster mãe $\left[\mathrm{Ru}_{3} \mathrm{O}(\mathrm{Ac})_{6}\left(\mathrm{CH}_{3} \mathrm{OH}\right)_{3}\right] \mathrm{CH}_{3} \mathrm{COO}$.

Em um balão de $500 \mathrm{~mL}$ fez-se reagir $5 \mathrm{~g}$ de $\mathrm{RuCl}_{3} \cdot \mathrm{nH}_{2} \mathrm{O}$ (24,1 mmol) com $10 \mathrm{~g}$ de $\mathrm{Na}\left(\mathrm{CH}_{3} \mathrm{COO}\right) .3 \mathrm{H}_{2} \mathrm{O}(73,5 \mathrm{mmol})$ em uma mistura de $125 \mathrm{~mL}$ de $\mathrm{EtOH}$ e $125 \mathrm{~mL}$ de $\mathrm{H}_{3} \mathrm{CCOOH}$ glacial sob refluxo de 4 horas. Deixou-se a solução resultante em repouso por uma noite para que o excesso de $\mathrm{Na}\left(\mathrm{CH}_{3} \mathrm{COO}\right) \cdot 3 \mathrm{H}_{2} \mathrm{O}$ decantasse. Após a separação do resíduo sólido por filtração, a solução foi rotaevaporada até a formação de um óleo. Este óleo foi ressuspendido em $100 \mathrm{~mL}$ de $\mathrm{MeOH}$ e rotaevaporado novamente até a secagem. $\mathrm{O}$ procedimento foi repetido por três vezes e finalmente adicionou-se $200 \mathrm{~mL}$ de ACT para a precipitação do complexo. O sólido verde obtido foi isolado por filtração, lavado com éter etílico, seco ao ar e sob vácuo em dessecador contendo sílica gel. $(\mathrm{MM}=828,7)$

Obteve-se 7,4 g de complexo. Nesta etapa não se calcula o rendimento, pois o produto final, a despeito da filtração e das etapas de lavagem, apresenta-se contaminado com $\mathrm{Na}\left(\mathrm{CH}_{3} \mathrm{COO}\right) .3 \mathrm{H}_{2} \mathrm{O}$. 


\section{III.2.1.2) Síntese do cluster simétrico $\left[\mathrm{Ru}_{3} \mathrm{O}(\mathrm{Ac})_{6}(\mathrm{py})_{3}\right] \mathrm{PF}_{6}$.}

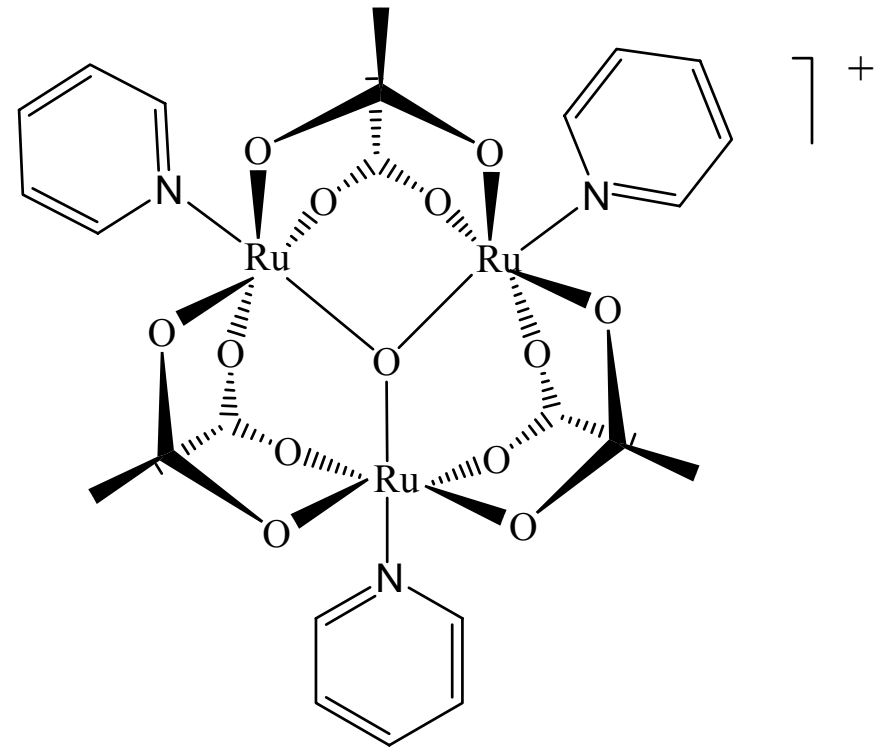

Figura 13: Estrutura do cluster simétrico $\left[\mathrm{Ru}_{3} \mathrm{O}(\mathrm{Ac})_{6}(\mathrm{py})_{3}\right] \mathrm{PF}_{6}$.

Em um balão de $500 \mathrm{~mL}$ fez-se reagir $7,4 \mathrm{~g}$ do cluster $\left[\mathrm{Ru}_{3} \mathrm{O}(\mathrm{Ac})_{6}\left(\mathrm{CH}_{3} \mathrm{OH}\right)_{3}\right] \mathrm{CH}_{3} \mathrm{COO}(9,38 \mathrm{mmol})$ com $22,2 \mathrm{~g}$ de piridina $(0,28 \mathrm{~mol})$ em 300 $\mathrm{mL}$ de $\mathrm{MeOH}$ durante refluxo de 5 minutos. Para que houvesse a troca do contra-íon do cluster formado, foi adicionada a mistura reacional uma solução de $\mathrm{NH}_{4} \mathrm{PF}_{6}$. Deixou-se a solução resultante em repouso por uma noite. A solução foi rotaevaporada até a formação de um óleo. A este óleo fez-se a adição de $100 \mathrm{~mL}$ de ACT para a precipitação do complexo. O sólido verde obtido foi isolado por filtração, lavado com éter etílico, seco ao ar e sob vácuo em dessecador contendo sílica gel.

Obteve-se 7,36 g complexo $(\eta=65 \%) .(M M=1201)$ 


\section{III.2.1.3) Síntese do cluster simétrico $\left[\mathrm{Ru}_{3} \mathrm{O}(\mathrm{Ac})_{6}(\mathrm{py})_{3}\right]$.}



Figura 14: Estrutura do cluster simétrico $\left[\mathrm{Ru}_{3} \mathrm{O}(\mathrm{Ac})_{6}(\mathrm{py})_{3}\right]$.

Em um balão de $500 \mathrm{~mL}$ dissolveu-se $6,0 \mathrm{~g}$ do cluster $\left[\mathrm{Ru}_{3} \mathrm{O}(\mathrm{Ac})_{6}(\mathrm{py})_{3}\right] \mathrm{PF}_{6}$ (5,00 mmol) em $200 \mathrm{~mL}$ de $\mathrm{MeOH}$ e $60 \mathrm{~mL}$ de ACN. Em seguida a solução foi resfriada em um banho de gelo e adicionou-se sob agitação, $70 \mathrm{~mL}$ de solução $25 \%$ de $\mathrm{N}_{2} \mathrm{H}_{4}$. Nesta etapa ocorre a precipitação do produto que foi isolado por filtração, lavado com pequenas porções de água, $\mathrm{MeOH}$ e éter etílico, seco ao ar em dessecador contendo sílica gel. Obteve-se 3,00g de complexo $(\eta=57 \%)$. $(\mathrm{MM}=1055,8)$

\section{III.2.1.4) Síntese do cluster $\left[\mathrm{Ru}_{3} \mathrm{O}(\mathrm{Ac})_{6}(\mathrm{py})_{2}(\mathrm{CO})\right] \mathrm{C}_{6} \mathrm{H}_{6}$.}

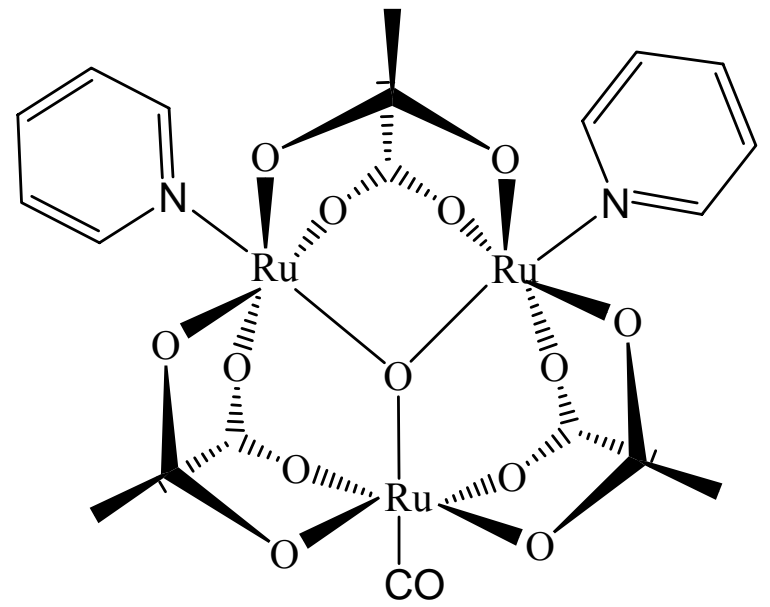

Figura 15: Estrutura do cluster $\left[\mathrm{Ru}_{3} \mathrm{O}(\mathrm{Ac})_{6}(\mathrm{py})_{2}(\mathrm{CO})\right] \mathrm{C}_{6} \mathrm{H}_{6}$. 
Em um balão de três bocas de $500 \mathrm{~mL}$ foram dissolvidas $3,00 \mathrm{~g}$ de $\left[\mathrm{Ru}_{3} \mathrm{O}(\mathrm{Ac})_{6}(\text { py })_{3}\right](2,84 \mathrm{mmol})$ em $200 \mathrm{~mL}$ de benzeno e $60 \mathrm{~mL}$ de $\mathrm{MeOH}$, que foi desaerada com $\operatorname{Ar}(\mathrm{g})$ por aproximadamente 40 minutos. Em seguida fez-se o refluxo durante 4 horas sob o fluxo de $\mathrm{CO}_{(\mathrm{g})}$ (gerado pela reação entre $\mathrm{H}_{2} \mathrm{SO}_{4}$ conc. com $\mathrm{HCOOH}$ ).

A solução foi rotaevaporada até aproximadamente $2 / 3$ do volume inicial e foi deixada em geladeira por 4 horas. Houve a formação um sólido azul escuro que foi isolado por filtração, lavado com éter etílico e seco ao ar em dessecador contendo sílica gel. Obteve-se $1,45 \mathrm{~g}$ de produto $(\eta=54 \%)$. $(\mathrm{MM}=937,8)$

\section{III.2.1.5) Síntese do cluster assimétrico $\left[\mathrm{Ru}_{3} \mathrm{O}(\mathrm{Ac})_{6}(\mathrm{py})_{2}\left(\mathrm{CH}_{3} \mathrm{OH}\right)\right] \mathrm{PF}_{6}$.}

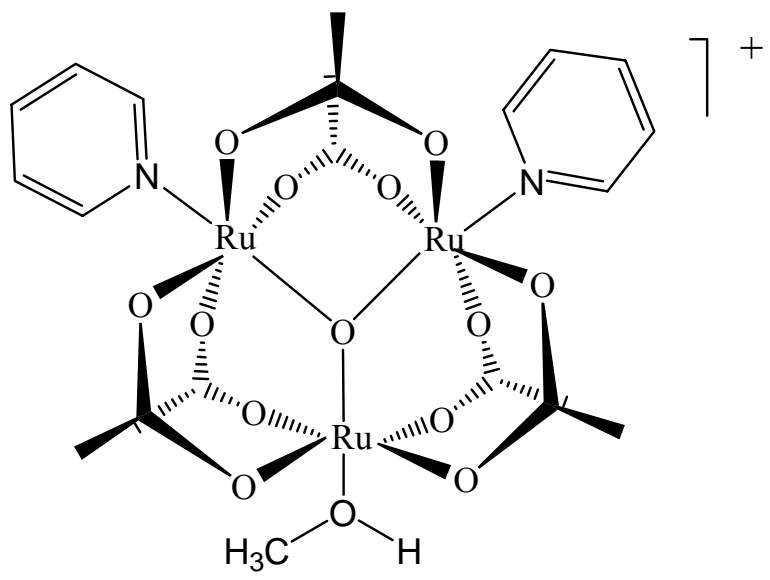

Figura 16: Estrutura do cluster assimétrico $\left[\mathrm{Ru}_{3} \mathrm{O}(\mathrm{Ac})_{6}(\text { py })_{2}\left(\mathrm{CH}_{3} \mathrm{OH}\right)\right] \mathrm{PF}_{6}$.

Em um balão de $500 \mathrm{~mL}$ dissolveu-se $1,45 \mathrm{~g}$ de $\left[\mathrm{Ru}_{3} \mathrm{O}(\mathrm{Ac})_{6}(\mathrm{py})_{2}(\mathrm{CO})\right] \mathrm{C}_{6} \mathrm{H}_{6}$ (1,54 mmol) em $110 \mathrm{~mL}$ de $\mathrm{CH}_{2} \mathrm{Cl}_{2}$. Adicionou-se lentamente, sob agitação, $27,5 \mathrm{~mL}$ de solução $0,15 \mathrm{~mol} \mathrm{~L}^{-1}$ de $\mathrm{Br}_{2}$ em $\mathrm{CH}_{2} \mathrm{Cl}_{2}$. A solução final foi agitada por 2 horas e rotaevaporada até a secagem completa; o resíduo foi ressuspendido $180 \mathrm{~mL}$ de $\mathrm{MeOH}$ e refluxado por 30 minutos. Em seguida adicionou-se uma solução de $\mathrm{NH}_{4} \mathrm{PF}_{6}$ preparada através da dissolução de 1,4g (8,3 mmol) em aproximadamente em $20 \mathrm{~mL}$ de $\mathrm{MeOH}$; a solução final foi resfriada a $0{ }^{\circ} \mathrm{C}$, quando ocorre a precipitação de um sólido azul escuro. $\mathrm{O}$ produto foi isolado por filtração, lavado com éter etílico, seco ao ar e sob vácuo em dessecador contendo sílica gel. Obteve-se $1,18 \mathrm{~g}$ de produto $(\eta=76 \%)$. Os resultados de microanálise são dados a seguir (os valores calculados estão entre parênteses):(MM = $1008,7) \% \mathrm{C}: 27,26(27,39) ; \% \mathrm{H}: 3,28(3,20) ; \% \mathrm{~N}: 2,73(2,78)$. 


\section{III.2.2) Síntese do Complexo $\left[\mathrm{Ru}(\mathrm{bpy})_{2} \mathrm{Cl}_{2}\right] \cdot 2 \mathrm{H}_{2} \mathrm{O}$}

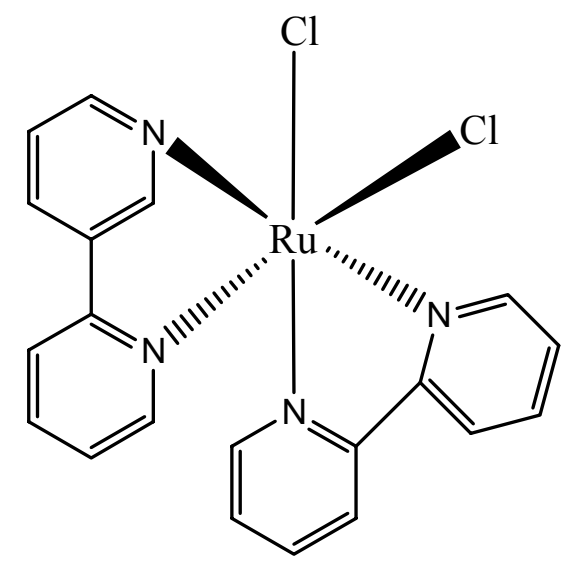

Figura 17: Estrutura do Complexo $\left[\mathrm{Ru}(\mathrm{bpy})_{2} \mathrm{Cl}_{2}\right] \cdot 2 \mathrm{H}_{2} \mathrm{O}$

Esta síntese foi realizada segundo procedimento descrito na literatura ${ }^{62}$. Em um balão de $250 \mathrm{~mL}$ fez-se reagir 5,0 g de $\mathrm{RuCl}_{3} \cdot \mathrm{nH}_{2} \mathrm{O}$ (24 mmol), 6,1 g de 2,2’bipiridina (39 mmol) e 5,8 g de $\operatorname{LiCl}(0,137 \mathrm{~mol})$ em $30 \mathrm{ml}$ de DMF destilada, sob refluxo durante 8 horas; a solução foi mantida sob fluxo de $\operatorname{Ar}(g)$ e protegida de luz direta. Em seguida a solução foi resfriada até temperatura ambiente. Nesta etapa existe grande quantidade de sólido no balão, o qual foi isolado por filtração. O material foi lavado com ACT e água, para remover o excesso de $\mathrm{LiCl}$ e $\left[\mathrm{Ru}(\mathrm{bpy})_{3}\right]^{+2}$ que pode eventualmente ter-se formado ao longo da reação; lavou-se com água até que o teste para $\mathrm{Cl}^{-}$do filtrado, feito com $\mathrm{Ag}^{+}$, fosse negativo. Por fim o produto foi lavado com ACT, seco ao ar e sob vácuo em dessecador contendo sílica gel.

Obteve-se 9,8 g de produto $(\eta=79 \%)$. Os resultados de microanálise são dados a seguir (valores calculados são dados entre parênteses): $(\mathrm{MM}=520,4) \% \mathrm{C}: 47,5$ (46,2); \%H: 3,6 $(3,9)$ e $\% \mathrm{~N}: 10,9(10,8)$. 


\section{III.3) Síntese de porfirinas 4-N-piridil e pentafluorofenil substituídas.}

As sínteses descritas neste item foi realizada segundo o método modificado de Adler e Longo.

\section{III.3.1) Primeira síntese}

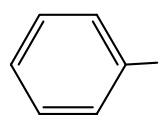

$\mathrm{Ph}$

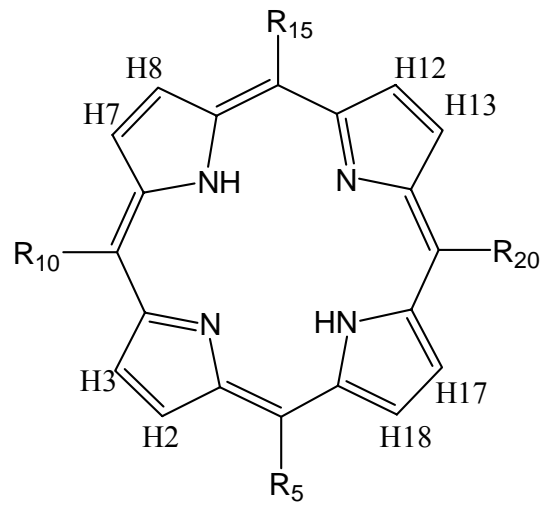

$2 \quad \mathbf{R}_{\mathbf{5}}=\mathbf{R}_{\mathbf{1 0}}=\mathbf{R}_{\mathbf{1 5}}=\mathbf{R}_{\mathbf{2 0}}=\mathrm{F}_{5} \mathrm{Ph}$

$3 \quad \mathbf{R}_{\mathbf{5}}=\mathbf{R}_{\mathbf{1 0}}=\mathbf{R}_{\mathbf{1 5}}=\mathrm{F}_{5} \mathrm{Ph}$

$$
\mathbf{R}_{\mathbf{2 0}}=4 \text { - N-piridil }
$$

$$
\mathbf{R}_{\mathbf{5}}=\mathbf{R}_{\mathbf{1 0}}=\mathrm{F}_{5} \mathrm{Ph}
$$

4

$$
\mathbf{R}_{\mathbf{1 5}}=\mathbf{R}_{\mathbf{2 0}}=4 \text {-N-piridil }
$$$$
\mathbf{R}_{\mathbf{5}}=\mathbf{R}_{\mathbf{1 5}}=\mathrm{F}_{5} \mathrm{Ph}
$$

$5 \quad \mathbf{R}_{\mathbf{1 0}}=\mathbf{R}_{\mathbf{2 0}}=4$-N-piridil

$$
\mathbf{R}_{5}=\mathrm{F}_{5} \mathrm{Ph}
$$

6

$\mathbf{R}_{\mathbf{1 0}}=\mathbf{R}_{\mathbf{1 5}}=\mathbf{R}_{\mathbf{2 0}}=4$ - N-piridil
Nomenclatura

5,10,15,20-fenilporfirina

$5,10,15,20-$

tetrapentafluorofenilporfirina

5,10,15-tris(pentafluorofenil)20-mono-(4-N-piridil)porfirina.

5,10-bis(pentafluorofenil)15,20-bis(4-N-piridil)porfirina. cis-B(4-N-Py)BPPH

5,15-bis(pentafluorofenil)5,15-bis(pentafluorofenil)-
10,20-bis(4-N-piridil)porfirina. 5-mono(pentafluorofenil)10-15-20-mono-(4-Npiridil)porfirina.

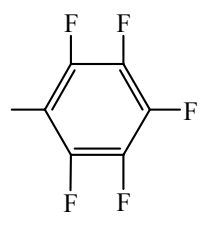

$\mathrm{F}_{5} \mathrm{Ph}$

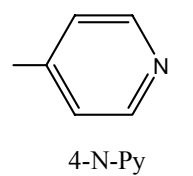

Abreviaturas

$\mathrm{TPPH}_{2}$

Comercial

$\mathrm{TFPPH}_{2}$

Comercial

$\mathrm{M}(4-\mathrm{N}-\mathrm{Py}) \mathrm{TFPPH}_{2}$ T(4-N-Py) $\mathrm{MFPPH}_{2}$ $\mathrm{T}(4-\mathrm{N}-\mathrm{Py}) \mathrm{PH}_{2}$ Comercial

$7 \quad \mathbf{R}_{\mathbf{5}}=\mathbf{R}_{\mathbf{1 0}}=\mathbf{R}_{\mathbf{1 5}}=\mathbf{R}_{\mathbf{2 0}}=4-\mathrm{N}-$

5,10,15,20-tetrapiridillporfirina

Figura 18: Porfirinas base livre obtidas nas sínteses.

Em um balão de $500 \mathrm{~mL}$ de duas bocas adicionou-se $200 \mathrm{~mL}$ de ácido propiônico $\left(8,0 \times 10^{-2} \mathrm{~mol}\right), 4,70 \mathrm{~mL}$ de pentafluoro-benzaldeído $\left(3,8 \times 10^{-2} \mathrm{~mol}\right)$ e $4,00 \mathrm{~mL}$ de 4 - 
piridilcarboxialdeído (4,2 x $\left.10^{-2} \mathrm{~mol}\right)$. Manteve-se a mistura sob agitação magnética e aquecimento sob condições aeróbicas. Fez-se a adição gradativa de 5,55 mL de pirrol $\left(8,0 \times 10^{-2} \mathrm{~mol}\right)$ após atingir-se o refluxo $\left(\mathrm{T}=150^{\circ} \mathrm{C}\right)$. A solução clara (amarela) tornou-se escura. Prosseguiu-se a reação por 2 horas e fez-se a interrupção pelo resfriamento do balão. O balão foi mantido em repouso até se atingir a temperatura ambiente. Rotaevaporou-se o ácido propiônico e posteriormente a mistura reacional foi percolada diretamente em coluna de sílica gel para pré-purificação. Após a separação das diferentes porfirinas detectou-se a presença das seguintes espécies: $\mathrm{TFPPH}_{2}, \mathrm{M}(4-\mathrm{N}-\mathrm{Py}) \mathrm{TFPPH}_{2}$, cis$\mathrm{B}(4-\mathrm{N}-\mathrm{Py}) \mathrm{BPPH}_{2}$, trans-B(4-N-Py)BPPH $\mathrm{B}_{2}$ (Figura 18) por CCD, mediante comparação com porfirinas padrões existentes no laboratório. As porfirinas de interesse foram identificadas e purificadas em coluna de sílica gel como mostra o fluxograma da Figura 19.

\section{III.3.2) Segunda síntese}

Com a finalidade de se obter mais porfirinas, especialmente a trans-B(4-N$\mathrm{Py}_{\mathrm{BPPH}}$ (Figura 18), a síntese foi repetida, variando a proporção dos reagentes. Em um balão de $500 \mathrm{~mL}$ de duas bocas adicionou-se $200 \mathrm{~mL}$ de ácido propiônico $\left(8,0 \times 10^{-2} \mathrm{~mol}\right)$, 3,70 $\mathrm{mL}$ de pentafluoro-benzaldeído $\left(3,0 \times 10^{-2} \mathrm{~mol}\right)$ e 4,80 $\mathrm{mL}$ de 4-piridilcarboxialdeído $\left(5,0 \times 10^{-2} \mathrm{~mol}\right)$. Manteve-se a mistura sob agitação magnética e aquecimento sob condições aeróbicas. Fez-se a adição gradativa de $5,55 \mathrm{~mL}$ de pirrol $\left(8,0 \times 10^{-2} \mathrm{~mol}\right)$ após atingir-se o refluxo $\left(\mathrm{T}=150^{\circ} \mathrm{C}\right)$. A solução clara (amarela) tornou-se escura. Prosseguiu-se a reação por 2 horas e fez-se a interrupção pelo resfriamento do balão. $\mathrm{O}$ balão foi mantido em repouso até atingir-se a temperatura ambiente. $\mathrm{O}$ ácido propiônico foi rota-evaporado e posteriormente fez-se a adição de $200 \mathrm{~mL}$ de EtOH à massa viscosa formada. A solução foi agitada e filtrada em funil de placa sinterizada. O sólido obtido foi lavado com EtOH até que a coloração preta inicial do filtrado desaparecesse. Em seguida, o sólido foi lavado com éter etílico e mantido num dessecador sob vácuo. Assim, foram obtidos 1,68 g de um sólido violeta brilhante constituído pela mistura, trans-B(4-N-Py)BPPH $\mathrm{B}_{2}$, cis-B(4-N$\mathrm{Py}_{\mathrm{BPPH}}$, T(4-N-Py) $\mathrm{MFPPH}_{2}$ e T(4-N-Py) $\mathrm{PH}_{2}$, além de uma pequena percentagem de outras impurezas. As porfirinas de interesse foram identificadas e purificadas em coluna de sílica gel como mostra o fluxograma da Figura 20. 


\section{III.4) Pré-purificação, separação e purificação das porfirinas 4-N-piridil e} pentafluorofenil substituídas por cromatografia em coluna

\section{III.4.1) Tentativa de pré-purificação dos produtos da primeira síntese das porfirinas.}

Após o termino da reação de condensação das porfirinas o ácido propiônico foi retirado através de rotaevaporação. Há a formação de uma massa viscosa. Com esta massa viscosa foi feito um teste de precipitação de porfirinas baseado na dissertação do aluno Fábio Engelmann ${ }^{63}$, que trabalhou com fenil-piridil-porfirinas. A uma pequena quantidade desta massa foram adicionados $2 \mathrm{~mL}$ da mistura DMF/EtOH 1:1, agitada e filtrada em funil de placa sinterizada. Ocorreu toda a solubilização da amostra, não sendo possível a separação das pentafluoro-piridil-porfirinas através deste método.

\section{III.4.2) Separação das porfirinas 4-N-piridil e pentafluorofenil substituídas} obtidas na primeira síntese, por cromatografia em coluna de sílica gel.

A mistura de porfirinas base livre obtida na síntese foi solubilizada em DCM e purificada em coluna de sílica gel. Para purificar e separar as porfirinas formadas fez-se uma única coluna cromatográfica $(\mathrm{CS} 1)$ de $6,0 \mathrm{~cm}$ de diâmetro contendo sílica até uma altura de $40 \mathrm{~cm}$ e utilizou-se o solvente/mistura de solventes pré-estabelecidos por CCD. A coluna foi montada seguindo o procedimento a seguir: agitou-se a sílica com a fase móvel (DCM) em excesso num béquer, a qual foi então transferida para a coluna até que fosse obtida a altura desejada. Fez-se a compactação da coluna dando pequenas batidas na mesma utilizando um bastão de vidro com uma rolha na ponta. Deixou-se à coluna em repouso por 30 minutos para que a mesma se torne homogênea. Fez-se a eluição do solvente e posteriormente percolou-se a solução de porfirinas em DCM com o auxílio de uma pipeta Pasteur.

A mistura de porfirinas foi eluída com as proporções de ACT em DCM representadas abaixo. As frações separadas nesta coluna estão representadas na Figura 19. 


\section{Fr1-5: DCM}

Fr6-15: 10\% de ACT e 90\% DCM

Fr14-18: 20\% de ACT e 80\% DCM

Fr19-24: 30\% de ACT e 70 DCM

Fr25-27: 40 de ACT e 60\% DCM

Fr28-32: $50 \%$ de ACT e $50 \%$ DCM

Fr33-36: 70\% de ACT e $30 \%$ DCM

Fr37-41: $\mathrm{MeOH}$

Muitas impurezas ficaram retidas no topo desta coluna e o principal objetivo era a separação e identificação das diferentes porfirinas formadas, e este foi alcançado.

Para se fazer a CCD utilizaram-se placas cromatográficas de sílica gel e aplicaramse pequenas quantidades dos padrões de porfirina disponíveis no laboratório $\left(\mathrm{TFPPH}_{2}, \quad \mathrm{M}(4-\mathrm{N}-\mathrm{Py}) \mathrm{TFPPH}_{2}\right.$, cis-B(4-N-Py)BFPPH 2 , T(4-N-Py)MFPPH $\mathrm{B}_{2}$ em cada placa, juntamente com as frações que foram eluídas das colunas. As amostras eram aplicadas nas placas cromatográficas com ajuda de um capilar. Após a aplicação coloca-se a placa em cuba com DCM, para permitir a separação das amostras. Não é necessária uma etapa de revelação dos cromatogramas, mas é necessário que se utilize uma lâmpada de ultravioleta, pois as porfïinas são excitadas no ultravioleta e emitem no visível e assim é possível identificar as diferentes porfirinas nas diversas frações eluídas através do $\mathrm{R}_{\mathrm{f}}$ característico de cada porfirina (Tabela 2). 
Tabela 2: $\mathrm{R}_{\mathrm{f}}$ das diferentes porfirinas obtidas na síntese

\begin{tabular}{cc}
\hline Porfirina & $\mathbf{R}_{\mathbf{f}}{ }^{\text {(a) }}$ \\
\hline TFPPH $_{2}$ & 0,98 \\
$\mathrm{M}(4-\mathrm{N}-\mathrm{Py}) \mathrm{TFPPH}_{2}$ & 0,34 \\
trans-B(4-N-Py)BFPPH & 0,15 \\
cis-B(4-N-Py)BFPPH $_{2}$ & 0,08 \\
$\mathrm{~T}(4-\mathrm{N}-\mathrm{Py}) \mathrm{MFPPH}_{2}$ & 0,04 \\
$\mathrm{~T}(4-\mathrm{N}-\mathrm{Py}) \mathrm{PH}_{2}$ & 0,01 \\
\hline
\end{tabular}

(a) medidas feitas utilizando sílica gel como fase estacionária e DCM como fase móvel.

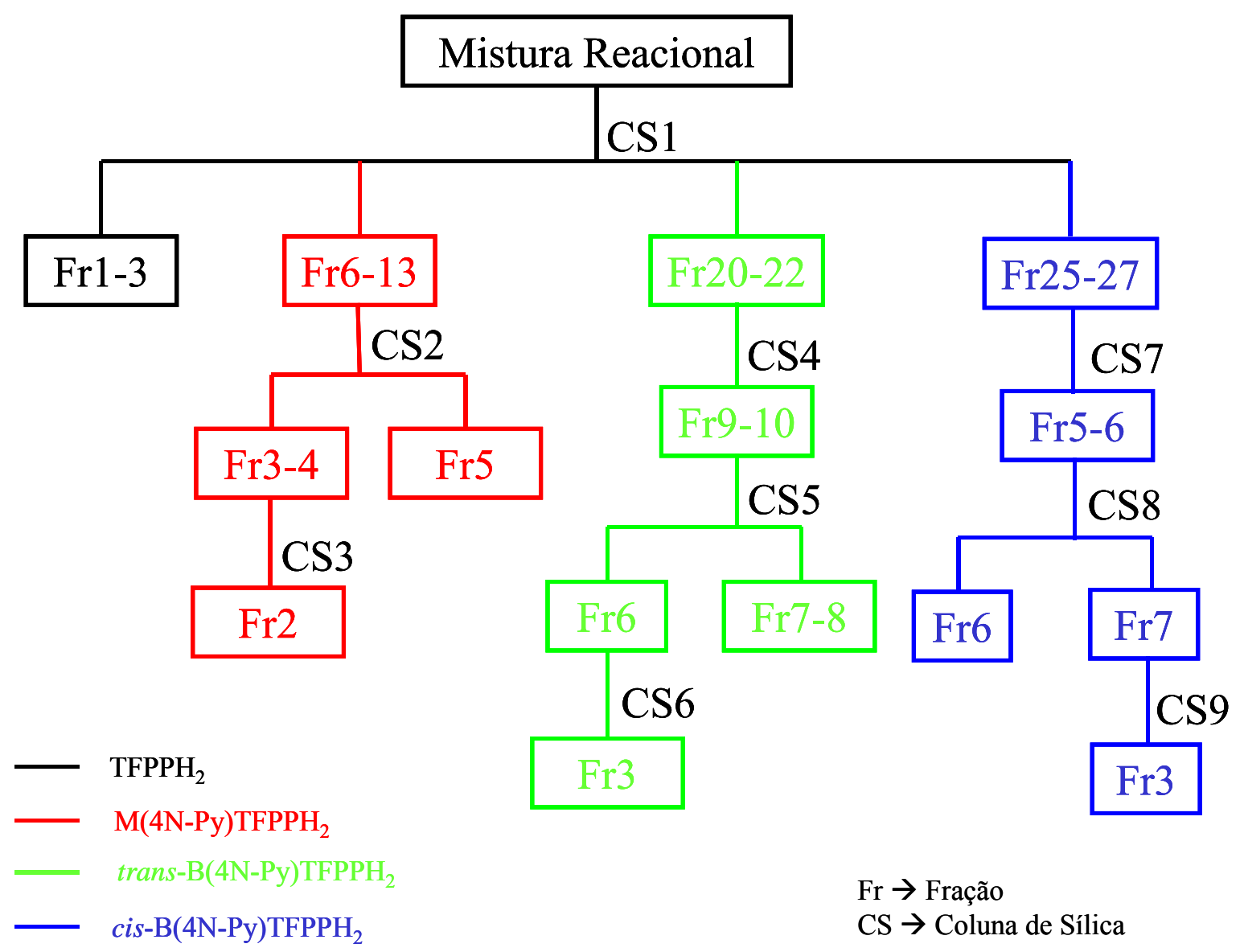

Figura 19: Fluxograma de separação da primeira síntese das porfirinas. 


\section{III.4.3) Purificação das porfirinas base livre pentafluorofenil e 4-N-piridil substituídas obtidas na primeira síntese.}

Pela CCD observou-se que as porfirinas obtidas foram separadas uma das outras e as mesmas estavam impuras. Procedeu-se então à purificação das frações que continham as porfirinas de interesse $\mathrm{M}(4-\mathrm{N}-\mathrm{Py}) \mathrm{BFPPH}_{2}$, trans-B(4-N-Py)BFPPH $\mathrm{B}_{2}$ e cis-B(4-N-Py)BFPPH ${ }_{2}$.

Para purificar as porfirinas descritas acima foram feitas 8 colunas de sílica (CS2 a CS9 Tabela 3), representadas na Figura 19, e o procedimento utilizado para todas as colunas, é o mesmo descrito no item III.4.2. Em todos os experimentos a eluição foi acompanhada por espectroscopia UV-Vis e CCD. Os solventes/misturas de solventes utilizados foram escolhidos previamente através de testes em CCD em sílica da fração a ser purificada e as condições da eluição da porfirina desejadas são apresentadas na Tabela 3. Para todas as colunas utilizou-se sílica gel 230-400 mesh. Os solventes utilizados foram DCM, ACT, MeOH e em diferentes proporções (Tabela 3).

Obteve-se $232 \mathrm{mg}$ da porfirina M(4-N-Py)TFPPH $2,166 \mathrm{mg}$ da porfirina trans-B(4$\mathrm{N}-\mathrm{Py}) \mathrm{BFPPH}_{2}$ e $437 \mathrm{mg}$ da porfirina cis-B(4-N-Py)BFPPH${ }_{2}$.

As microanálises dos compostos de interesse foram feitas no Laboratório de Microanálise do Instituto de Química - USP. Encontraram-se os seguintes valores (os valores calculados estão entre parênteses): para a porfirina $\mathrm{M}(4-\mathrm{N}-\mathrm{Py}) \mathrm{TFPPH}_{2} \% \mathrm{C}: 58,42$ $(58,32), \% \mathrm{~N}: 7,88(7,91), \% \mathrm{H}: 1,55(1,59)$, para a porfirina trans-B(4-N-Py)BFPPH ${ }_{2} \% \mathrm{C}$ : $63,67(63,33), \% \mathrm{~N}: 10,44(10,55), \% \mathrm{H}: 2,21(2,27)$ e para a porfirina cis-B(4-NPy)BFPPH 2 \%C: 63,10 (63,33 ), \% N: 10,10 (10,55), \%H: 2,37 (2,27). Os valores obtidos são compatíveis com os calculados. 
Tabela 3: Purificação das porfirinas $\mathrm{M}(4-\mathrm{N}-\mathrm{Py}) \mathrm{TFPPH}_{2}$, trans-B(4-N-Py) $\mathrm{BFPPH}_{2}$ e cis-B(4-N-Py)BFPPH ${ }_{2}$

\begin{tabular}{|c|c|c|c|c|}
\hline $\begin{array}{c}\text { Coluna de } \\
\text { Sílica }\end{array}$ & Diametro & Altura (cm) & Eluente & $\begin{array}{c}\text { Frações } \\
\text { recolhidas }\end{array}$ \\
\hline \multirow[t]{4}{*}{ CS2 } & 4,0 & 30 & DCM & 1 \\
\hline & & & $5 \%$ ACT em DCM & $2-3$ \\
\hline & & & $10 \%$ ACT em DCM & $4-5$ \\
\hline & & & $15 \%$ ACT em DCM & $6-10$ \\
\hline \multirow[t]{2}{*}{ CS3 } & 2,0 & 20 & DCM & 1 \\
\hline & & & $10 \%$ ACT em DCM & $2-4$ \\
\hline \multirow[t]{6}{*}{ CS4 } & 4,0 & 22 & DCM & $1-3$ \\
\hline & & & $5 \%$ ACT em DCM & $4-5$ \\
\hline & & & $10 \%$ ACT em DCM & $6-7$ \\
\hline & & & $15 \%$ ACT em DCM & 8 \\
\hline & & & $20 \%$ ACT em DCM & $9-11$ \\
\hline & & & $\mathrm{MeOH}$ & $12-13$ \\
\hline \multirow[t]{3}{*}{ CS5 } & 2,0 & 25 & DCM & 1 \\
\hline & & & $30 \%$ ACT em DCM & $2-10$ \\
\hline & & & $\mathrm{MeOH}$ & 11 \\
\hline \multirow[t]{2}{*}{ CS6 } & 2,0 & 15 & DCM & 1 \\
\hline & & & $30 \%$ ACT em DCM & $2-5$ \\
\hline \multirow[t]{6}{*}{ CS7 } & 4,0 & 27 & DCM & 1 \\
\hline & & & $10 \%$ ACT em DCM & $2-3$ \\
\hline & & & $20 \%$ ACT em DCM & 4 \\
\hline & & & $30 \%$ ACT em DCM & $5-6$ \\
\hline & & & $40 \%$ ACT em DCM & $7-9$ \\
\hline & & & $\mathrm{MeOH}$ & $10-11$ \\
\hline \multirow[t]{3}{*}{ CS8 } & 2,0 & 23 & DCM & 1 \\
\hline & & & $50 \% \mathrm{ACT}$ em DCM & $2-8$ \\
\hline & & & $\mathrm{MeOH}$ & 9 \\
\hline \multirow[t]{2}{*}{ CS9 } & 2,0 & 16 & DCM & 1 \\
\hline & & & $50 \%$ ACT em DCM & $2-5$ \\
\hline
\end{tabular}




\section{III.4.4) Pré-purificação dos produtos da segunda síntese das porfirinas.}

Após o termino da reação de condensação das porfirinas o ácido propiônico foi retirado através de rotaevaporação. Há a formação de uma massa viscosa. Na primeira síntese foi feito um teste para a precipitação das porfirinas (baseado na dissertação de mestrado de Fábio Engelmann, trabalhou com fenil-piridil-porfirinas), usando uma mistura DMF/EtOH 1:1, não sendo possível precipitação das pentafluoro-piridil-porfirinas através deste método.

Nesta nova síntese de porfirinas foram feitos novos testes com outros solventes. Descobriu-se que é possível fazer uma pré-purificação utilizando o EtOH. Muitos dos subprodutos da síntese de porfirinas são solúveis em EtOH e as pentafluorofenil-piridilporfirinas apresentam solubilidade um pouco menor neste solvente. Tratou-se a mistura com porção de $250 \mathrm{~mL}$ de EtOH, separou-se a porfirina. O filtrado foi rotaevaporado e tratado novamente com porção de $250 \mathrm{~mL}$ de EtOH, e separada a porfirina sólida, repetindo-se o processo mais uma vez. Os sólidos obtidos das três filtrações foram juntados e purificados de acordo com o fluxograma da Figura 20. Comparando o fluxograma da Figura 20 com o fluxograma da Figura 19 percebe-se que há uma maior facilidade de purificação das porfirinas quando se faz uma pré-purificação com EtOH, porque envolveu um número muito menor de separações cromatográficas.

\section{III.4.5) Separação das porfirinas 4-N-piridil e pentafluorofenil substituídas} obtidas na seguna síntese, por cromatografia em coluna de sílica gel

Após a pré-purificação, a mistura de porfirinas base livre obtida na síntese foi solubilizada em DCM e purificada em coluna de sílica gel. Para purificar e separar as porfirinas formadas fez-se uma única coluna cromatográfica $(\mathrm{CS} 1)$ de $6,0 \mathrm{~cm}$ de diâmetro contendo sílica até uma altura de $40 \mathrm{~cm}$ e utilizou-se o solvente/mistura de solventes préestabelecidos por CCD. A coluna foi montada seguindo o procedimento descrito no item III.4.2.

A mistura de porfirinas foi eluída com as proporções de ACT em DCM representadas abaixo. As frações separadas nesta coluna estão representadas na Figura 20 


\section{Fr1: DCM}

Fr2-3: $10 \%$ de ACT e 90\% DCM

Fr4: 50\% de ACT e 50\% DCM

Fr5: $80 \%$ de ACT e 20\% DCM

Muitas impurezas foram retiradas na pré-purificação com EtOH e outras ficaram retidas no topo desta coluna, o principal objetivo era a separação e identificação das diferentes porfirinas formadas, e este foi alcançado.

A identificação das porfirinas por CCD foi feita do mesmo modo descrito no item III.4.2.

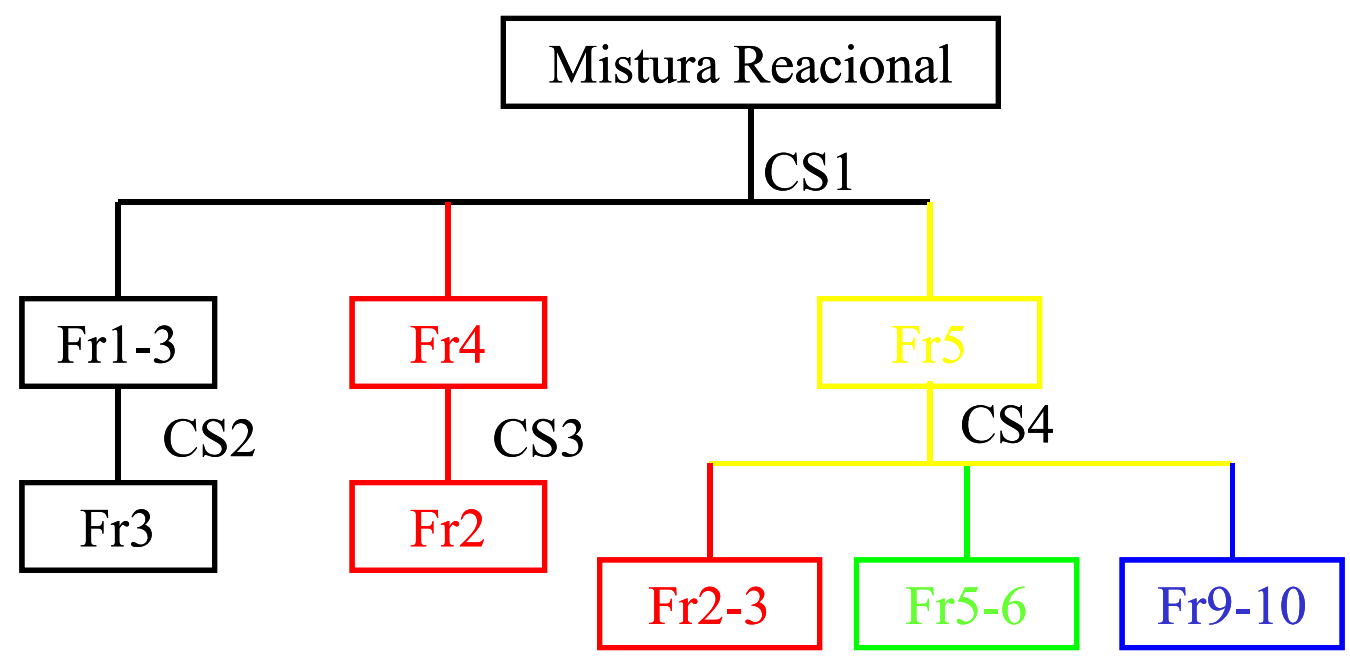

\footnotetext{
trans-B(4N-Py) $\mathrm{TFPPH}_{2}$

cis-B(4N-Py) $\mathrm{TFPPH}_{2}$ $\mathrm{T}(4 \mathrm{~N}-\mathrm{Py}) \mathrm{MFPPH}_{2}$

$-\quad \mathrm{T}(4-\mathrm{N}-\mathrm{Py}) \mathrm{PH}_{2}$
}

Fr $\rightarrow$ Fração

$\mathrm{CS} \rightarrow$ Coluna de Sílica

Figura 20: Fluxograma de separação da segunda síntese das porfirinas. 


\section{III.4.6) Purificação das porfirinas base livre pentafluorofenil e 4-N-piridil} substituídas obtidas na segunda síntese.

No fluxograma apresentado na Figura 20 mostra como as porfirinas foram separadas na CS1. Pela CCD observou-se que as porfirinas obtidas na CS1 estavam impuras. As purificações das frações que continham as porfirinas de interesse trans-B(4N-Py)BFPPH ${ }_{2}$, cis-B(4-N-Py)BFPPH ${ }_{2}$, T(4-N-Py)MFPPH 2 e T(4-N-Py)PH $\mathrm{MH}_{2}$ foram feitas em 3 colunas de sílica (CS2 a CS4 Tabela 4), representadas na Figura 20. O procedimento utilizado para todas as colunas foi o mesmo descrito no item III.4.2.

Tabela 4: Purificação das porfirinas trans-B(4-N-Py)BFPPH ${ }_{2}$, cis-B(4-N-Py)BFPPH ${ }_{2}$, $\mathrm{T}(4-\mathrm{N}-\mathrm{Py}) \mathrm{MFPPH}_{2}, \mathrm{~T}(4-\mathrm{N}-\mathrm{Py}) \mathrm{PH}_{2}$

\begin{tabular}{|c|c|c|c|c|}
\hline $\begin{array}{l}\text { Coluna de } \\
\text { Sílica }\end{array}$ & Diametro & Altura (cm) & Eluente & $\begin{array}{c}\text { Frações } \\
\text { recolhidas }\end{array}$ \\
\hline \multirow[t]{4}{*}{ CS2 } & 4,0 & 30 & DCM & 1 \\
\hline & & & $10 \%$ ACT em DCM & 2 \\
\hline & & & $20 \%$ ACT em DCM & 3 \\
\hline & & & $30 \%$ ACT em DCM & 4 \\
\hline \multirow[t]{3}{*}{ CS3 } & 4,0 & 30 & $30 \%$ ACT em DCM & 1 \\
\hline & & & $40 \%$ ACT em DCM & 2 \\
\hline & & & $50 \%$ ACT em DCM & 3 \\
\hline \multirow[t]{6}{*}{ CS4 } & 4,0 & 30 & $40 \%$ ACT em DCM & 1 \\
\hline & & & $50 \%$ ACT em DCM & $2-3$ \\
\hline & & & $60 \%$ ACT em DCM & 4 \\
\hline & & & $70 \%$ ACT em DCM & $5-6$ \\
\hline & & & $80 \%$ ACT em DCM & $7-9$ \\
\hline & & & $90 \%$ ACT em DCM & $10-11$ \\
\hline
\end{tabular}

As eluições foram acompanhadas por espectroscopia UV-Vis e CCD. Os solventes /misturas de solventes utilizados foram estabelecidos previamente através de testes em CCD em sílica. As condições da eluição das porfirinas são apresentadas na Tabela 4. Para todas as colunas utilizou-se sílica gel 230-400 mesh. Os solventes utilizados foram DCM, ACT, MeOH em diferentes proporções (Tabela 4). 
Obteve-se $79 \mathrm{mg}$ da porfirina da porfirina trans-B(4-N-Py)BFPPH $2,182 \mathrm{mg}$ da porfirina cis-B(4-N-Py)BFPPH $2315 \mathrm{mg}$ da porfirina T(4-N-Py)MFPPH 2 e $23 \mathrm{mg}$ da porfirina $\mathrm{T}(4-\mathrm{N}-\mathrm{Py}) \mathrm{PH}_{2}$.

A análise elementar da porfirina T(4-N-Py) $\mathrm{MFPPH}_{2}$ foi feita no Laboratório de Microanálise do Instituto de Química - USP, encontrou-se os seguintes valores (os valores calculados estão entre parênteses): para a porfirina T(4-N-Py) $\mathrm{MFPPH}_{2} \cdot 2 \mathrm{H}_{2} \mathrm{O} \% \mathrm{C}$ : 65,56 $(66,20), \% \mathrm{~N}: 12,94(13,18), \% \mathrm{H}: 3,54(3,53)$. Os valores obtidos são compatíveis com os calculados. As outras porfirinas já foram caracterizadas por análise elementar e nesta etapa do desenvolvimento do projeto estas porfirinas foram caracterizadas somente por comparação dos valores de $\mathrm{R}_{\mathrm{f}}$ e por ressonância magnética nuclear (RMN).

\section{III.5) Síntese e purificação de supermoléculas}

\section{III.5.1) Síntese e purificação da díade $\left[M(4-N-P y) \operatorname{TFPPH}_{2}\left\{\operatorname{Ru}_{3} \mathrm{O}(\mathrm{Ac})_{6}(\mathrm{py})_{2}\right\}\right]$ $\mathrm{PF}_{6}$ (Supermolécula 1, Figura 21).}

Em um balão de $250 \mathrm{~mL}$ dissolveram-se $101 \mathrm{mg}$ da porfirina $\mathrm{M}(4-\mathrm{N}-\mathrm{Py}) \mathrm{TFFPH}_{2}$ $\left(1,1 \times 10^{-4} \mathrm{~mol}\right)$ em $10 \mathrm{~mL}$ de DCM e separadamente foi dissolvido $170 \mathrm{mg}$ de cluster assimétrico $\left[\mathrm{Ru}_{3} \mathrm{O}(\mathrm{Ac})_{6}(\mathrm{py})_{2}\left(\mathrm{CH}_{3} \mathrm{OH}\right)\right] \mathrm{PF}_{6}\left(1,7 \times 10^{-4} \mathrm{~mol}\right)$ em $40 \mathrm{~mL}$ de DCM. A proporção utilizada foi de 1,5:1 (cluster/porfirina). A solução de cluster foi introduzida no balão de $250 \mathrm{~mL}$ onde estava a porfirina dissolvida. A reação foi feita em temperatura ambiente sob condições aeróbicas e teve duração de 82 horas sob agitação magnética. Após o término da síntese, a solução foi rotaevaporada até a formação de um sólido de cor roxa. Obteve-se $260 \mathrm{mg}$ de produtos. A purificação dos produtos foi feita através de coluna cromatográfica em alumina neutra, utilizando procedimento já descrito no item III.4.2. Utilizou-se uma coluna de $19,5 \mathrm{~cm}$ de altura $\mathrm{com} 2,6 \mathrm{~cm}$ de diâmetro. A eluição foi acompanhada por espectroscopia UV-Vis e CCD. Primeiramente foi utilizado DCM como eluente, depois foi adicionado gradativamente $\mathrm{ACN}$, até que a proporção final no eluente 




Supermolécula 1

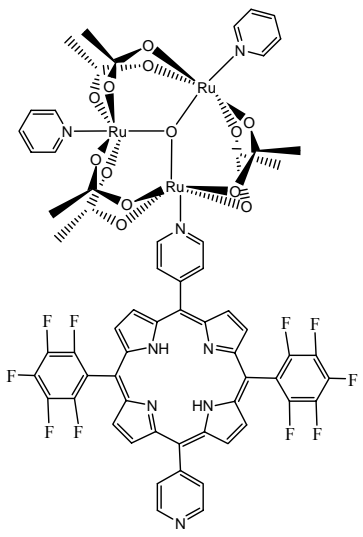

Supermolécula 3

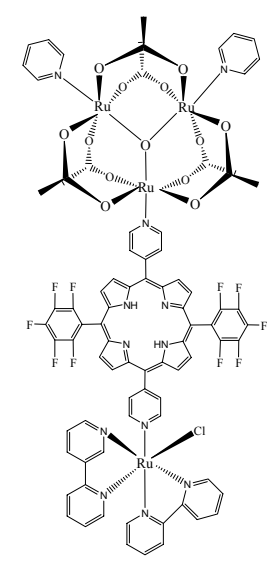

Supermolécula 5

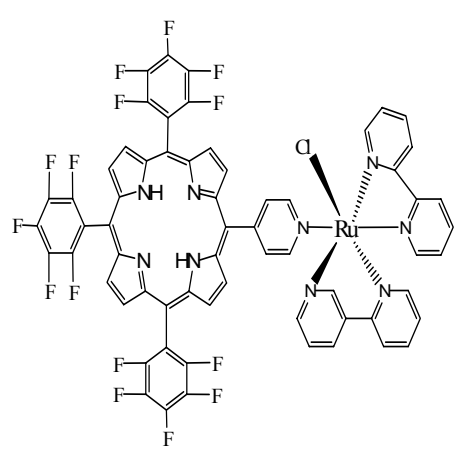

Supermolécula 2



Supermolécula 4

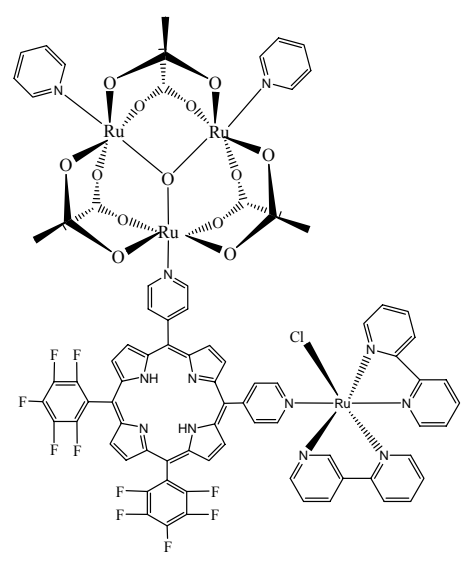

Supermolécula 6

Supermolécula 1: [M(4-N-Py)TFPPH $\left.{ }_{2}\left\{\mathrm{Ru}_{3} \mathrm{O}(\mathrm{Ac})_{6}(\mathrm{py})_{2}\right\}\right] \mathrm{PF}_{6}$.

Supermolécula 2: [M(4-N-Py) $\left.\mathrm{TFPPH}_{2}\left\{\mathrm{Ru}(\mathrm{bpy})_{2} \mathrm{Cl}\right\}\right] \mathrm{PF}_{6}$.

Supermolécula 3: díade trans-[B(4-N-Py)BFFPH $\left.\mathrm{B}_{2}\left\{\mathrm{Ru}_{3} \mathrm{O}(\mathrm{Ac})_{6}(\mathrm{py})_{2}\right\}\right] \mathrm{PF}_{6}$;

Supermolécula 4: díade cis-[B(4-N-Py) $\left.\mathrm{BFFPH}_{2}\left\{\mathrm{Ru}_{3} \mathrm{O}(\mathrm{Ac})_{6}(\mathrm{py})_{2}\right\}\right] \mathrm{PF}_{6}$;

Supermolécula 5: tríade trans-[B(4-N-Py) $\left.\mathrm{BFFPH}_{2}\left\{\mathrm{Ru}_{3} \mathrm{O}(\mathrm{Ac})_{6}(\mathrm{py})_{2}\right\}\left\{\mathrm{Ru}(\mathrm{bpy})_{2} \mathrm{Cl}\right\}\right]\left(\mathrm{PF}_{6}\right)_{2}$;

Supermolécula 6: tríade cis-[B(4-N-Py)BFFPH $\left.{ }_{2}\left\{\mathrm{Ru}_{3} \mathrm{O}(\mathrm{Ac})_{6}(\mathrm{py})_{2}\right\}\left\{\mathrm{Ru}(\mathrm{bpy})_{2} \mathrm{Cl}\right\}\right]\left(\mathrm{PF}_{6}\right)_{2}$.

Figura 21: Representação da estrutura das novas supermoléculas. 
fosse de 20\% de ACN em DCM. Esta coluna cromatográfica teve 5 frações eluídas, sendo que a fração 1 foi descartada. O possível composto de interesse foi eluído nas frações 2 a 4. Nesta coluna não foi possível acompanhar a eluição das frações através de lâmpada de ultravioleta porque quando o cluster se ligou à porfirina, houve uma supressão da luminescência, que é característica da porfirina. Obteve-se $198 \mathrm{mg}$ do composto de interesse $(\eta=90 \%)$. $(\mathrm{MM}=1862,2)$.

\section{III.5.2) Síntese e purificação da díade $\left[\mathrm{M}(4-\mathrm{N}-\mathrm{Py}) \mathrm{TFPPH}_{2}\left\{\mathrm{Ru}(\mathrm{bpy})_{2} \mathrm{Cl}\right\}\right] \mathrm{PF}_{6}$} (Supermolécula 2, Figura 21) pelo método direto.

Em um balão de $250 \mathrm{~mL}$ dissolveram-se $49 \mathrm{mg}$ da porfirina M(4-N-Py) $\mathrm{TFFPH}_{2}$ $\left(5,5 \times 10^{-5} \mathrm{~mol}\right)$ em $10 \mathrm{~mL}$ de DCM e separadamente foi dissolvido $39 \mathrm{mg}$ de complexo $\left[\mathrm{Ru}(\mathrm{bpy})_{2} \mathrm{Cl}_{2}\right] \cdot 2 \mathrm{H}_{2} \mathrm{O}\left(8,0 \times 10^{-5} \mathrm{~mol}\right)$ em $40 \mathrm{~mL}$ de DCM. A proporção utilizada foi de 1,5:1 (complexo/porfirina). A solução de complexo foi adicionada ao balão de $250 \mathrm{~mL}$ onde estava a porfirina dissolvida. A reação foi feita em temperatura ambiente sob condições aeróbicas e teve duração de 90 horas sob agitação magnética. Após o término da síntese, a solução foi rotaevaporada até a formação de um sólido de cor roxa. Para a troca do contra-íon da díade a ser formada gotejou-se a solução da mistura reacional sob uma solução alcoólica saturada de $\mathrm{NH}_{4} \mathrm{PF}_{6}$ e deixou-se reagir por 2 horas Obteve-se $85 \mathrm{mg}$ de um sólido.

A purificação do sólido foi feita através de coluna cromatográfica em alumina neutra. Utilizou-se uma coluna de $20 \mathrm{~cm}$ de altura com 2,6 cm de diâmetro. A eluição foi acompanhada por espectroscopia UV-Vis e CCD. Primeiramente foi utilizado DCM como eluente e após um certo período foi adicionado gradativamente $\mathrm{ACN}$, até que a proporção final no eluente fosse de 50\% de ACN em DCM. Esta coluna teve 4 frações eluídas, sendo que as frações 1, 2 e 4 foram descartadas. O possível composto de interesse foi eluído na fração 3. Obteve-se $6 \mathrm{mg}$ do composto de interesse $(\eta=13 \%)$. $(\mathrm{MM}=1479,45)$. 


\section{III.5.3) Síntese e purificação da díade $\left[\mathrm{M}(4-\mathrm{N}-\mathrm{Py}) \mathrm{TFPPH}_{2}\left\{\mathrm{Ru}(\mathrm{bpy})_{2} \mathrm{Cl}_{\}}\right] \mathrm{PF}_{6}\right.$} (Supermolécula 2, Figura 21) através da formação do aqua complexo $\left[\mathrm{Ru}(\mathrm{bpy})_{2} \mathrm{Cl}\left(\mathrm{H}_{2} \mathrm{O}\right)\right]^{+}$.

$\mathrm{O}$ complexo $\left[\mathrm{Ru}(\mathrm{bpy})_{2} \mathrm{Cl}\left(\mathrm{H}_{2} \mathrm{O}\right)\right]^{+}$foi preparado inicialmente utilizando-se $\mathrm{o}$ seguinte procedimento: dissolveu-se em um balão de $25 \mathrm{~mL}, 50 \mathrm{mg}$ de $\left[\mathrm{Ru}(\mathrm{bpy}){ }_{2} \mathrm{Cl}_{2}\right] \cdot 2 \mathrm{H}_{2} \mathrm{O}\left(1,0 \times 10^{-4} \mathrm{~mol}\right)$ em $5,5 \mathrm{~mL}$ de uma mistura DMF/EtOH 2:1, e acrescentou-se em seguida $2 \mathrm{~mL}$ de uma solução contendo $18 \mathrm{mg}$ de $\mathrm{AgNO}_{3}$ $\left(1,1 \times 10^{-4} \mathrm{~mol}\right)$ de $\mathrm{AgNO}_{3}$. A mistura reacional foi mantida sob agitação e aquecimento brando $\left(\mathrm{T}=50^{\circ} \mathrm{C}\right)$ por 30 minutos, levando à precipitação de $\mathrm{AgCl}$. A mistura foi então filtrada num funil de placa sinterizada, através de uma camada de aproximadamente $1 \mathrm{~cm}$ de celite. A reação tem rendimento elevado, de modo que o filtrado (solução marrom) contém essencialmente o complexo $\left[\mathrm{Ru}(\mathrm{bpy})_{2} \mathrm{Cl}\left(\mathrm{H}_{2} \mathrm{O}\right)\right]^{+}$. Depois da filtração reduziu-se o volume da solução de aquacomplexo para aproximadamente $2 \mathrm{~mL}$ no evaporador rotatório, e posteriormente foi adicionado $1,5 \mathrm{~mL}$ de DCM. Em um outro recipiente dissolveu-se $91 \mathrm{mg}$ da porfirina $\mathrm{M}(4-\mathrm{N}-\mathrm{Py}) \mathrm{TFFPH}_{2}\left(1,0 \times 10^{-4} \mathrm{~mol}\right) \mathrm{em} 5 \mathrm{~mL}$ de uma mistura de DCM/DMF 4:1. Esta solução da porfirina foi adicionada sobre a solução do aqua complexo obtida acima. Após cerca de 30 minutos de agitação e aquecimento brando, o volume do solvente foi reduzido para aproximadamente $3 \mathrm{~mL}$ no evaporador rotatório. A solução foi então gotejada sobre uma solução aquosa concentrada de $\mathrm{NH}_{4} \mathrm{PF}_{6}$ para que houvesse a troca do contra íon, e filtrada num funil de placa sinterizada recoberta com uma camada de $2 \mathrm{~cm}$ de celite. $\mathrm{O}$ sólido foi lavado com água a fim de remover a fração de $\left[\mathrm{Ru}(\mathrm{bpy})_{2} \mathrm{Cl}\left(\mathrm{H}_{2} \mathrm{O}\right)\right]^{+}$que não reagiu e o excesso de $\mathrm{NH}_{4} \mathrm{PF}_{6}$. Após a lavagem, a supermolécula do funil foi dissolvida com $\mathrm{ACN}$, e o produto sólido foi obtido após remoção do solvente no evaporador rotatório.

Posteriormente o produto foi purificado em coluna de alumina neutra. Utilizou-se uma coluna de $15 \mathrm{~cm}$ de altura com 2,6 cm de diâmetro e a eluição foi acompanhada por espectroscopia UV-Vis e CCD. Utilizou-se DCM como eluente e após certo período foi adicionado gradativamente $\mathrm{ACN}$, até que a proporção final no eluente fosse de $20 \%$ de ACN em DCM. Foram obtidas 4 frações eluídas, e o possível composto de interesse foi 
eluído na fração 2, sendo as outras frações descartadas. Obteve-se $43 \mathrm{mg}$ do produto $(\eta=$ $28 \%)$. (MM=1479,45).

\section{III.5.4) Síntese e purificação da díade trans-[B(4-N-Py)BFFPH 2 $\left\{\mathrm{Ru}_{3} \mathrm{O}(\mathrm{Ac})_{6}(\mathrm{py})_{2}\right\} \mathrm{PF}_{6}($ Supermolécula 3, Figura 21).}

Em um balão de $250 \mathrm{~mL}$ foi dissolvido $45 \mathrm{mg}$ da porfirina trans-B(4-N-Py)BFFPH $2\left(5,6 \times 10^{-5} \mathrm{~mol}\right)$ em $5 \mathrm{~mL}$ de DCM e separadamente foram dissolvidas $51 \mathrm{mg}$ de cluster assimétrico $\left[\mathrm{Ru}_{3} \mathrm{O}(\mathrm{Ac})_{6}(\mathrm{py})_{2}\left(\mathrm{CH}_{3} \mathrm{OH}\right)\right] \mathrm{PF}_{6}\left(5,1 \times 10^{-5} \mathrm{~mol}\right)$ em $70 \mathrm{~mL}$ de DCM. O cluster assimétrico $\left[\mathrm{Ru}_{3} \mathrm{O}\left(\mathrm{CH}_{3} \mathrm{COO}\right)_{6}(\mathrm{py})_{2}\left(\mathrm{CH}_{3} \mathrm{OH}\right)\right] \mathrm{PF}_{6}$ foi colocado em um funil de separação e foi gotejado lentamente sobre a solução de porfirina trans-B(4-N-Py)BFFPH 2 . A reação foi feita em temperatura ambiente, em condições aeróbicas e teve duração de 24 horas sob agitação magnética. Após o término da síntese, a solução foi rotaevaporada até a secura, com formação de um sólido (95 mg) de cor roxa.

Para purificar utilizou-se uma coluna cromatográfica em alumina neutra de $19 \mathrm{~cm}$ de altura com 2,6 cm de diâmetro e como eluente utilizou-se DCM (pré-selecionado por CCD). A eluição foi acompanhada por espectroscopia UV-Vis e CCD. Esta coluna teve 15 frações eluídas, sendo que na fração 1, recolheu-se porfirina sem reagir e as frações 2 a 7 e 14 foram descartadas. O possível composto de interesse foi eluído nas frações 8 a 13, e na fração 15 possivelmente foi eluída a tríade formada por uma molécula de porfirina com duas moléculas de clusters. Obteve-se 40 mg da díade trans-[B(4-N-Py)BFFPH $2\left\{\mathrm{Ru}_{3} \mathrm{O}(\mathrm{Ac})_{6}\left(\mathrm{py}_{2}\right\}\right] \mathrm{PF}_{6}(\eta=45 \%)(\mathrm{MM}=1769)$ (Supermolécula 3) e $13 \mathrm{mg}$ da tríade trans-[B(4-N-Py)BFFPH $\left.{ }_{2}\left\{\mathrm{Ru}_{3} \mathrm{O}(\mathrm{Ac})_{6}(\mathrm{py})_{2}\right\}_{2}\right]\left(\mathrm{PF}_{6}\right)_{2} \quad(\eta=9 \%)$ $(\mathrm{MM}=2763)$.

\section{III.5.5) Síntese e purificação da díade cis-[B(4-N-Py)BFFPH $\left.\left\{\mathrm{Ru}_{3} \mathrm{O}(\mathrm{Ac})_{6}(\mathrm{py})_{2}\right\}\right] \mathrm{PF}_{6}$ (Supermolécula 4, Figura 21).}

Em um balão de $250 \mathrm{ml}$ foi dissolvido $50 \mathrm{mg}$ da porfirina cis-B(4-N-Py)BFFPH $2\left(6,2 \times 10^{-5} \mathrm{~mol}\right)$ em $5 \mathrm{~mL}$ de DCM e separadamente foi dissolvida $57 \mathrm{mg}$ de cluster assimétrico $\left[\mathrm{Ru}_{3} \mathrm{O}\left(\mathrm{CH}_{3} \mathrm{COO}\right)_{6}(\mathrm{py})_{2}\left(\mathrm{CH}_{3} \mathrm{OH}\right)\right] \mathrm{PF}_{6}$ 
$\left(5,1 \quad \mathrm{x} \quad 10^{-5} \mathrm{~mol}\right)$ em $70 \mathrm{~mL}$ de DCM. O cluster assimétrico $\left[\mathrm{Ru}_{3} \mathrm{O}\left(\mathrm{CH}_{3} \mathrm{COO}\right)_{6}(\mathrm{py})_{2}\left(\mathrm{CH}_{3} \mathrm{OH}\right)\right] \mathrm{PF}_{6}$ foi colocado em um funil de separação e foi gotejado lentamente sobre a solução de porfirina cis-B(4-N-Py)BFFPH ${ }_{2}$. A reação foi feita em temperatura ambiente, em condições aeróbicas e teve duração de 24 horas sob agitação magnética. Após o término da síntese, a solução foi rotaevaporada até a secura, com formação de um sólido (103 mg) de cor roxa.

Para purificar utilizou-se uma coluna cromatográfica de alumina neutra de $22,5 \mathrm{~cm}$ de altura com 2,6 cm de diâmetro e como eluente utilizou-se DCM (pré-selecionado por CCD), a eluição foi acompanhada por espectroscopia UV-Vis e CCD. Esta coluna cromatográfica teve 3 frações eluídas, sendo que na fração 1 recolheu-se porfirina sem reagir, a fração 2 foi descartada e no início da fração 3 houve um rachamento da coluna, o que impossibilitou a separação dos produtos de interesse. Como houve este problema, eluiu-se esta fração com ACN para que todos os compostos ainda restantes na coluna fossem removidos. A fração 3 foi rotaevaporada para que pudesse ser feita uma nova purificação. A nova coluna cromatográfica teve $18 \mathrm{~cm}$ de altura com 2,6 cm de diâmetro e como eluente utilizou-se DCM novamente. Esta nova coluna teve 5 frações eluídas, sendo que o possível composto de interesse foi eluído na fração 1 , as frações 2 à 4 foram descartadas e na fração 5, possivelmente foi eluída a tríade formada por uma molécula de porfirina com duas moléculas de cluster. Obteve-se $40 \mathrm{mg}$ da díade cis-[B(4-N-Py)BFFPH $\left.{ }_{2}\left\{\mathrm{Ru}_{3} \mathrm{O}(\mathrm{Ac})_{6}(\mathrm{py})_{2}\right\}\right] \mathrm{PF}_{6}(\eta=31 \%)(\mathrm{MM}=1769)$ (supermolécula 4) e $9 \mathrm{mg}$ da tríade $c i s-\left[\mathrm{B}(4-\mathrm{N}-\mathrm{Py}) \mathrm{BFFPH}_{2}\left\{\mathrm{Ru}_{3} \mathrm{O}(\mathrm{Ac})_{6}(\mathrm{py})_{2}\right\}_{2}\right]\left(\mathrm{PF}_{6}\right)_{2}(\eta=6 \%)(\mathrm{MM}=2763)$.

\section{III.5.6) Síntese e purificação da tríade trans-[B(4-N-Py)BFFPH $\left.\left\{\mathrm{Ru}_{3} \mathrm{O}(\mathrm{Ac})_{6}(\mathrm{py})_{2}\right\}\left\{\mathrm{Ru}(\mathrm{bpy})_{2} \mathrm{Cl}\right\}\right]\left(\mathrm{PF}_{6}\right)_{2} \quad($ Supermolécula 5 , Figura 21) através da formação do aqua complexo $\left[\mathrm{Ru}(\mathrm{bpy})_{2} \mathrm{Cl}\left(\mathrm{H}_{2} \mathrm{O}\right)\right]^{+}$.}

$\mathrm{O}$ complexo $\left[\mathrm{Ru}(\text { bpy })_{2} \mathrm{Cl}\left(\mathrm{H}_{2} \mathrm{O}\right)\right]^{+}$foi preparado inicialmente utilizando-se $\mathrm{o}$ seguinte procedimento: Dissolveu-se em um balão de $50 \mathrm{~mL}, 12 \mathrm{mg}$ de $\left[\mathrm{Ru}(\mathrm{bpy}){ }_{2} \mathrm{Cl}_{2}\right]$ $\left(2,5 \times 10^{-5} \mathrm{~mol}\right)$ em $20 \mathrm{~mL}$ de $\mathrm{ACN}$, e acrescentou-se em seguida $2 \mathrm{~mL}$ de uma solução contendo 3,7 mg de $\mathrm{AgNO}_{3}\left(2,2 \times 10^{-5} \mathrm{~mol}\right)$ de $\mathrm{AgNO}_{3}$. A mistura reacional foi mantida sob agitação e aquecimento brando $\left(\mathrm{T}=50^{\circ} \mathrm{C}\right)$ por 30 minutos, levando à precipitação de 
$\mathrm{AgCl}$. A mistura foi então filtrada num funil de placa sinterizada, através de uma camada de aproximadamente $1 \mathrm{~cm}$ de celite. Aparentemente a reação teve rendimento elevado, de modo que o filtrado (solução marrom) deveria conter o complexo $\left[\mathrm{Ru}(\mathrm{bpy})_{2} \mathrm{Cl}\left(\mathrm{H}_{2} \mathrm{O}\right)\right]^{+}$. Depois da filtração reduziu-se o volume da solução de aquacomplexo para aproximadamente $7 \mathrm{~mL}$ no evaporador rotatório. Em um outro recipiente dissolveu-se 33 $\mathrm{mg}$ da díade trans-[B(4-N-Py)BFFPH $\left.{ }_{2}\left\{\mathrm{Ru}_{3} \mathrm{O}(\mathrm{Ac})_{6}(\mathrm{py})_{2}\right\}\right] \mathrm{PF}_{6}\left(1,85 \times 10^{-5} \mathrm{~mol}\right) \mathrm{em} 10 \mathrm{~mL}$ de DCM. Esta solução da díade foi adicionada sobre a solução do aqua complexo obtida acima. Após cerca de 30 minutos de agitação e aquecimento brando, o volume do solvente foi reduzido para aproximadamente $5 \mathrm{~mL}$ no evaporador rotatório. A solução foi então gotejada sobre uma solução alcólica concentrada de $\mathrm{NH}_{4} \mathrm{PF}_{6}$ para que houvesse a troca do contra íon. Após o término da síntese, a solução foi rotaevaporada até a secura, com formação de um sólido de cor preta.

Posteriormente o produto foi purificado em coluna de alumina neutra. Utilizou-se uma coluna de $20 \mathrm{~cm}$ de altura com 2,6 cm de diâmetro e como eluente utilizou-se $1 \%$ de EtOH em DCM (pré-selecionado por CCD). A eluição foi acompanhada por espectroscopia UV-Vis e CCD. Esta coluna teve 6 frações eluídas, sendo que na fração 1 recolheu-se a díade sem reagir, as frações 2 à 6 foram descartadas. Infelizmente não foi observada a eluição de fração com absorções em 300 nm e 414 nm simultaneamente, característica espectral correspondente ao possível composto de interesse. O fragmento $\left[\mathrm{Ru}(\mathrm{bpy})_{2}\right]$ tem absorção característica próximo ao comprimento de onda de $300 \mathrm{~nm}$ e a porfirina tem absorção característica em 414 nm (Banda Soret). Discussão detalhada no item IV.2.

\section{III.5.7) Síntese e purificação da tríade trans-[B(4-N-Py)BFFPH ${ }_{2}\left\{\mathrm{Ru}_{3} \mathrm{O}(\mathrm{Ac})_{6}\right.$ $\left.\left.(\text { py) })_{2}\right\}\left\{\mathrm{Ru}(\mathrm{bpy})_{2} \mathrm{Cl}\right\}\right]\left(\mathrm{PF}_{6}\right)_{2}($ Supermolécula 5, Figura 21) pelo método direto.}

Em um balão de $25 \mathrm{~mL}$ dissolveu-se $38 \mathrm{mg}$ da díade trans-[B(4-N$\mathrm{Py} \mathrm{BFFPH}_{2}\left\{\mathrm{Ru}_{3} \mathrm{O}(\mathrm{Ac})_{6}\left(\mathrm{py}_{2}\right\}\right] \mathrm{PF}_{6}\left(2,1 \times 0^{-5} \mathrm{~mol}\right)$ em $5 \mathrm{~mL}$ de DCM e em seguida acrescentou-se $5 \mathrm{~mL}$ de uma solução de $12 \mathrm{mg}$ do complexo $\left[\mathrm{Ru}(\mathrm{bpy})_{2} \mathrm{Cl}_{2}\right]\left(2,5 \mathrm{x} 10^{-5}\right.$ mol) em DCM. As soluções da díade e do complexo foram colocadas no balão para que houvesse a reação. Esta foi feita com aquecimento brando, em condições aeróbicas e teve 
duração de 48 horas sob agitação magnética. A solução foi então gotejada sobre uma solução alcoólica concentrada de $\mathrm{NH}_{4} \mathrm{PF}_{6}$ para que houvesse a troca do contra íon e, depois de 2 horas, a solução foi rotaevaporada até secura, com formação de um sólido de cor preta.

Posteriormente o produto foi purificado em coluna de alumina neutra. Utilizou-se uma coluna de 19,5 cm de altura com 2,6 cm de diâmetro e como eluente utilizou-se 1\% de $\mathrm{EtOH}$ em DCM (pré-estabelecido por CCD) e a eluição foi acompanhada por espectroscopia UV-Vis e CCD. Esta coluna teve 4 frações eluídas, sendo que na fração 1 recolheu-se a díade sem reagir, as frações 2 e 4 foram descartadas. O possível composto de interesse foi eluído na fração 3. Obteve-se $3,4 \mathrm{mg}$ da tríade trans-[B(4-N-Py)BFFPH $\left.{ }_{2}\left\{\mathrm{Ru}_{3} \mathrm{O}(\mathrm{Ac})_{6}(\mathrm{py})_{2}\right\}\left\{\mathrm{Ru}(\mathrm{bpy})_{2} \mathrm{Cl}\right\}\right]\left(\mathrm{PF}_{6}\right)_{2}(\eta=6 \%)(\mathrm{MM}=2520)$.

\section{III.5.8) Síntese e purificação da tríade cis-[B(4-N-Py)BFFPH $\left.\left\{\mathrm{Ru}_{3} \mathrm{O}(\mathrm{Ac})_{6}(\mathrm{py})_{2}\right\}\left\{\mathrm{Ru}(\mathrm{bpy})_{2} \mathrm{Cl}\right\}\right]\left(\mathrm{PF}_{6}\right)_{2}$ (Supermolécula 6, Figura 21) pelo método direto.}

Em um balão de $15 \quad \mathrm{~mL}$ dissolveu-se $20 \quad \mathrm{mg}$ da díade cis-[B(4-N-Py)BFFPH ${ }_{2}\left\{\mathrm{Ru}_{3} \mathrm{O}(\mathrm{Ac})_{6}\left(\mathrm{py}_{2}\right\} \mathrm{PF}_{6}\left(1,1 \times 10^{-5} \mathrm{~mol}\right)\right.$ em $5 \mathrm{~mL}$ de DCM e em seguida acrescentou-se $5 \mathrm{~mL}$ de uma solução de $6,5 \mathrm{mg}$ do complexo [Ru(bpy $)_{2} \mathrm{Cl}_{2}$ ] $\left(1,4 \times 10^{-5} \mathrm{~mol}\right)$ em DCM. As soluções da díade e do complexo foram colocadas no balão para que houvesse a reação. Esta foi feita com aquecimento brando, em condições aeróbicas e teve duração de 48 horas sob agitação magnética. A solução foi então gotejada sobre uma solução alcoólica concentrada de $\mathrm{NH}_{4} \mathrm{PF}_{6}$ para que houvesse a troca do contra íon e, depois de 2 horas, a solução foi rotaevaporada até a secura, com formação de um sólido de cor preta.

Posteriormente o produto foi purificado em coluna de alumina neutra. Utilizou-se uma coluna de 19,5 cm de altura com 2,6 cm de diâmetro e como eluente utilizou-se $1 \%$ de EtOH em DCM (pré-selecionado por $\mathrm{CCD}$ e a eluição foi acompanhada por espectroscopia UV-Vis e CCD. Esta cromatografia teve 4 frações eluídas, sendo que na fração 1 recolheu-se a díade sem reagir, as frações 2 e 4 foram descartadas. O possível composto de interesse foi eluído na fração 3. Nesta coluna não foi possível acompanhar a 
eluição das frações através de lâmpada de ultravioleta porque, quando o cluster se ligou à porfirina, houve uma supressão da luminescência, característica da porfirina. Obteve-se $8,3 \mathrm{mg}$ da tríade cis-[B(4-N-Py)BFFPH $\left.{ }_{2}\left\{\mathrm{Ru}_{3} \mathrm{O}(\mathrm{Ac})_{6}(\mathrm{py})_{2}\right\}\left\{\mathrm{Ru}(\mathrm{bpy})_{2} \mathrm{Cl}\right\}\right]\left(\mathrm{PF}_{6}\right)_{2}(\eta=30$ \%) $(\mathrm{MM}=2520)$.

\section{III.6) Tratamento de Resíduo}

\section{III.6.1) Recuperação da sílica $\mathrm{SiO}_{2}$}

Para a recuperação da sílica utilizou-se $\mathrm{MeOH}$ e ETOH para lavar a sílica até que a mesma ficasse límpida, em seguida lavou-se algumas vezes com água destilada. Preparouse então uma solução de $\mathrm{KMnO}_{4} 3 \%$ e deixou-se a sílica em solução por aproximadamente 3 dias agitando esporadicamente.

Passados os 3 dias, agitou-se a sílica com Ácido Oxálico 3\% e um pouco de $\mathrm{HCl}$ $3 \%$ a fim de abaixar o $\mathrm{pH}$ da solução para aproximadamente 1, utilizando como uma fonte alternativa $\mathrm{HCl}$ concentrado adicionado lentamente na solução.

Em seguida lavou-se novamente com água destilada ate a obtenção de $\mathrm{pH}$ neutro filtrando-se a vácuo para maior rapidez. Secou-se em estufa $\left(110-120{ }^{\circ} \mathrm{C}\right)$ por 24 horas para em seguida peneirar.

A sílica recuperada é utilizada pelo grupo para pré-purificação de síntese de porfirinas.

\section{III.6.2) Recuperação de solventes (acetona, diclorometano)}

$\rightarrow$ Destilação dos solventes utilizados:

- DCM nas colunas de purificação

- $\quad$ ACT na lavagem das vidrarias

Os solventes são reutilizados após serem destilados.

\section{III.7) Caracterização}




\section{III.7.1) Espectroscopia Eletrônica}

Os espectros eletrônicos apresentados foram obtidos em um espectrofotômetro HP 8453 Diode Array acoplado ao microcomputador HP Vectra ES/12 "Diode Array" na região de $300 \mathrm{~nm}$ a $800 \mathrm{~nm}$ em soluções de DCM com concentrações $\sim 10^{-5}$ mol.L $\mathrm{L}^{-1}$, utilizando um cubeta de quartzo de 0,20 cm de caminho óptico.

\section{III.7.2) Ressonância Magnética Nuclear ${ }^{1} \mathrm{H}$ e ${ }^{19} \mathrm{~F}$}

Os espectros de ${ }^{1} \mathrm{H}$ e ${ }^{19} \mathrm{~F}$ e $\mathrm{COSY}$ das porfirinas $\mathrm{M}(4-\mathrm{N}-\mathrm{Py}) \mathrm{TFPPH}_{2}$, trans-B(4-N-Py)BFPPH ${ }_{2}$, cis-B(4-N-Py)BFPPH,$\quad$ T(4-N-Py) $\mathrm{MFPPH}_{2}$ e da díade $\left[\mathrm{M}(4-\mathrm{N}-\mathrm{Py}) \mathrm{TFFPH}_{2}\left\{\mathrm{Ru}_{3} \mathrm{O}(\mathrm{Ac})_{6}(\mathrm{py})_{2}\right\}\right] \mathrm{PF}_{6}$, foram feitos em solução de clorofórmio deuterado. $\mathrm{O}$ espectro da díade $\left[\mathrm{M}(4-\mathrm{N}-\mathrm{Py}) \mathrm{TFFPH}_{2}\left\{\mathrm{Ru}(\text { bpy })_{2} \mathrm{Cl}\right\}\right] \mathrm{PF}_{6}$ foi feito em solução de acetonitrila deuterada. Os espectros de ${ }^{1} \mathrm{H},{ }^{19} \mathrm{~F}$ e COSY foram feitos com concentrações $\sim 10^{-2}$ mol.L $L^{-1}$, os aparelhos de RMN utilizados foram: Brucker Advanced DPX-300, Brucker Advanced DRX-400 e Brucker Advanced DRX-500.

\section{III.7.3) Cristalografia.}

Toda a análise de difração de Raios-X foi feita em colaboração com a prof. Dra. Alba D. Q. Ferreira e a especialista em difração de Raios-X Sumitra Mukhopadhyay do Departamento de Química do Instituto de Tecnologia de Massachusetts, MIT, USA

Os dados foram coletados usando um difratometro Bruker SMART CCD (charge couple device) equipado com um criostato de nitrogênio KRYOFLEX BVT-AXS que opera a temperatura de $173 \mathrm{~K}$. O cristal apropriado foi escolhido e montado em uma fibra de vidro usando o óleo Infineum V8512 e a graxa APIEZON-T. Os dados foram medidos usando varreduras de omega de $0.3^{\circ}$ por frame por 30 segundos, tais que um hemisfério foi coletado. Foram coletados 1271 frames com uma definição máxima de $0.75 \AA$. Os primeiros 50 frames foram gravados para monitorar a deterioração do cristal. Os cristais usados para o estudo de difração não mostraram decomposição durante a realização do experimento. Os parâmetros de cela foram recuperados usando o software SMART ${ }^{64}$ e 
refinados usando o software $\mathrm{SAINT}^{65}$ para todas as reflexões observadas. A redução dos dados foi executada usando o software SAINT. A estrutura foi resolvida pelo método direto usando o software SHELXS ${ }^{66}$ e refinada pelo método dos mínimos quadrados no $\mathrm{F}^{2}$ utilizando o software SHELXL ${ }^{67}$ e incorporados no software SHELXTL ${ }^{68}$. Todos os átomos da molécula, excetos os de hidrogênio, foram refinados com parâmetros térmicos anisotrópico. As posições dos átomos de hidrogênio foram calculados por métodos geométricos e refinados pelo modelo riding.

\section{III.7.4) Voltametria Cíclica e Voltametria por Pulso Diferencial}

As medidas de voltametria cíclica foram efetuadas com Potenciostato/galvanostato AUTOLAB $®$, modelo PGSTAT 30, acoplado a um microcomputador compatível.

Os voltamogramas das porfirinas foram obtidos a partir de soluções com concentrações de $1,0 \times 10^{-4} \mathrm{~mol} \mathrm{~L}^{-1}$ em DMF pré-destilada $0,1 \mathrm{~mol} \mathrm{~L}^{-1}$ em $\mathrm{TBAPF}_{6}$, numa faixa de potencial que vai de $-1,5 \mathrm{~V}$ até $+1,9 \mathrm{~V}$, em três velocidades diferentes de varredura $(50,100$ e $200 \mathrm{mV} / \mathrm{s})$. Os voltamogramas das supermoléculas foram obtidos em ACN nas mesmas condições acima, mas em concentraçoes de $1,0 \times 10^{-3} \mathrm{~mol} \mathrm{~L}^{-1}$.

As análises foram efetuadas sob um fluxo de gás nitrogênio, mantido no interior da célula para garantir a realização do estudo em atmosfera inerte. Antes de cada experimento, cada solução foi desaerada por 5 minutos com a passagem de gás nitrogênio.

O sistema eletroquímico utilizado é constituído de uma célula de três eletrodos, o eletrodo de trabalho, o eletrodo de referência e o eletrodo auxiliar. O primeiro consiste em um disco de platina e é onde o processo redox ocorre, o segundo é um fio de prata mergulhado em solução saturada de $\mathrm{AgCl}$ como eletrodo de referência e o terceiro um fio de platina mergulhado em solução de $\mathrm{TBAPF}_{6} \quad 0,1 \mathrm{~mol} \mathrm{~L}^{-1}$ em ACN como eletrodo auxiliar. Este eletrólito $\left(\mathrm{TBAPF}_{6}\right)$ foi escolhido por ser muito solúvel em solventes orgânicos, e confere alta condutividade para as soluções em estudo. Utilizou-se como padrão interno ferroceno $\left(\mathrm{Cp}_{2} \mathrm{Fe}\right)$.

$$
\begin{array}{llllll}
\mathrm{Cp}_{2} \mathrm{Fe}^{+} & +\mathrm{e}^{-} & \rightarrow & \mathrm{Cp}_{2} \mathrm{Fe} & +0,548 \text { vs EPH } \\
\mathrm{AgCl} & +\mathrm{e}^{-} & \rightarrow & \mathrm{Ag}^{\mathrm{o}}+\mathrm{Cl}^{-} & +0,222 \text { vs EPH }
\end{array}
$$


Após terminar todos os experimentos de eletroquímica para uma determinada molécula, era adicionado uma pequena quantidade de ferroceno na célula eletroquímica e realizava-se um novo experimento, isto era necessário para se conhecer os valores de $\mathrm{E}_{1 / 2}$ no sistema em questão, assim pode-se fazer a correção dos valores experimentais obtidos.

Para a realização dos experimentos de voltametria de pulso diferencial (DPV) utilizou-se DMF como solvente. Todos os potenciais foram convertidos para escala de EPH (eletrodo padrão de hidrogênio) pela adição de $0,222 \mathrm{~V}$ aos dados experimentais obtidos para as porfirinas $\mathrm{M}(4-\mathrm{N}-\mathrm{Py}) \mathrm{TPPH}_{2}$, trans-B(4-N-Py)BPPH $\mathrm{H}_{2}$, cis-B(4-N-Py)BPPH ${ }_{2}$ e T(4-N-Py) $\mathrm{MPPH}_{2}$, o valor experimental obtido para o $\mathrm{Cp}_{2} \mathrm{Fe}$ no sistema usado para as porfirinas $\mathrm{M}(4-\mathrm{N}-\mathrm{Py}) \mathrm{TPPH}_{2}$ e cis-B(4-N-Py) $\mathrm{BPPH}_{2}$ foi de $0,692 \mathrm{~V}$ (vs EPH), para a porfirina trans-B(4-N-Py)BPPH ${ }_{2}$ foi de $0,711 \mathrm{~V}$ (vs EPH) e para a porfirina $\mathrm{T}(4-\mathrm{N}-\mathrm{Py}) \mathrm{MPPH}_{2}$. Como o valor teórico para o $\mathrm{Cp}_{2} \mathrm{Fe}$ é de $0,548 \mathrm{~V}$ (vs EPH), fez-se a correção dos valores experimentais subtraindo o valor de $0,144 \mathrm{~V}$ dos potenciais obtidos para as porfirinas $\mathrm{M}(4-\mathrm{N}-\mathrm{Py}) \mathrm{TFPPH}_{2}$ e cis-B(4-N-Py) $\mathrm{BPPH}_{2}$, subtraiu-se o valor de $0,163 \mathrm{~V}$ dos potenciais obtidos para a porfirina trans-B(4-N-Py) $\mathrm{BPPH}_{2}$ e subtraiu-se o valor de $0,145 \mathrm{~V}$ dos potenciais obtidos para a porfirina T(4-N-Py) $\mathrm{MPPH}_{2}$.

Para a análise das supermoléculas foi adotado o mesmo procedimento realizado para as porfirinas. Os experimentos foram feitos em ACN. Todos os potenciais obtidos para a díades $\left[\mathrm{M}\right.$ (4-N-Py)TFPPH $\left.{ }_{2}\left\{\mathrm{Ru}_{3} \mathrm{O}(\mathrm{Ac})_{6}(\mathrm{py})_{2}\right\}\right] \mathrm{PF}_{6}$ e $\left[\mathrm{M}\right.$ (4-N-Py)TFPPH $\mathrm{T}_{2}$ $\left\{\mathrm{Ru}(\mathrm{bpy})_{2} \mathrm{Cl}\right\} \mathrm{PF}_{6}$ foram convertidos para escala de $\mathrm{EPH}$, o valor experimental obtido para o $\mathrm{Cp}_{2} \mathrm{Fe}$ no sistema usado para a díade [M (4-N-Py)TFPPH $\left.{ }_{2}\left\{\mathrm{Ru}_{3} \mathrm{O}(\mathrm{Ac})_{6}(\mathrm{py})_{2}\right\}\right] \mathrm{PF}_{6}$ foi de $0,633 \mathrm{~V}$ (vs EPH) e para a díade [M (4-N-Py)TFPPH $\left.\mathrm{H}_{2}\left\{\mathrm{Ru}(\mathrm{bpy})_{2} \mathrm{Cl}\right\}\right] \mathrm{PF}_{6}$ foi de $0,646 \mathrm{~V}$ (vs EPH). fez-se a correção dos valores experimentais subtraindo o valor de 0,102 $\mathrm{V}$ dos potenciais obtidos para díade [M (4-N-Py)TFPPH $\left.\mathrm{H}_{2}\left\{\mathrm{Ru}_{3} \mathrm{O}(\mathrm{Ac})_{6}(\mathrm{py})_{2}\right\}\right] \mathrm{PF}_{6}$ e para a díade [M (4-N-Py) $\mathrm{TFPPH}_{2}\left\{\mathrm{Ru}(\mathrm{bpy})_{2} \mathrm{Cl}_{\}}\right] \mathrm{PF}_{6}$ fez-se a correção dos valores experimentais subtraindo o valor de $0,124 \mathrm{~V}$ dos potenciais obtidos. 


\section{III.7.5.) Espectometria de masssa}

Os espectros de massa ESI MS das díades [M(4-N-Py)TFFPH $\left.{ }_{2}\left\{\mathrm{Ru}_{3} \mathrm{O}(\mathrm{Ac})_{6}(\mathrm{py})_{2}\right\}\right]$ $\mathrm{PF}_{6}$ e $\left[\mathrm{M}(4-\mathrm{N}-\mathrm{Py}) \mathrm{TFFPH}_{2}\left\{\mathrm{Ru}(\mathrm{bpy})_{2} \mathrm{Cl}\right\}\right] \mathrm{PF}_{6}$ foram obtidos em um aparelho Espectrômetro de Massas Brucker Q TOF, com fonte de eletrospray operando em modo positivo (ESI+). Os espectros de massa ESI MS e ESI MSMS das porfirinas cise trans-B(4-N-Py)BFFPH 2 , das díades cis- e trans-[B(4-N-Py)BFFPH 2 $\left.\left\{\mathrm{Ru}_{3} \mathrm{O}(\mathrm{Ac})_{6}(\mathrm{py})_{2}\right\}\right] \mathrm{PF}_{6}$ e das tríades cis- e trans-[B(4-N-Py)BFFPH ${ }_{2}$ $\left.\left\{\mathrm{Ru}_{3} \mathrm{O}(\mathrm{Ac})_{6}(\mathrm{py})_{2}\right\}\left\{\mathrm{Ru}(\mathrm{bpy})_{2} \mathrm{Cl}\right\}\right]\left(\mathrm{PF}_{6}\right)_{2}$ foram obtidos em um aparelho Espectrômetro de Massas Q-TOF II, com fonte de eletrospray operando em modo positivo (ESI+). Temperatura da fonte e do gás de nebulização 80 e $200^{\circ} \mathrm{C}$, respectivamente.

\section{III.7.6) Ensaios Fotofísicos}

Os espectros de emissão e excitação foram obtidos a partir de soluções de porfirinas, díades e tríades (com concentrações $6,0 \times 10^{-6} \mathrm{~mol} / \mathrm{L}$ ) em DCM no espectrofluorímetro SPEX FLUOROLOG 2, utilizando-se uma célula de quartzo de 1,0 X $1,0 \mathrm{~cm}$.

Pode-se calcular o rendimento quântico de fluorescência $\left(\varphi_{\mathrm{fl}}\right)$ de um composto, para isso é necessário que os experimentos sejam realizados nas mesmas condições experimentais (solvente, comprimento de onda, temperatura) e que seja conhecido o rendimento quântico de fluorescência $\left(\varphi_{\mathrm{fl}}\right)$ de um padrão (meso-tetrafenilporfirina (TPP, $\varphi f l=0,099))$. Para isso é necessário conhecer o número de fótons absorvidos e o número de fótons emitidos do estado excitado singlete $\left(\mathrm{S}_{1}\right)$. O primeiro é diretamente proporcional à absorbância no comprimento de onda de excitação. O segundo pode ser estimado calculando-se a integral das bandas de emissão. Assim, como o método é comparativo, basta calcular as razões entre o número de fótons absorvidos e emitidos pela amostra e pelo padrão e relacioná-los com o rendimento quântico do padrão, conforme a equação : 


\section{$\phi_{\mathrm{x}}=\phi_{\mathrm{TPP}} \cdot \frac{\operatorname{int}(\mathrm{x})}{\mathrm{abs}(\mathrm{X})} \cdot \frac{\mathrm{abs}(\mathrm{TPP})}{\operatorname{int}(\mathrm{TPP})} \cdot \frac{\eta_{\mathrm{TPF}}^{2}}{\eta_{\mathrm{x}}^{2}}$}

onde, $\operatorname{int}(\mathrm{x})$ e $\operatorname{int}(\mathrm{TPP})$ são os valores das integrais das bandas de fluorescência da amostra e do TPP; abs(x) e abs(TPP) são suas respectivas absorbâncias no comprimento de onda de excitação e $\eta_{x}^{2}$ e $\eta^{2}$ TPP os índices de refração das duas amostras. Para o caso das amostras estarem no mesmo solvente que o padrão, $\eta_{x}^{2}=\eta^{2}$ тPр. 


\section{IV - Resultados e Discussão}

\section{IV.1) Síntese}

\section{IV.1.1) Síntese de porfirinas base livre 4-N-piridil substituídas e pentafluorofenil.}

As sínteses das porfirinas $\mathrm{M}(4-\mathrm{N}-\mathrm{Py}) \mathrm{TFPPH}_{2}$, trans-B(4-N-Py) $\mathrm{BFPPH}_{2}$ e cis-B(4-N-Py)BFPPH ${ }_{2}$ foram feitas através do método de Adler e Longo modificado. As modificações feitas neste método inclui a utilização de outros aldeídos, bem como, diferentes proporções entre os mesmos de acordo com a porfirina desejada. Esta síntese envolve a reação de condensação entre pirrol, pentafluorobenzadeído e 4piridilcarboxialdeído numa relação de 4:1,9: 2,1 respectivamente, em ácido propiônico sob refluxo a $150^{\circ} \mathrm{C}$. A quantidade relativa de cada uma das porfirinas pode ser modulada pela variação da relação molar dos dois aldeídos utilizados. Nesta primeira síntese a proporção de pentafluorobenzadeído foi um pouco menor do que a de 4-piridilcarboxaldeído porque o pentafluorobenzaldeído possui uma maior velocidade de ciclização e, portanto, um aldeído mais reativo ${ }^{69}$. O objetivo é a obtenção de uma maior percentagem das porfirinas com um e dois grupos 4-piridis.

Foi feita uma segunda síntese das porfirinas base livre em virtude da pouca quantidade obtida da porfirina trans-B(4-N-Py) $\mathrm{BFPPH}_{2}$ na primeira síntese realizada neste projeto. Novamente a síntese das porfirinas foi feita através do método de Adler e Longo modificado. A relação dos reagentes (pirrol/pentafluorobenzadeído/4piridilcarboxialdeído) utilizadas foi de 4:1,5:2,5, respectivamente Nesta síntese a proporção de pentafluorobenzadeído foi um pouco menor do que a de 4piridilcarboxaldeído porque o objetivo foi a obtenção de uma maior percentagem da porfirina trans-B(4-N-Py)BFPPH${ }_{2}$. 
<smiles>O=Cc1c(F)c(F)c(F)c(F)c1C=O</smiles>

Figura 22: Síntese de porfirinas 4-N-piridil e pentafluorofenil substituídas pelo método modificado de Adler e Longo.

A reação foi monitorada através de registros de espectros de UV-Visível retirando alíquotas do meio reacional. Com este monitoramento foi possível verificar a efetiva formação da porfirina através do aumento da absorbância de sua banda Soret característica em $414 \mathrm{~nm}$.

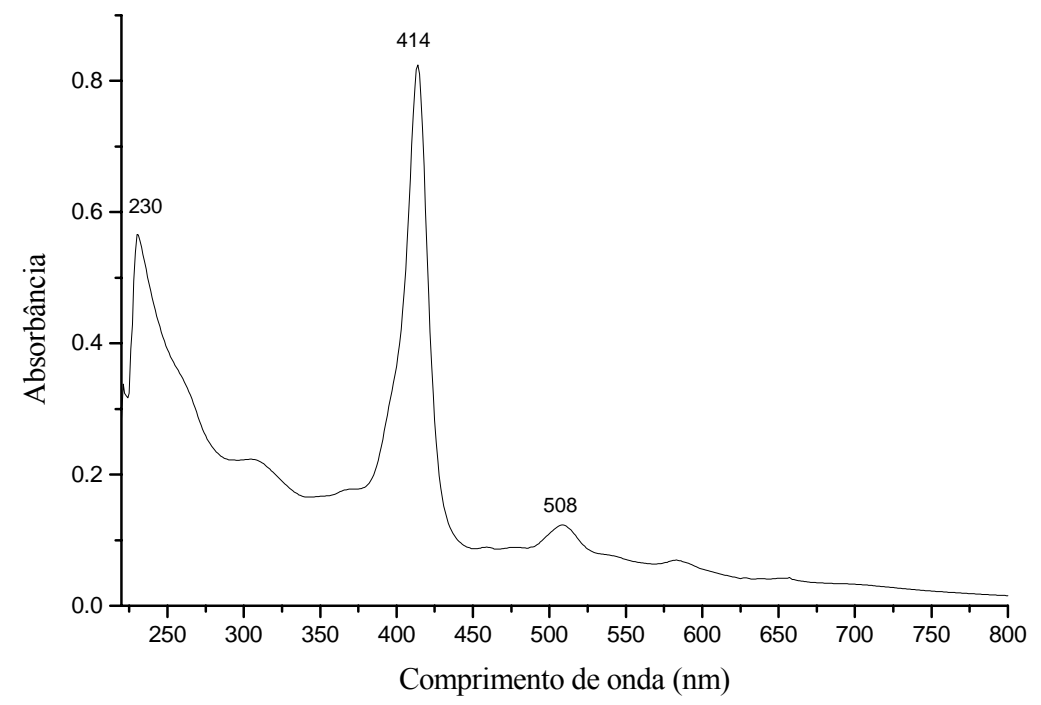

Figura 23: Espectro UV-Visível em DCM do meio reacional de porfirinas 4-N-piridil e pentafluorofenil substituídas (final da síntese).

$\mathrm{Na}$ primeira síntese tentou-se fazer uma pré-purificação utilizando mistura de solventes, mas os resultados obtidos não foram satisfatórios. Na segunda síntese com EtOH conseguiu-se solubilizar muitos dos sub-produtos formados na síntese das porfirinas, e assim as purificações puderam ser feitas de forma mais ágil e mais fácil. 
$\mathrm{O}$ inconveniente de fazer esta pré-purificação com $\mathrm{EtOH}$ foi que o rendimento das porfirinas ficou inferior ao da primeira síntese, mas há que se observar que a proporção dos aldeídos também foi modificada, então é difícil afirmar que este menor rendimento é devido a esta etapa no processo de purificação.

Como a proporção do 4-piridilcarboxialdeído foi aumentada, houve a formação das porfirinas $\mathrm{T}(4-\mathrm{N}-\mathrm{Py}) \mathrm{MFPPH}_{2} \mathrm{~T}(4-\mathrm{N}-\mathrm{Py}) \mathrm{PH}_{2}$ que na primeira síntese não haviam sido detectadas e as porfirinas $\mathrm{TFPPH}_{2}$ e M(4-N-Py)TFPPH${ }_{2}$ que haviam sido formadas, desta vez não foram detectadas.

O rendimento da primeira síntese das porfirinas foi calculado após purificação, obteve-se um rendimento de $1,3 \%$ da porfirina $\mathrm{M}(4-\mathrm{N}-\mathrm{Py}) \mathrm{TFPPH}_{2}, 1,0 \%$ da porfirina trans-B(4-N-Py)BFPPH $\mathrm{B}_{2}$ e 2,7 \% da cis-B(4-N-Py) $\mathrm{BFPPH}_{2}$, portanto o rendimento total da síntese foi de 5,0\%. O rendimento da segunda síntese das porfirinas foi de $0,5 \%$ da porfirina trans-B(4-N-Py)BFPPH $2, \quad 1,1 \%$ da porfirina cis(4-N-Py)BFPPH 2 e 2,2 \% da porfirina $\mathrm{T}(4-\mathrm{N}-\mathrm{Py}) \mathrm{MPPH}_{2}$ e $0,2 \%$ da porfirina $\mathrm{T}(4-\mathrm{N}-\mathrm{Py}) \mathrm{PH}_{2}$, portanto o rendimento total da síntese foi de $4,0 \%$.

\section{IV.1.2) Síntese da díade $\left[\mathrm{M}(4-\mathrm{N}-\mathrm{Py}) \mathrm{TFFPH}_{2}\left\{\mathrm{Ru}_{3} \mathrm{O}(\mathrm{Ac})_{6}(\mathrm{py})_{2}\right\}\right] \mathrm{PF}_{6}$}

\section{(Supermolécula 1, Figura 21)}

A síntese da díade $\left[\mathrm{M}(4-\mathrm{N}-\mathrm{Py}) \mathrm{TFFPH}_{2}\left\{\mathrm{Ru}_{3} \mathrm{O}(\mathrm{Ac})_{6}(\mathrm{py})_{2}\right\}\right] \mathrm{PF}_{6}$ foi feita em condições semelhantes às estabelecidas para a síntese dos isômeros cis- e trans-[B(4-N-Py) $\left.\mathrm{TFFPH}_{2}\left\{\mathrm{Ru}_{3} \mathrm{O}(\mathrm{Ac})_{6}(\mathrm{py})_{2}\right\}\right] \mathrm{PF}_{6}$ (item IV.1.4). A principal diferença nesta síntese está no fato da utilização de uma solução mais concentrada do cluster. Como a molécula M(4-N-Py)TFFPH 2 apresenta somente um sítio de coordenação, utilizou-se um excesso do cluster $\left.\left[\mathrm{Ru}_{3} \mathrm{O}(\mathrm{Ac})_{6}(\mathrm{py})_{2}\left(\mathrm{CH}_{3} \mathrm{OH}\right)\right\}\right] \mathrm{PF}_{6}$ para tentar obter um maior rendimento da díade. $\mathrm{O}$ excesso utilizado foi de suma importância para que a reação tivesse um elevado rendimento. $(\eta=90 \%)$.

Após o término da reação, fez-se uma CCD em alumina e pode-se perceber que havia porfirina e cluster sem reagir e duas manchas distintas. Por isso foi feita cromatografia em coluna de alumina para purificar os produtos da reação. Com esta cromatografia recolheram-se duas frações diferentes. A primeira fração por comparação de 
$\mathrm{R}_{\mathrm{f}}$ continha a porfirina e o cluster sem reagir, a segunda fração continha um composto com um Rf diferente da porfirina e do cluster. Para a elucidação deste composto foram registrados espectros de UV-Visível, RMN ${ }^{1} \mathrm{H}, \mathrm{RMN}{ }^{19} \mathrm{~F}$, COSY e espectro de massa ESI MS. Após as análises pode-se confirmar que o composto sintetizado era a díade $\left[\mathrm{M}(4-\mathrm{N}-\mathrm{Py}) \mathrm{TFFPH}_{2}\left\{\mathrm{Ru}_{3} \mathrm{O}(\mathrm{Ac})_{6}(\mathrm{py})_{2}\right\}\right] \mathrm{PF}_{6}$.

\section{IV.1.3) Síntese da díade $\left[\mathrm{M}(4-\mathrm{N}-\mathrm{Py}) \mathrm{TFFPH}_{2}\left\{\mathrm{Ru}(\mathrm{bpy})_{2} \mathrm{Cl}\right\}\right] \mathrm{PF}_{6}$} (Supermolécula 2, Figura 21)

Inicialmente para a síntese da díade $\left[\mathrm{M}(4-\mathrm{N}-\mathrm{Py}) \mathrm{TFFPH}_{2}\left\{\mathrm{Ru}(\mathrm{bpy})_{2} \mathrm{Cl}\right\}\right] \mathrm{PF}_{6}$ foi feita a reação direta utilizando como reagentes a porfirina $\mathrm{M}(4-\mathrm{N}-\mathrm{Py}) \mathrm{TFFPH}_{2}$ e o complexo de rutênio $\left[\mathrm{Ru}(\mathrm{bpy})_{2} \mathrm{Cl}_{2}\right] \cdot 2 \mathrm{H}_{2} \mathrm{O}$. A proporção utilizada foi de 1,5:1 (complexo $\left[\mathrm{Ru}(\mathrm{bpy})_{2} \mathrm{Cl}_{2}\right] \cdot 2 \mathrm{H}_{2} \mathrm{O}$ /porfirina). A reação teve a duração de 90 horas sob aquecimento brando. Para a troca do contra-íon da possível díade formada gotejou-se a solução da mistura reacional sob uma solução alcoólica saturada de $\mathrm{NH}_{4} \mathrm{PF}_{6}$ e deixou-se reagir por 2 horas. Após o término da reação fez-se a purificação dos produtos através de coluna cromatográfica em alumina neutra utilizando como eluente várias proporções de ACN/DCM. Esta cromatografia teve 4 frações eluídas, sendo que as frações 1,2 e 4 foram descartadas porque pelo espectro de UV-Vísivel estas frações não apresentavam a banda Soret que é característica da porfirina. A fração 3 apresentava no espectro UV-Vísivel, as bandas Soret e bandas Q da porfirina, além de uma banda intensa em $296 \mathrm{~nm}$ que pode ser atribuída à transição interna $\pi-\pi^{*}$ da bipiridina coordenada ao íon rutênio(II). Esta fração foi caracterizada por técnicas de UV-Visível, RMN ${ }^{1} \mathrm{H}, \mathrm{RMN}{ }^{19} \mathrm{~F}$, COSY e espectro de massa ESI MS. Pelas análises pode-se confirmar que a fração 3 continha o composto de interesse $\left[\mathrm{M}(4-\mathrm{N}-\mathrm{Py}) \mathrm{TFFPH}_{2}\left\{\mathrm{Ru}(\mathrm{bpy})_{2} \mathrm{Cl}\right\}\right] \mathrm{PF}_{6}$. $\mathrm{O}$ rendimento desta síntese por este procedimento foi de $13 \%$ portanto, considerado baixo.

Na busca de melhores resultados foi feita a coordenação do complexo de rutênio $\left[\mathrm{Ru}(\mathrm{bpy})_{2} \mathrm{Cl}_{2}\right] \cdot 2 \mathrm{H}_{2} \mathrm{O}$ à porfirina $\mathrm{M}(4-\mathrm{N}-\mathrm{Py}) \mathrm{TFFPH}_{2}$ através do método que usa o aquacomplexo $\left[\mathrm{Ru}(\mathrm{bpy})_{2} \mathrm{Cl}\left(\mathrm{H}_{2} \mathrm{O}\right)\right]^{+}$como reagente, porque o aqua complexo deve ser mais reativo do que o complexo $\left[\mathrm{Ru}(\text { bpy })_{2} \mathrm{Cl}_{2}\right] \cdot 2 \mathrm{H}_{2} \mathrm{O}$, devido ao fato do ligante $\mathrm{H}_{2} \mathrm{O}$ ser mais lábil que o $\mathrm{Cl}^{-63}$. A proporção utilizada foi de $1: 1$ (complexo $\left[\mathrm{Ru}(\mathrm{bpy})_{2} \mathrm{Cl}_{2}\right] \cdot 2 \mathrm{H}_{2} \mathrm{O}$ 
/porfirina). A reação teve a duração de 30 minutos sob agitação e aquecimento brando. Para a troca do contra-íon da possível díade formada gotejou-se a solução da mistura reacional sob uma solução alcoólica saturada de $\mathrm{NH}_{4} \mathrm{PF}_{6}$ e deixou-se reagir por 2 horas. A troca do contra-íon foi feita com o intuito do composto formado ser solúvel em solventes orgânicos. Após o término da reação fez-se a purificação dos produtos através de coluna cromatográfica em alumina neutra utilizando como eluente várias proporções de $\mathrm{ACN} /$ DMF. Esta cromatografia teve 4 frações eluídas. Como a díade [M(4-NPy) $\left.\mathrm{TFFPH}_{2}\left\{\mathrm{Ru}(\mathrm{bpy})_{2} \mathrm{Cl}\right\}\right] \mathrm{PF}_{6}$ já tinha sido sintetizada e caracterizada, o seu $\mathrm{R}_{\mathrm{f}}$ era conhecido. Por comparação dos $\mathrm{R}_{\mathrm{f}}$ e espectros de UV-Vísivel pode-se identificar que o composto de interesse estava na fração 2. Novamente para a elucidação da estrutura da díade $\left[\mathrm{M}(4-\mathrm{N}-\mathrm{Py}) \mathrm{TFFPH}_{2}\left\{\mathrm{Ru}(\mathrm{bpy})_{2} \mathrm{Cl}\right\}\right] \mathrm{PF}_{6}$ foram registrados espectros de UV-Visível,

RMN ${ }^{1} \mathrm{H}, \mathrm{RMN}{ }^{19} \mathrm{~F}$ e espectro de massa ESI MS. Por este método obteve-se um rendimento de $28 \%$.

\section{IV.1.4) Síntese das díades trans- e cis-[B(4-N-Py)BFFPH $\left.\left\{\mathrm{Ru}_{3} \mathrm{O}(\mathrm{Ac})_{6}(\mathrm{py})_{2}\right\}\right] \mathrm{PF}_{6}$ (Supermoléculas 3 e 4 , Figura 21)}

As sínteses das díades cis- e trans-[B(4-N-Py) $\left.\mathrm{BFFPH}_{2} \quad\left\{\mathrm{Ru}_{3} \mathrm{O}(\mathrm{Ac})_{6}(\mathrm{py})_{2}\right\}\right] \mathrm{PF}_{6}$ foram feitas com condições semelhantes estabelecidas para a síntese da díade [M(4-N-Py)TFFPH $\left.2\left\{\mathrm{Ru}_{3} \mathrm{O}(\mathrm{Ac})_{6}(\mathrm{py})_{2}\right\}\right] \mathrm{PF}_{6}$ (item IV.1.2). A proporção utilizada foi de 1:0,9 (complexo/porfirina). A reação foi feita em temperatura ambiente, em condições aeróbicas e teve duração de 24 horas sob agitação magnética. Após o término da síntese, a solução foi rotaevaporada até a secura, com formação de um sólido de cor roxa. Obteve-se $95 \mathrm{mg}$ de produtos.

As principais diferenças nas sínteses das díades [M(4-N-Py) $\mathrm{TFFPH}_{2}$ $\left.\left\{\mathrm{Ru}_{3} \mathrm{O}(\mathrm{Ac})_{6}(\mathrm{py})_{2}\right\}\right] \mathrm{PF}_{6}$ e trans-[B(4-N-Py)BFFPH $\left.\left\{\mathrm{Ru}_{3} \mathrm{O}(\mathrm{Ac})_{6}(\mathrm{py})_{2}\right\}\right] \mathrm{PF}_{6}$ está no fato de se usar uma solução diluída de cluster, esta solução foi gotejada lentamente sobre a solução de porfirina a fim de garantir um excesso local de porfirina, e utilizou-se um menor tempo de reação, isto foi feito com o intuito de minimizar a chance de formar uma tríade trans[B(4-N-Py)BFFPH $\left.\mathrm{B}_{2}\left\{\mathrm{Ru}_{3} \mathrm{O}(\mathrm{Ac})_{6}(\mathrm{py})_{2}\right\}_{2}\right]\left(\mathrm{PF}_{6}\right)_{2}$, visto que a reação de interesse é a mono substituição com formação da díade trans-[B(4-N-Py)BFFPH $\left.2\left\{\mathrm{Ru}_{3} \mathrm{O}(\mathrm{Ac})_{6}(\mathrm{py})_{2}\right\}\right] \mathrm{PF}_{6}$. 
Após o término da reação, fez-se uma $\mathrm{CCD}$ em alumina e pôde-se perceber que havia porfirina, cluster sem reagir e duas manchas distintas (díade ou tríade). Foi feito uma coluna de alumina para purificar os produtos da reação. Foram recolhidas duas frações diferentes. Estas frações foram encaminhadas para o laboratório Thomson de Espectrometria de Massa (UNICAMP), sob responsabilidade do prof. Dr. Marcos N. Eberlin. Concluiu-se tratar da díade trans-[B(4-N-Py)BFFPH $\left.\mathrm{H}_{2}\left\{\mathrm{Ru}_{3} \mathrm{O}(\mathrm{Ac})_{6}(\mathrm{py})_{2}\right\}\right] \mathrm{PF}_{6}$ (rendimento de $45 \%$ ) e da tríade trans-[B(4-N-Py)BFFPH $\left.{ }_{2}\left\{\mathrm{Ru}_{3} \mathrm{O}(\mathrm{Ac})_{6}(\mathrm{py})_{2}\right\}_{2}\right]\left(\mathrm{PF}_{6}\right)_{2}$ (rendimento de $9 \%$ ).

Para a síntese da díade cis-[B(4-N-Py)BFFPH $\left.{ }_{2}\left\{\mathrm{Ru}_{3} \mathrm{O}(\mathrm{Ac})_{6}(\mathrm{py})_{2}\right\}\right] \mathrm{PF}_{6}$ adotou-se o mesmo procedimento descrito acima. A proporção utilizada foi de 1:0,8 (complexo/porfirina). A reação foi feita à temperatura ambiente, em condições aeróbicas e teve duração de 24 horas sob agitação magnética. Após o término da síntese, a solução foi rotaevaporada até a secura, com formação de um sólido de cor roxa. Obteve-se $103 \mathrm{mg}$ de produtos que posteriormente foi purificado em coluna de alumina neutra, foram recolhidas duas frações, que foram identificadas por espectrometria de massa. $\mathrm{O}$ rendimento para esta díade cis-[B(4-N-Py) $\left.\mathrm{BFFPH}_{2}\left\{\mathrm{Ru}_{3} \mathrm{O}(\mathrm{Ac})_{6}(\mathrm{py})_{2}\right\}\right] \mathrm{PF}_{6}$ foi de $31 \%$ e para a tríade cis-[B(4$\left.\mathrm{N}-\mathrm{Py}) \mathrm{BFFPH}_{2}\left\{\mathrm{Ru}_{3} \mathrm{O}(\mathrm{Ac})_{6}(\mathrm{py})_{2}\right\}_{2}\right]\left(\mathrm{PF}_{6}\right)_{2}$ foi de $6 \%$. O menor rendimento para a díade cis$\left[\mathrm{B}(4-\mathrm{N}-\mathrm{Py}) \mathrm{BFFPH}_{2}\left\{\mathrm{Ru}_{3} \mathrm{O}(\mathrm{Ac})_{6}(\mathrm{py})_{2}\right\}\right] \mathrm{PF}_{6}$ em relação à díade trans- pode estar relacionado com a utilização de uma menor proporção complexo/porfirina.

\section{IV.1.5) Síntese das tríades trans- e cis-[B(4-N-Py)BFFPH ${ }_{2}\left\{\mathrm{Ru}_{3} \mathrm{O}(\mathrm{Ac})_{6}(\mathrm{py})_{2}\right\}$ $\left.\left\{\mathrm{Ru}(\mathrm{bpy})_{2} \mathrm{Cl}\right\}\right]\left(\mathrm{PF}_{6}\right)_{2 \cdot 2}$ (Supermoléculas 5 e 6, Figura 21)}

Inicialmente para a síntese da tríade trans-[B(4-N-Py)BFFPH ${ }_{2}\left\{\mathrm{Ru}_{3} \mathrm{O}(\mathrm{Ac})_{6}(\mathrm{py})_{2}\right\}$ $\left.\left\{\mathrm{Ru}(\mathrm{bpy})_{2} \mathrm{Cl}\right\}\right]\left(\mathrm{PF}_{6}\right)_{2}$ foi feita a reação utilizando como reagentes a díade trans-[B(4-N$\mathrm{Py} \mathrm{BFFPH}_{2}\left\{\mathrm{Ru}_{3} \mathrm{O}(\mathrm{Ac})_{6}(\mathrm{py})_{2}\right\} \mathrm{PF}_{6}$ e o aquacomplexo de rutênio $\left[\mathrm{Ru}(\mathrm{bpy})_{2} \mathrm{Cl}\left(\mathrm{H}_{2} \mathrm{O}\right)\right]^{+}$. A proporção utilizada foi de 1,2:1 (complexo $\left[\mathrm{Ru}(\mathrm{bpy}){ }_{2} \mathrm{Cl}_{2}\right] \cdot 2 \mathrm{H}_{2} \mathrm{O}$ /porfirina). A reação teve a duração de 30 minutos sob agitação e aquecimento brando. Para a troca do contra-íon da possível díade formada gotejou-se a solução da mistura reacional sob uma solução alcoólica saturada de $\mathrm{NH}_{4} \mathrm{PF}_{6}$ e deixou-se reagir por 2 horas. Após o término da reação fez-se a purificação dos produtos através de coluna cromatográfica em alumina neutra. 
Pela cromatografia e análise de UV-Vísivel ficou evidenciado que não houve a formação da tríade esperada. Fato este que pode estar associado ao pouco tempo de reação, meio reacional diluído ou, ao invés de ocorrido a coordenação de uma molécula de água ao complexo $\left[\mathrm{Ru}(\mathrm{bpy})_{2} \mathrm{Cl}_{2}\right]$, pode ter ocorrido a coordenação de acetonitrila $\left[\mathrm{Ru}(\mathrm{bpy})_{2} \mathrm{Cl}\right.$ $\left.\left(\mathrm{CH}_{3} \mathrm{CN}\right)\right]$ e a estabilização do reagente.

Outra tentativa para a síntese da tríade trans-[B(4-N-Py) $\mathrm{BFFPH}_{2}$ $\left.\left\{\mathrm{Ru}_{3} \mathrm{O}(\mathrm{Ac})_{6}(\mathrm{py})_{2}\right\}\left\{\mathrm{Ru}(\mathrm{bpy})_{2} \mathrm{Cl}\right\}\right]\left(\mathrm{PF}_{6}\right)_{2}$ foi fazer a reação direta utilizando como reagentes a díade trans-[B(4-N-Py) $\left.\mathrm{BFFPH}_{2}\left\{\mathrm{Ru}_{3} \mathrm{O}(\mathrm{Ac})_{6}(\mathrm{py})_{2}\right\}\right] \mathrm{PF}_{6}$ e o complexo de rutênio $\left[\mathrm{Ru}(\mathrm{bpy})_{2} \mathrm{Cl}_{2}\right.$. A reação teve a duração de 48 horas sob aquecimento brando. Para a troca do contra-íon da possível tríade formada gotejou-se a solução da mistura reacional sob uma solução alcoólica de $\mathrm{NH}_{4} \mathrm{PF}_{6}$ e deixou-se reagir por 2 horas. Após o término da reação fez-se a purificação dos produtos através de coluna cromatográfica em alumina neutra. Pela cromatografia e análise de UV-Vísivel ficou evidenciado que poderia haver a formação da tríade esperada porque há uma fração que apresenta a banda Soret em $416 \mathrm{~nm}$ e uma banda em $296 \mathrm{~nm}$ característica do fragmento [Ru(bpy $)_{2}$ ]. Esta fração foi encaminhada para o laboratório Thomson de Espectrometria de Massa (UNICAMP), sob responsabilidade do prof. Dr. Marcos N. Eberlin, a fim de ser identificada.

Para a síntese da tríade cis-[B(4-N-Py) $\mathrm{BFFPH}_{2}\left\{\mathrm{Ru}_{3} \mathrm{O}(\mathrm{Ac})_{6}(\mathrm{py})_{2}\right\}$ $\left.\left\{\mathrm{Ru}(\mathrm{bpy})_{2} \mathrm{Cl}\right\}\right]\left(\mathrm{PF}_{6}\right)_{2}$ adotou-se o mesmo procedimento que a síntese da tríade trans-[B(4-N-Py) $\left.\mathrm{BFFPH}_{2}\left\{\mathrm{Ru}_{3} \mathrm{O}(\mathrm{Ac})_{6}(\mathrm{py})_{2}\right\}\left\{\mathrm{Ru}(\mathrm{bpy})_{2} \mathrm{Cl}\right\}\right]\left(\mathrm{PF}_{6}\right)_{2}$. A purificação foi feita do mesmo modo da tríade trans-[B(4-N-Py) $\mathrm{BFFPH}_{2}\left\{\mathrm{Ru}_{3} \mathrm{O}(\mathrm{Ac})_{6}(\mathrm{py})_{2}\right\}$ $\left.\left\{\mathrm{Ru}(\mathrm{bpy})_{2} \mathrm{Cl}\right\}\right]\left(\mathrm{PF}_{6}\right)_{2}$. A tríade cis-[B(4-N-Py)BFFPH $\left.\mathrm{H}_{2}\left\{\mathrm{Ru}_{3} \mathrm{O}(\mathrm{Ac})_{6}(\mathrm{py})_{2}\right\} \quad\left\{\mathrm{Ru}(\mathrm{bpy})_{2} \mathrm{Cl}\right\}\right]$ $\left(\mathrm{PF}_{6}\right)_{2}$ teve um rendimento de $30 \%$ a tríade trans-[B(4-N-Py) $\mathrm{BFFPH}_{2}\left\{\mathrm{Ru}_{3} \mathrm{O}(\mathrm{Ac})_{6}(\mathrm{py})_{2}\right\}$ $\left.\left\{\mathrm{Ru}(\mathrm{bpy})_{2} \mathrm{Cl}\right\}\right]\left(\mathrm{PF}_{6}\right)_{2}$ teve um rendimento de $6 \%$.

\section{IV.2) Espectroscopia Eletrônica}

$\mathrm{O}$ espectro eletrônico da porfirina $\mathrm{M}(4-\mathrm{N}-\mathrm{Py}) \mathrm{TFFPH}_{2}$, obtido em DCM é mostrado na Figura 24. Os espectros eletrônicos das outras porfirinas são mostrados na Figura 25. Percebe-se que, nesta série de porfirinas, há um pequeno deslocamento hypsocrômico no comprimento de onda da banda Soret e das bandas $\mathrm{Q}$ à medida que aumenta o número de substituintes pentafluorofenil na porfirina. Isto pode ser atribuído ao fato do grupo 
pentafluorofenil remover a densidade eletrônica do anel e alterar a densidade eletrônica da porfirina $^{70}$, estabilizando os orbitais HOMO e, portanto, aumentando de maneira geral a energia das bandas. Este comportamento é coerente com os resultados de voltametria cíclica, que mostraram maior dificuldade na oxidação dos compostos à medida que aumentava a capacidade eletro-retiradora dos substituintes, conforme relatado por Kadish . Este substituinte tem uma pequena influência sobre o coeficiente de extinção molar das porfirinas, o que pode ser explicado pela restrição de rotação deste grupo.

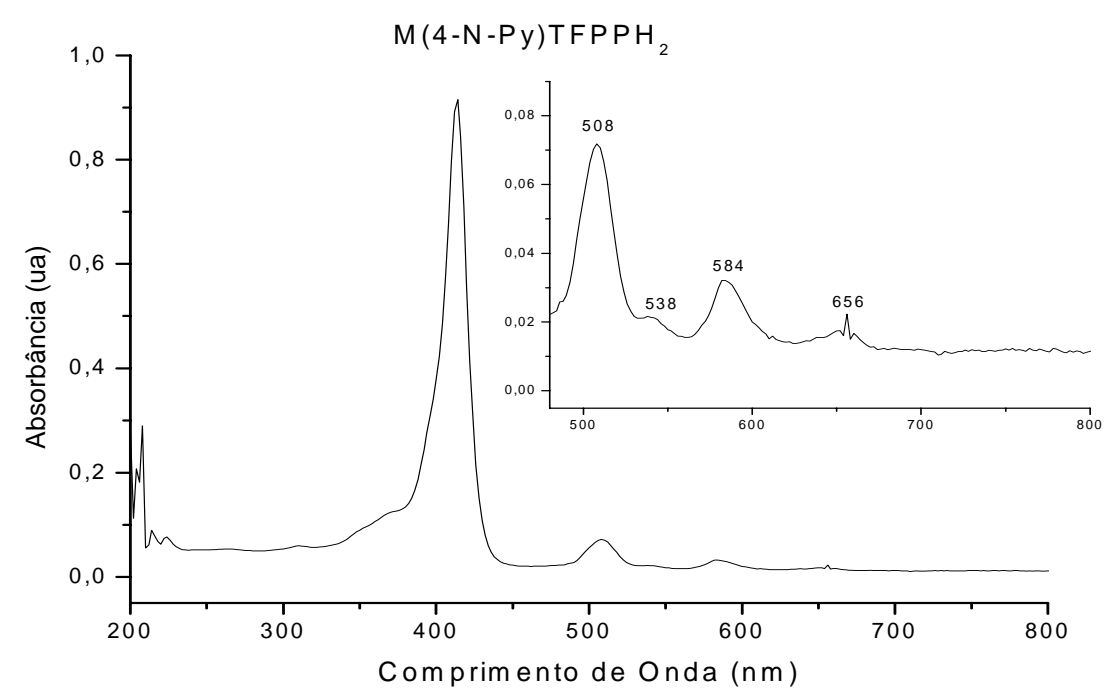

Figura 24: Espectro de UV-Vísivel de uma solução da porfirina M(4-N-Py)TFPPH ${ }_{2}$.

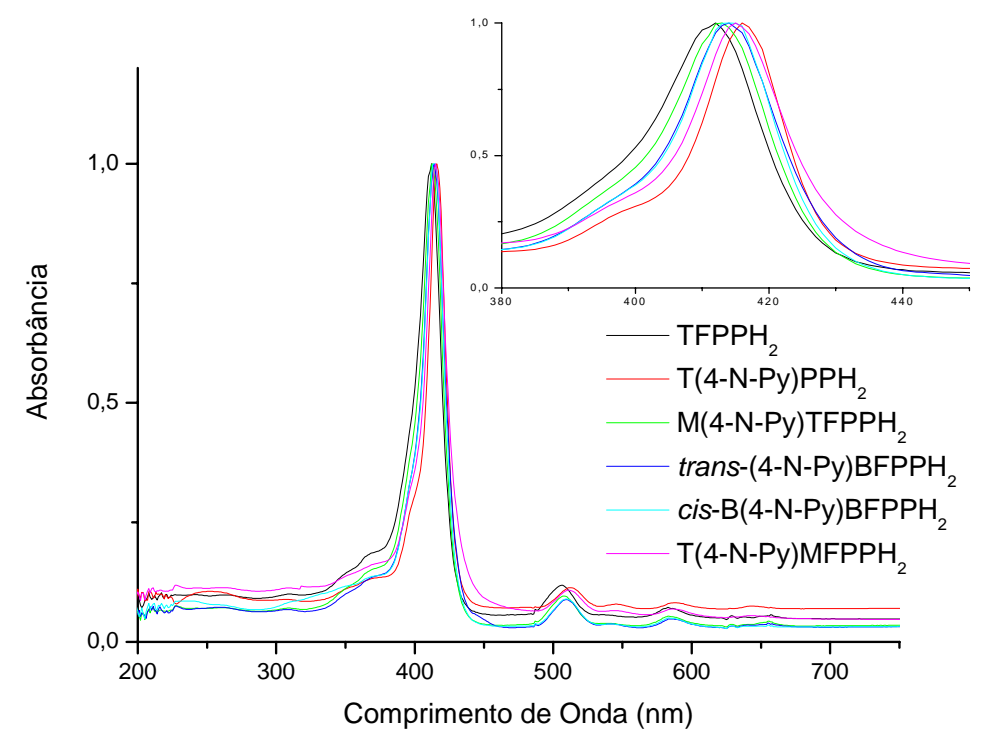

Figura 25: Espectro de UV-Vísivel da série de porfirinas. 
A absortividade molar da banda Soret é da ordem de $10^{5} \mathrm{~L} \cdot \mathrm{mol}^{-1} \mathrm{~cm}^{-1}$. Esta banda é a escolhida para determinações espectrofotométricas de porfirinas. Os espectros UV-Visível das porfirinas M(4-N-Py)TFPPH $\mathrm{H}_{2}$ (Figura 25), trans-B(4-N-Py)BFPPH ${ }_{2}$, cis-B(4-N-Py)BFPPH ${ }_{2}$ e T(4-N-Py)MFPPH ${ }_{2}$ apresentaram um perfil característico de porfirinas base livre ${ }^{71}$, com banda Soret em torno de $\lambda=414 \mathrm{~nm}$ e as bandas na região visível em torno de $\mathrm{Q}_{\mathrm{y}}(1,0) 508 \mathrm{~nm}, \mathrm{Q}_{\mathrm{y}}(0,0) 538 \mathrm{~nm}, \mathrm{Q}_{\mathrm{x}}(1,0) 584 \mathrm{~nm}$ e $\mathrm{Q}_{\mathrm{x}}(0,0) 656 \mathrm{~nm}$.

Os espectros UV-Visível das porfirinas $\mathrm{M}(4-\mathrm{N}-\mathrm{Py}) \mathrm{TFPPH}_{2}$, trans-B(4-N-Py)BFPPH ${ }_{2}$, cis-B(4-N-Py)BFPPH 2 e T(4-N-Py)MFPPH 2 são do tipo phyllo, pois os grupos pentafluorofenil apresentam átomos de halogênios na posição orto e como já foi descrito acima, os átomos de halogênio na posição orto causam uma restrição na rotação do grupo pentafluorofenil.


Figura 26: Espectros de porfirina base livre dos tipos etio e phyllo.

Calculou-se os valores de $\varepsilon$ (absortividade molar) das bandas observadas através da Lei de Beer-Lambert, os dados se encontram na tabela 5 que resume os dados de espectoscopia eletrônica de todas as moléculas sintetizadas.

Por espectroscopia eletrônica não é possível diferenciar uma porfirina da outra, por isso é necessário a utilização da técnica de ressonância magnética nuclear. 
1 Porfirina $\mathrm{TFPPH}_{2}$

2 Porfirina $\mathrm{M}(4-\mathrm{N}-\mathrm{Py}) \mathrm{TFPPH}_{2}$

3 Porfirina trans-B(4-N-Py) $\mathrm{BFPPH}_{2}$

$4 \quad$ Porfirina cis-B(4-N-Py)BFPPH

5 Porfirina $\mathrm{T}(4-\mathrm{N}-\mathrm{Py}) \mathrm{MFPPH}_{2}$

6 Porfirina $T(4-\mathrm{N}-\mathrm{Py}) \mathrm{PH}_{2}$

7 Díade $\left[\mathrm{M}(4-\mathrm{N}-\mathrm{Py}) \mathrm{TFPPH}_{2}\left\{\mathrm{Ru}_{3} \mathrm{O}(\mathrm{Ac})_{6}(\mathrm{py})_{2}\right\}\right] \mathrm{PF}_{6}$

8 Díade $\left[\mathrm{M}(4-\mathrm{N}-\mathrm{Py}) \mathrm{TFPPH}_{2}\left\{\mathrm{Ru}(\mathrm{bpy})_{2} \mathrm{Cl}\right\}\right] \mathrm{PF}_{6}$

9 Díade trans-[B(4-N-Py)BFPPH $\left.{ }_{2}\left\{\mathrm{Ru}_{3} \mathrm{O}(\mathrm{Ac})_{6}(\mathrm{py})_{2}\right\}\right] \mathrm{PF}_{6}$

10 Díade cis-[B(4-N-Py)BFPPH $\left.2\left\{\mathrm{Ru}_{3} \mathrm{O}(\mathrm{Ac})_{6}(\mathrm{py})_{2}\right\}\right] \mathrm{PF}_{6}$

11 Tríade trans-[B(4-N-Py)BFPPH $\left.2\left\{\mathrm{Ru}_{3} \mathrm{O}(\mathrm{Ac})_{6}(\mathrm{py})_{2}\right\}\left\{\mathrm{Ru}(\mathrm{bpy})_{2} \mathrm{Cl}\right\}\right]\left(\mathrm{PF}_{6}\right)_{2}$

12 Tríade cis-[B(4-N-Py)BFPPH $\left.{ }_{2}\left\{\mathrm{Ru}_{3} \mathrm{O}(\mathrm{Ac})_{6}(\mathrm{py})_{2}\right\}\left\{\mathrm{Ru}(\mathrm{bpy})_{2} \mathrm{Cl}\right\}\right]\left(\mathrm{PF}_{6}\right)_{2}$

Tabela 5: Comprimento de onda e logaritmo das absortividades molares $(\log \varepsilon)$ das bandas das moléculas sintetizadas

\begin{tabular}{|c|c|c|c|c|c|c|c|}
\hline Molécula & $\pi-\pi^{*}$ & Soret & $\mathrm{Q}_{\mathrm{y}}(1,0)$ & $\mathrm{Q}_{\mathrm{y}}(0,0)$ & $\mathrm{Q}_{\mathrm{x}}(1,0)$ & $\mathrm{Q}_{\mathrm{x}}(0,0)$ & I.C. \\
\hline 1 & & $412(5,4)$ & $506(4,2)$ & $541(3,3)$ & $583(3,8)$ & $649(3,0)$ & \\
\hline 2 & & $413(5,4)$ & $508(4,3)$ & $540(3,4)$ & $583(3,8)$ & $649(3,2)$ & \\
\hline 3 & & $414(5,3)$ & $509(4,1)$ & $540(3,4)$ & $583(3,8)$ & $649(3,1)$ & \\
\hline 4 & & $415(5,4)$ & $509(4,2)$ & $541(3,4)$ & $583(3,7)$ & $649(2,8)$ & \\
\hline 5 & & $416(5,4)$ & $509(4,3)$ & $541(3,6)$ & $583(3,8)$ & $649(3,1)$ & \\
\hline 6 & & $416(5,4)$ & $512(4,2)$ & $546(3,8)$ & $587(3,7)$ & $648(3,2)$ & \\
\hline 7 & & $414(5,2)$ & $510(4,1)$ & $538(3,5)$ & $585(3,8)$ & $655(3,7)$ & $690(3,6)$ \\
\hline 8 & $296(4,5)$ & $414(5,1)$ & $509(4,2)$ & $538(3,7)$ & $585(3,7)$ & $655(3,0)$ & \\
\hline 9 & & $414(5,4)$ & $510(4,4)$ & $545(3,8)$ & $587(4,0)$ & $655(3,9)$ & $691(3,9)$ \\
\hline 10 & & $414(5,5)$ & $510(4,4)$ & $545(3,9)$ & $587(4,1)$ & $655(4,0)$ & $691(4,0)$ \\
\hline 11 & $295(4,3)$ & $416(4,8)$ & $512(3,9)$ & $548(3,5)$ & $588(3,6)$ & $650(3,4)$ & $690(3,4)$ \\
\hline 12 & $296(4,4)$ & $417(5,0)$ & $511(4,0)$ & $545(3,7)$ & $587(3,7)$ & $650(3,5)$ & $691(3,5)$ \\
\hline
\end{tabular}

A coordenação de complexos $\left[\mathrm{Ru}(\mathrm{bpy})_{2} \mathrm{Cl}\right]^{+}$à meso-pentafluorofenil-piridilporfirina acrescenta duas novas bandas ao espectro, como pode se observar na Figura 27. 
A primeira banda em $296 \mathrm{~nm}$ pode ser atribuída à transição interna $\pi-\pi^{*}$ da bipiridina coordenada ao íon rutênio(II). A segunda banda do complexo $\left[\mathrm{Ru}(\mathrm{bpy})_{2} \mathrm{Cl}\right]^{+}$aparece em torno de $490 \mathrm{~nm}$ sob a banda Soret e pode ser atribuída à transição de transferência de carga rutênio(II) $\rightarrow$ bipiridina ou a transferência de carga do rutênio (II) $\rightarrow$ porfirina.

A porfirina $\mathrm{M}(4-\mathrm{N}-\mathrm{Py}) \mathrm{TFPPH}_{2}$ coordenada ao complexo $\left[\mathrm{Ru}(\mathrm{bpy})_{2} \mathrm{Cl}\right]^{+}$apresenta um aumento no $\varepsilon$ da banda $\pi-\pi^{*}(296 \mathrm{~nm})$ e uma diminuição no $\varepsilon$ da banda Soret. Além disso, também foi observado um alargamento da banda Soret em relação à pentafluorofenil-piridilporfirinas Figura 27. A diminuição da banda Soret pode ser causada pela sobreposição da banda transferência de carga (MLCT) rutênio (II) $\rightarrow$ bipiridina, que provoca seu alargamento e conseqüente diminuição de intensidade. Há um aumento de intensidade nas bandas $\mathrm{Q}_{\mathrm{y}(0,0)}, \mathrm{Q}_{\mathrm{y}(1,0)}$ que pode ser devido a uma contribuição da banda MLCT do complexo periférico, entretanto nas bandas $\mathrm{Q}_{\mathrm{x}(0,0)}$ e $\mathrm{Q}_{\mathrm{x}(1,0)}$ há uma pequena influência da banda MLCT do complexo de rutênio, por esse motivo sua intensidade mantém-se praticamente constante e semelhante as das pentafluorofenil-piridilporfirinas.

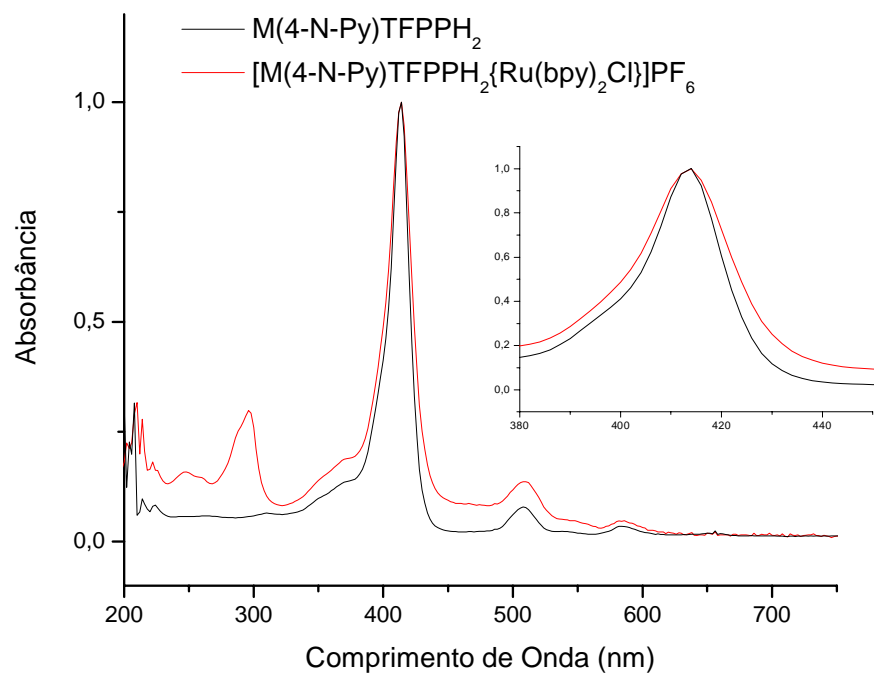

Figura 27: Espectro de UV-Vísivel da díade $\left[\mathrm{M}(4-\mathrm{N}-\mathrm{Py}) \mathrm{TFPPH}_{2}\left\{\mathrm{Ru}(\mathrm{bpy})_{2} \mathrm{Cl}\right\}\right] \mathrm{PF}_{6} \mathrm{em}$ comparação com a porfirina $\mathrm{M}(4-\mathrm{N}-\mathrm{Py}) \mathrm{TFPPH}_{2}$.

A coordenação do cluster $\left[\mathrm{Ru}_{3} \mathrm{O}(\mathrm{Ac})_{6}(\mathrm{py})_{2}\right]^{+}$não causa mudanças significativas no perfil dos espectros de UV-Vísivel (Figura 28 e Figura 29) das díades $\left[\mathrm{M}(4-\mathrm{N}-\mathrm{Py}) \mathrm{TFPPH}_{2}\left\{\mathrm{Ru}_{3} \mathrm{O}(\mathrm{Ac})_{6}(\mathrm{py})_{2}\right\}\right] \mathrm{PF}_{6}, \quad$ cis- $\quad$ e trans-[B(4-N-Py) $\mathrm{BFPPH}_{2}$ $\left.\left\{\mathrm{Ru}_{3} \mathrm{O}(\mathrm{Ac})_{6}(\mathrm{py})_{2}\right\}\right] \mathrm{PF}_{6}$ em comparação com os espectros de UV-Visível das porfirinas 
base livres. Há um alargamento da banda Soret e um aumento de intensidade das bandas $\mathrm{Q}_{\mathrm{y}(1,0)}, \mathrm{Q}_{\mathrm{y}(0,0)}, \mathrm{Q}_{\mathrm{x}(1,0)}$ e $\mathrm{Qx}_{(0,0)}$, no comprimento de onda de $690 \mathrm{~nm}$ é possível identificar a transição intracluster (I.C.) ${ }^{72}$, em uma banda alargada.

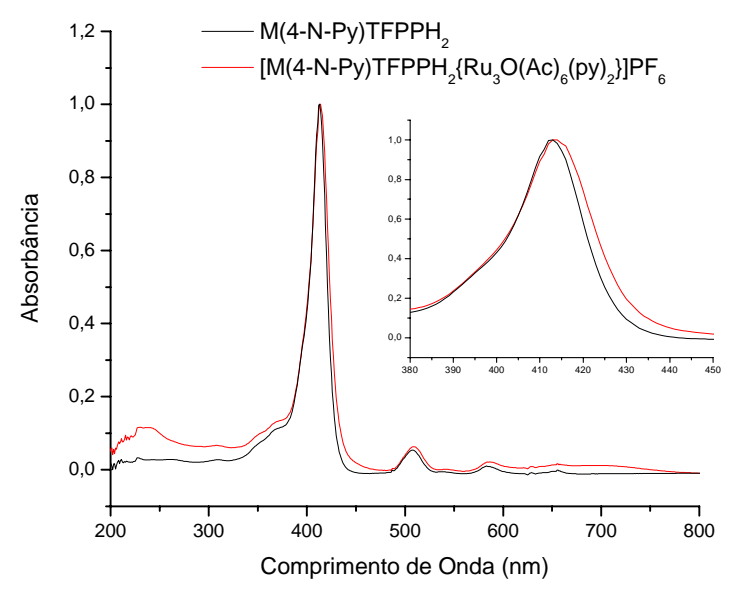

Figura 28: Espectro de UV-Vísivel da díade $\left[\mathrm{M}(4-\mathrm{N}-\mathrm{Py}) \mathrm{TFPPH}_{2}\left\{\mathrm{Ru}_{3} \mathrm{O}(\mathrm{Ac})_{6}(\mathrm{py})_{2}\right\}\right] \mathrm{PF}_{6}$ em comparação com a porfirina $\mathrm{M}(4-\mathrm{N}-\mathrm{Py}) \mathrm{TFPPH}_{2}$.

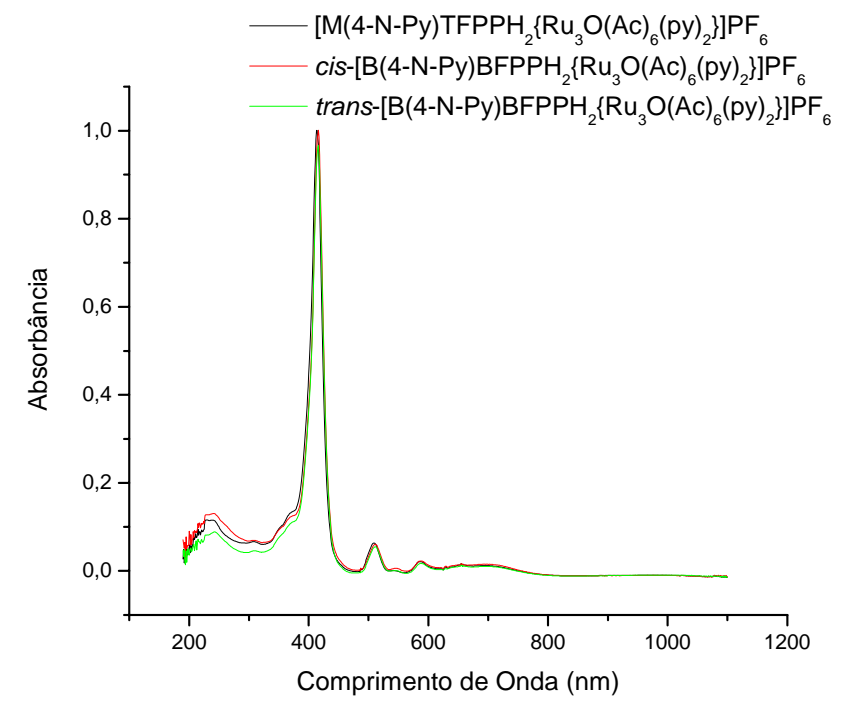

Figura 29: Espectro de UV-Vísivel das díades substituídas com o cluster $\left[\mathrm{Ru}_{3} \mathrm{O}(\mathrm{Ac})_{6}(\mathrm{py})_{2}\right]^{+}$.

Os dados de espectroscopia eletrônica para as tríades cis- e trans-[B(4-N-Py) BFFPH $\left.{ }_{2}\left\{\mathrm{Ru}_{3} \mathrm{O}(\mathrm{Ac})_{6}(\mathrm{py})_{2}\right\}\left\{\mathrm{Ru}(\mathrm{bpy})_{2} \mathrm{Cl}\right\}\right]\left(\mathrm{PF}_{6}\right)_{2}$ (Figura 30) mostram que os espectros, de um modo geral, são apenas uma somatória do perfil espectral dos componentes, sugerindo ausência de comunicação eletrônica. As tríades apresentam duas bandas características do fragmento $\mathrm{Ru}(\mathrm{bpy})_{2} \mathrm{Cl}^{+}$, como no caso da díade 
$\mathrm{M}(4-\mathrm{N}-\mathrm{Py}) \mathrm{TFFPH}_{2}\left\{\mathrm{Ru}(\mathrm{bpy})_{2} \mathrm{Cl}_{\}}\right\} \mathrm{PF}_{6}$, uma banda em $296 \mathrm{~nm}$ que pode ser atribuída à transição interna $\pi-\pi^{*}$ da bipiridina coordenada ao íon rutênio(II). A segunda banda do complexo $\left[\mathrm{Ru}(\text { bpy })_{2} \mathrm{Cl}\right]^{+}$aparece na região de $490 \mathrm{~nm}$ e pode ser atribuída à transição de transferência de carga rutênio(II) $\rightarrow$ bipiridina ou a transferência de carga do rutênio (II) $\rightarrow$ porfirina. Uma banda característica do fragmento $\left[\mathrm{Ru}_{3} \mathrm{O}(\mathrm{Ac})_{6}(\mathrm{py})_{2}\right]^{+}$pode ser vista no comprimento de onda de $690 \mathrm{~nm}$, que é devido à transição intracluster (I.C.). As tríades também apresentam uma banda Soret e quatro bandas Q, relativas às porfirinas. A banda Soret é ligeiramente alargada e tem sua intensidade diminuída como ocorre no caso de todas as díades.

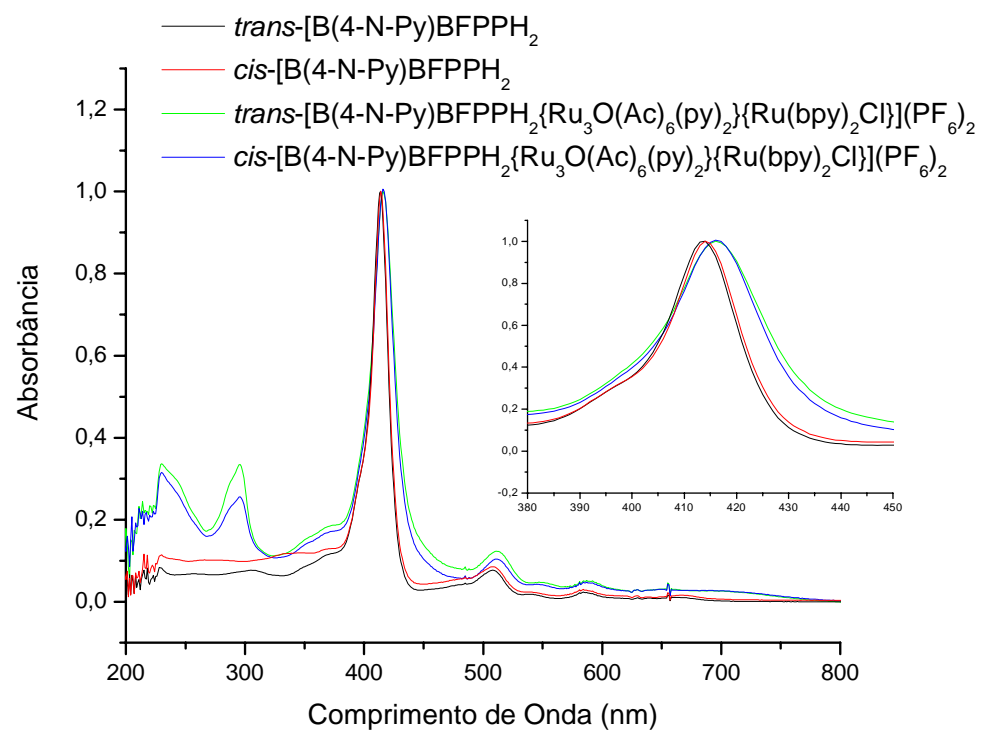

Figura 30: Espectro de UV-Vísivel comparativo das diferentes tríades obtidas com as respectivas porfirinas.

\section{IV.3) Ressonância Magnética Nuclear}

\section{IV.3.1) Porfirinas}

Fez-se a caracterização das porfirinas $\mathrm{M}(4-\mathrm{N}-\mathrm{Py}) \mathrm{TFPPH}_{2}$, trans-B(4-NPy)BFPPH ${ }_{2}$ e cis-B(4-N-Py)BFPPH $\mathrm{B}_{2}$ por RMN ${ }^{1} \mathrm{H}, \mathrm{RMN}{ }^{19} \mathrm{~F}$ e COSY e, para a porfirina $\mathrm{T}(4-\mathrm{N}-\mathrm{Py}) \mathrm{MFPPH}_{2}$ foram feitos apenas experimentos de RMN ${ }^{1} \mathrm{H}$, e COSY. Na Figura 31 estão representadas essas moléculas com as numerações para seus respectivos prótons e 
núcleos de flúor. Nas Tabelas 6 e 7 encontram-se os valores de deslocamentos químicos (ס) dos prótons e núcleos de flúor de cada porfirina. Na Figura 32 estão representados os padrões básicos de $\mathrm{RMN}{ }^{1} \mathrm{H}$ dos prótons $\mathrm{H} \beta$-pirrólicos de porfirinas base livre. Os deslocamentos químicos, padrões e intensidades relativas dos sinais de RMN ${ }^{1} \mathrm{H}$ foram utilizados para atribuir a estrutura das porfirinas.

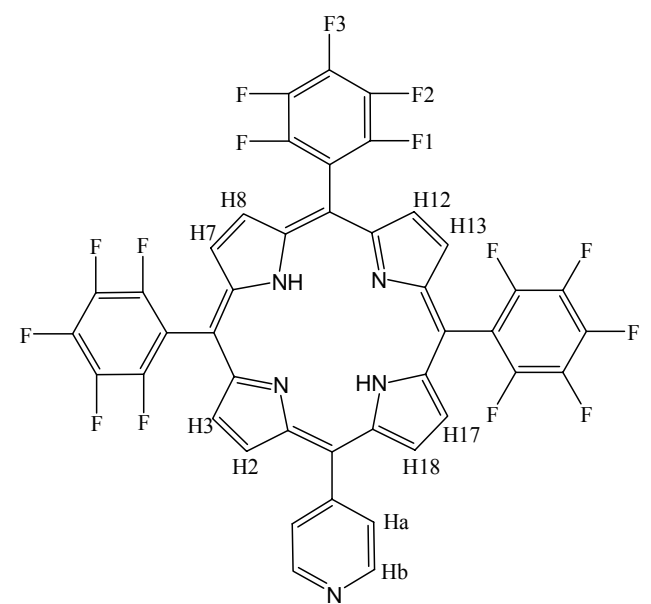

$\mathrm{M}(4-\mathrm{N}-\mathrm{Py}) \mathrm{TFPPH}_{2}$

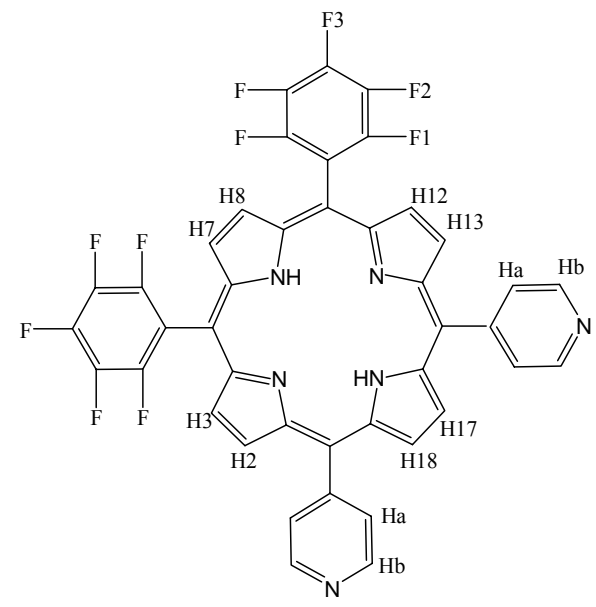

cis-B(4-N-Py)BFPPH 2

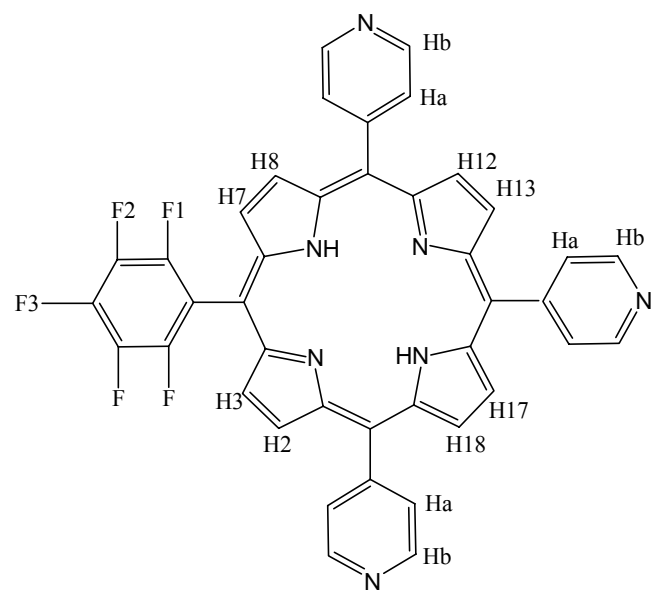

T(4-N-Py) $\mathrm{MFPPH}_{2}$

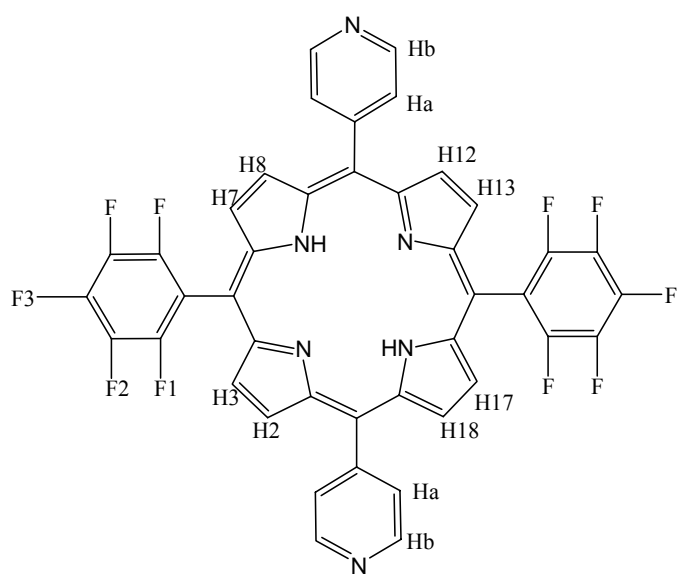

trans-B(4-N-Py)BFPPH

Figura 31: Esquema de numeração dos prótons das porfirinas. 
Tabela 6: Atribuição tentativa dos espectros de RMN ${ }^{1} \mathrm{H}$ das porfirinas sintetizadas

\begin{tabular}{|c|c|c|c|c|c|}
\hline Porfirina & \multicolumn{2}{|l|}{ H- $\beta$ pirrólicos } & \multicolumn{2}{|c|}{ H piridínicos } & N-H \\
\hline $\mathrm{TFPPH}_{2}$ & \multicolumn{2}{|l|}{$8,82 \mathrm{~s}(8)$} & & - & $-2,93 \mathrm{~s}(2)$ \\
\hline \multirow{2}{*}{$\mathrm{M}(4-\mathrm{N}-\mathrm{Py}) \mathrm{TFPPH}_{2}$} & $\mathrm{H}_{2}, \mathrm{H}_{18}$ & 8,87 (2) & $\mathrm{H}_{\mathrm{a}}$ & $8,17 \mathrm{~d}(2)$ & \multirow{2}{*}{$-2,90 \mathrm{~s}(2)$} \\
\hline & $\mathrm{H}_{3}, \mathrm{H}_{7}, \mathrm{H}_{8}, \mathrm{H}_{12}, \mathrm{H}_{13}, \mathrm{H}_{17}$ & $8,92 \mathrm{~s}(6)$ & $\mathrm{H}_{\mathrm{b}}$ & $9,07 \mathrm{~d}(2)$ & \\
\hline \multirow{2}{*}{ trans-B(4-NPy)BFPPH } & $\mathrm{H}_{2}, \mathrm{H}_{8}, \mathrm{H}_{12}, \mathrm{H}_{18}$ & $8,86 \mathrm{~d}(4)$ & $\mathrm{H}_{\mathrm{a}}$ & $8,19 \mathrm{~d}(4)$ & \multirow{2}{*}{$-2,92 \mathrm{~s}(2)$} \\
\hline & $\mathrm{H}_{3}, \mathrm{H}_{7}, \mathrm{H}_{13}, \mathrm{H}_{17}$ & $8,92 \mathrm{~d}(4)$ & $\mathrm{H}_{\mathrm{b}}$ & $9,08 \mathrm{~d}(4)$ & \\
\hline \multirow{4}{*}{ cis-B(4-N-Py)BFPPH 2} & $\mathrm{H}_{17}, \mathrm{H}_{18}$ & $8,85(2)$ & & & \multirow{4}{*}{$-2,88 \mathrm{~s}(2)$} \\
\hline & $\mathrm{H}_{2}, \mathrm{H}_{13}$ & $8,87(2)$ & $\mathrm{H}_{\mathrm{a}}$ & $8,17 \mathrm{~d}(4)$ & \\
\hline & $\mathrm{H}_{3}, \mathrm{H}_{12}$ & $8,90(2)$ & $\mathrm{H}_{\mathrm{b}}$ & $9,08 \mathrm{~d}(4)$ & \\
\hline & $\mathrm{H}_{7}, \mathrm{H}_{8}$ & $8,92(2)$ & & & \\
\hline \multirow{2}{*}{ T(4-N-Py)MFPPH 2} & $\mathrm{H}_{2}, \mathrm{H}_{8}, \mathrm{H}_{12}, \mathrm{H}_{13}, \mathrm{H}_{17}, \mathrm{H}_{18}$ & $8,87 \mathrm{~s}(6)$ & $\mathrm{H}_{\mathrm{a}}$ & $8,17 \mathrm{~d}(6)$ & \multirow{2}{*}{$-2,90 \mathrm{~s}(2)$} \\
\hline & $\mathrm{H}_{3}, \mathrm{H}_{7}$ & $8,93(2)$ & $\mathrm{H}_{\mathrm{b}}$ & $9,08 \mathrm{~d}(6)$ & \\
\hline
\end{tabular}

$\delta\left(\mathrm{CDCL}_{3}\right)$ em ppm; referência TMS; (valor da integral, correspondendo ao número de prótons); $\mathrm{s}=$ singlete; $\mathrm{d}=$ dupleto.

Tabela 7: Atribuição tentativa dos espectros de $\mathrm{RMN}{ }^{19} \mathrm{~F}$ das porfirinas sintetizadas.

\begin{tabular}{|c|c|c|c|}
\hline Porfirina & F1 & F2 & F3 \\
\hline $\mathrm{M}(4-\mathrm{N}-\mathrm{Py}) \mathrm{TFPPH}_{2}$ & $-137,5(6)$ & $-162,4(6)$ & $-152,3 \mathrm{t}(3)$ \\
\hline trans-B(4-N-Py)BFPPH ${ }_{2}$ & $-140,5(4)$ & $-165,3(4)$ & $-155,4 \mathrm{t}(2)$ \\
\hline cis-B(4-N-Py)BFPPH 2 & $-140,7(4)$ & $-165,4(4)$ & $-155,4 \mathrm{t}(2)$ \\
\hline Supermolécula 1 & $-137,5(6)$ & $-162,4(6)$ & $-152,3 \mathrm{t}(3)$ \\
\hline Supermolécula 2 & $-137,5(6)$ & $-162,4(6)$ & $-152,3 \mathrm{t}(3)$ \\
\hline
\end{tabular}

$\delta\left(\mathrm{CDCL}_{3}\right)$ em ppm; referência $\mathrm{CF}_{3} \mathrm{C}_{6} \mathrm{H}_{5}$; (valor da integral, correspondendo ao número de prótons); $\mathrm{t}=$ triplete. 




Figura 32: Padrões básicos para o espectro de $\mathrm{RMN}{ }^{1} \mathrm{H}$ de prótons $\mathrm{H} \beta$-pirrólicos ${ }^{73}$.

Na Figura 33 pode-se fazer uma comparação dos espectros de $\mathrm{RMN}{ }^{1} \mathrm{H}$ (região dos protons $\mathrm{H} \beta$-pirrólicos) das diferentes porfirinas obtidas na síntese. Os prótons piridínicos tem um padrão semelhante, a maior mudança ocorre com os prótons $\mathrm{H} \beta$-pirrólicos, isto ocorre porque na série, as porfirinas apresentam simetrias diferentes, além desses prótons sofrerem diferentes efeitos indutivos dos grupos pentafluorofenil e piridil.

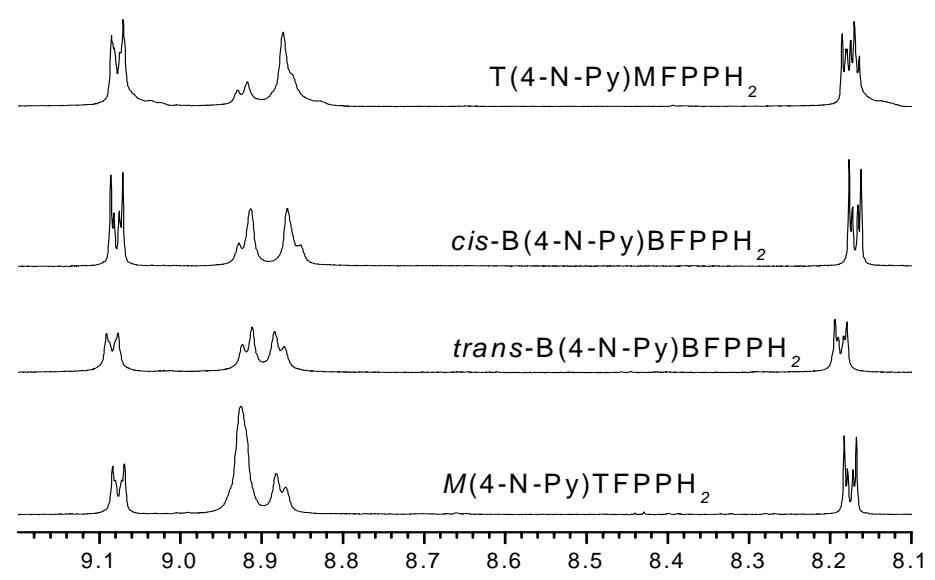

Figura 33: Comparação do $\mathrm{RMN}{ }^{1} \mathrm{H}$ das série meso-pentafluorofenil-piridil-porfirina. 


\section{IV.3.1.1) M(4-N-Py)TFPPH 2}

Observando o espectro de $\mathrm{RMN}{ }^{1} \mathrm{H}$ da M(4-N-Py)TFPPH ${ }_{2}$ (Figura 33) verifica-se a presença de quatro prótons piridínicos, o que é condizente com a sua estrutura. Baseandose nos dados de RMN ${ }^{1} \mathrm{H}$ encontrados na literatura, fez-se a atribuição dos sinais referentes aos prótons $\mathrm{H} \beta$-pirrólicos e piridínicos da $\mathrm{M}(4-\mathrm{N}-\mathrm{Py}) \mathrm{TFPPH}_{2}$.

De acordo com o relatado por Lindsay e colaboradores ${ }^{74}$ e James e colaboradores atribui-se o dupleto em $\delta=8,17 \mathrm{ppm}$ aos prótons piridínicos $\mathrm{H}_{\mathrm{a}}$ e o dupleto em $\delta=9,07 \mathrm{ppm}$ aos prótons piridínicos $\mathrm{H}_{\mathrm{b}}$. Esta atribuição foi feita baseando-se no princípio de que os prótons $\mathrm{H}_{\mathrm{b}}$ seriam mais desprotegidos do que os prótons $\mathrm{H}_{\mathrm{a}}$, por se encontrarem ligados a um átomo de carbono vizinho a um átomo de nitrogênio piridínico, que possui caráter eletronegativo. Os prótons $\mathrm{H}_{\mathrm{a}}$ e $\mathrm{H}_{\mathrm{b}}$ apresentam a mesma constante de acoplamento $\mathrm{J}_{(1,2)}=5,81 \mathrm{~Hz}$ e como pode ser visto através da Figura 36, estes prótons acoplam entre si, o que condiz com a estrutura proposta para esta molécula.

O padrão de $\mathrm{RMN}{ }^{1} \mathrm{H}$ dos prótons $\mathrm{H} \beta$-pirrólicos para o sistema $\mathrm{R}_{5}, \mathrm{R}_{10}=\mathrm{R}_{15}=\mathrm{R}_{20}$ (padrão II, Figura 32) prediz o aparecimento de um singleto e dois dupletos. No RMN de ${ }^{1} \mathrm{H}$ para as pentafluoro-piridil-porfirinas isto ocorre, mas há a sobreposição do singleto com um dos dupletos, isto pode ser observado em $\delta=8,92 \mathrm{ppm}$ (Figura 33). Pela integração dos sinais e pelo fato que os prótons $\mathrm{H}_{3}, \mathrm{H}_{7}, \mathrm{H}_{8}, \mathrm{H}_{12}, \mathrm{H}_{13}, \mathrm{H}_{17}$ se encontrarem ligados mais próximos do grupo pentafluorofenil (grupo retirador de densidade eletrônica do macrociclo) do que os prótons $\mathrm{H}_{2}, \mathrm{H}_{18}$ pode-se afirmar que o sinal em $\delta=8,92 \mathrm{ppm}$ corresponde aos prótons $\mathrm{H}_{3}, \mathrm{H}_{7}, \mathrm{H}_{8}, \mathrm{H}_{12}, \mathrm{H}_{13}, \mathrm{H}_{17}$ e que o sinal em $\delta=8,86 \mathrm{ppm}$ corresponde aos prótons $\mathrm{H}_{2}, \mathrm{H}_{18}$, (Figura 33).

Os prótons mais protegidos que a molécula apresenta são os prótons internos do anel porfirínico. A grande diferença observada no deslocamento químico desses prótons é decorrente da forte influência do efeito de corrente do anel. Esse efeito proporciona uma acentuada blindagem e conseqüente deslocamento do sinal para regiões de baixa freqüência (campo alto). Estes prótons $(\mathrm{N}-\mathrm{H})$ têm um deslocamento químico de $\delta=-2,90$ ppm (Figura 34) e são utilizados como pico base para se fazer a integral dos outros picos da molécula. 
No espectro de $\mathrm{RMN} \quad{ }^{19} \mathrm{~F}$ utilizou-se como referência trifluorotolueno $\left(\mathrm{CF}_{3} \mathrm{C}_{6} \mathrm{H}_{5}\right)$.Observando-se o espectro de $\mathrm{RMN}{ }^{19} \mathrm{~F}$ da porfirina $\mathrm{M}(4-\mathrm{N}-\mathrm{Py}) \mathrm{TFFPH}_{2}$ (Figura 35, Tabela 7) e baseando-se em dados relatados na literatura ${ }^{75}$, atribui-se o sinal em $\delta=-137,5 \mathrm{ppm}$ aos átomos de flúor em orto $\left(\mathrm{F}_{1}\right)$. O triplete em $\delta=-152,3 \mathrm{ppm}$ foi atribuído aos átomos de flúor na posição para $\left(\mathrm{F}_{3}\right)$ e o sinal em $\delta=-162,4$ ppm foi atribuído aos átomos de flúor na posição meta $\left(\mathrm{F}_{2}\right)$.

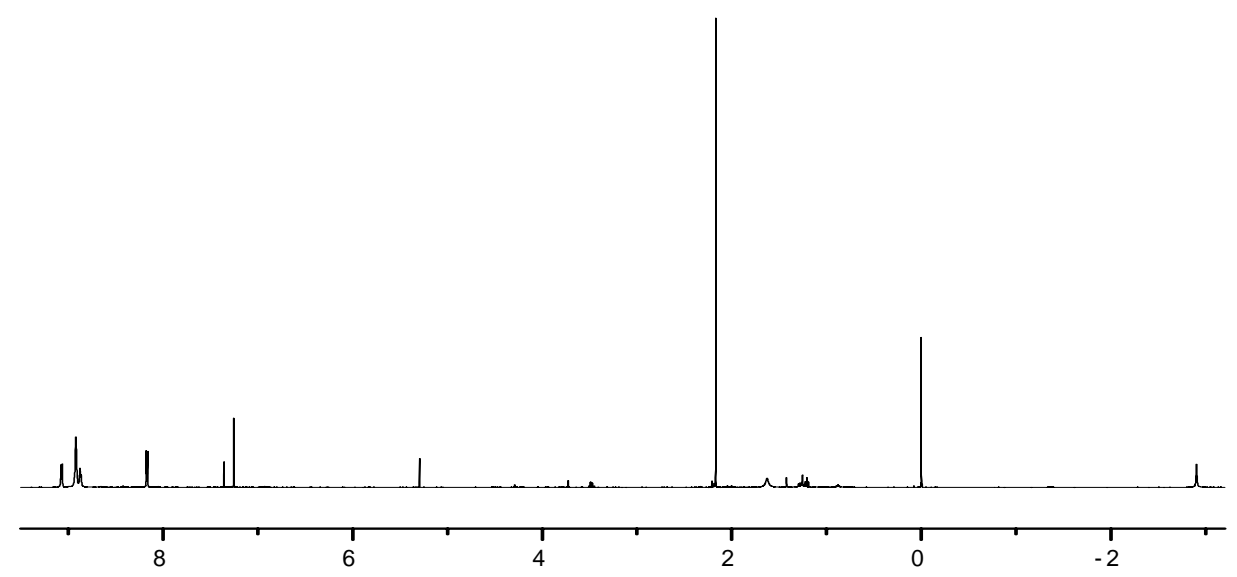

Figura 34: Espectro de RMN de ${ }^{1} \mathrm{H}$ da porfirina $\mathrm{M}(4-\mathrm{N}-\mathrm{Py}) \mathrm{TFFPH}_{2}$ em $\mathrm{CDCl}_{3}$.

Alguns sinais de impureza que aparecem nos espectros de RMN ${ }^{1} \mathrm{H}$ podem ser devido a utilização de $\mathrm{CDCl}_{3}$ de uso comum no laboratório, pois pela análise elementar e pela espectometria de massa os resultados estão de acordo com as estruturas das moléculas.

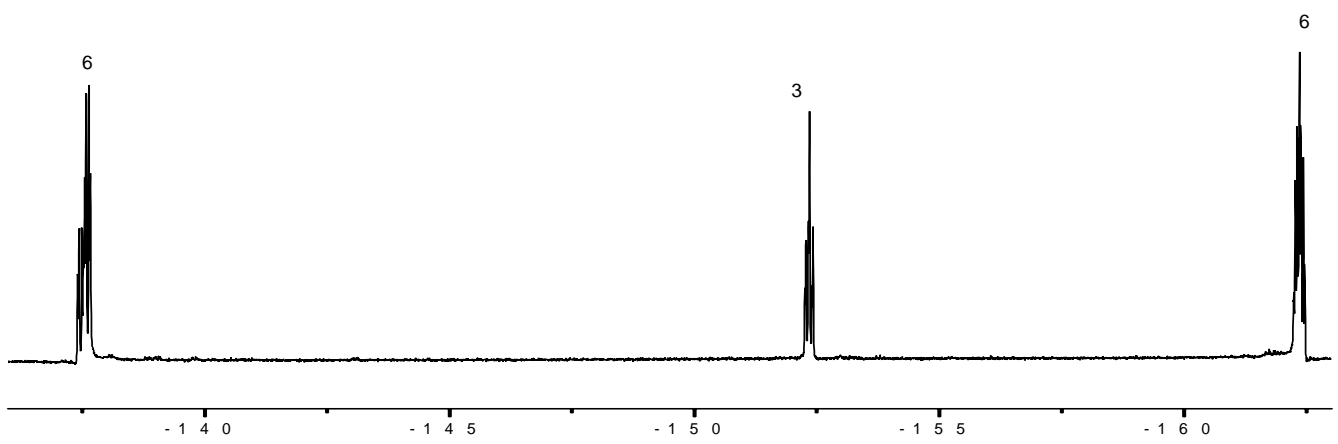

Figura 35: Espectro de RMN de ${ }^{19} \mathrm{~F}$ da porfirina $\mathrm{M}(4-\mathrm{N}-\mathrm{Py}) \mathrm{TFFPH}_{2}$ em $\mathrm{CDCl}_{3}$. 


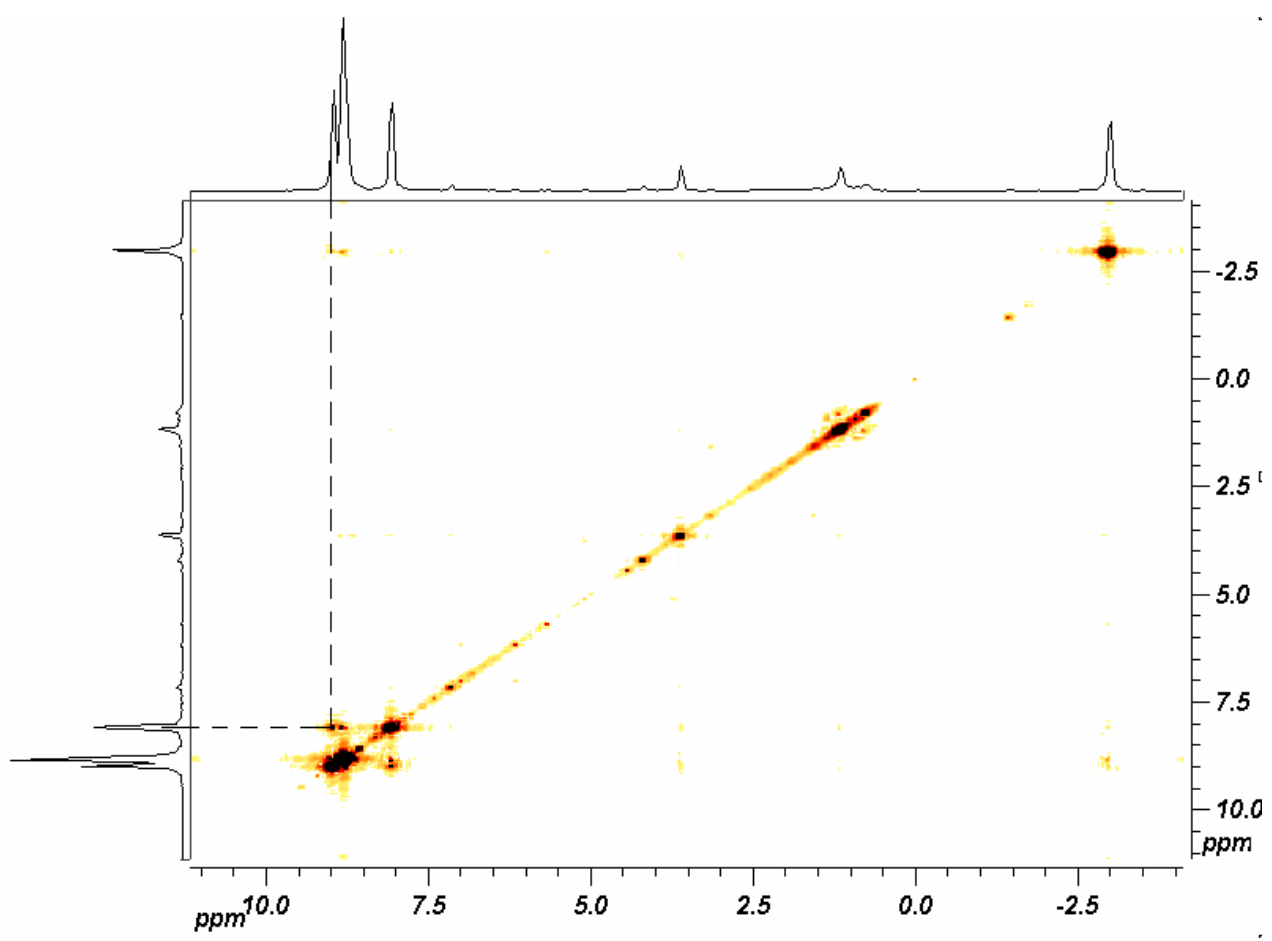

Figura 36: Espectro COSY da porfirina M(4-N-Py)TFPPH $\mathrm{TH}_{2}$

\section{IV.3.1.2) cis-B(4-N-Py)TFPPH}

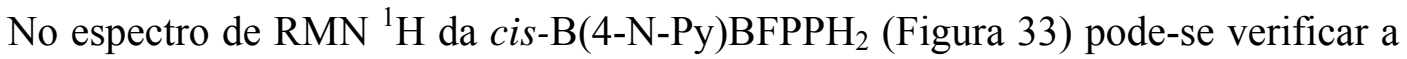
presença de oito prótons piridínicos, o que é condizente com a sua estrutura.

Como no caso da M(4-N-Py) $\mathrm{TFPPH}_{2}{ }^{73,74}$, atribui-se o dupleto em $\delta=8,16 \mathrm{ppm}$ aos prótons piridínicos $\mathrm{H}_{\mathrm{a}}$ e o dupleto em $\delta=9,07 \mathrm{ppm}$ aos prótons piridínicos $\mathrm{H}_{\mathrm{b}}$. Os prótons $\mathrm{H}_{\mathrm{a}}$ e $\mathrm{H}_{\mathrm{b}}$ apresentam a mesma constante de acoplamento $\mathrm{J}_{(1,2)}=5,81 \mathrm{~Hz}$ e como pode ser visto através da Figura 39 estes prótons acoplam entre si, o que condiz com a estrutura proposta para esta molécula.

$\mathrm{O}$ padrão de $\mathrm{RMN}{ }^{1} \mathrm{H}$ dos prótons $\mathrm{H} \beta$-pirrólicos para o sistema $\mathrm{R}_{5}=\mathrm{R}_{10}, \mathrm{R}_{15}=\mathrm{R}_{20}$ (padrão III, Figura 32) prediz o aparecimento de dois singletos e dois dupletos. Há a sobreposição dos singletos com os dois dupletos, isto pode ser observado em $\delta=8,92 \mathrm{ppm}$ e $\delta=8,86$ ppm (Figura 33).

A molécula cis-B(4-N-Py)TFPPH 2 é assimétrica, tem simetria $\mathrm{C}_{2 \mathrm{v}}$ e proporciona quatro tipo de prótons $\mathrm{H} \beta$-pirrólicos magneticamente diferentes (Figura 33). Os prótons $\mathrm{H}_{7}, \mathrm{H}_{8}$ são aqueles que se encontram entre os grupos pentafluorofenil, os prótons $\mathrm{H}_{3}, \mathrm{H}_{12}$ são aqueles que se encontram próximos aos grupos pentafluorofenil, os prótons $\mathrm{H}_{17}, \mathrm{H}_{18}$ 
são aqueles que se encontram entre os grupos piridil e os prótons $\mathrm{H}_{2}, \mathrm{H}_{13}$ são aqueles que se encontram próximos aos grupos piridil.

A atribuição dos sinais $\mathrm{H} \beta$-pirrólicos (Figura 33) se baseia em que os prótons próximos ao substituinte pentafluorofenil, se encontrarem em região mais desprotegida do espectro em relação aos prótons próximos ao grupo 4-N-piridil, isto se deve ao efeito indutivo do anel pentafluoro, que remove densidade eletrônica do anel porfirínico devido à eletronegatividade dos átomos de flúor.

Os prótons mais protegidos que a molécula apresenta são os prótons internos do anel porfirínico. A grande diferença observada no deslocamento químico desses prótons é decorrente da forte influência do efeito de corrente do anel. Esse efeito proporciona uma acentuada blindagem e conseqüente deslocamento do sinal para regiões de baixa freqüência (campo alto). Estes prótons $(\mathrm{N}-\mathrm{H})$ têm um deslocamento químico de $\delta=-2,88$ ppm (Figura 37) e são utilizados como pico base para se fazer a integral dos outros picos da molécula.

No espectro de $\mathrm{RMN}{ }^{19} \mathrm{~F}$ utilizou-se como referência trifluorotolueno $\left(\mathrm{CF}_{3} \mathrm{C}_{6} \mathrm{H}_{5}\right)$. Observando-se o espectro de RMN ${ }^{19} \mathrm{~F}$ da porfirina cis-M(4-N-Py) $\mathrm{TFFPH}_{2}$ (Figura 38, tabela 7) e baseando-se em dados relatados na literatura, atribui-se o sinal em $\delta=-140,5$ ppm aos átomos de flúor em orto $\left(\mathrm{F}_{1}\right)$. O triplete em $\delta=-155,4 \mathrm{ppm}$ foi atribuído aos átomos de flúor na posição para $\left(\mathrm{F}_{3}\right)$ e o sinal em $\delta=-165,3$ ppm foi atribuído aos átomos de flúor na posição meta $\left(\mathrm{F}_{2}\right)$.

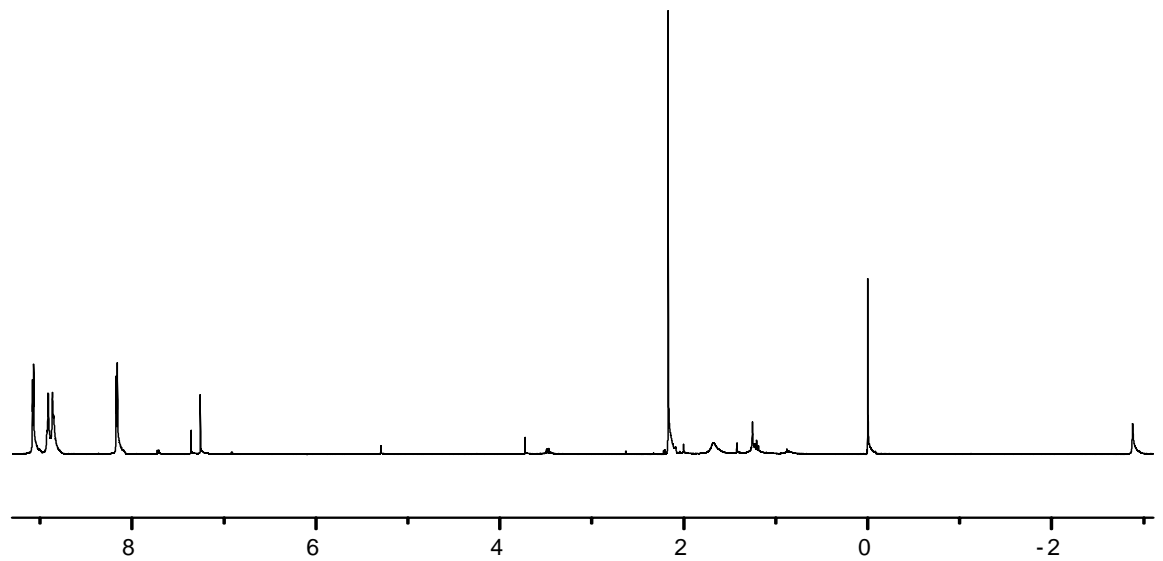

Figura 37: Espectro de $\mathrm{RMN}$ de ${ }^{1} \mathrm{H}$ da cis-B(4-N-Py)TFPPH $\mathrm{em} \mathrm{CDCl}_{3}$. 


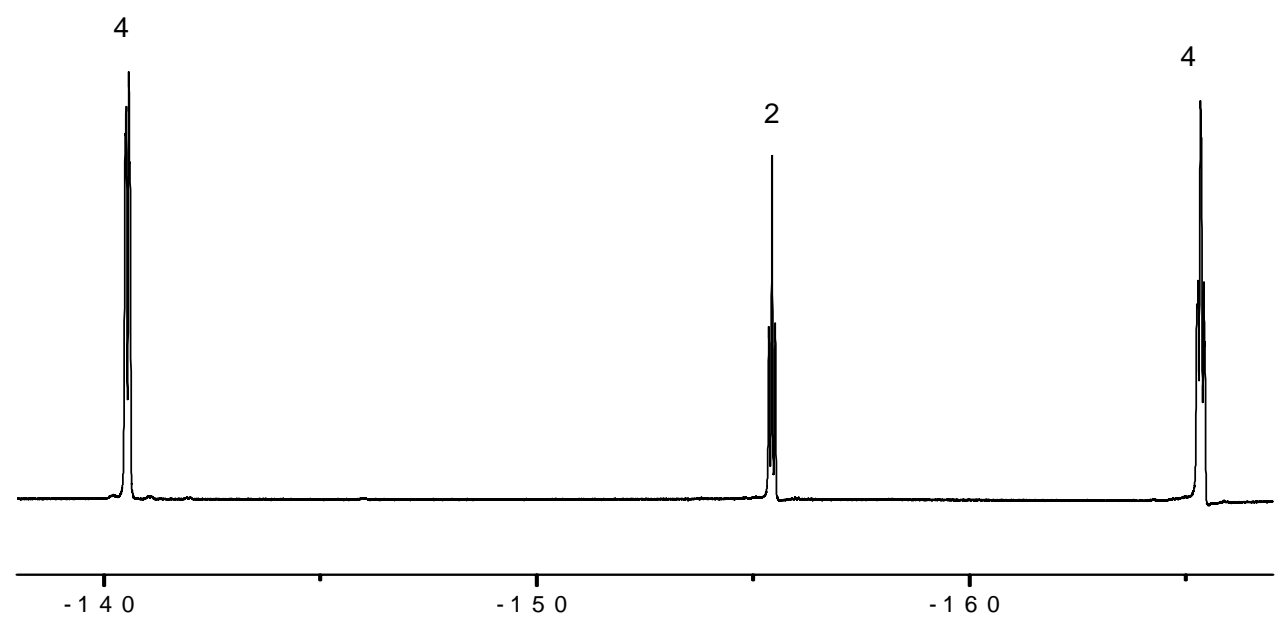

Figura 38: Espectro de $\mathrm{RMN}$ de ${ }^{19} \mathrm{~F}$ da porfirina cis-B(4-N-Py)BFFPH $\mathrm{Bem}_{2} \mathrm{CDCl}_{3}$

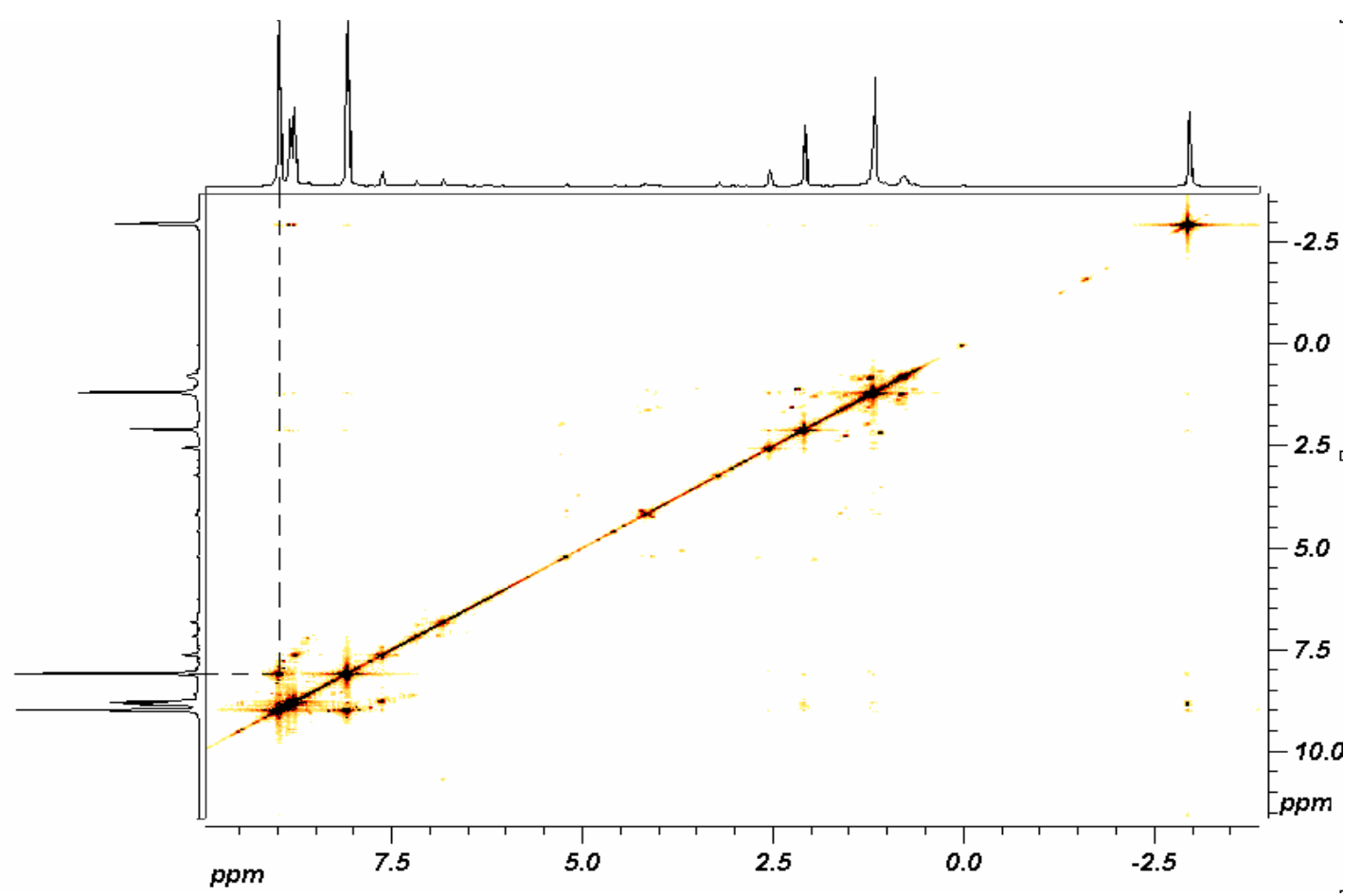

Figura 39: Espectro COSY da porfirina cis-B(4-N-Py)TFPPH 2.

\section{IV.3.1.3) trans-B(4-N-Py)TFPPH}

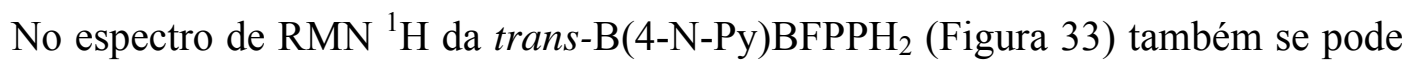
verificar a presença de oito prótons piridínicos, o que é condizente com a sua estrutura.

Como no caso da M(4-N-Py)TFPPH 2 e da cis-B(4-N-Py)BFPPH ${ }_{2}{ }^{73}, 74$, atribui-se o dupleto em $\delta=8,18$ ppm aos prótons piridínicos $\mathrm{H}_{\mathrm{a}}$ e o dupleto em $\delta=9,08$ ppm aos 
prótons piridínicos $\mathrm{H}_{\mathrm{b}}$. Os prótons $\mathrm{H}_{\mathrm{a}} \mathrm{e} \mathrm{H}_{\mathrm{b}}$ apresentam a mesma constante de acoplamento $\mathrm{J}_{(1,2)}=5,81 \mathrm{~Hz}$ e como pode ser visto através da Figura 42 estes prótons acoplam entre si, o que condiz com a estrutura proposta para esta molécula.

O padrão de $\mathrm{RMN}{ }^{1} \mathrm{H}$ dos prótons $\mathrm{H} \beta$-pirrólicos para o sistema $\mathrm{R}_{5}=\mathrm{R}_{15}, \mathrm{R}_{10}=\mathrm{R}_{20}$ (padrão IV Figura 32) prediz o aparecimento de dois dupletos, para a porfirina trans-B(4-N-Py)BFPPH ${ }_{2}$ este padrão pode ser observado em torno de $\delta=8,90$ (Figura 33).

A molécula trans-B(4-N-Py)TFPPH ${ }_{2}$ é simétrica, tem simetria $\mathrm{D}_{2 \mathrm{~h}}$ e proporciona dois tipos de prótons $H \beta$-pirrólicos magneticamente diferentes. Os prótons $\mathrm{H}_{3}, \mathrm{H}_{7}, \mathrm{H}_{13}, \mathrm{H}_{17}$, são aqueles que se encontram próximos ao grupo pentafluorofenil e os prótons $\mathrm{H}_{2}, \mathrm{H}_{8}, \mathrm{H}_{12}$, $\mathrm{H}_{18}$ são aqueles que se encontram próximos ao grupo 4-N-piridil.

Este fato permite atribuir os sinais em $\delta=8,92 \mathrm{ppm}$ (tabela 6, Figura 33) aos prótons $\mathrm{H} \beta$-pirrólicos $\mathrm{H}_{3}, \mathrm{H}_{7}, \mathrm{H}_{13}, \mathrm{H}_{17}$ e os sinais em $\delta=8,86 \mathrm{ppm}$ ao prótons $\mathrm{H} \beta$ pirrólicos $\mathrm{H}_{2}, \mathrm{H}_{8}, \mathrm{H}_{12}, \mathrm{H}_{18}$, pois os prótons próximos ao substituinte pentafluorofenil, se encontrarem em região mais desprotegida do espectro em relação aos prótons próximos ao grupo 4-N-piridil, isto se deve ao efeito indutivo do anel pentafluoro, que remove densidade eletrônica do anel porfirínico devido à eletronegatividade dos átomos de flúor.

Os prótons mais protegidos que a molécula apresenta são os prótons internos do anel porfirínico. A grande diferença observada no deslocamento químico desses prótons é decorrente da forte influência do efeito de corrente do anel. Esse efeito proporciona uma acentuada blindagem e conseqüente deslocamento do sinal para regiões de baixa freqüência (campo alto). Estes prótons $(\mathrm{N}-\mathrm{H})$ têm um deslocamento químico de $\delta=-2,92$ ppm (Figura 40) e são utilizados como pico base para se fazer a integral dos outros picos da molécula.

Observando-se o espectro de RMN ${ }^{19} \mathrm{~F}$ da porfirina cis-M(4-N-Py)TFFPH ${ }_{2}$ (Figura 41, tabela 7) e baseando-se em dados relatados na literatura, atribui-se o sinal em $\delta=-$ $140,7 \mathrm{ppm}$ aos átomos de flúor em orto $\left(\mathrm{F}_{1}\right)$. O triplete em $\delta=-155,4 \mathrm{ppm}$ foi atribuído aos átomos de flúor na posição para $\left(\mathrm{F}_{3}\right)$ e o sinal em $\delta=-165,4 \mathrm{ppm}$ foi atribuído aos átomos de flúor na posição meta $\left(\mathrm{F}_{2}\right)$.

$\mathrm{O}$ que se pode perceber pela análise de RMN ${ }^{1} \mathrm{H}$ e RMN ${ }^{19} \mathrm{~F}$ dos isômeros cis-e trans-B(4-N-Py)TFPPH $\mathrm{H}_{2}$ que esta não é a melhor técnica para a identificação e 
caracterização destes compostos, pois estes isômeros apresentam espectros de RMN ${ }^{1} \mathrm{H}$ e RMN ${ }^{19} \mathrm{~F}$ semelhantes e de difícil interpretação. A melhor técnica para a caracterização destes compostos seria a análise por difração de Raios-X (item IV.3.1.4).

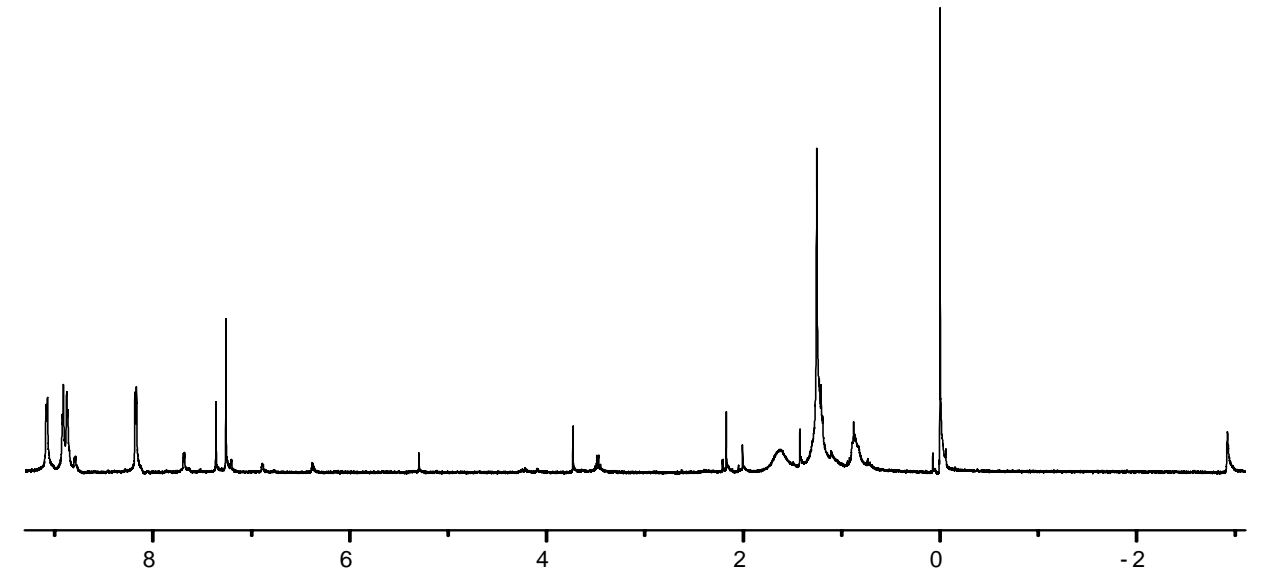

Figura 40: Espectro de RMN de ${ }^{1} \mathrm{H}$ da trans-B(4-N-Py)TFPPH $\mathrm{H}_{2} \mathrm{em} \mathrm{CDCl}_{3}$.

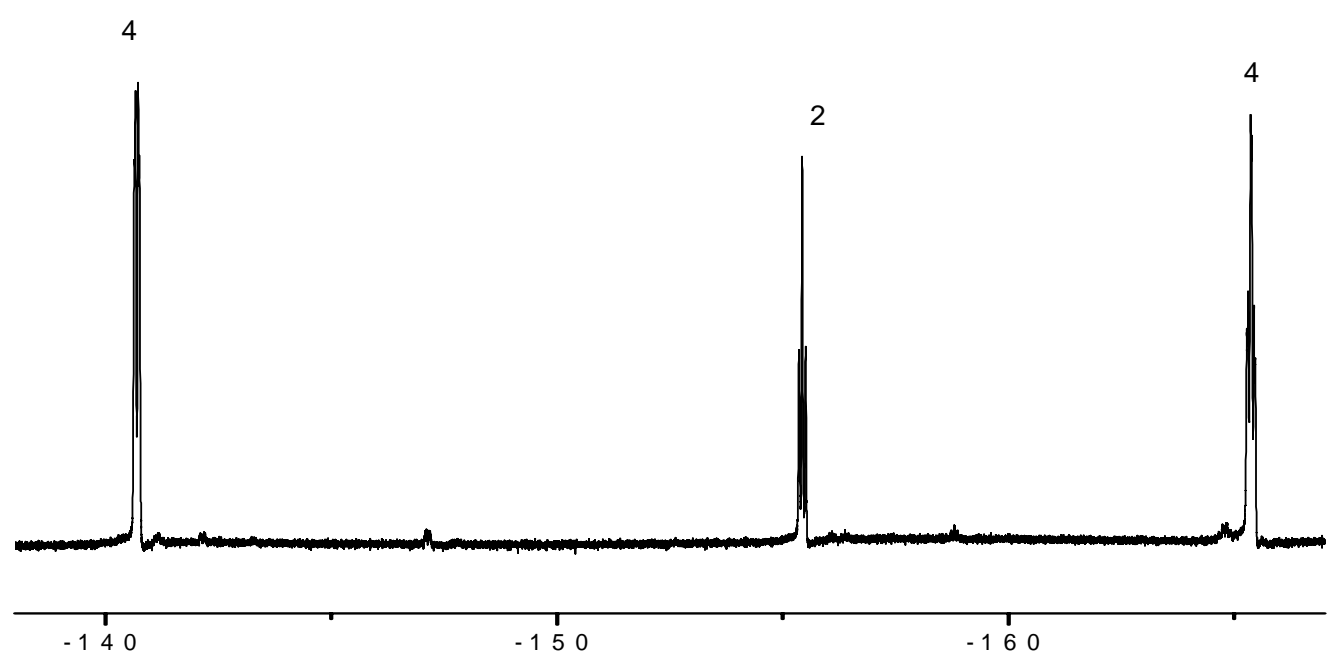

Figura 41: Espectro de RMN de ${ }^{19} \mathrm{~F}$ da porfirina trans-B(4-N-Py)BFFPH $\mathrm{em} \mathrm{CDCl}_{3}$. 


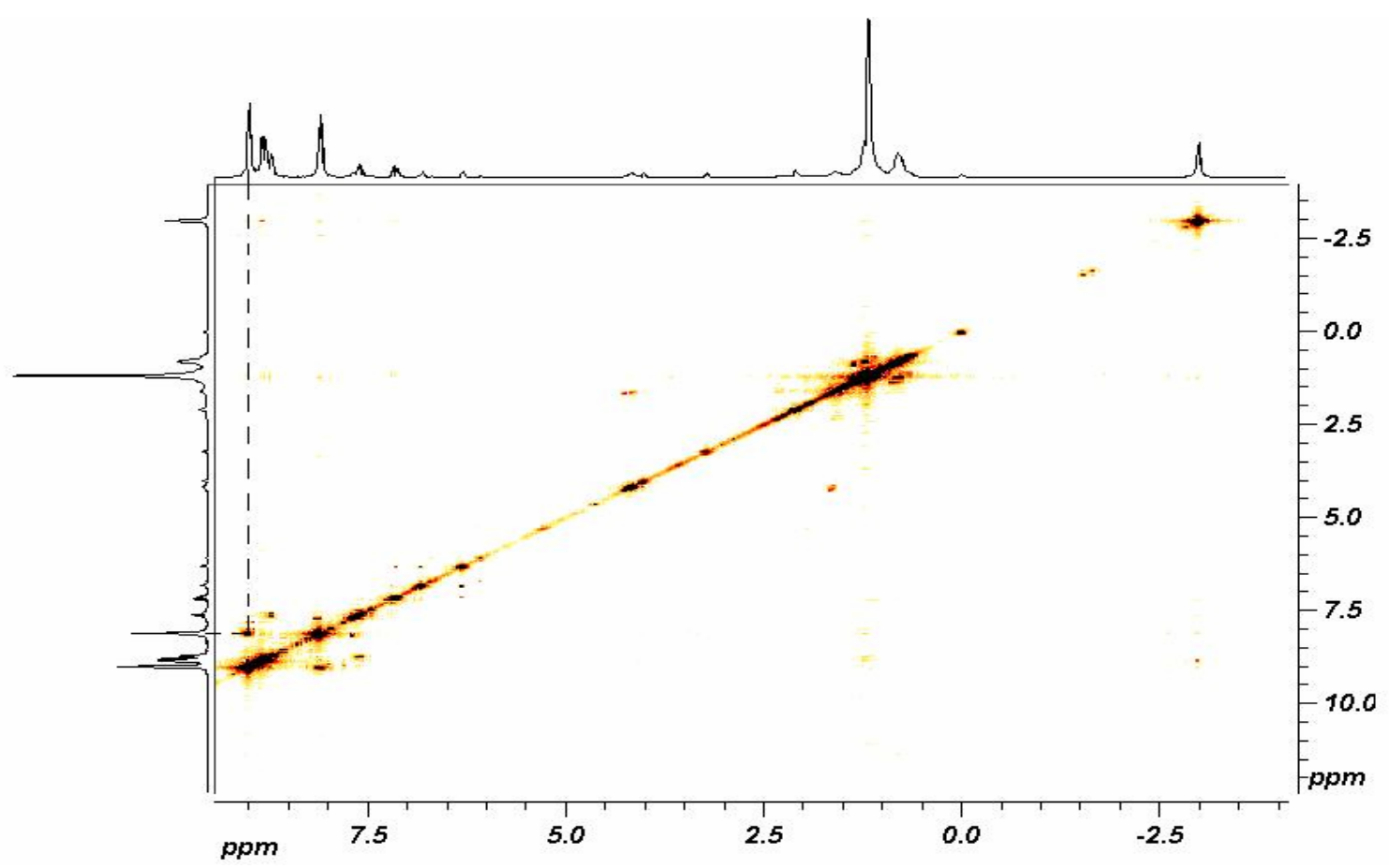

Figura 42: Espectro COSY da porfirina trans-B(4-N-Py) $\mathrm{TFPPH}_{2}$.

\section{IV.3.1.4) T(4-N-Py)MFPPH}

$\mathrm{O}$ espectro de $\mathrm{RMN}{ }^{1} \mathrm{H}$ da T(4-N-Py) $\mathrm{MFPPH}_{2}$ (Figura 33) indica a presença de doze prótons piridínicos, o que é condizente com a sua estrutura. Baseando-se nos dados de $\mathrm{RMN}{ }^{1} \mathrm{H}$ encontrados na literatura, fez-se a atribuição dos sinais referentes aos prótons $\mathrm{H} \beta$-pirrólicos e piridínicos da T(4-N-Py) $\mathrm{MFPPH}_{2}$.

Atribui-se o dupleto em $\delta=8,18 \mathrm{ppm}$ aos prótons piridínicos $\mathrm{H}_{\mathrm{a}}$ e o dupleto em $\delta=9,08$ ppm aos prótons piridínicos $\mathrm{H}_{\mathrm{b}}$. Esta atribuição foi feita baseando-se no princípio de que os prótons $\mathrm{H}_{\mathrm{b}}$ seriam mais desprotegidos do que os prótons $\mathrm{H}_{\mathrm{a}}$, por se encontrarem ligados a um átomo de carbono vizinho a um átomo nitrogênio piridínico, que possui caráter eletronegativo. Os prótons $\mathrm{H}_{\mathrm{a}}$ apresentam a constante de acoplamento $\mathrm{J}_{(1,2)}=5,81$ $\mathrm{Hz}$ (tabela 6), não foi possível determinar a constante de acoplamento dos prótons $\mathrm{H}_{\mathrm{b}}$ porque o sinal relativo a estes prótons aparece na forma de um multiplete.

$\mathrm{O}$ padrão de $\mathrm{RMN}{ }^{1} \mathrm{H}$ dos prótons $\mathrm{H} \beta$-pirrólicos para o sistema $\mathrm{R}_{5}, \mathrm{R}_{10}=\mathrm{R}_{15}=\mathrm{R}_{20}$ (padrão II, Figura 32) prediz o aparecimento de um singleto e dois dupletos. Há a sobreposição do singleto com um dos dupletos, isto pode ser observado em $\delta=8,87 \mathrm{ppm}$ 
(Figura 33). Pela integração dos sinais e pelo fato que os prótons $\mathrm{H}_{3}, \mathrm{H}_{7}$ se encontrarem ligados mais próximos do grupo pentafluorofenil (grupo retirador de densidade eletrônica do macrociclo) do que os prótons $\mathrm{H}_{2}, \mathrm{H}_{8}, \mathrm{H}_{12}, \mathrm{H}_{13}, \mathrm{H}_{17}, \mathrm{H}_{18}$ pode-se afirmar que o sinal em $\delta=8,93$ ppm corresponde ao próton $\mathrm{H}_{3}, \mathrm{H}_{7}$ e que o sinal em $\delta=8,87$ ppm corresponde aos prótons $\mathrm{H}_{2}, \mathrm{H}_{8}, \mathrm{H}_{12}, \mathrm{H}_{13}, \mathrm{H}_{17}, \mathrm{H}_{18}$ (tabela 6, Figura 33).

Os prótons internos do anel porfirínico $(\mathrm{N}-\mathrm{H})$ têm um deslocamento químico de $\delta=-2,90$ ppm (Figura 43) e são utilizados como pico base para se fazer a integral dos outros picos da molécula.

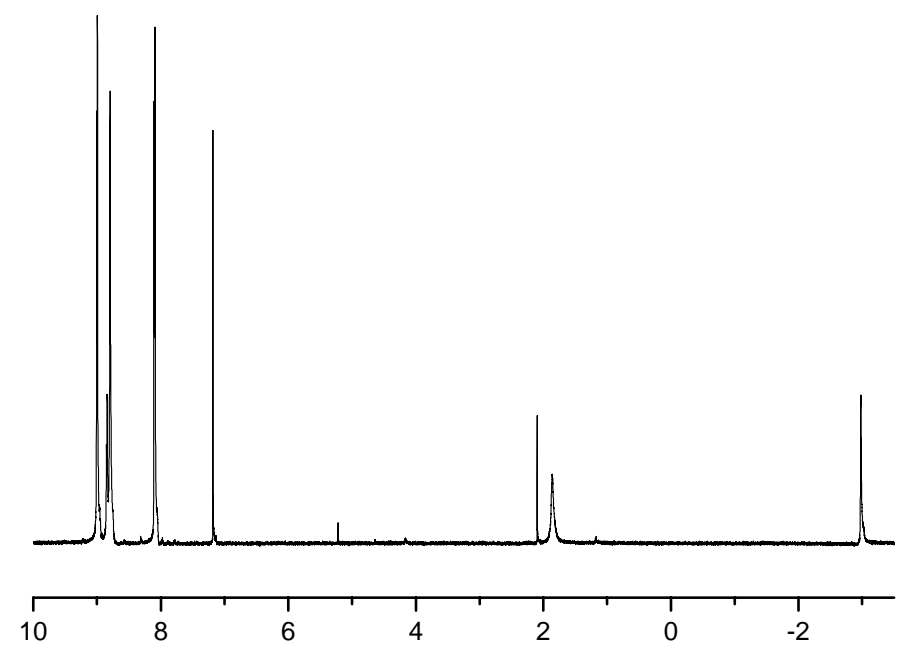

Figura 43: Espectro de RMN de ${ }^{1} \mathrm{H}$ da porfirina $\mathrm{T}(4-\mathrm{N}-\mathrm{Py}) \mathrm{MFFPH}_{2}$ em $\mathrm{CDCl}_{3}$.

\section{IV.3.2) Supermoléculas}

Fez-se a caracterização das díades $\left[\mathrm{M}(4-\mathrm{N}-\mathrm{Py}) \mathrm{TFPPH}_{2}\left\{\mathrm{Ru}_{3} \mathrm{O}(\mathrm{Ac})_{6}(\mathrm{py})_{2}\right] \mathrm{PF}_{6}\right.$ e $\left[\mathrm{M}(4-\mathrm{N}-\mathrm{Py}) \mathrm{TFPPH}_{2}\left\{\mathrm{Ru}(\mathrm{bpy})_{2} \mathrm{Cl}\right] \mathrm{PF}_{6}\right.$ por RMN ${ }^{1} \mathrm{H}, \mathrm{RMN}{ }^{19} \mathrm{~F}$ e COSY. Nas Figura $44 \mathrm{e}$ Figura 48 estão representadas as díades com as numerações para seus respectivos prótons e núcleos de flúor. Nas Tabela 8 e 9 encontram-se os valores de deslocamentos químicos ( $\delta$ ) dos prótons das díades. Os deslocamentos químicos, padrões $^{76,}$ e intensidades relativas dos sinais de $\mathrm{RMN}{ }^{1} \mathrm{H}$ e RMN ${ }^{19} \mathrm{H}$ foram utilizados para atribuir as estruturas das díades. Já as tríades cis- e trans-[B(4-N-Py) $\left.\mathrm{BFPPH}_{2}\left\{\mathrm{Ru}_{3} \mathrm{O}(\mathrm{Ac})_{6}(\mathrm{py})_{2}\right\} \quad\left\{\mathrm{Ru}(\mathrm{bpy})_{2} \mathrm{Cl}\right\}\right]\left(\mathrm{PF}_{6}\right)_{2}$ não foram caracterizadas por $\mathrm{RMN}{ }^{1} \mathrm{H}$ porque a quantidade sintetizada foi insuficiente para se 
fazer uma solução com concetração ideal para realização de experimento de RMN. Essas moléculas foram analisadas por espectometria de massa.

\section{IV.3.2.1) $\left[\mathrm{M}(4-\mathrm{N}-\mathrm{Py}) \mathrm{BFFPH}_{2}\left\{\mathrm{Ru}_{3} \mathrm{O}(\mathrm{Ac})_{6}(\mathrm{py})_{2}\right\}\right] \mathrm{PF}_{6}$}

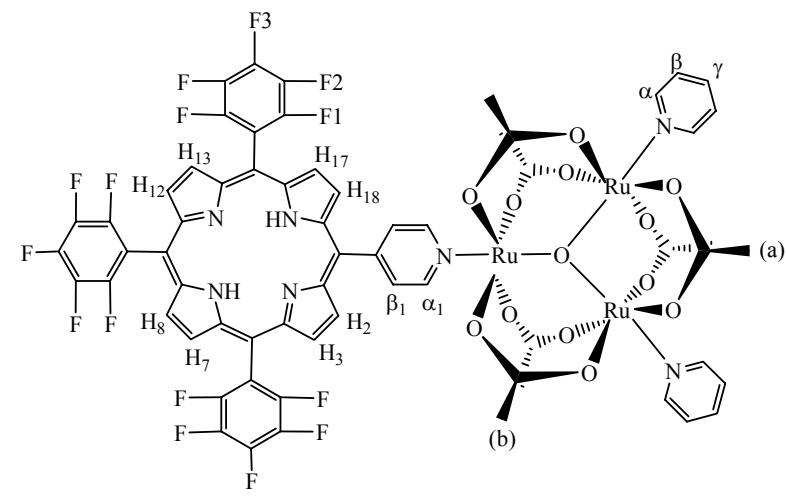

Figura 44: Representação da estrutura da díade. $\left[\mathrm{M}(4-\mathrm{N}-\mathrm{Py}) \mathrm{TFPPH}_{2}\left\{\mathrm{Ru}_{3} \mathrm{O}(\mathrm{Ac})_{6}(\mathrm{py})_{2}\right\}\right] \mathrm{PF}_{6}$.

Tabela 8: Atribuição tentativa dos espectros de $\mathrm{RMN}{ }^{1} \mathrm{H}$ da díade $\left[\mathrm{M}(4-\mathrm{N}-\mathrm{Py}) \mathrm{BFFPH}_{2}\right.$ $\left.\left\{\mathrm{Ru}_{3} \mathrm{O}(\mathrm{Ac})_{6}(\mathrm{py})_{2}\right\}\right] \mathrm{PF}_{6}$

\section{H- $\beta$ pirrólicos}

H cluster H ponte

\section{N-H}

\begin{tabular}{lcccccc}
\hline & & $\alpha$ & $0,07 \mathrm{a}(4)$ & & \\
$\mathrm{H}_{2}, \mathrm{H}_{18}$ & $8,14 \mathrm{~d}(2)$ & $\beta$ & $5,70 \mathrm{a}(4)$ & $\alpha_{1}$ & $1,26 \mathrm{a}(2)$ & $-3,17 \mathrm{~s}(2)$ \\
$\mathrm{H}_{3}, \mathrm{H}_{17}$ & $8,63 \mathrm{~d}(2)$ & $\gamma$ & $6,38 \mathrm{t}(2)$ & $\beta_{1}$ & $6,60 \mathrm{a}(2)$ & \\
$\mathrm{H}_{7}, \mathrm{H}_{8}, \mathrm{H}_{12}, \mathrm{H}_{13}$ & $8,83 \mathrm{~s}(4)$ & $\mathrm{CH}_{3}(\mathrm{a})$ & $5,13 \mathrm{~s}(6)$ & & \\
& & $\mathrm{CH}_{3}(\mathrm{~b})$ & $4,98 \mathrm{~s}(12)$ & & \\
& &
\end{tabular}

$\delta\left(\mathrm{CDCL}_{3}\right)$ em ppm; referência TMS; (valor da integral, correspondendo ao número de prótons); $\mathrm{s}=$ singlete; $\mathrm{d}=$ dupleto; $\mathrm{t}=$ triplete; $\mathrm{a}=$ alargado . 
Pelo fato da molécula $\left[\mathrm{M}(4-\mathrm{N}-\mathrm{Py}) \mathrm{BFFPH}_{2}\left\{\mathrm{Ru}_{3} \mathrm{O}(\mathrm{Ac})_{6}(\mathrm{py})_{2}\right\}\right] \mathrm{PF}_{6}$ ser uma molécula complexa, fez-se necessário o uso de técnicas de RMN ${ }^{1} \mathrm{H}$ (1D) e COSY (bidimensional) para atribuição dos prótons da mesma. Os prótons mais protegidos que a molécula [M(4-N-Py) $\left.\mathrm{BFFPH}_{2}\left\{\mathrm{Ru}_{3} \mathrm{O}(\mathrm{Ac})_{6}(\mathrm{py})_{2}\right\}\right] \mathrm{PF}_{6}$ apresenta são os prótons internos do anel porfirínico. Estes prótons $(\mathrm{N}-\mathrm{H})$ têm um deslocamento químico de $\delta=-3,17 \mathrm{ppm}$ (Figura 45) e são utilizados como pico base para se fazer a integral dos outros picos da molécula.

A introdução da molécula de cluster adiciona 5 novos sinais aos espectros de ${ }^{1} \mathrm{H}$ RMN da supermolécula. O sinal das metilas dos acetatos coordenados ao cluster aparece duplicado, uma vez que há dois tipos de acetatos magneticamente diferentes: quatro vicinais e dois em posição trans em relação à porfirina. $\mathrm{O}$ deslocamento químico da metila $\mathrm{CH}_{3}$ (a) é de $\delta=5,13$ ppm e o da outra metila é $\delta=4,98$ ppm (Figura 45).

Para os prótons $(\alpha, \beta, \gamma)$ da piridina do cluster, são esperadas duas manchas de correlação no espectro $\operatorname{COSY}(\alpha-\beta$ e $\beta-\gamma)$ (Figura 47). Esta correlação é encontrada e sabe-se que os prótons $\alpha$ sofrem uma maior blindagem devido à anisotropia paramagnética do centro $\left[\mathrm{Ru}_{3} \mathrm{O}\right]$, que contém um elétron desemparelhado. Esse efeito pode manifestar-se através de dois mecanismos; o primeiro é chamado de pseudocontato e envolve uma interação dipolar através do espaço, que, portanto decresce com a distância ${ }^{77}$. Por outro lado, esta interação depende também da orientação relativa dos núcleos observados e do centro paramagnético, promovendo deslocamentos tanto para campo mais alto quanto para campo mais baixo. Outro aspecto que merece nota é o alargamento observado para os núcleos em posição $\alpha$, que também ocorre em função da relaxação rápida destes núcleos através da interação com o elétron desemparelhado. O próton $\alpha$ apresenta sinal em $\delta=0,07 \mathrm{ppm}$ (Figura 45) e pelo espectro COSY (Figura 47) através do acoplamento do próton $\beta$ com o próton $\alpha$, é possível fazer a atribuição do sinal em $\delta=5,70 \mathrm{ppm}$ para o próton $\beta$. Já o próton $\gamma$ sofre a menor influência do centro $\left[\mathrm{Ru}_{3} \mathrm{O}\right]$ e o efeito é menor, mas ainda é deslocado para campo alto, pois no ligante livre $\delta_{\gamma}=7,6 \mathrm{ppm}$. Através do espectro COSY (Figura 47) pode-se fazer a atribuição do próton $\gamma \operatorname{em~} \delta=6,38 \mathrm{ppm}$ pois este acopla com o próton $\beta$. 
Outro próton que sofre uma maior blindagem devido à anisotropia paramagnética do centro $\left[\mathrm{Ru}_{3} \mathrm{O}\right]$ é o próton $\alpha_{1}$. Para atribuir o sinal deste próton faz-se necessário o uso do espectro de COSY (Figura 47). Espera-se encontrar uma mancha de correlação do próton $\alpha_{1}$ com o próton $\beta_{1}$. Através da correlação do sinal em $\delta=1,26 \mathrm{ppm}$ com o sinal em $\delta=6,60 \mathrm{ppm}$ fica evidenciado que o sinal em em $\delta=1,26 \mathrm{ppm}$ corresponde ao $\alpha_{1}$, já que é um sinal em campo alto. $O$ outro sinal em $\delta=6,60 \mathrm{ppm}$ corresponde ao $\beta_{1}$.

$\mathrm{Na}$ análise dos prótons pirrólicos oriundos da porfirina não se pode utilizar o espectro COSY, já que estes prótons apresentam um deslocamento químico muito semelhantes. Os prótons pirrólicos apresentam deslocamento químico entre 8,0 e 9,0 ppm. Pela integração e pelos valores de $\delta$, pode-se dizer que o sinal em $\delta=8,83 \mathrm{ppm}$ corresponde aos prótons $\mathrm{H}_{7}, \mathrm{H}_{8}, \mathrm{H}_{12}, \mathrm{H}_{13}$. Estes quatros prótons são equivalentes, como o próton $\mathrm{H}_{3}$ é equivalente ao próton $\mathrm{H}_{17}$, são numerados diferentemente para fins didáticos. Pressupõe-se que o sinal em $\delta=8,14$ ppm seja dos prótons $\mathrm{H}_{2}, \mathrm{H}_{18}$, e o sinal em $\delta=8,63$ ppm seja dos prótons $\mathrm{H}_{3}, \mathrm{H}_{17}$, pois devido a maior proximidade do cluster, os prótons $\mathrm{H}_{2} \mathrm{e}$ $\mathrm{H}_{18}$ sofrem uma maior blindagem devido à anisotropia paramagnética do centro $\left[\mathrm{Ru}_{3} \mathrm{O}\right]$.

Observando-se $\quad \mathrm{o}$ espectro de $\mathrm{RMN} \quad{ }^{19} \mathrm{~F}$ da díade [M(4-N-Py) $\mathrm{TFFPH}_{2}$ $\left.\left\{\mathrm{Ru}_{3} \mathrm{O}(\mathrm{Ac})_{6}(\mathrm{py})_{2}\right\}\right] \mathrm{PF}_{6}$ (Figura 46, Tabela 7) e baseando-se em dados relatados na literatura, atribui-se o sinal em $\delta=-137,5 \mathrm{ppm}$ aos átomos de flúor em orto $\left(\mathrm{F}_{1}\right)$. $\mathrm{O}$ triplete em $\delta=-152,3$ ppm foi atribuído aos átomos de flúor na posição para $\left(\mathrm{F}_{3}\right)$ e o sinal em $\delta=-162,4 \mathrm{ppm}$ foi atribuído aos átomos de flúor na posição meta $\left(\mathrm{F}_{2}\right)$. Como pode ser observado através das Figura 35 e Figura 46 a coordenação do grupo $\left[\mathrm{Ru}_{3} \mathrm{O}(\mathrm{Ac})_{6}(\mathrm{py})_{2}\right]^{+}$ não influencia nos deslocamentos químicos dos núcleos de flúor. 
A)

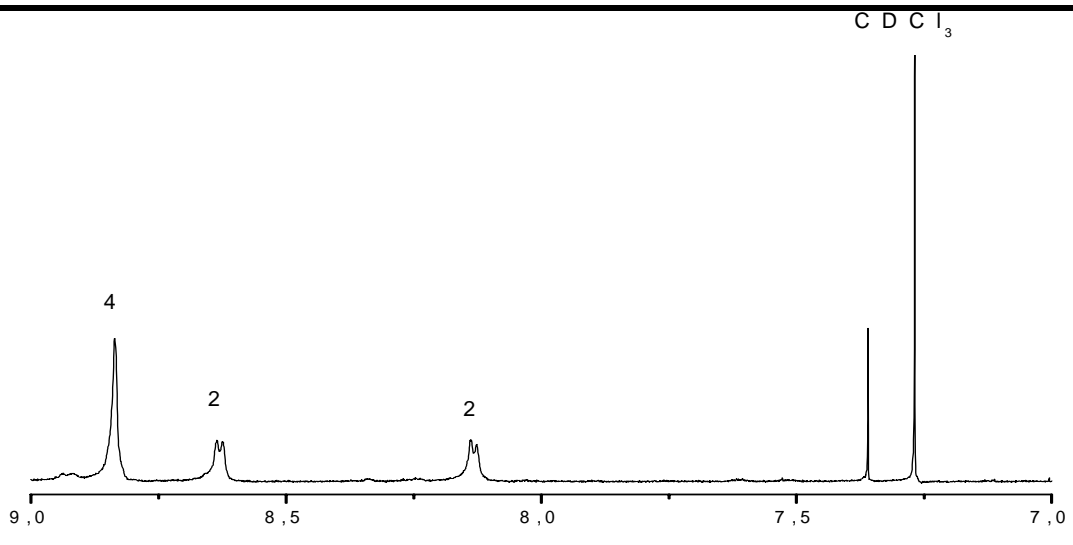

B)

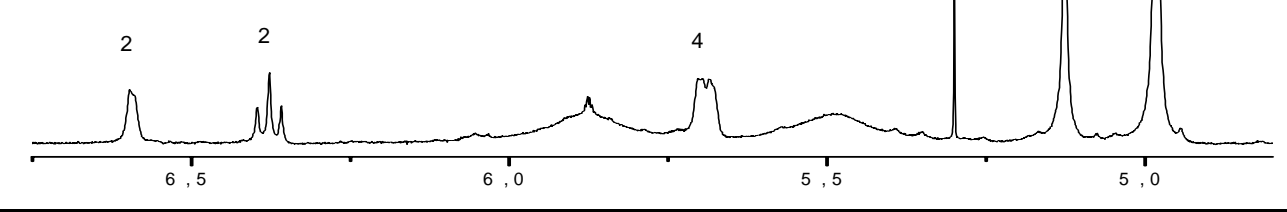

C)

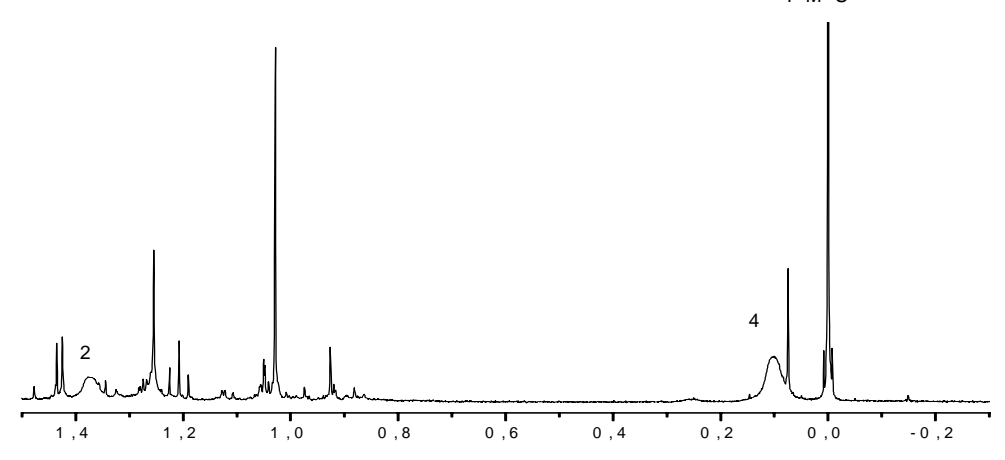

D)

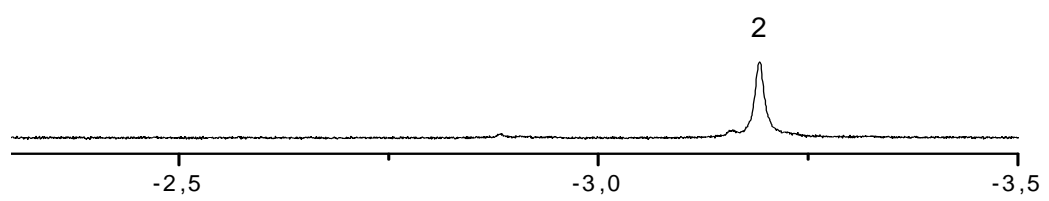

Figura 45: Espectro de $\mathrm{RMN}$ de ${ }^{1} \mathrm{H}$ da díade $\left[\mathrm{M}(4-\mathrm{N}-\mathrm{Py}) \mathrm{TFFPH}_{2}\left\{\mathrm{Ru}_{3} \mathrm{O}(\mathrm{Ac})_{6}(\mathrm{py})_{2}\right\}\right] \mathrm{PF}_{6}$ em $\mathrm{CDCl}_{3}$; A) Ampliação na região de 9,0 a 7,0 ppm; B) Ampliação na região de 7,0 a 4,8 ppm; C) Ampliação na região de 1,5 a -0,3 ppm; D) ampliação na região de -2,2 a -3,5 ppm. (os números na figura correspondem ao valor da integral para cada sinal). 


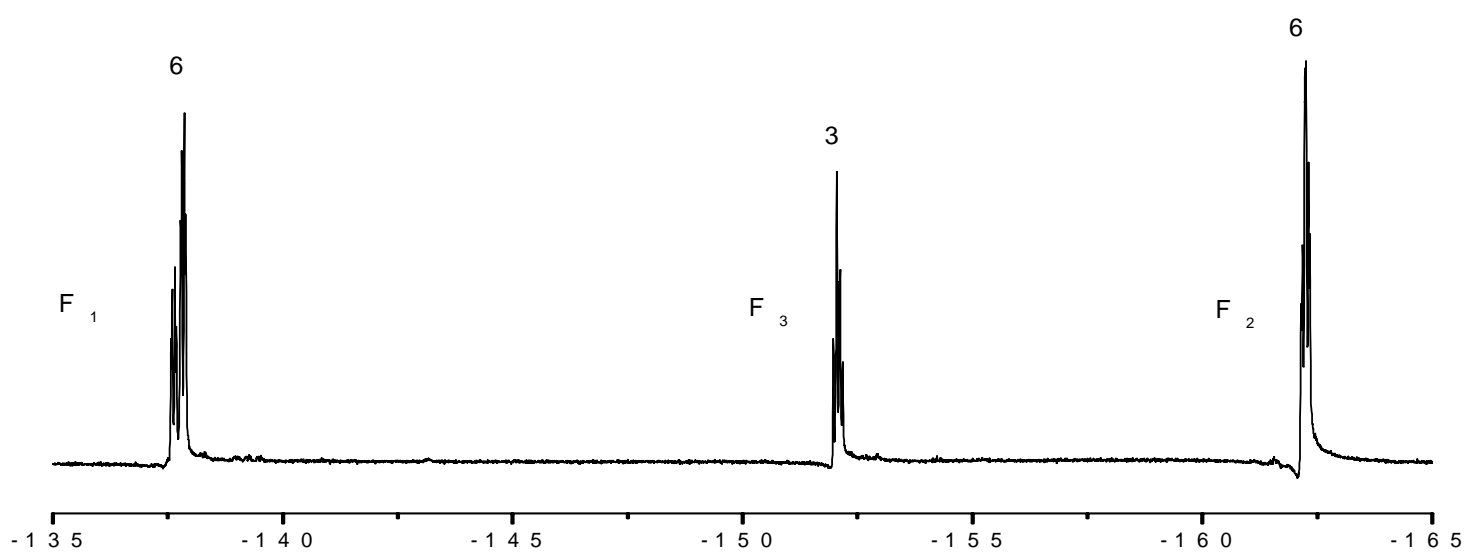

Figura 46: Espectro de $\mathrm{RMN}$ de ${ }^{19} \mathrm{~F}$ da díade $\left[\mathrm{M}(4-\mathrm{N}-\mathrm{Py}) \mathrm{TFFPH}_{2}\left\{\mathrm{Ru}_{3} \mathrm{O}(\mathrm{Ac})_{6}(\mathrm{py})_{2}\right\}\right] \mathrm{PF}_{6} \mathrm{em} \mathrm{CDCl}_{3}$.

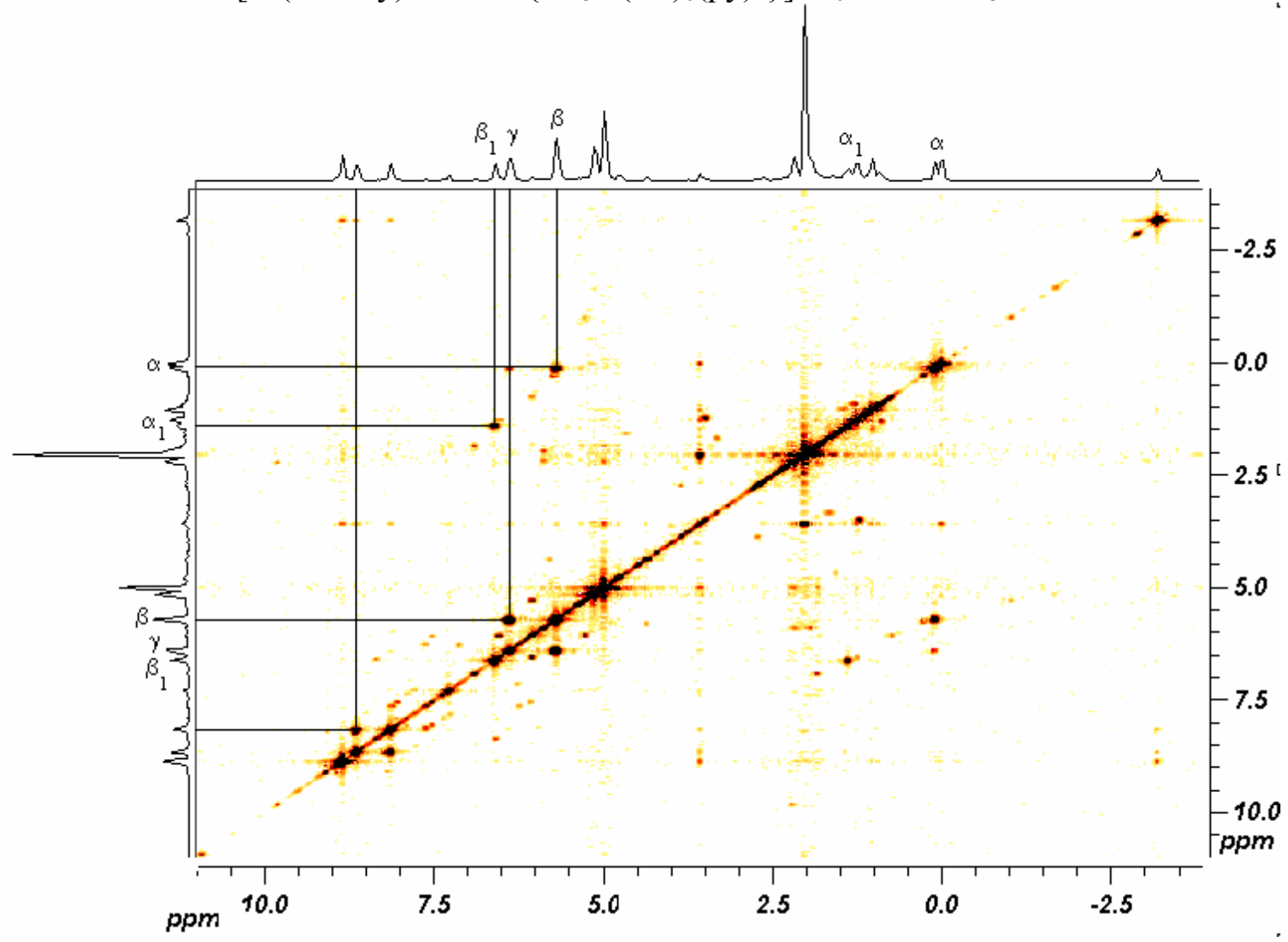

Figura 47: Espectro COSY da díade $\left[\mathrm{M}(4-\mathrm{N}-\mathrm{Py}) \mathrm{TFPPH}_{2}\left\{\mathrm{Ru}_{3} \mathrm{O}(\mathrm{Ac})_{6}(\mathrm{py})_{2}\right\}\right] \mathrm{PF}_{6}$. 


\section{IV.3.2.2) $\left[\mathrm{M}(4-\mathrm{N}-\mathrm{Py}) \mathrm{TFFPH}_{2}\left\{\mathrm{Ru}(\mathrm{bPy})_{2} \mathrm{Cl}\right\}\right] \mathrm{PF}_{6}$}

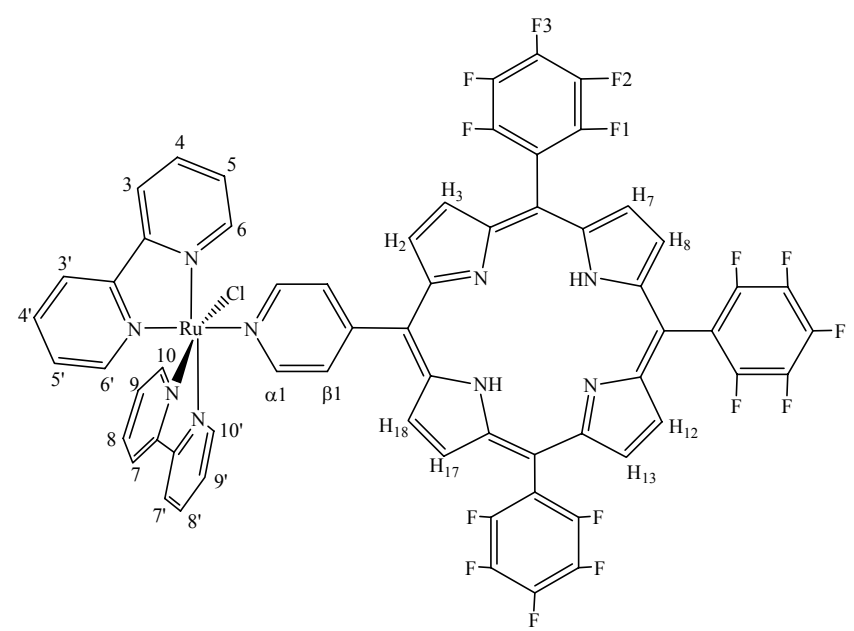

Figura 48: Estrutura da díade $\left[\mathrm{M}(4-\mathrm{N}-\mathrm{Py}) \mathrm{TFPPH}_{2}\left\{\mathrm{Ru}(\mathrm{bpy})_{2} \mathrm{Cl}\right\}\right] \mathrm{PF}_{6}$.

Tabela 9: Atribuições tentativas dos espectros de $\mathrm{RMN}$ de ${ }^{1} \mathrm{H}$ da díade [M(4-NPy)TFPPH $\left.{ }_{2}\left\{\mathrm{Ru}(\text { bpy })_{2} \mathrm{Cl}\right\}\right] \mathrm{PF}_{6}$

\begin{tabular}{|c|c|c|c|}
\hline Próton & $\delta / \mathrm{ppm}$ & \multicolumn{2}{|c|}{ Acoplamento } \\
\hline $10^{\prime}$ & $10,22 \mathrm{~d}(1)$ & prótons & $\delta / \mathrm{ppm}$ \\
\hline 10 & $9,02 \mathrm{~d}(1)$ & $10^{\prime}-8^{\prime}$ & $10,22-8,11$ \\
\hline $\mathrm{H}_{3}, \mathrm{H}_{7}, \mathrm{H}_{8}, \mathrm{H}_{12}, \mathrm{H}_{13}, \mathrm{H}_{17}$ & $8,89 \mathrm{~s}(6)$ & 10'-9' & $10,22-7,77$ \\
\hline $\mathrm{H}_{2}, \mathrm{H}_{18}$ & $8,83 \mathrm{~s}(2)$ & $10^{\prime}-7^{\prime}$ & $10,22-8,45$ \\
\hline 7 & $8,45 \mathrm{~d}(1)$ & $10-8$ & $9,02-8,02$ \\
\hline $3{ }^{\prime}$ & $8,34 \mathrm{~d}(1)$ & $10-9$ & $9,02-7,79$ \\
\hline 7 & $8,29 \mathrm{~m}(1)$ & $10-7$ & $9,02-8,29$ \\
\hline 3 & $8,12 \mathrm{~m}$ & $7 ’-8$ ' & $8,45-8,11$ \\
\hline 8 & $8,11 \mathrm{~m}$ & $7^{\prime}-99^{\prime}$ & $8,45-7,77$ \\
\hline 6 , & $8,06 \mathrm{~m}$ & $3^{\prime}-4$ ' & $8,34-7,76$ \\
\hline 8 & $8,02 \mathrm{~m}$ & $3^{\prime}-5$ ' & $8,34-7,25$ \\
\hline 9 & $7,79 \mathrm{~m}$ & $7-8$ & $8,29-8,02$ \\
\hline 9' & $7,77 \mathrm{~m}$ & $7-9$ & $8,29-7,79$ \\
\hline $4{ }^{\prime}$ & $7,76 \mathrm{~m}$ & $3-4$ & $8,12-7,68$ \\
\hline$\alpha_{1}$ & $7,72 \mathrm{~m}$ & $3-5$ & $8,12-7,04$ \\
\hline 4 & $7,68 \mathrm{~m}$ & $8^{\prime}-9^{\prime}$ & $8,11-7,77$ \\
\hline 6 & $7,61 \mathrm{~d}$ & $6^{\prime}-4^{\prime}$ & $8,06-7,76$ \\
\hline$\beta_{1}$ & $7,52 \mathrm{~m}$ & $6 '-5$ & $8,06-7,25$ \\
\hline 5 & $7,25 \mathrm{t}(1)$ & $8-9$ & $8,02-7,79$ \\
\hline 5 & $7,11 \mathrm{t}(1)$ & $4^{\prime}-5$ ' & $7,76-7,25$ \\
\hline N-H & $-2,99 \mathrm{~s}(2)$ & $\alpha_{1}-\beta_{1}$ & $7,72-7,52$ \\
\hline & & $4-6$ & $7,68-7,61$ \\
\hline & & $4-5$ & $7,68-7,11$ \\
\hline & & $6-5$ & $7,61-7,11$ \\
\hline
\end{tabular}

$\delta\left(\mathrm{CDCL}_{3}\right)$ em ppm; referência TMS; (valor da integral, correspondendo ao número de prótons); $\mathrm{s}=$ singleto; $\mathrm{d}=$ dupleto; $\mathrm{t}=$ tripleto. 
A introdução do complexo de rutênio adiciona 16 novos prótons bipiridínicos aos espectros de ${ }^{1} \mathrm{H}-\mathrm{RMN}$ da supermolécula. Os espectros mostram um grande número de sinais, especialmente na faixa dos prótons aromáticos (tipicamente entre $7 \mathrm{ppm}$ e $9 \mathrm{ppm}$ ) em função da não equivalência magnética dos anéis piridínicos. Faz-se necessário o uso de técnicas de RMN bidimensionais para a interpretação de todos os prótons da molécula (Figura 51). A atribuição dos espectros Tabela 9 (Figura 49), foi realizada por comparação com os espectros das meso-piridil(fenilpiridil)porfirinas correspondentes e os resultados obtidos por Nikolaou ${ }^{78}$ e também por Maruyama ${ }^{79}$ com complexos de rutênio(bipiridina). Novamente para a análise desta molécula parte-se do princípio que os prótons mais protegidos que a molécula $\left[\mathrm{M}(4-\mathrm{N}-\mathrm{Py}) \mathrm{BFFPH}_{2}\left\{\mathrm{Ru}(\mathrm{bpy})_{2} \mathrm{Cl}\right\}\right] \mathrm{PF}_{6}$ apresenta são os prótons internos do anel porfirínico. Estes prótons $(\mathrm{N}-\mathrm{H})$ têm um deslocamento químico de $\delta=-2,99$ ppm (Figura 49) e são utilizados como pico base para se fazer a integral dos outros picos da molécula. Pela integração, pelo deslocamento químico e comparação com o respectivo espectro da porfirina base livre (Figura 34, Figura 49) pode-se dizer que o sinal em $\delta=8,89$ ppm corresponde aos prótons $\mathrm{H}_{3}, \mathrm{H}_{7}, \mathrm{H}_{8}, \mathrm{H}_{12}, \mathrm{H}_{13}, \mathrm{H}_{17}$, e o sinal em $\delta=$ 8,83 ppm corresponde aos prótons $\mathrm{H}_{2}$ e $\mathrm{H}_{18 \text {., }}$ A atribuição dos prótons $\alpha_{1}$ e $\beta_{1}$ só pode ser feita através do espectro bidimensional (Figura 51), pelo espectro há um acoplamento destes prótons. $\mathrm{O}$ sinal em $\delta=7,72 \mathrm{ppm}$ é atribuído aos prótons $\alpha_{1}$ e o sinal em $\delta=7,52$ ppm é atribuído aos prótons $\beta_{1}$. Esta atribuição foi feita baseando-se no princípio de que os prótons $\alpha_{1}$ seriam mais desprotegidos do que os prótons $\beta_{1}$, por se encontrarem ligados a um átomo de carbono vizinho a um átomo nitrogênio piridínico, que possui caráter eletronegativo. Com relação aos prótons oriundos do ligante $\left[\mathrm{Ru}(\text { bpy })_{2} \mathrm{Cl}\right]^{+}$, pela integração, deslocamento químicos, análise do espectro COSY e comparação com o espectro RMN ${ }^{1} \mathrm{H}$ da piridil(fenil)porfirina coordenada ao mesmo ligante pode-se supor que o sinal em $\delta=10,22 \mathrm{ppm}$ é devido ao próton $10^{\prime}$ e que o sinal em $\delta=9,02 \mathrm{ppm}$ é devido ao próton 10. No espectro COSY o próton 10' acopla com os prótons 9' e 8'. Por comparação com o ligante livre e pelos acoplamentos entre si, atribui-se o sinal em $\delta=$ $8,11 \mathrm{ppm}$ ao próton 8' e o sinal em 7,77 ppm ao próton 9'. Novamente pelo espectro COSY o próton 10 acopla com os prótons 9 e 8 . Por comparação com o ligante livre e pelos acoplamentos entre si, atribui-se o sinal em $\delta=8,02 \mathrm{ppm}$ ao próton 8 e o sinal em $7,79 \mathrm{ppm}$ ao próton 9 . O próton 10' está sujeito ao efeito indutivo do ligante cloro, e o 
próton 10 sofre um grande efeito de corrente de anel e seus sinais aparecem em campo baixo do espectro de RMN ${ }^{1} \mathrm{H}$. Outra suposição que pode ser feita é que o sinal em $\delta=$ $7,11 \mathrm{ppm}$ é proveniente ao próton 5 e o sinal em $\delta=7,25 \mathrm{ppm}$ corresponde ao prótons 5, estes prótons também sofrem grande influência da corrente de anel, mas com efeito contrário. Na medida em que um anel aromático é submetido a um campo magnético externo $\mathrm{B}_{0}$, seus elétrons $\pi$ passam a circular de modo a gerar um campo magnético local, em resposta à perturbação externa. Desta forma, em função das linhas do campo gerado, a região imediatamente acima do anel aromático sofre a chamada blindagem, uma vez que nesta região o campo magnético local é contrário ao campo $\mathrm{B}_{0}$. Em contrapartida, na região lateral ao anel ocorre a chamada desblindagem, uma vez que o campo magnético local se soma ao campo externo. Esta é a razão pela qual prótons aromáticos tem deslocamentos químicos em região de campo baixo, tipicamente entre $7 \mathrm{ppm}$ e 9 ppm ${ }^{80}$. No espectro COSY o próton 5 acopla com os prótons 3, 4 e 6. Por comparação com o ligante livre e pelos acoplamentos entre si, atribui-se o sinal em $\delta=8,12$ ppm ao próton 3, o sinal em 7,68 ppm ao próton 4 e o sinal em 7,61 ppm ao próton 6. Novamente pelo espectro COSY o próton 5' acopla com os prótons 3',4' e 6'. Por comparação com o ligante livre e pelos acoplamentos entre si atribui-se o sinal em $\delta=8,34 \mathrm{ppm}$ ao próton 3', o sinal em 7,75 ppm ao próton 4' e o sinal em 8,06 ppm ao próton 6'. Todos os outros prótons da molécula foram atribuídos através da manchas de correlação encontradas no espectro COSY. Ao todo são 23 acoplamentos distintos que estão representados na Tabela 9.

Observando-se o espectro de $\mathrm{RMN}{ }^{19} \mathrm{~F}$ da díade [M(4-N-Py)TFFPH $\mathrm{T}_{2}$ $\left\{\mathrm{Ru}(\mathrm{bpy})_{2} \mathrm{Cl}\right\} \mathrm{PF}_{6}$ (Figura 50, tabela 7) e baseando-se em dados relatados na literatura, atribui-se o sinal em $\delta=-137,5 \mathrm{ppm}$ aos átomos de flúor em orto $\left(\mathrm{F}_{1}\right)$. O triplete em $\delta=-152,3$ ppm foi atribuído aos átomos de flúor na posição para $\left(\mathrm{F}_{3}\right)$ e o sinal em $\delta=-162,4 \mathrm{ppm}$ foi atribuído aos átomos de flúor na posição meta $\left(\mathrm{F}_{2}\right)$. Como pode ser observado através das Figura 35, Figura 46 e Figura 50 a coordenação dos grupos $\left[\mathrm{Ru}_{3} \mathrm{O}(\mathrm{Ac})_{6}(\mathrm{py})_{2}\right]^{+}$e $\left[\mathrm{Ru}(\mathrm{bpy})_{2} \mathrm{Cl}\right]^{+}$não influenciam nos deslocamentos químicos dos núcleos de flúor 


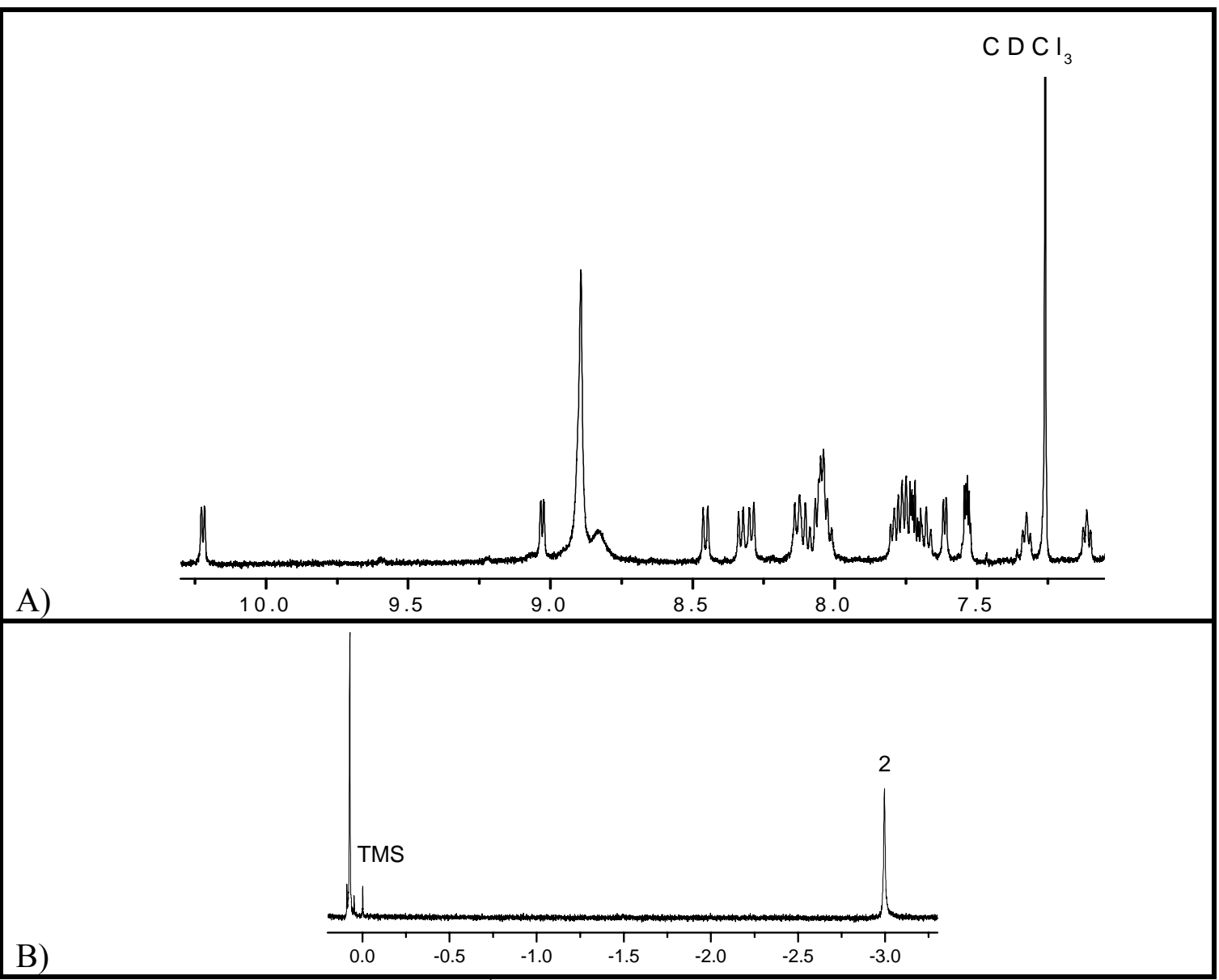

Figura 49: Espectro de RMN de ${ }^{1} \mathrm{H}$ da díade $\left[\mathrm{M}(4-\mathrm{N}-\mathrm{Py}) \mathrm{TFFPH}_{2}\left\{\mathrm{Ru}(\mathrm{bpy})_{2} \mathrm{Cl}_{\}}\right] \mathrm{PF}_{6} \mathrm{em}\right.$ $\mathrm{CDCl}_{3}$; A) ampliação na região de 10,3 a 7,0 ppm; B) ampliação na região de 0,2 a $-3,2$ ppm ( os números na figura correspondem ao valor da integral para cada sinal).

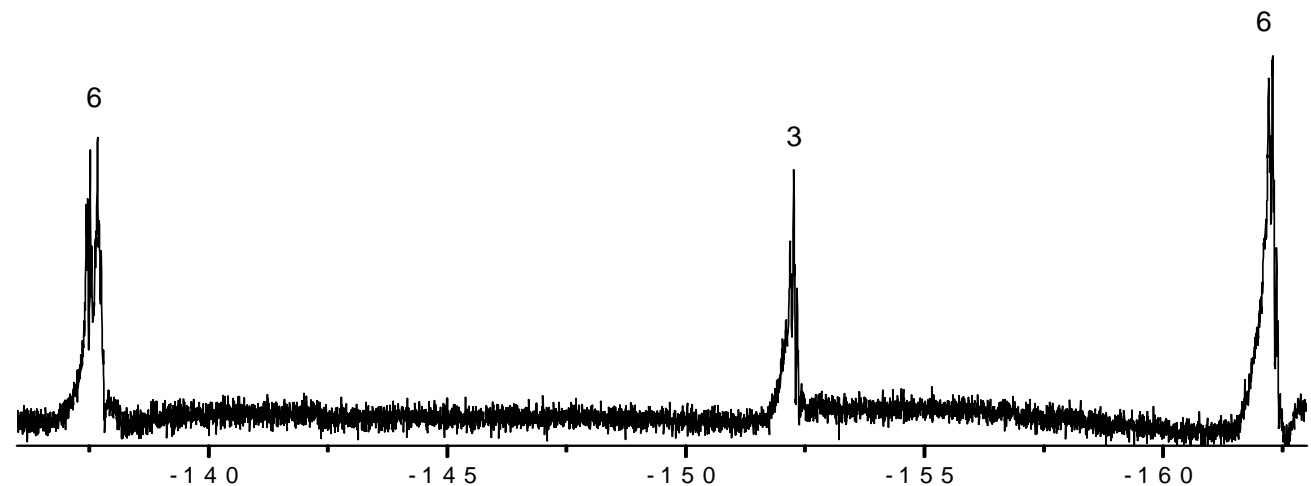

Figura 50: Espectro de $\mathrm{RMN}$ de ${ }^{19} \mathrm{~F}$ da díade $\left[\mathrm{M}(4-\mathrm{N}-\mathrm{Py}) \mathrm{TFFPH}_{2}\left\{\mathrm{Ru}(\mathrm{bpy})_{2} \mathrm{Cl}\right\}\right] \mathrm{PF}_{6} \mathrm{em}$ $\mathrm{CDCl}_{3}$. 


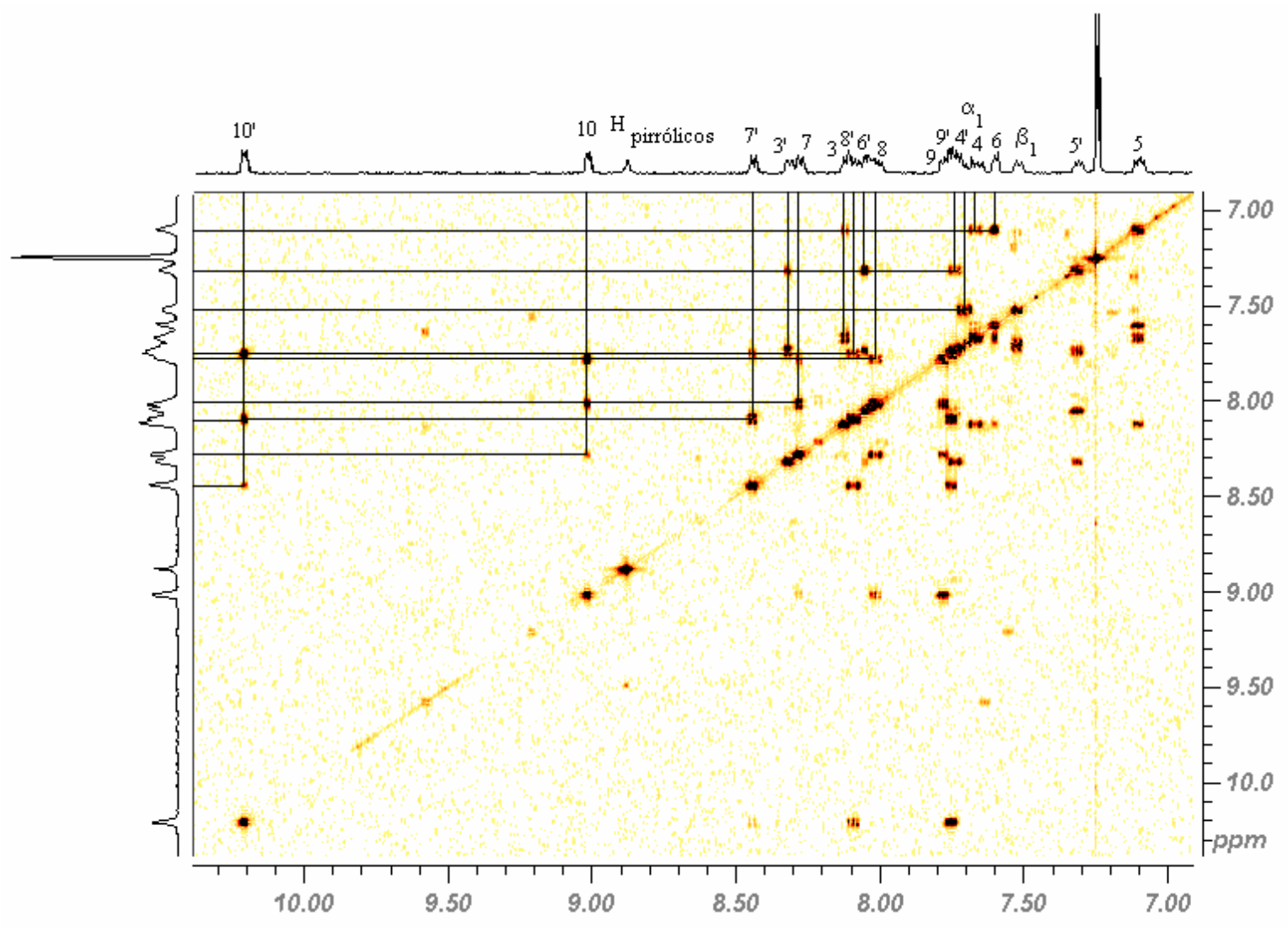

Figura 51: Espectro COSY da díade $\left[\mathrm{M}(4-\mathrm{N}-\mathrm{Py}) \mathrm{TFPPH}_{2}\left\{\mathrm{Ru}(\mathrm{bpy})_{2} \mathrm{Cl}\right\}\right] \mathrm{PF}_{6}$.

\section{IV.4) Difração de Raios-X da porfirina trans-B(4-N-Py)TFPPH 2.}

A primeira cristalização desta porfirina ocorreu foi acidentalmente. A porfirina impura, recém tirada da primeira coluna de cromatografia, estava solubilizada em aproximadamente $100 \mathrm{~mL}$ de DCM em um erlermeyer de $125 \mathrm{~mL}$ dentro da capela. Este erlermeyer ficou durante 50 horas dentro da capela, todo o DCM evaporou e houve a formação de cristais da trans-B(4-N-Py)TFPPH 2 . Estes cristais que se formaram não eram bons para um estudo cristalográfico, pois eles eram opacos e pequenos.

Para se obter um bom cristal da porfirina trans-B(4-N-Py) $\mathrm{TFPPH}_{2}$ foi feito um estudo com diversos tipos de solventes e misturas de solventes. Utilizou solventes como $\mathrm{MeOH}$, ciclohexano, DCM, ACT, EtOH, clorofórmio e como mistura de solventes utilizou 4:1 DCM/ACT, 3:1 DCM/ACT, 2:1 DCM/ACT, 1:1 DCM/ACT, 4:1 CLF/CH, 3:1 $\mathrm{CLF} / \mathrm{CH}, 2: 1 \mathrm{CLF} / \mathrm{CH}$ e 1:1 CLF/CH. Foi pesado aproximadamente cerca de $10 \mathrm{mg}$ da porfirina impura, solubilizado em aproximadamente $15 \mathrm{ml}$ de solvente e colocado dentro 
de um erlermeyer de $50 \mathrm{~mL}$. Foi colocado um pedaço de Parafilm ${ }^{\circledR}$ na boca do erlermeyer e foram feitos pequenos furos com uma agulha, estes pequenos orifícios tinham a finalidade de permitir que o solvente evaporasse da forma mais lenta possível. Este erlermeyer foi mantido na capela até que todo o solvente fosse evaporado. A mistura de solventes na proporção de 3:1 de ciclohexano/clorofórmio foi a que resultou nos melhores cristais.

Tentou-se a cristalização das outras porfirinas e supermoléculas, mas os cristais obtidos não foram bons para a análise cristalográfica.

Pela análise cristalográfica é possível afirmar que o cristal tem a estrutura da porfirina trans-B(4-N-Py)TFPPH $\mathrm{H}_{2}$. Alguns destes cristais da porfirina trans-B(4-NPy) $\mathrm{TFPPH}_{2}$ foram solubilizados em DCM para fazer uma CCD e calcular o valor de $\mathrm{R}_{\mathrm{f}} \mathrm{O}$ valor encontrado de Rf para a porfirina trans-B(4-N-Py)TFPPH $\mathrm{H}_{2}$ foi de 0,15 . Já o valor encontrado para a porfirina cis-B(4-N-Py) $\mathrm{TFPPH}_{2}$ foi de $\mathrm{Rf}=0,08$ (Tabela 2), a medida de $\mathrm{R}_{\mathrm{f}}$ por $\mathrm{CCD}$, é a única análise que se consegue diferenciar um isômero do outro, pois os isômeros apresentam espectros UV-Vísivel e espectros de RMN ${ }^{1} \mathrm{H}$ e ${ }^{19} \mathrm{~F}$ bem semelhantes.

A estrutura do cristal da porfirina trans-B(4-N-Py) $\mathrm{BPPH}_{2}$ foi representada nas Figura 52 e Figura 53. Na Tabela 10 estão mostrados os parâmetros cristalinos. Os parâmetros posicionais da molécula estão mostrados nas Tabela 11 e Tabela 12.

A porfirina trans-B(4-N-Py)BPPH 2 cristalizou no grupo espacial $\mathrm{C}_{2 / \mathrm{c}}$, com quatro moléculas de porfirinas por cela unitária. As duas moléculas paralelas estão distantes 7.1 $\AA$ (Figura 54). Sabe-se que em estruturas porfirínicas supramoleculares a interação $\pi-\pi$ ocorre quando a distância entre duas moléculas é aproximadamente $3,5 \AA^{81}$, devido à nuvem eletrônica $\pi$. Em contrapartida, Natash et al. sugeriu que fraca interação $\pi-\pi$ ocorre quando a distância entre duas moléculas de porfirinas paralelas é aproximadamente $7.5 \AA^{82}$. Neste caso temos uma fraca interação $\pi-\pi$ stacking na molécula estudada. 


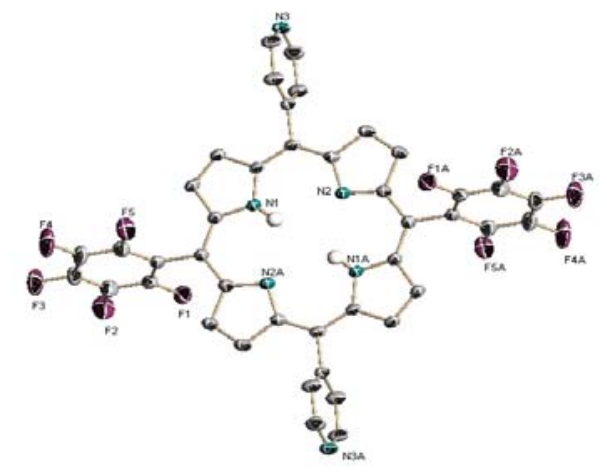

Figura 52: Estrutura da porfirina trans-B(4-N-Py) $\mathrm{TFPPH}_{2}$.

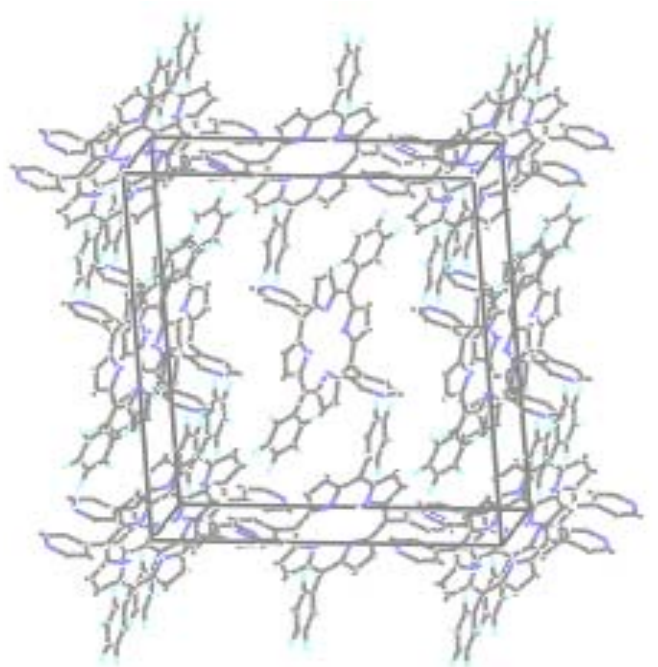

Figura 53: Diagrama da cela unitária da porfirina trans-B(4-N-Py) $\mathrm{TFPPH}_{2}$.

Tabela 10: Dados cristalinos e refinamento da estrutura trans-B(4-N-Py) $\mathrm{TFPPH}_{2}$

\begin{tabular}{lll}
\hline Formula Empírica & $\mathrm{C}_{42} \mathrm{H}_{18} \mathrm{~F}_{10} \mathrm{~N}_{6}$ & \\
Massa Molar & $796,62 \mathrm{~g}$ & \\
Temperatura & $173(2) \mathrm{K}$ & \\
Comprimento de Onda & $0.71073 \AA$ & \\
Sistema Cristalino & Monoclínico & \\
Grupo Espacial & $\mathrm{C}_{2 / \mathrm{c}}$ & \\
Dimensões da cela unitária & $\mathrm{a}=20,314(2) \AA \quad \alpha=90^{\circ}$ \\
& $\mathrm{b}=7,1098(7) \AA \quad \beta=90,752(3)^{\circ}$ \\
& $\mathrm{c}=23,597(2) \AA$ & $\gamma=90^{\circ}$ \\
Volume & $3407,8(6) \AA^{3}$ & \\
$Z$ & 4 & \\
Densidade (calculado) & $1,553 \mathrm{Mg} / \mathrm{m}^{3}$ & \\
Coeficiente de Absorção & $0,132 \mathrm{~mm}^{-1}$ & \\
F(000) & 1608 & \\
Tamanho do cristal & $0,30 \times 0,20 \times 0,08 \mathrm{~mm}^{3}$ \\
Variação de $\theta$ & 1,73 to $28,27^{\circ}$. & \\
\hline
\end{tabular}


Tabela 11: Coordenadas atômicas $\left(x 10^{4}\right)$ e parâmetro de deslocamento isotrópico $\left(\AA^{2} \times 10^{3}\right)$ para a trans-B(4-N-Py)TFPPH ${ }_{2}, \mathrm{U}(\mathrm{eq})$ é definido como um terço do traço do tensorUij ortogonalizado.

\begin{tabular}{|c|c|c|c|c|}
\hline & $\mathrm{x}$ & $\mathrm{y}$ & $\mathrm{z}$ & $\mathrm{U}(\mathrm{eq})$ \\
\hline $\mathrm{F}(1)$ & $1518(1)$ & 13591(1) & $1654(1)$ & $49(1)$ \\
\hline $\mathrm{N}(2)$ & $93(1)$ & $8226(2)$ & $-663(1)$ & $28(1)$ \\
\hline $\mathrm{F}(5)$ & $613(1)$ & $7820(2)$ & $2230(1)$ & $51(1)$ \\
\hline $\mathrm{N}(1)$ & $702(1)$ & $8515(2)$ & $479(1)$ & $26(1)$ \\
\hline $\mathrm{N}(3)$ & $2265(1)$ & $1650(2)$ & $-663(1)$ & $33(1)$ \\
\hline $\mathrm{F}(2)$ & $2084(1)$ & 13994(2) & $2677(1)$ & $63(1)$ \\
\hline$C(3)$ & $1525(1)$ & $6512(2)$ & $689(1)$ & $28(1)$ \\
\hline $\mathrm{C}(18)$ & $522(1)$ & $6750(2)$ & $-690(1)$ & $28(1)$ \\
\hline$C(5)$ & $716(1)$ & $10475(2)$ & $1336(1)$ & $28(1)$ \\
\hline $\mathrm{F}(3)$ & 1914(1) & 11361(2) & $3482(1)$ & $71(1)$ \\
\hline$C(1)$ & $937(1)$ & $8986(2)$ & $1005(1)$ & $26(1)$ \\
\hline$C(6)$ & 1033(1) & $10708(2)$ & 1904(1) & $28(1)$ \\
\hline$C(13)$ & $1417(1)$ & $4597(2)$ & $-395(1)$ & $25(1)$ \\
\hline $\mathrm{C}(12)$ & $966(1)$ & $6193(2)$ & $-264(1)$ & $25(1)$ \\
\hline$C(2)$ & $1458(1)$ & $7699(2)$ & $1136(1)$ & $28(1)$ \\
\hline$C(14)$ & 2023(1) & 4939(2) & $-631(1)$ & $35(1)$ \\
\hline $\mathrm{C}(4)$ & $1047(1)$ & $7021(2)$ & $269(1)$ & $25(1)$ \\
\hline $\mathrm{F}(4)$ & $1175(1)$ & $8262(2)$ & $3253(1)$ & $77(1)$ \\
\hline$C(7)$ & $966(1)$ & $9373(2)$ & $2329(1)$ & $34(1)$ \\
\hline $\mathrm{C}(11)$ & $1418(1)$ & $12255(2)$ & 2041(1) & $33(1)$ \\
\hline $\mathrm{C}(17)$ & $1245(1)$ & $2757(2)$ & $-292(1)$ & $34(1)$ \\
\hline $\mathrm{C}(21)$ & $-225(1)$ & $8234(2)$ & $-1174(1)$ & $30(1)$ \\
\hline$C(16)$ & $1683(1)$ & $1350(2)$ & $-435(1)$ & $38(1)$ \\
\hline $\mathrm{C}(9)$ & $1628(1)$ & 11141(2) & $2976(1)$ & $44(1)$ \\
\hline $\mathrm{C}(19)$ & $473(1)$ & $5808(2)$ & $-1236(1)$ & $39(1)$ \\
\hline$C(15)$ & $2426(1)$ & $3424(2)$ & $-753(1)$ & $37(1)$ \\
\hline $\mathrm{C}(20)$ & $11(1)$ & $6736(2)$ & $-1537(1)$ & $40(1)$ \\
\hline$C(10)$ & 1711(1) & $12482(2)$ & $2565(1)$ & $40(1)$ \\
\hline$C(8)$ & $1256(1)$ & $9580(2)$ & $2857(1)$ & $44(1)$ \\
\hline
\end{tabular}


Tabela 12: Comprimento de ligação $[\AA]$ e ângulos $\left[{ }^{\circ}\right]$ para a trans-B $(4-\mathrm{N}-\mathrm{Py}) \mathrm{TFPPH}_{2}$

\begin{tabular}{|c|c|}
\hline $\mathrm{F}(1) \mathrm{C}(11)$ & $1,3361(16)$ \\
\hline$N(2) C(21)$ & $1,3614(18)$ \\
\hline $\mathrm{N}(2) \mathrm{C}(18)$ & $1,3663(16)$ \\
\hline $\mathrm{F}(5) \mathrm{C}(7)$ & $1,3354(17)$ \\
\hline $\mathrm{N}(1) \mathrm{C}(1)$ & $1,3666(17)$ \\
\hline $\mathrm{N}(1) \mathrm{C}(4)$ & $1,3697(16)$ \\
\hline$N(3) C(15)$ & $1,321(2)$ \\
\hline$N(3) C(16)$ & $1,323(2)$ \\
\hline$F(2) C(10)$ & $1,3396(18)$ \\
\hline$C(3) C(2)$ & $1,3586(19)$ \\
\hline$C(3) C(4)$ & $1,4235(18)$ \\
\hline$C(18) C(12)$ & $1,3995(18)$ \\
\hline$C(18) C(19)$ & $1,4529(19)$ \\
\hline$C(5) C(1)$ & $1,3931(18)$ \\
\hline$C(5) C(21) \# 1$ & $1,4044(18)$ \\
\hline$C(5) C(6)$ & $1,4893(18)$ \\
\hline $\mathrm{F}(3) \mathrm{C}(9)$ & $1,3296(18)$ \\
\hline$C(1) C(2)$ & $1,4289(17)$ \\
\hline$C(6) C(11)$ & $1,386(2)$ \\
\hline$C(6) C(7)$ & $1,389(2)$ \\
\hline$C(13) C(17)$ & $1,377(2)$ \\
\hline$C(13) \mathrm{C}(14)$ & $1,380(2)$ \\
\hline$C(13) \mathrm{C}(12)$ & $1,4947(16)$ \\
\hline$C(12) C(4)$ & $1,3957(18)$ \\
\hline$C(14) C(15)$ & $1,3844(19)$ \\
\hline $\mathrm{F}(4) \mathrm{C}(8)$ & $1,3351(18)$ \\
\hline $\mathrm{C}(7) \mathrm{C}(8)$ & $1,380(2)$ \\
\hline $\mathrm{C}(11) \mathrm{C}(10)$ & $1,374(2)$ \\
\hline$C(17) C(16)$ & $1,3837(19)$ \\
\hline$C(21) C(5) \# 1$ & $1,4044(18)$ \\
\hline$C(21) C(20)$ & $1,4512(19)$ \\
\hline $\mathrm{C}(9) \mathrm{C}(8)$ & $1,368(2)$ \\
\hline$C(9) C(10)$ & $1,372(2)$ \\
\hline
\end{tabular}




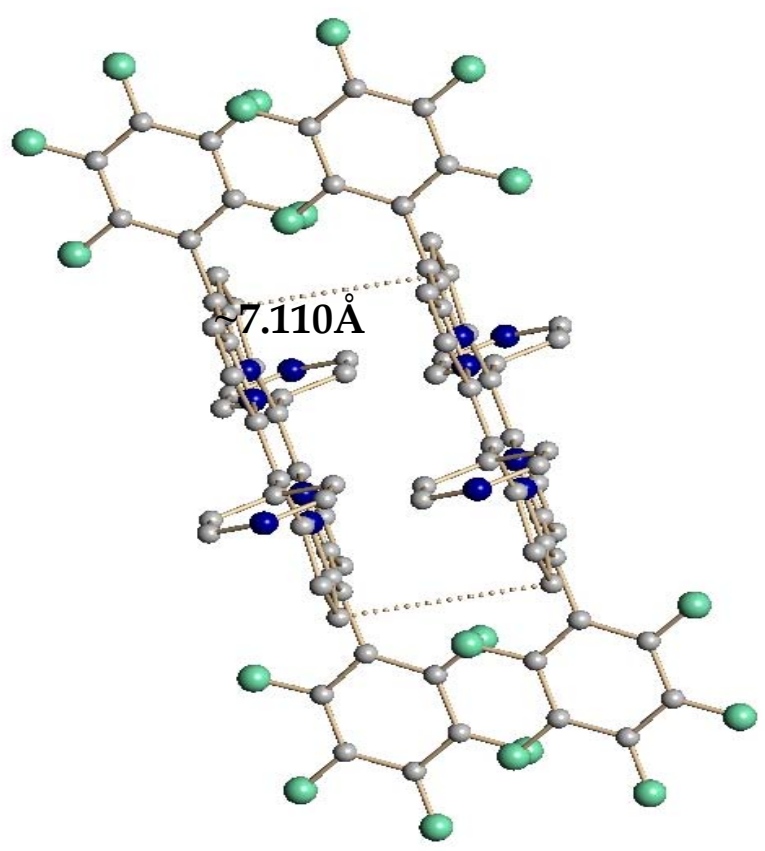

Figura 54: Interação das nuvens $\pi$ entre moléculas da porfirina trans-B(4-N-Py) $\mathrm{TFPPH}_{2}$.

\section{IV.5) Análise Estrutural por Espectrometria de Massa}

A espectometria de ionização com eletrospray (ESI) é uma técnica que primeiro ioniza as moléculas e depois as transfere para a fase gasosa, para serem detectadas pelo espectrômetro de massa ${ }^{83}$. Essa técnica expandiu as possibilidades da espectrometria de massa para novas classes de moléculas, supermoléculas ${ }^{84}$ incluindo uma variedade de compostos inorgânicos, orgânicos, espécies organometálicas ${ }^{85}$ e intermediários de reação ${ }^{86}$.

Porfirinas e metaloporfirinas são de grande importância em muitas áreas como biologia, catálise, geologia, e fotoquímica, e a espectroscopia de ionização com eletrospray ESI-MS(/MS) têm sido fundamental para a caracterização destas moléculas.

A vantagem desta técnica frente ao RMN é que a ESI necessita de pouco material para ser feita a análise e o RMN necessita de soluções de $1,0 \times 10^{-2} \mathrm{~mol} . \mathrm{L}^{-1}$, o que é muito difícil de se obter com supermolécula por problemas de solubilidade.

Há uma desvantagem dessa técnica frente ao RMN, quando se trabalha com sistemas porfirinicos cis- e trans-, não é possível notar diferença nos espectros de massa 
dos isômeros. Por isso, na dissertação estão apresentados os dados referentes às moléculas cis-. A escolha da caracterização das moléculas por ESI-MS e ESI-MSMS foi em função da pouca quantidade obtida dos produtos de interesse.

Para a caracterização das supermoléculas por ESI, foi necessário fazer um estudo com os constituintes das supermoléculas. Foram feitas as análises com as porfirinas cis- e trans-B(4-N-Py)BFFPH $\mathrm{H}_{2}$, para as duas moléculas os resultados obtidos foram os mesmos. Percebe-se pelo experimento ESI-MS da porfirina cis-B(4-N-Py)BFFPH ${ }_{2}$ (Figura 55) que há o aparecimento de um pico em $\mathrm{m} / \mathrm{z}=797$. Sabe-se pela diferença entre os picos da distribuição isotópica observando espectro de massa (Figura 55) que este íon tem carga +1 . A massa molar da porfirina é $796 \mathrm{~g} \mathrm{~mol}^{-1}$ e como a medida é feita em meio ácido, há a protonação da porfirina que leva ao aparecimento do pico em $\mathrm{m} / \mathrm{z}=797$. O experimento está configurado para só detectar moléculas com carga positivas, pois quando há a protonação da porfirina, esta fica com carga +1 . O pico em $\mathrm{m} / \mathrm{z}=797$ está de acordo com a massa molar e a carga da porfirina em meio ácido. Não fica evidenciado se a protonação ocorre nos nitrogênio pirrólico ou piridínico da porfirina.

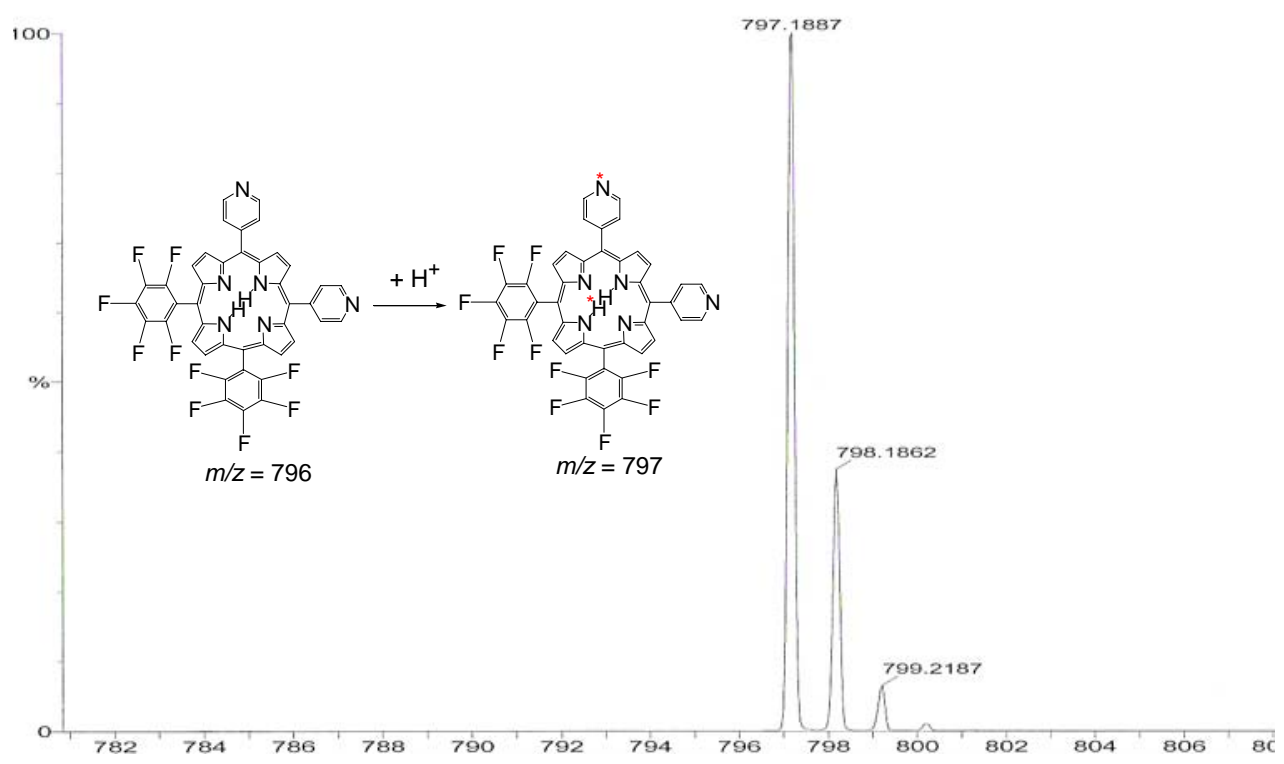

Figura 55: Espectro ESI MS da porfirina cis-B(4-N-Py)BFFPH 2 .

Para tentar verificar a fragmentação da porfirina fez-se estudos ESI-MSMS. No espectro de massa apresentado na Figura 56 isolou-se o íon $\mathrm{m} / \mathrm{z}=797$ (Figura 55). A fragmentação apresentada pela porfirina (Figura 56) mostra que há a perda consecutiva de 20 unidades de massa, isso pode estar indicando que há a perda de HF da molécula. 


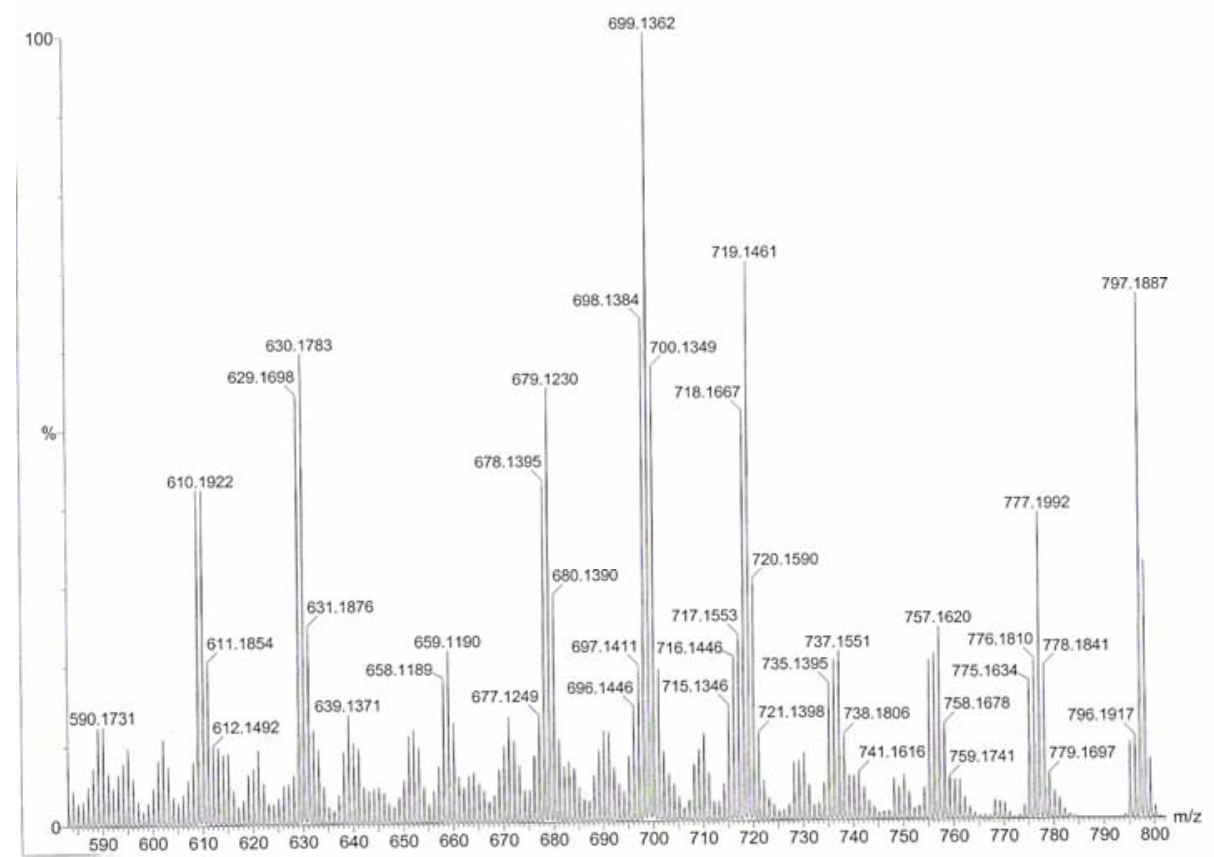

Figura 56: Espectro ESI MSMS do íon m/z 797 da porfirina cis-B(4-N-Py)BFFPH 2.

Na Figura 57 está representado o espectro de massa obtido por experimento ESIMS para o cluster $\left[\mathrm{Ru}_{3} \mathrm{O}(\mathrm{Ac})_{6}(\mathrm{py})_{2}(\mathrm{MeOH})\right]^{+}$. Nesse espectro de massa (Figura 57) podemos ver que não há o aparecimento do pico molecular do composto em $\mathrm{m} / \mathrm{z}=863$. O pico em $\mathrm{m} / \mathrm{z}=863$ não é detectado porque conforme a molécula ionizada vai para o estado gasoso, há a perda de uma molécula de $\mathrm{MeOH}$ da estrutura, resultando no pico $\mathrm{m} / \mathrm{z}=831$, que corresponde ao composto $\left[\mathrm{Ru}_{3} \mathrm{O}(\mathrm{Ac})_{6}(\mathrm{py})_{2}\right]^{+}$. $\mathrm{O}$ pico em $\mathrm{m} / \mathrm{z}=752$ corresponde à perda de uma molécula de piridina do composto $\mathrm{m} / \mathrm{z}=831$, resultando no composto $\left[\mathrm{Ru}_{3} \mathrm{O}(\mathrm{Ac})_{6}(\mathrm{py})\right]^{+}$. Pode ocorrer a perda de mais uma molécula de piridina da estrutura $\left[\mathrm{Ru}_{3} \mathrm{O}(\mathrm{Ac})_{6}(\mathrm{py})\right]^{+}$e há a formação do composto $\left[\mathrm{Ru}_{3} \mathrm{O}(\mathrm{Ac})_{6}\right]^{+}$que aparece com o pico $\mathrm{m} / \mathrm{z}=673$. Pode ocorrer a perda de 4 moléculas de acetato do composto com pico em $\mathrm{m} / \mathrm{z}=752$ ou do composto com o pico em $\mathrm{m} / \mathrm{z}=673$. Não se sabe ainda as estruturas desses produtos, que apresentam picos em $\mathrm{m} / \mathrm{z}=516 \mathrm{e} \mathrm{m} / \mathrm{z}=437$, as prováveis fórmulas moleculares dos compostos estão representadas em vermelho na Figura 57. 


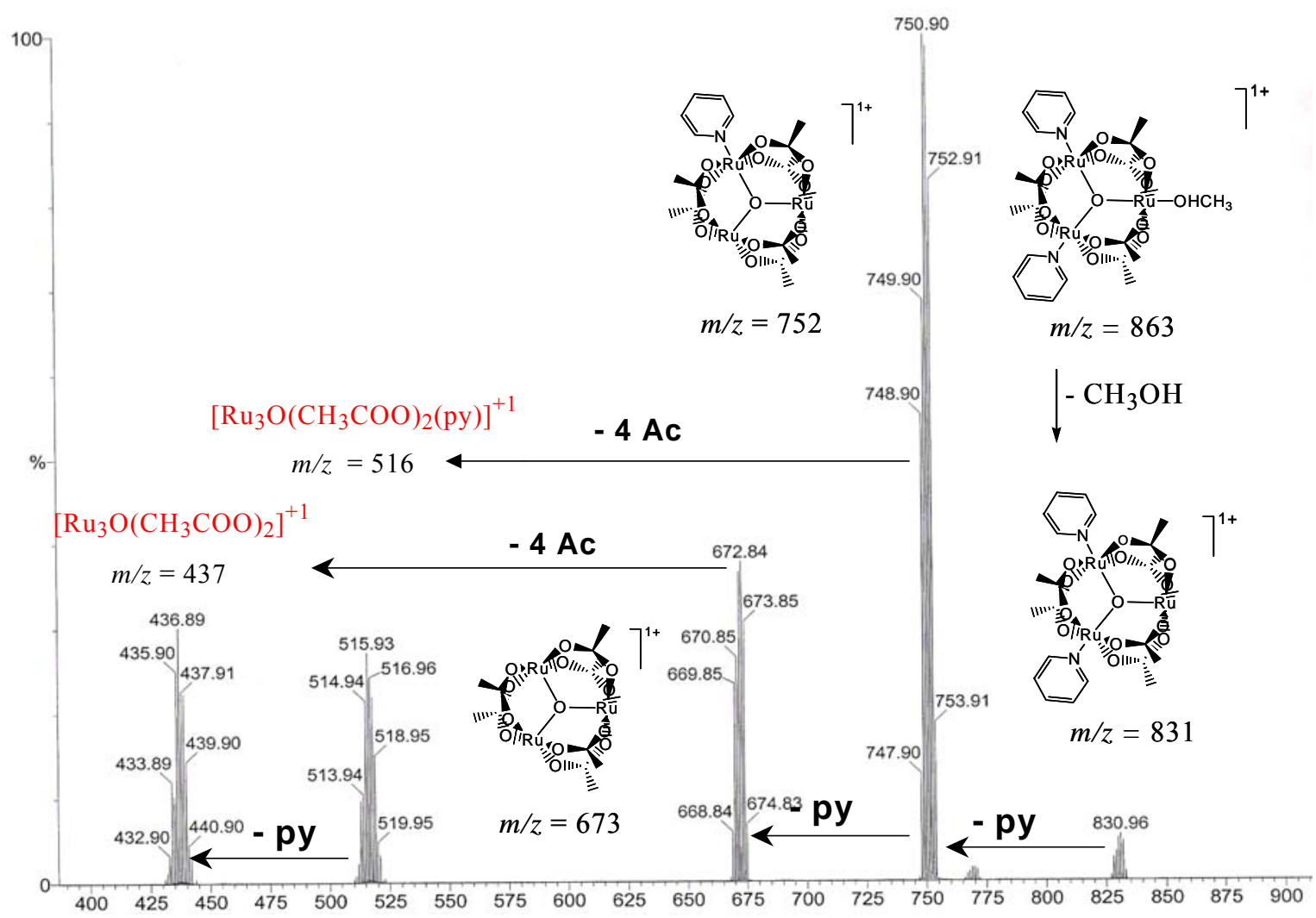

Figura 57: Espectro ESI MS do cluster $\left[\mathrm{Ru}_{3} \mathrm{O}(\mathrm{Ac})_{6}(\mathrm{py})_{2}\left(\mathrm{CH}_{3} \mathrm{OH}\right)\right]$.

Na Figura 58 está representado o espectro de massa obtido por experimento ESIMS para a díade cis-[B(4-N-Py) $\left.\mathrm{BFFPH}_{2}\left\{\mathrm{Ru}_{3} \mathrm{O}(\mathrm{Ac})_{6}(\mathrm{py})_{2}\right\}\right]^{+}$. Para o isômero da díade trans-[B(4-N-Py) $\left.\mathrm{BFFPH}_{2}\left\{\mathrm{Ru}_{3} \mathrm{O}(\mathrm{Ac})_{6}(\mathrm{py})_{2}\right\}\right]^{+}$o resultado obtido foi o mesmo. Nota-se que neste espectro de massa (Figura 58) há o aparecimento de um pico $\mathrm{m} / \mathrm{z}=1629$ que corresponde à díade cis-[B(4-N-Py) $\left.\mathrm{BFFPH}_{2}\left\{\mathrm{Ru}_{3} \mathrm{O}(\mathrm{Ac})_{6}(\mathrm{py})_{2}\right\}\right]^{+}$, o outro pico em $\mathrm{m} / \mathrm{z}=815$ corresponde a molécula da díade protonada. A molécula da díade protonada apresenta carga $2+$ e por isso um pico resultante em $\mathrm{m} / \mathrm{z}=815$. 




Figura 58: Espectro ESI MS da díade cis-[B(4-N-Py)BFFPH $\left.{ }_{2}\left\{\mathrm{Ru}_{3} \mathrm{O}(\mathrm{Ac})_{6}(\mathrm{py})_{2}\right\}\right] \mathrm{PF}_{6}$.

Para verificar a fragmentação da díade cis-[B(4-N-Py)BFFPH $\left.2\left\{\mathrm{Ru}_{3} \mathrm{O}(\mathrm{Ac})_{6}(\mathrm{py})_{2}\right\}\right]$ $\mathrm{PF}_{6}$ fez-se estudos ESI-MSMS com os íons $\mathrm{m} / \mathrm{z}=815$ e $\mathrm{m} / \mathrm{z}=1629$ (Figura 58). Na Figura 59 está representado o experimento ESI-MSMS para o íon $\mathrm{m} / \mathrm{z}=1629$. Pode-se notar que há o aparecimento de um pico $\mathrm{m} / \mathrm{z}=1550$ (Figura 59) que corresponde à perda de uma molécula de piridina da estrutura original do composto cis-[B(4-N-Py)BFFPH $\mathrm{B}_{2}$ $\left.\left\{\mathrm{Ru}_{3} \mathrm{O}(\mathrm{Ac})_{6}(\mathrm{py})_{2}\right\}\right] \mathrm{PF}_{6} . \mathrm{O}$ pico em m/z=1471 (Figura 59) corresponde à perda da segunda molécula de piridina da estrutura original do composto cis-[B(4-N-Py)BFFPH $\mathrm{B}_{2}$ $\left.\left\{\mathrm{Ru}_{3} \mathrm{O}(\mathrm{Ac})_{6}(\mathrm{py})_{2}\right\}\right] \mathrm{PF}_{6}$, estas piridinas são provenientes do cluster. Neste espectro não se pode ver um pico correspondente somente à porfirina, pois como a porfirina está neutra ela não é detectada. O contrário ocorre com o cluster, na quebra da ligação do cluster com a porfirina, há o aparecimento do pico em $\mathrm{m} / \mathrm{z}=831$ (Figura 59) que corresponde à molécula $\left[\mathrm{Ru}_{3} \mathrm{O}(\mathrm{Ac})_{6}(\mathrm{py})_{2}\right]^{+}$. Novamente há perda de uma molécula de piridina do cluster e posteriormente há a perda da segunda molécula de piridina, resultando nos picos 
$\mathrm{m} / \mathrm{z}=752$ e 673 , respectivamente. $\mathrm{O}$ cluster segue o mesmo padrão de fragmentação apresentado na Figura 57.

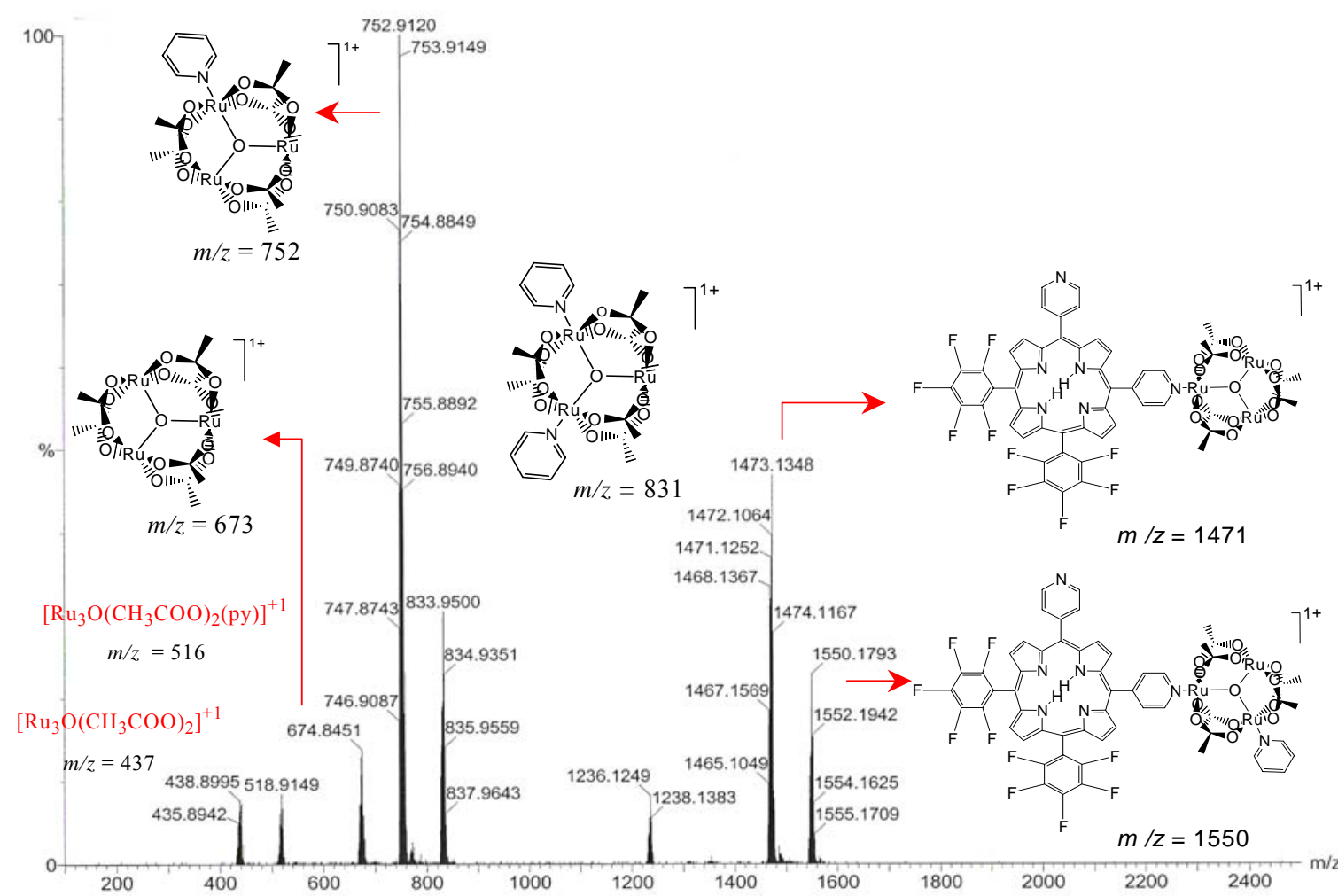

Figura 59: Espectro ESI MSMS do íon m/z 1629 da díade cis-[B(4-N-Py) $\left.\mathrm{BFFPH}_{2}\left\{\mathrm{Ru}_{3} \mathrm{O}(\mathrm{Ac})_{6}(\mathrm{py})_{2}\right\}\right] \mathrm{PF}_{6}$.

Na Figura 60 está representado o experimento ESI-MSMS para o íon $\mathrm{m} / \mathrm{z}=815$. Pode-se notar que há novamente o aparecimento de um pico $\mathrm{m} / \mathrm{z}=815$ (Figura 60) que indica que nem todas as moléculas da díade protonada foram fragmentadas. $\mathrm{O}$ pico em $\mathrm{m} / \mathrm{z}=775$ corresponde à díade protonada com a perda de uma molécula de piridina, proveniente do cluster. $\mathrm{O}$ pico em $\mathrm{m} / \mathrm{z}=775$ tem carga +2 porque apresenta separação entre os picos da distribuição isotópica igual à $1 / 2$ unidade de massa. Como a porfirina está protonada, com a quebra da ligação da porfirina com o cluster, haverá um pico que corresponderá à porfirina e outro que corresponderá ao cluster. $\mathrm{O}$ pico correspondente à porfirina está em $\mathrm{m} / \mathrm{z}=797$ e tem carga +1 , já o pico correspondente ao cluster se encontra em $\mathrm{m} / \mathrm{z}=831$. Há novamente a perda de moléculas de piridina do cluster, como se pode notar no pico em $\mathrm{m} / \mathrm{z}=752$. 


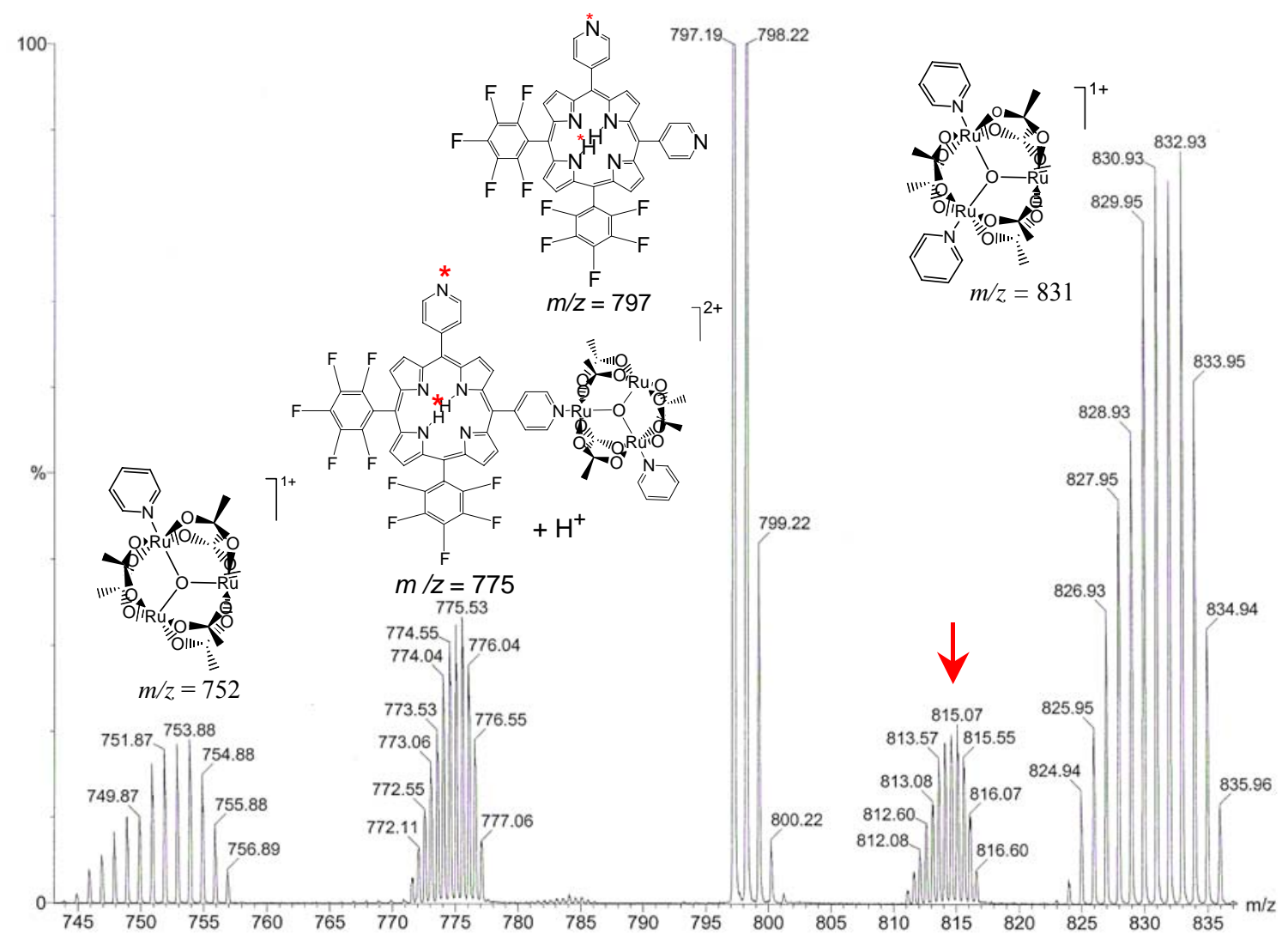

Figura 60: Espectro ESI MSMS do íon $\mathrm{m} / \mathrm{z} 815$ da díade cis-[B(4-N-Py)BFFPH $\left.{ }_{2}\left\{\mathrm{Ru}_{3} \mathrm{O}(\mathrm{Ac})_{6}(\mathrm{py})_{2}\right\}\right] \mathrm{PF}_{6}$.

Na Figura 61 está representado o espectro de massa obtido por experimento ESIMS para a tríade cis-[B(4-N-Py) $\left.\mathrm{BFFPH}_{2}\left\{\mathrm{Ru}_{3} \mathrm{O}(\mathrm{Ac})_{6}(\mathrm{py})_{2}\right\}\left\{\mathrm{Ru}(\mathrm{bpy})_{2} \mathrm{Cl}\right\}\right]^{++}$. Para o isômero da tríade trans-[B(4-N-Py) $\left.\mathrm{BFFPH}_{2}\left\{\mathrm{Ru}_{3} \mathrm{O}(\mathrm{Ac})_{6}(\mathrm{py})_{2}\right\}\left\{\mathrm{Ru}(\mathrm{bpy})_{2} \mathrm{Cl}\right\}\right]^{++}$o resultado obtido foi o mesmo. Nota-se que neste espectro de massa (Figura 61) há o aparecimento de um pico $\mathrm{m} / \mathrm{z}=1039$ com carga $2+$ que corresponde à tríade cis-[B(4-N-Py)BFFPH ${ }_{2}$ $\left.\left\{\mathrm{Ru}_{3} \mathrm{O}(\mathrm{Ac})_{6}(\mathrm{py})_{2}\right\}\left\{\mathrm{Ru}(\mathrm{bpy})_{2} \mathrm{Cl}\right\}\right]^{++}$. 


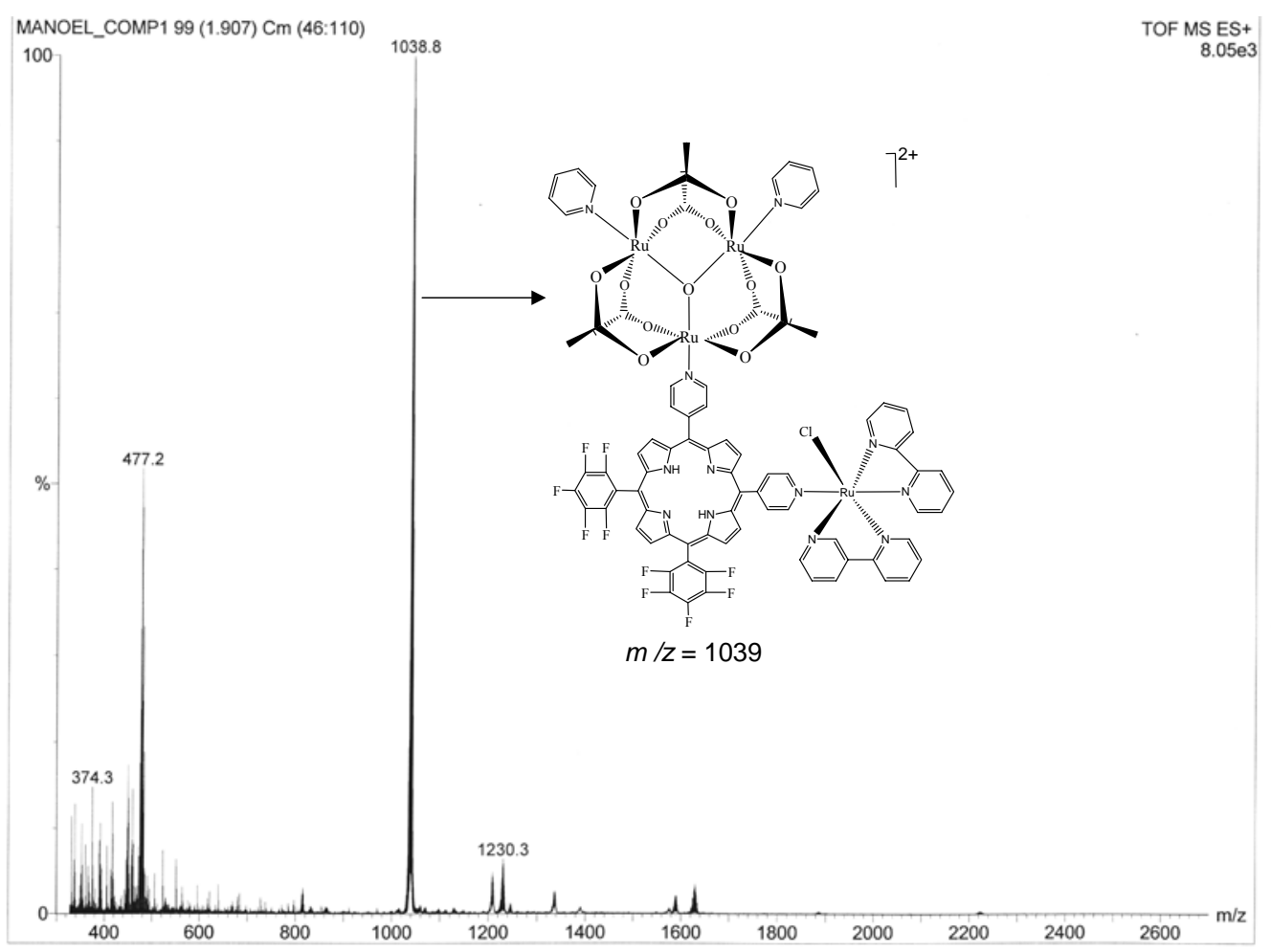

Figura 61: Espectro ESI MS da tríade cis-[B(4-N-Py)BFFPH $\left.2\left\{\mathrm{Ru}_{3} \mathrm{O}(\mathrm{Ac})_{6}(\mathrm{py})_{2}\right\}\left\{\mathrm{Ru}(\mathrm{bpy})_{2} \mathrm{Cl}\right\}\right]\left(\mathrm{PF}_{6}\right)_{2}$.

Para verificar a fragmentação da tríade cis-[B(4-N-Py)BFFPH 2 $\left.\left\{\mathrm{Ru}_{3} \mathrm{O}(\mathrm{Ac})_{6}(\mathrm{py})_{2}\right\}\left\{\mathrm{Ru}(\mathrm{bpy})_{2} \mathrm{Cl}\right\}\right]^{++}$fez-se estudo ESI-MSMS com o íon $\mathrm{m} / \mathrm{z}=1039$ (Figura 61). Novamente não é possível observar no espectro de massa (Figura 62) nenhuma estrutura correspondente à dupla ligação do cluster e do complexo de rutênio $\left[\mathrm{Ru}(\mathrm{bpy})_{2} \mathrm{Cl}\right]^{+}$com a porfirina e a posterior perda de piridina. Isso indica que a segunda ligação de um complexo metálico com a díade é bem mais fraca. Pode-se notar que há novamente o aparecimento de um pico $\mathrm{m} / \mathrm{z}=1039$ (Figura 62) que indica que nem todas as moléculas da tríade foram fragmentadas. Tão logo ela é fragmentada, ela perde uma molécula de cluster ou do complexo de rutênio $\left[\mathrm{Ru}(\mathrm{bpy})_{2} \mathrm{Cl}\right]^{+}$. Isso fica evidente, pois temos o pico em $\mathrm{m} / \mathrm{z}=1629$ que corresponde a quebra de ligação do complexo $\left[\mathrm{Ru}(\mathrm{bpy})_{2} \mathrm{Cl}\right]^{+}$com a tríade cis-[B(4-N$\left.\mathrm{Py}_{\mathrm{BFFPH}_{2}}\left\{\mathrm{Ru}_{3} \mathrm{O}(\mathrm{Ac})_{6}(\mathrm{py})_{2}\right\}\left\{\mathrm{Ru}(\mathrm{bpy})_{2} \mathrm{Cl}\right\}\right]^{++}$e o pico em $\mathrm{m} / \mathrm{z}=1245$ corresponde à quebra da ligação do cluster com a tríade cis-[B(4-N-Py) $\left.\mathrm{BFFPH}_{2}\left\{\mathrm{Ru}_{3} \mathrm{O}(\mathrm{Ac})_{6}(\mathrm{py})_{2}\right\}\left\{\mathrm{Ru}(\mathrm{bpy})_{2} \mathrm{Cl}\right\}\right]^{++}$e posterior formação da díade cis-[B(4-N-Py) $\left.\mathrm{BFFPH}_{2}\left\{\mathrm{Ru}(\mathrm{bpy})_{2} \mathrm{Cl}\right\}\right]^{+}$. 


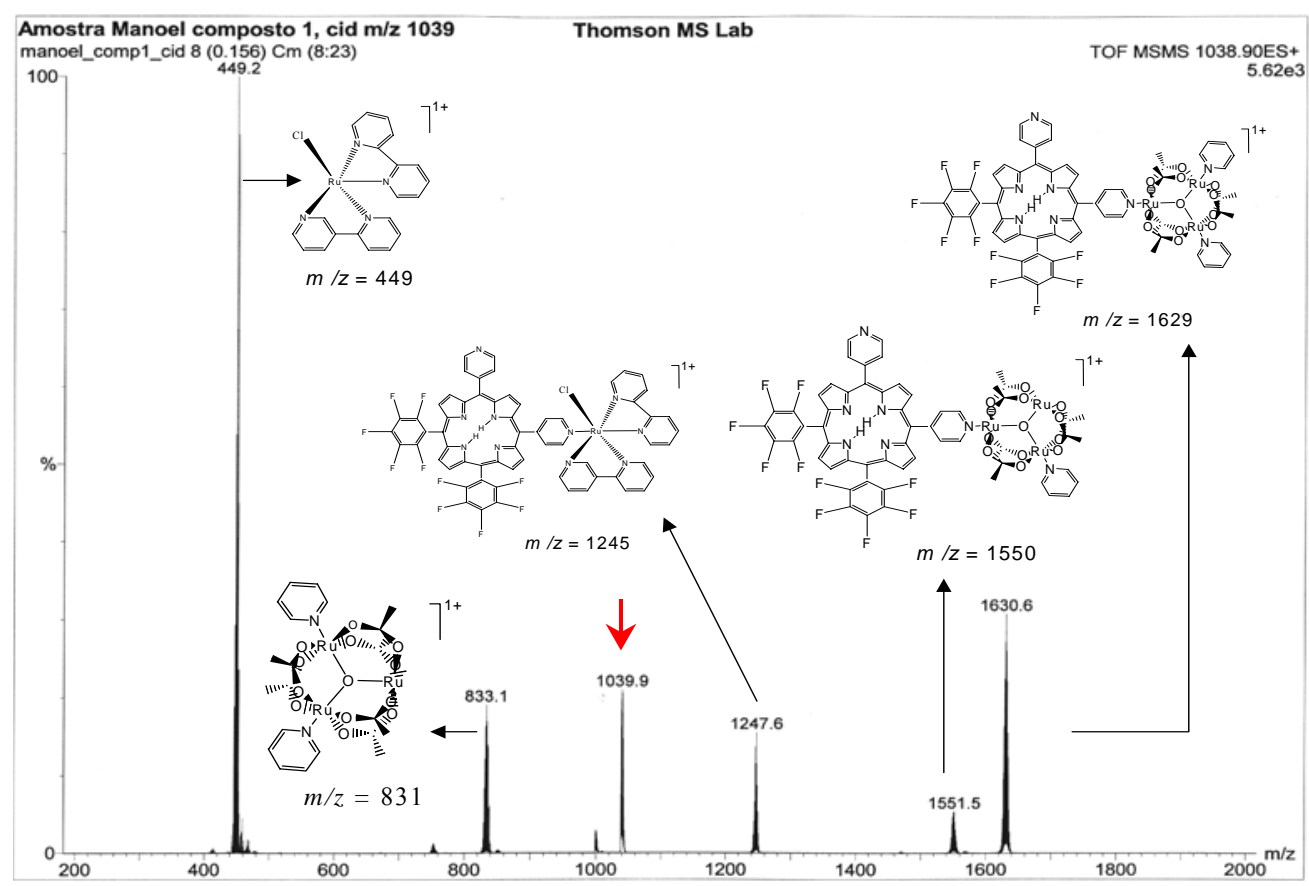

Figura 62: Espectro ESI MSMS do íon $\mathrm{m} / \mathrm{z} 1039$ da tríade cis-[B(4-N-Py)BFFPH $\left.\left.\mathrm{Bu}_{2} \mathrm{O}(\mathrm{Ac})_{6}(\mathrm{py})_{2}\right\}\left\{\mathrm{Ru}(\mathrm{bpy})_{2} \mathrm{Cl}\right\}\right]\left(\mathrm{PF}_{6}\right)_{2}$.

Todos os espectros anteriores ESI-MS e ESI-MSMS das porfirinas, cluster, díades e tríades foram feitos no laboratório Thomson de Espectrometria de Massa (UNICAMP), sob responsabilidade do prof. Dr. Marcos N. Eberlin. Os espectros ESI MS das díades $\left[\mathrm{M}(4-\mathrm{N}-\mathrm{Py}) \mathrm{TFFPH}_{2}\left\{\mathrm{Ru}_{3} \mathrm{O}(\mathrm{Ac})_{6}(\mathrm{py})_{2}\right\}\right] \mathrm{PF}_{6} \quad($ Figura $\quad 63)$ e $\quad\left[\mathrm{M}(4-\mathrm{N}-\mathrm{Py}) \mathrm{TFFPH}_{2}\right.$ $\left\{\mathrm{Ru}(\mathrm{bpy})_{2} \mathrm{Cl}\right\} \mathrm{PF}_{6}$ (Figura 64) foram feitos no laboratório da FCFRP-USP sob responsabilidade do Prof. Dr. Norberto Peporine Lopes, estes espectros tem o intuito de fornecer mais uma informação do caracter estrutural destas moléculas.

Pelo espectro ESI-MS da díade [M (4-N-Py)TFFPH $\left.{ }_{2}\left\{\mathrm{Ru}_{3} \mathrm{O}(\mathrm{Ac})_{6}(\mathrm{py})_{2}\right\}\right] \mathrm{PF}_{6}$ Figura 63 pode-se perceber que a síntese desta supermolécula foi realizada com sucesso. O pico em $\mathrm{m} / \mathrm{z}=1717$ está de acordo com a massa molar e a carga da supermolécula. Nota-se que neste espectro de massa (Figura 63) existe fragmentação da molécula na fonte, pois há o aparecimento de um pico em $\mathrm{m} / \mathrm{z}=1213$ que corresponde à perda de três moléculas de pentafluorfenil da estrutura da díade [M (4-N-Py)TFFPH $\left.2\left\{\mathrm{Ru}_{3} \mathrm{O}(\mathrm{Ac})_{6}(\mathrm{py})_{2}\right\}\right] \mathrm{PF}_{6}$, também existe o pico em $\mathrm{m} / \mathrm{z}=550$ que corresponde à perda de três moléculas de pentafluorfenil da porfirina $\mathrm{M}(4-\mathrm{N}-\mathrm{Py}) \mathrm{TFFPH}_{2}$. 


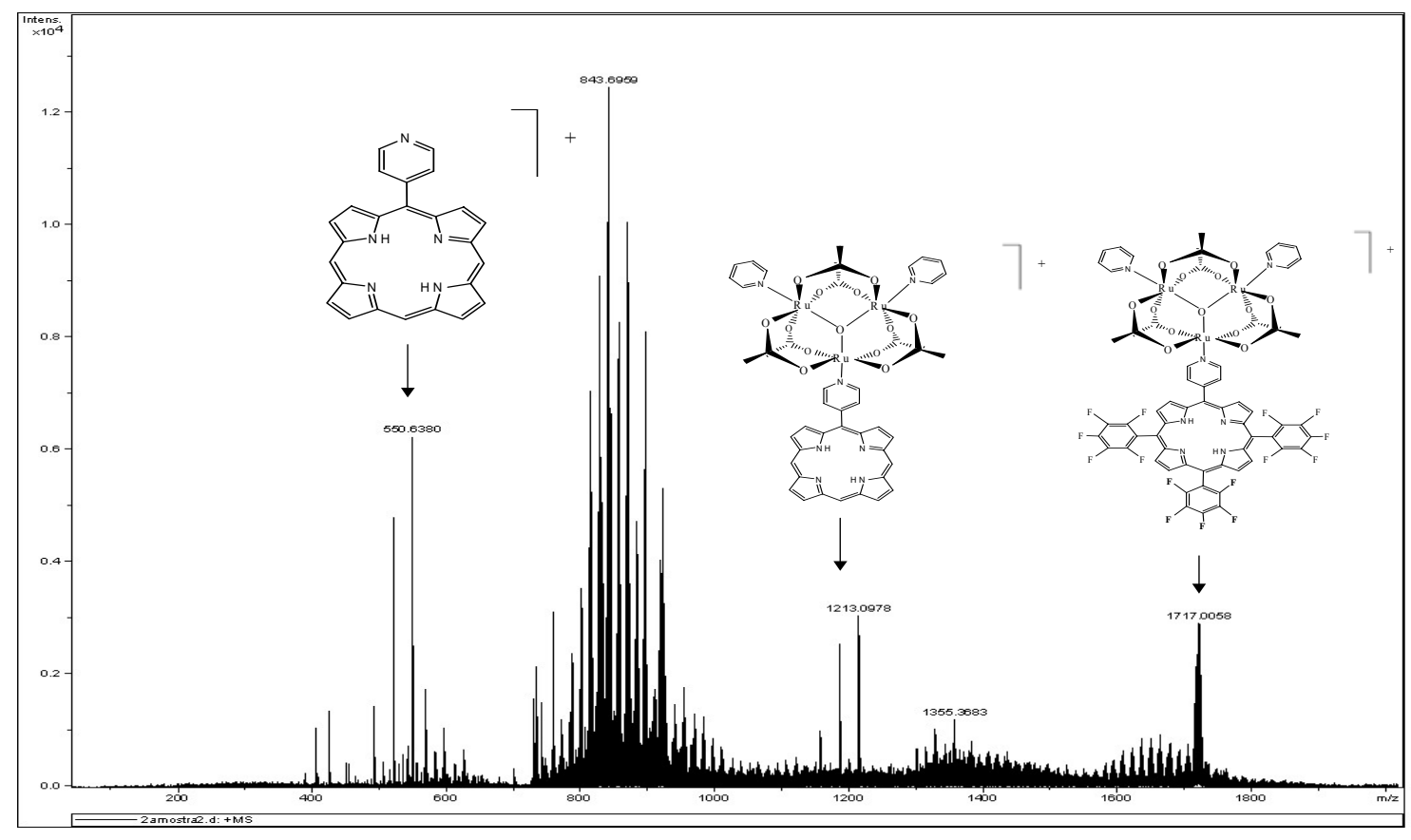

Figura 63: Espectro ESI MS da díade $\left[\mathrm{M}(4-\mathrm{N}-\mathrm{Py}) \mathrm{TFFPH}_{2}\left\{\mathrm{Ru}_{3} \mathrm{O}(\mathrm{Ac})_{6}(\mathrm{py})_{2}\right\}\right] \mathrm{PF}_{6}$.

Pelo espectro ESI-MS da díade [M (4-N-Py)TFFPH $\mathrm{H}_{2}\left\{\mathrm{Ru}(\mathrm{bpy})_{2} \mathrm{ClPF}_{6}\right.$ Figura 64 pode-se perceber que a síntese desta supermolécula foi realizada com sucesso. O pico em $\mathrm{m} / \mathrm{z}=1334$ está de acordo com a massa molar e a carga da supermolécula. Nota-se que neste espectro de massa (Figura 64) existe fragmentação da molécula na fonte, pois há o aparecimento de um pico em $\mathrm{m} / \mathrm{z}=832$ que corresponde à perda de três moléculas de pentafluorfenil da estrutura da díade $\left[\mathrm{M}(4-\mathrm{N}-\mathrm{Py}) \mathrm{TFFPH}_{2}\left\{\mathrm{Ru}_{3} \mathrm{O}(\mathrm{Ac})_{6}(\mathrm{py})_{2}\right\}\right] \mathrm{PF}_{6}$, também existe o pico em $\mathrm{m} / \mathrm{z}=550$ que corresponde à perda de três moléculas de pentafluorfenil da porfirina $\mathrm{M}(4-\mathrm{N}-\mathrm{Py}) \mathrm{TFFPH}_{2}$. 


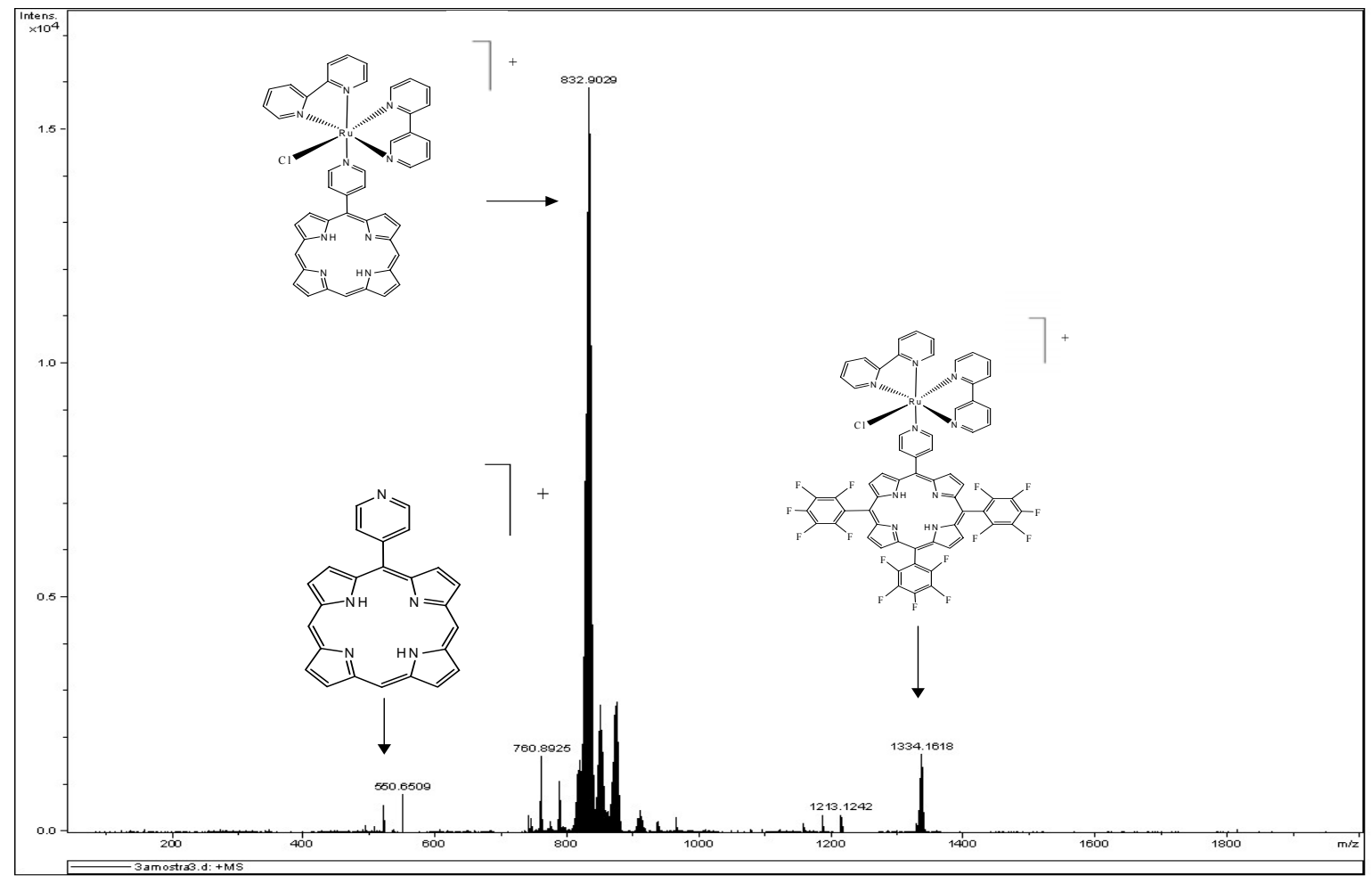

Figura 64: Espectro ESI MS da díade $\left[\mathrm{M}(4-\mathrm{N}-\mathrm{Py}) \mathrm{TFFPH}_{2}\left\{\mathrm{Ru}(\mathrm{bpy})_{2} \mathrm{Cl}\right\}\right] \mathrm{PF}_{6}$.

\section{IV.6) Voltametria Cíclica e Voltametria de Pulso Diferencial}

\section{IV.6.1.) Porfirinas: Voltametria de Pulso Diferencial}

Podem ser observados nos voltamogramas da Figura 65, pares de ondas quase reversíveis com os potenciais de redução por volta de $-0,60$ e $-1,10 \mathrm{~V}$ para as porfirinas. Estes processos foram atribuídos à primeira e segunda redução monoeletrônica do anel

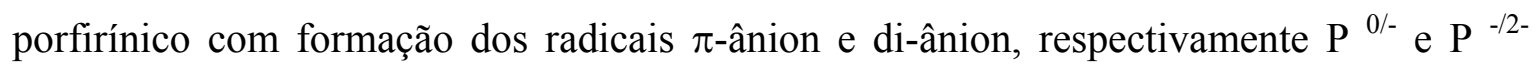
Quando se utiliza DMF só é possível visualizar um processo de oxidação no anel porfirínico (Figura 66), e este ocorre por volta de $1,10 \mathrm{~V}$. No caso da porfirina $\mathrm{M}(4-\mathrm{N}-\mathrm{Py}) \mathrm{TPPH}_{2}$, não foi possível visualizar processos oxidativos utilizando DMF como solvente porque estes processos ocorrem em valores de potenciais fora da janela de trabalho em DMF, em função do maior número de grupos pentafluorofenil (retiradores de densidade eletrônica). 
Comparando-se com os valores de oxidação e redução para a tetrafenil-porfirina $\mathrm{TPPH}_{2}{ }^{87}$ (Tabela 13), nota-se que os valores de potencias de meia onda $\left(\mathrm{E}_{1 / 2}\right)$ de oxidação são deslocados para valores maiores, enquanto que para os valores de potenciais de redução têm-se um deslocamento para valores menos negativos, indicando que a adição de grupo pentafluorofenil (receptor de elétron) remove a densidade eletrônica do anel porfirínico e conduzem a oxidações mais difíceis e reduções mais fáceis (Figura 67). Esta tendência é coerente com a natureza de "retiradores de densidade eletrônica" promovido pelos halogênios colocados nos meso-substituintes fenila do anel porfirínico. Sendo assim, a porfirina $\mathrm{M}(4-\mathrm{N}-\mathrm{Py}) \mathrm{TFPPH}_{2}$ apresenta o potencial de redução menos negativo e o potencial de oxidação mais positivo. Kadish e colaboradores observaram que existe uma correlação entre a planaridade do anel porfirínico e a aditividade dos efeitos provocados pelos substituintes nele adicionados. Quanto mais distorcido for o anel (podendo ser a distorção provocada por diversos fatores, tais como os promovidos por substituintes volumosos), menor interferência nos potenciais redox um substituinte causará. Alem disso, observou que cada substituinte afeta de maneira diferente os processos de oxidação e de redução, por exemplo, alterações na posição orto e para dos grupos fenila colocados nas posições meso do anel porfirínico, conduzem a uma variação linear dos potenciais redox, desde que a porfirina continue planar. Esta observação sugere uma soma de efeitos afetando os potenciais redox. Coutsolelos e colaboradores também relatam que porfirinas com diferentes graus de halogenação nas posições $\beta$-pirrólicas têm os orbitais de fronteira afetados de maneira distinta. Quanto mais halogenada for a porfirina mais distorcida, portanto, maior será a diferença de energia entre os orbitais HOMO e o LUMO. .

A diferença $\left[\Delta \mathrm{E}_{1 / 2}=\left(\Delta \mathrm{E}_{1 / 2}{ }^{\text {ox1 }}-\Delta \mathrm{E}_{1 / 2}{ }^{\text {red1 }}\right)\right]$ entre o $\mathrm{E}_{1 / 2}$ da primeira oxidação do anel, que gera o radical $\pi$-cátion, e o $E_{1 / 2}$ da primeira redução do anel, que gera o radical $\pi$ ânion é sempre da ordem de $2,25+0,15 \mathrm{~V}^{88}$, este valor mostra a diferença do HOMOLUMO das porfirinas. A partir destes dados pode-se avaliar como os substituintes halogenados influenciam esta separação. Para a série das pentafluoro-piridil-porfirinas não se pode fazer estes cálculos devido a limitações experimentais para a determinação do valor de $\mathrm{E}_{1 / 2}$ da primeira oxidação do anel porfirínico, como relatado acima. 


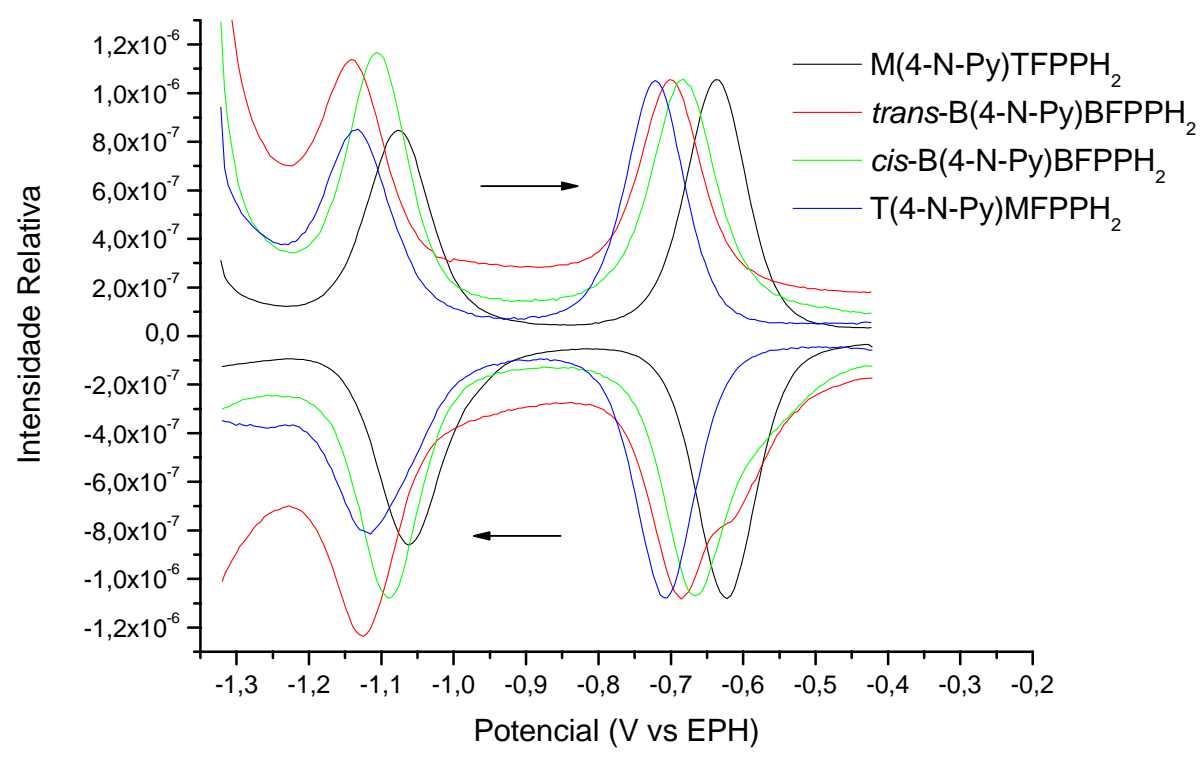

Figura 65: Voltametria de pulso diferencial na região catódica das soluções de porfirina com concentração de aproximadamente $1,0 \times 10^{-4} \mathrm{~mol} \cdot \mathrm{L}^{-1} \mathrm{em} \mathrm{DMF}$. Eletrólito 0,10 mol.L ${ }^{-1}$ de $\mathrm{TBAPF}_{6}$ em ACN. Velocidade de varredura $10 \mathrm{mV} / \mathrm{s}$.

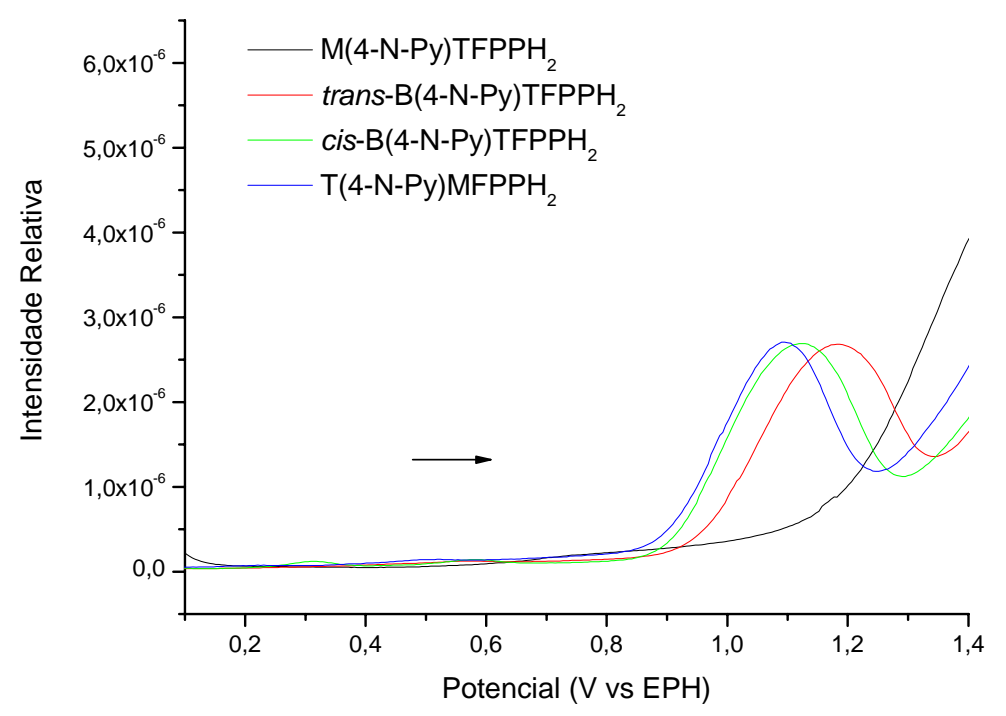

Figura 66: Voltametria de pulso diferencial na região anódica das soluções de porfirina com concentração de aproximadamente $1,0 \times 10^{-4} \mathrm{~mol} . \mathrm{L}^{-1} \mathrm{em}$ DMF.

Eletrólito 0,10 mol. $\mathrm{L}^{-1}$ de $\mathrm{TBAPF}_{6} \mathrm{em} \mathrm{ACN}$. Velocidade de varredura $10 \mathrm{mV} / \mathrm{s}$. 
Tabela 13: Potenciais de meia onda da série meso- pentafluorofenil-piridil-porfirina, em $\mathrm{DMF}, \mathrm{a}=$ pico anódico

\begin{tabular}{|c|c|c|c|}
\hline Porfirina & $\mathbf{P}^{-/ 2-}$ & $\mathbf{P}^{0 /-}$ & $\mathbf{P}^{+/ 0}$ \\
\hline $\mathrm{TPPH}_{2}{ }^{89}$ & -1.46 & -1.08 & 1.18 \\
\hline M(4-N-Py)TPPH 2 & $-1,07$ & $-0,62$ & --- \\
\hline trans- B(4-N-Py)BPPH 2 & $-1,13$ & $-0,69$ & $1,18^{\mathrm{a}}$ \\
\hline cis- $\mathrm{B}(4-\mathrm{N}-\mathrm{Py}) \mathrm{BPPH}_{2}$ & $-1,10$ & $-0,67$ & $1,12^{\mathrm{a}}$ \\
\hline $\mathrm{T}(4-\mathrm{N}-\mathrm{Py}) \mathrm{MPPH}_{2}$ & $-1,13$ & $-0,71$ & $1,09^{\mathrm{a}}$ \\
\hline
\end{tabular}

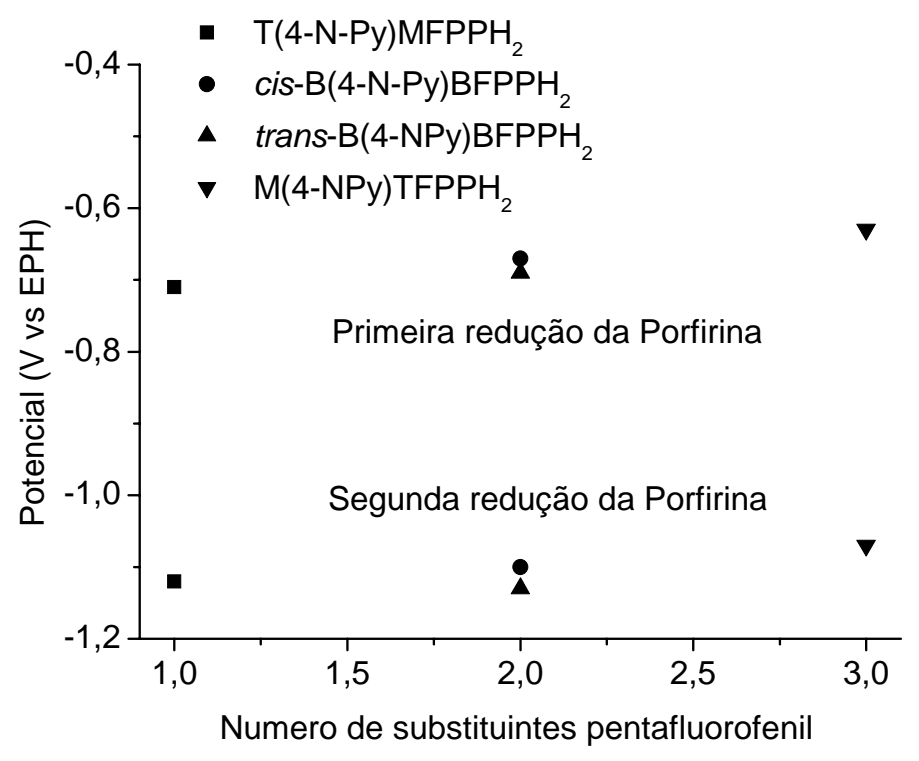

Figura 67: Comparação dos potenciais de redução das porfirinas.

\section{IV.6.2.) Porfirina: Voltametria Ciclica}

Para a porfirina $\mathrm{M}(4-\mathrm{N}-\mathrm{Py}) \mathrm{TPPH}_{2}$ houve a necessidade de se realizar experimentos de voltametria cíclica para posterior comparação com as supermoléculas [M (4-NPy)TFPPH $\left.2\left\{\mathrm{Ru}_{3} \mathrm{O}(\mathrm{Ac})_{6}(\text { py })_{2}\right\}\right] \mathrm{PF}_{6}$ e $\left[\mathrm{M}\right.$ (4-N-Py)TFPPH $\left.2\left\{\mathrm{Ru}(\text { bpy })_{2} \mathrm{Cl}\right\}\right] \mathrm{PF}_{6}$. Também houve a necessidade de usar ferroceno como padrão interno ${ }^{90}$.

A porfirina $\mathrm{M}(4-\mathrm{N}-\mathrm{Py}) \mathrm{TPPH}_{2}$ teve solubilidade suficiente para se realizar experimentos com concentração de aproximadamente $1,1 \times 10^{-3}$ mol.L ${ }^{-1} \mathrm{em}$ ACN.

Podem ser observados nos voltamogramas da Figura 68, pares de ondas quase reversíveis com $\mathrm{E}_{1 / 2}=-0,68 ;-1,10$ para a porfirina $\mathrm{M}(4-\mathrm{N}-\mathrm{Py}) \mathrm{TPPH}_{2}$. Estes processos 
foram atribuídos à primeira e segunda redução monoeletrônica do anel porfirínico com formação dos radicais $\pi$-ânion e di-ânion, respectivamente $\mathrm{P}^{-/ 2-}$ e $\mathrm{P}^{0 /-}$. Nota-se dois processos de oxidações no anel porfirínico $\mathrm{P}^{+/ 0}$ e $\mathrm{P}^{2+/+}$, o primeiro processo de oxidação é irreversível $\mathrm{E}_{\mathrm{pa}}=1,19$ e o segundo processo é quase reversível com $\mathrm{E}_{1 / 2}=1,60$.

Novamente comparando-se com os valores de oxidação e redução para a tetrafenilporfirina $\mathrm{TPPH}_{2}$, nota-se que os valores de potencias de meia onda $\left(\mathrm{E}_{1 / 2}\right)$ de oxidação são deslocados para maiores valores, enquanto que para os valores de potenciais de redução têm-se um deslocamento para valores menos negativos, indicando que a adição de grupo pentafluorofenil (receptor de elétron) remove a densidade eletrônica do anel porfirínico e conduzem a oxidações mais difíceis e reduções mais fáceis. No caso da porfirina $\mathrm{M}(4-\mathrm{N}-\mathrm{Py}) \mathrm{TPPH}_{2}$, não foi possível visualizar processos oxidativos utilizando DMF como solvente porque estes processos ocorrem em valores de potenciais fora da janela de trabalho em DMF, em função do maior número de grupos pentafluor (retiradores de densidade eletrônica). Considerando as diferenças de condições experimentais ao se utilizar DMF ou ACN como solvente os valores de $\mathrm{E}_{1 / 2}$ obtidos para a porfirina M(4-NPy) $\mathrm{TPPH}_{2}$ são bem similares. (Tabela 13 e Tabela 14).

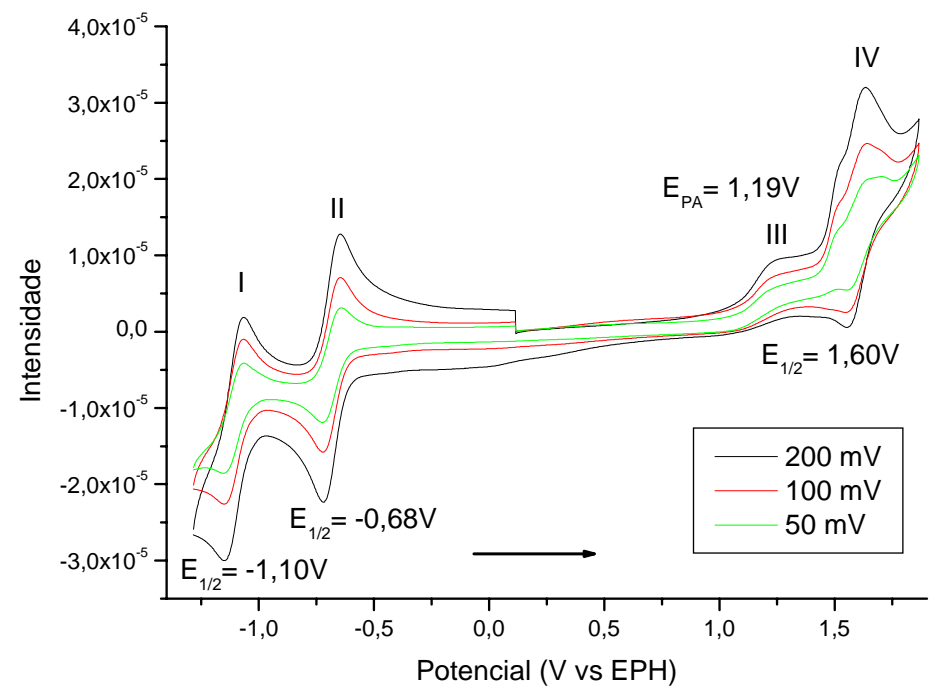

Figura 68: Voltamogramas cíclicos de uma solução $1.10 \times 10^{-3} \mathrm{~mol} . \mathrm{L}^{-1}$ da porfirina $\mathrm{M}(4-\mathrm{N}-\mathrm{Py}) \mathrm{TFPPH}_{2}$ em ACN. Eletrólito 0,10 mol. $^{-1}$ de TBAPF 6 em ACN.

\section{IV.6.3.) Supermolécula: Voltametria Cíclica}


Foram realizados estudos de voltametria cíclica para as díades $\left[\mathrm{M}(4-\mathrm{N}-\mathrm{Py}) \mathrm{TFPPH}_{2}\left\{\mathrm{Ru}_{3} \mathrm{O}(\mathrm{Ac})_{6}(\mathrm{py})_{2}\right\}\right] \mathrm{PF}_{6}$ e $\left[\mathrm{M}(4-\mathrm{N}-\mathrm{Py}) \mathrm{TFPPH}_{2}\left\{\mathrm{Ru}(\mathrm{bpy})_{2} \mathrm{Cl}\right\}\right] \mathrm{PF}_{6}$ para as tríades cis- e trans-[B(4-N-Py)BFFPH $\left.2\left\{\mathrm{Ru}_{3} \mathrm{O}(\mathrm{Ac})_{6}(\mathrm{py})_{2}\right\}\left\{\mathrm{Ru}(\mathrm{bpy})_{2} \mathrm{Cl}\right\}\right]\left(\mathrm{PF}_{6}\right)_{2}$ estes estudos não puderam ser realizados devido a pouca quantidade de material sintetizada.

Tabela 14: Potenciais de meia onda da porfirina e supermoléculas em ACN, a = pico anódico

\begin{tabular}{|c|c|c|c|c|c|c|c|c|}
\hline & $\begin{array}{l}R u^{\text {III }} \mathrm{Ru}^{\mathrm{III}} \mathrm{Ru} u^{\mathrm{III}} / \\
\mathrm{Ru}{ }^{\mathrm{III}} \mathrm{Ru}{ }^{\mathrm{III}} \mathrm{Ru}{ }^{\mathrm{II}}\end{array}$ & $\mathrm{P}^{-/ 2-}$ & $\mathbf{P}^{0 /-}$ & $\begin{array}{c}R u^{\text {III }} R u^{I I I} R u^{I I I} / \\
R u^{I I I} R u^{I I} R u^{I I}\end{array}$ & $R u^{I I I / I I}$ & $\begin{array}{c}R u^{\mathrm{III}} R u^{\mathrm{III}} R u^{\mathrm{III} /} \\
\mathrm{Ru}^{\mathrm{IV}} \mathrm{Ru}{ }^{\mathrm{II}} \mathrm{Ru} u^{\mathrm{III}}\end{array}$ & $\mathrm{P}^{+/ 0}$ & $\mathrm{P}^{2+/+}$ \\
\hline $\mathrm{M}(4 \mathrm{NPy}) \mathrm{TFPPH}_{2}$ & - & $-1,10$ & $-0,68$ & - & & - & $1,19^{\mathrm{a}}$ & 1,60 \\
\hline$\left[\mathrm{Ru}_{3} \mathrm{O}(\mathrm{Ac})_{6}(\mathrm{py})_{3}\right]$ & $-1,08$ & - & - & 0,19 & & 1,21 & & * \\
\hline$\left[\mathrm{Ru}(\mathrm{bpy})_{3}\right]$ & & & & & 1,05 & & - & - \\
\hline Supermolécula $1^{91}$ & $-1,22$ & $-1,08$ & $-0,72$ & $-0,11$ & & 1,14 & 1,14 & \\
\hline Supermolécula $2^{92}$ & & $-1,26$ & $-0,88$ & & 0,69 & & 1,37 & \\
\hline
\end{tabular}

Através de comparação com resultados obtidos para as unidades de montagem isoladamente $^{93}$, fez-se a atribuição tentativa dos processos redox da supermolécula $\left[\mathrm{M}(4-\mathrm{N}-\mathrm{Py}) \mathrm{TFFPH}_{2}\left\{\mathrm{Ru}_{3} \mathrm{O}(\mathrm{Ac})_{6}(\mathrm{py})_{2}\right\}\right] \mathrm{PF}_{6}\left(\mathrm{E}_{1 / 2}\right.$ vs EPH). Em -0,11V e -1,22V ocorrem dois processos de redução centrados no cluster $\left(\mathrm{Ru}^{\mathrm{III}}, \mathrm{Ru}^{\mathrm{III}}, \mathrm{Ru}^{\mathrm{III}} / \mathrm{Ru}{ }^{\mathrm{III}}, \mathrm{Ru}^{\mathrm{III}}, \mathrm{Ru}^{\mathrm{II}} / \mathrm{Ru}{ }^{\mathrm{III}}\right.$, $\left.\mathrm{Ru}^{\mathrm{II}}, \mathrm{Ru}^{\mathrm{II}}\right)$; em $-0,72 \mathrm{~V}$ e $-1,08 \mathrm{~V}$ ocorrem os dois processos de redução da porfirina, com formação dos radicais $\pi$-ânion e di-ânion. Em 1,14V, em função da relação das correntes $\mathrm{I}_{\mathrm{pa}} / \mathrm{I}_{\mathrm{pc}}$ pode estar ocorrendo processos acoplados: a oxidação do cluster $\mathrm{Ru}{ }^{\mathrm{III}}, \mathrm{Ru}^{\mathrm{III}}, \mathrm{Ru}^{\mathrm{III}} /$ $\mathrm{Ru}^{\mathrm{IV}}, \mathrm{Ru}^{\mathrm{III}}, \mathrm{Ru}^{\mathrm{III}}$ e a oxidação irreversível da porfirina, com a formação do radical $\pi$ cátion. Por fim, ocorre uma onda irreversível em $1,61 \mathrm{~V}$, atribuída à segunda oxidação da porfirina.

Comparando os valores de potenciais eletroquímicos de meia onda $\left(\mathrm{E}_{1 / 2}\right)$ da supermolécula com as unidades de montagem pode-se perceber que os potenciais de meia onda $\left(E_{1 / 2}\right)$ da supermolécula nos processos centrados no cluster estão deslocados para potenciais negativos, enquanto que os potenciais de meia onda nos processos $\mathrm{P}^{-/ 2-}$ e $\mathrm{P}^{2+/+}$ centrados na porfirina estão deslocados para potenciais mais positivos. Há uma perturbação eletrônica mutua. Pelo resultado da eletroquímica é possível inferir que, na 
díade, o cluster funciona como um aceitador de densidade eletrônica, portanto fica mais fácil oxidá-lo e mais fácil reduzir o núcleo porfirínico ${ }^{58,59}$.



Figura 69: Voltamogramas cíclicos de uma solução $1.10 \times 10^{-3} \mathrm{~mol}^{-L^{-1}}$ da díade $\left[\mathrm{M}(4-\mathrm{N}-\mathrm{Py}) \mathrm{TFFPH}_{2}\left\{\mathrm{Ru}_{3} \mathrm{O}(\mathrm{Ac})_{6}(\mathrm{py})_{2}\right\}\right] \mathrm{PF}_{6}$ em ACN. Eletrólito $0,10 \mathrm{~mol}^{-L^{-1}}$ de $\mathrm{TBAPF}_{6}$ em ACN.

Para a díade $\left[\mathrm{M}(4-\mathrm{N}-\mathrm{Py}) \mathrm{TFFPH}_{2}\left\{\mathrm{Ru}(\mathrm{bpy})_{2} \mathrm{Cl}\right\}\right] \mathrm{PF}_{6}$ também realizou-se a comparação dos resultados obtidos com as unidades de montagem isoladamente, fez-se a atribuição tentativa dos processos redox da supermolécula também com o auxilio dos potenciais redox de outras supermoléculas tais como a $\left[\mathrm{TPPH}_{2}\left\{\mathrm{Ru}(\mathrm{bpy})_{2} \mathrm{Cl}\right\}_{4}\right]^{4+} 45,46,50$.

Podem ser observados nos voltamogramas das Figura 70, pares de ondas quase reversíveis com os potenciais de redução em $-0,88$ e $-1,26$ V para a díade $\left[\mathrm{M}(4-\mathrm{N}-\mathrm{Py}) \mathrm{TFFPH}_{2}\left\{\mathrm{Ru}(\mathrm{bpy})_{2} \mathrm{Cl}\right\}\right] \mathrm{PF}_{6}$. Estes processos foram atribuídos à primeira e segunda redução monoeletrônica do anel porfirínico com formação dos radicais $\pi$-ânion e di-ânion, respectivamente $\mathrm{P}^{-/ 2-}$ e $\mathrm{P}^{0 /-}$. A onda reversível em 0,69 V foi atribuída ao par $\mathrm{Ru}^{3+/ 2+}$ do complexo de rutênio periférico. Para a tetrafenilporfirina substituída com quatro moléculas de $\mathrm{Ru}(\mathrm{bpy})_{2} \mathrm{Cl}\left[\mathrm{TPPH}_{2}\left\{\mathrm{Ru}(\mathrm{bpy})_{2} \mathrm{Cl}\right\}_{4}\right]^{4+}$, Koiti et all ${ }^{94}$ observou os potencias de redução da porfirina em $-0,93$ e $-0,68 \mathrm{~V}$ e o processo de oxidação do $\mathrm{Ru}(\mathrm{II}) \rightarrow \mathrm{Ru}(\mathrm{III})$ em 0,92 V. Comparando os valores dos potenciais de redução da supermolécula $\left[\mathrm{TPPH}_{2}\left\{\mathrm{Ru}(\mathrm{bpy})_{2} \mathrm{Cl}\right\}_{4}\right]^{4+} \quad$ com a supermolécula $\quad\left[\mathrm{M}(4-\mathrm{N}-\mathrm{Py}) \mathrm{TFFPH}_{2}\left\{\mathrm{Ru}(\mathrm{bpy})_{2} \mathrm{Cl}\right\}\right]$ percebe-se que todos os potenciais estâo deslocados para valores mais negativos. Assim 
comprova-se que a adição de grupo pentafluorofenil (receptor de elétron) remove a densidade eletrônica do anel porfirínico. No processo de oxidação do $\operatorname{Ru}(\mathrm{II}) \rightarrow \mathrm{Ru}(\mathrm{III})$ também é muito afetado, deslocado cerca de $0,3 \mathrm{~V}$ para potenciais mais negativos, a oxidação do $R u($ II $) \rightarrow R u(I I I)$ é muito facilitada, isto é indício de que, na díade, o complexo funciona como um aceitador de densidade eletrônica.

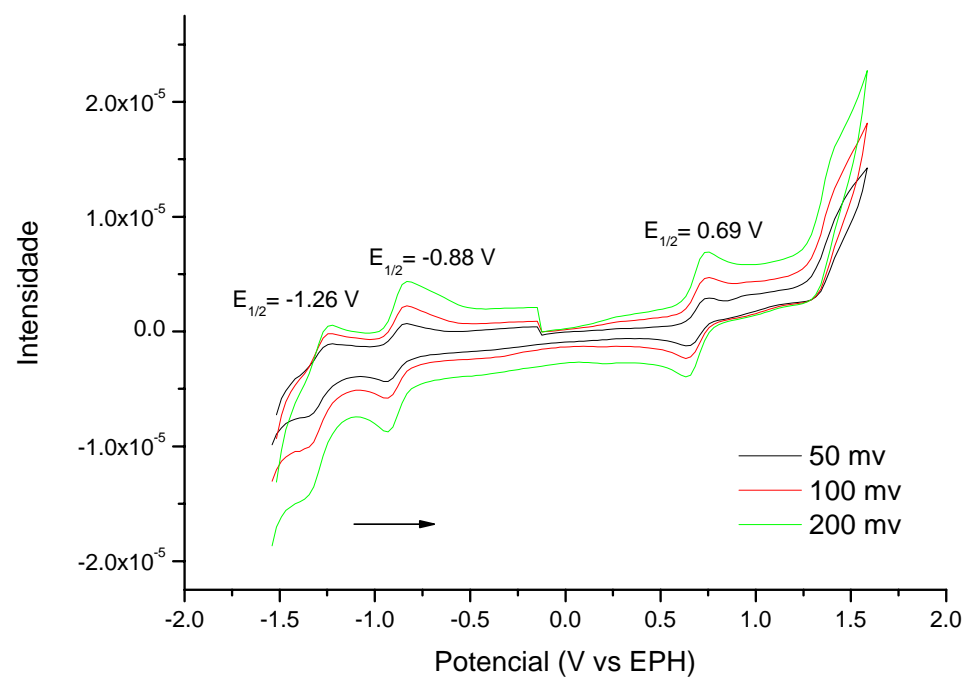

Figura 70: Voltamogramas cíclicos de uma solução $1.10 \times 10^{-3} \mathrm{~mol}^{-L^{-1}}$ da díade $\left[\mathrm{M}(4-\mathrm{N}-\mathrm{Py}) \mathrm{TFFPH}_{2}\left\{\mathrm{Ru}(\mathrm{bpy})_{2} \mathrm{Cl}_{\}}\right] \mathrm{PF}_{6}\right.$ em acetonitrila. Eletrólito $0,10 \mathrm{~mol}^{-\mathrm{L}^{-1}}$ de $\mathrm{TBAPF}_{6}$ em acetonitrila.

\section{IV.7) Ensaios Fotofísicos Preliminares}

Muitas moléculas orgânicas em seu estado fundamental estão em seu estado singlete. Quando uma molécula absorve energia radiativa (fóton), um elétron é excitado para um nível de maior energia, com o spin conservado. As porfirinas base-livre emitem intensamente quando excitadas em qualquer de suas bandas de absorção, mesmo à temperatura ambiente. Segundo a regra de $\mathrm{Kasha}^{95}$, a transição ocorrerá do estado excitado de menor energia para o fundamental. Além disso, o espectro de emissão apresenta duas bandas de fluorescência $\mathrm{Q}_{(0,0)}$ e $\mathrm{Q}_{(0,1)}$ em torno de 650 e $710 \mathrm{~nm}$ como pode ser visto na Figura 72, atribuídos às transições dos estados vibracionais 0 , do estado excitado, para o estado vibracional 0 e 1 , do estado fundamental. 


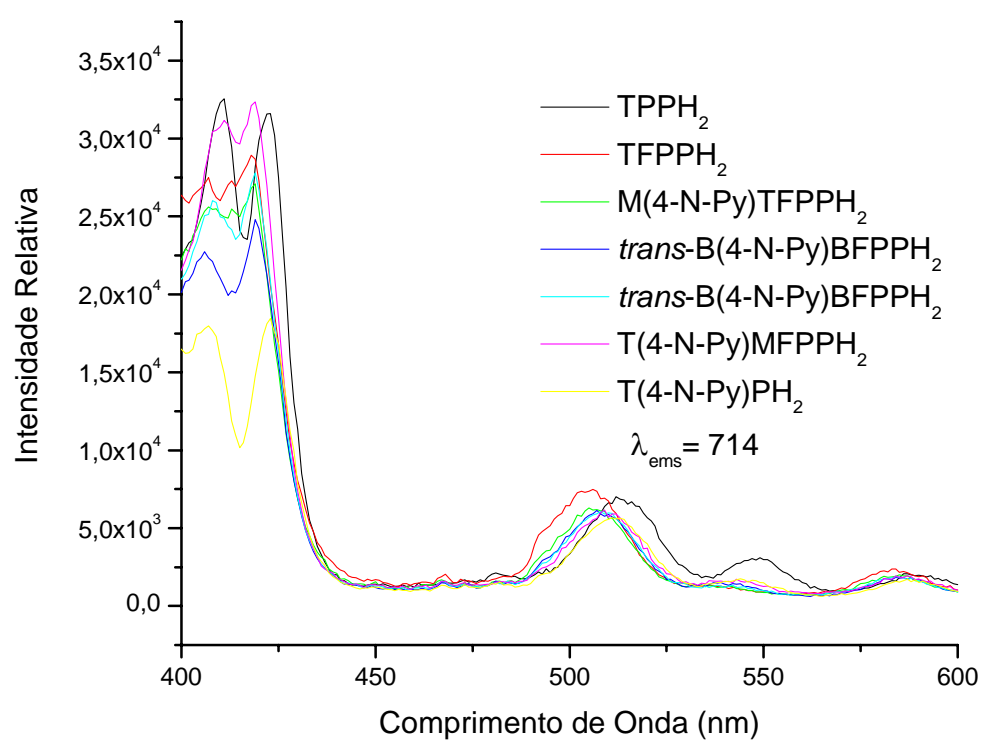

Figura 71: Espectro de excitação de uma solução com concentração de aproximadamente $1,0 \times 10^{-6} \mathrm{~mol} . \mathrm{L}^{-1}$ de porfirinas em DCM.

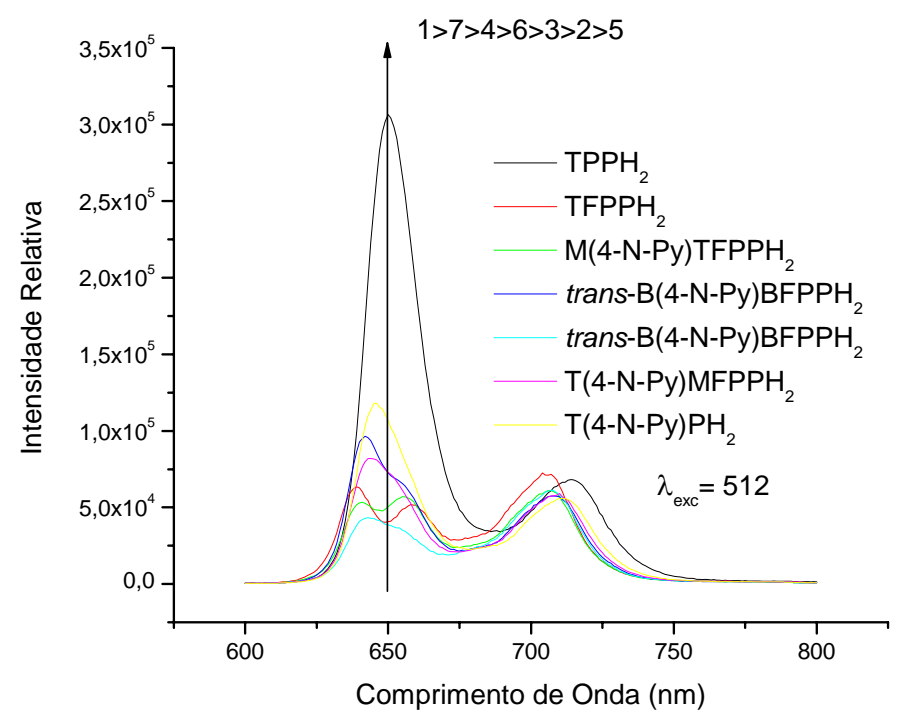

Figura 72: Espectro de emissão de uma solução com concentração de aproximadamente $1,0 \times 10^{-6}$ mol. $\mathrm{L}^{-1}$ de porfirinas em DCM

Em $650 \mathrm{~nm}$ junto com o aumento do número de grupos pentafluorofenil na porfirina, há a diminuição da intensidade de emissão de fluorescência, isto pode ser devido ao aumento do processo de desativação por processos não-radiativos do estado eletrônico singlete excitado. A porfirina $\mathrm{TPPH}_{2}$ que é aquela com simetria mais elevada e com menor 
número de átomos eletronegativos é a que possui maior rendimento quântico, por sua vez outra molécula com simetria elevada T-(4-N-Py) $\mathrm{PH}_{2}$ não tem o mesmo rendimento quântico do que a $\mathrm{TPPH}_{2}$. Já a $\mathrm{TFPPH}_{2}$ apresenta a mesma simetria que a $\mathrm{TPPH}_{2}$ e a $\mathrm{TPyPH}_{2}$, mas com a presença de quatro grupos substituintes pentafluorofenil, o que resulta em um rendimento quântico menor, assim percebe-se que o grupo pentafluorofenil tem uma maior influência na redução do rendimento quantico do que o grupo piridil das porfirinas. Uma situação intermediária ocorre na porfirina trans-B(4-N-Py)BFPPH porque esta porfirina é substítuida com dois grupos pentafluorofenil, dois grupos piridil e tem simetria elevada, como era o esperado o rendimento quântico de fluorêscencia seria entre as porfirinas $\mathrm{TFPPH}_{2}$ e a $\mathrm{TPyPH}_{2}$, mas ocorre que o rendimento quântico é ligeiramente maior que o da porfirina $\mathrm{TFPPH}_{2}$. As moléculas menos simétricas cis-B(4-NPy) $\mathrm{BFPPH}_{2}, \mathrm{~T}(4-\mathrm{N}-\mathrm{Py}) \mathrm{MFPPH}_{2}$ e $\mathrm{M}(4-\mathrm{N}-\mathrm{Py}) \mathrm{TFPPH}_{2}$ são aquelas que apresentam os menores rendimentos quânticos da série, a cis-B(4-N-Py) $\mathrm{BFPPH}_{2}$ por apresentar dois grupos substituintes pentafluorofenil e ter baixa simetria apresenta o menor rendimento quântico da série (Figura 72 e Tabela 15) ${ }^{96}$.

Tabela 15: Comprimento de onda e rendimento quântico das moléculas estudadas

\begin{tabular}{|c|c|c|c|c|}
\hline Molécula & $\mathrm{Q}(0,0)$ & $\mathrm{Q}(0,1)$ & $\mathrm{T}(0,0)$ & $\phi_{\mathrm{fl}}$ \\
\hline $\mathrm{TPPH}_{2}$ & 652.0 & 716.0 & & 0,099 \\
\hline $\mathrm{TFPPH}_{2}$ & 639.4 & 703.4 & & 0,045 \\
\hline $\mathrm{M}(4-\mathrm{N}-\mathrm{Py}) \mathrm{TFPPH}_{2}$ & 655.6 & 706.2 & & 0,041 \\
\hline trans-B(4-N-Py)BFPPH ${ }_{2}$ & 642.6 & 706.8 & & 0,046 \\
\hline cis-B(4-N-Py)BFPPH ${ }_{2}$ & 646.6 & 706.8 & & 0,035 \\
\hline $\mathrm{T}(4-\mathrm{N}-\mathrm{Py}) \mathrm{MFPPH}_{2}$ & 645.2 & 707.8 & & 0,043 \\
\hline$T(4-\mathrm{N}-\mathrm{Py}) \mathrm{PH}_{2}$ & 634.7 & 709.2 & & 0,051 \\
\hline Supermolécula 1 (Figura 21) & 652.0 & 705.0 & 770 & 0.0012 \\
\hline Supermolécula 2 (Figura 21) & 652.2 & 706.6 & 770 & 0.0027 \\
\hline Supermolécula 5 (Figura 21) & 647.5 & 709.2 & 770 & 0.0062 \\
\hline Supermolécula 6 (Figura 21) & 649.1 & 711.9 & 770 & 0.0061 \\
\hline
\end{tabular}


Quando submetidas à radiação ultravioleta, as porfirinas base livre apresentam intensa fluorescência vermelho-alaranjada, porém essa característica é perdida ou bastante diminuída quando elas são metaladas ou quando um composto que possui um metal pesado é coordenado a porfirina como exemplo: $\left[\mathrm{Ru}_{3} \mathrm{O}(\mathrm{Ac})_{6}(\mathrm{py})_{2}\right]^{+}$ou $\left.\left[\mathrm{Ru}(\mathrm{bpy})_{2} \mathrm{Cl}\right\}\right]^{+}$. Todas as porfirinas base livre, quando complexadas com íons diamagnéticos, mantêm a fluorescência, enquanto que os derivados paramagnéticos perdem esta característica. Isto explica porque, em porfirinas de zinco, cádmio, bário, magnésio entre outras ${ }^{97}$, se observa fluorescência, com intensidade menor e comprimento de onda diferente da porfirina base livre. O acompanhamento da diminuição da fluorescência é muito importante, pois através dele o processo de metalação ou da coordenação de $\left[\mathrm{Ru}_{3} \mathrm{O}(\mathrm{Ac})_{6}(\mathrm{py})_{2}\right]^{+}$ou $\left[\mathrm{Ru}(\mathrm{bpy})_{2} \mathrm{Cl}\right]^{+}$ pode ser facilmente monitorado pela retirada de uma alíquota do meio de reação, submetendo a amostra a uma rápida separação por cromatografia de camada delgada (CCD) e expondo a placa de CCD a uma lâmpada com emissão de luz ultravioleta. A diferença de fluorescência com uma amostra de controle da porfirina base livre é bem pronunciada durante o processo de metalação.

Os espectros de excitação das porfirnas são muito semelhantes aos espectros UVVísivel, mas com uma pequena diferença. No espectro de excitação (Figura 71) é possível observar uma banda em torno de $410 \mathrm{~nm}$, cuja diferença de energia em relação à banda Soret é próxima de $1250 \mathrm{~cm}^{-1}$ da banda Soret $(423 \mathrm{~nm}) \mathrm{B}_{(0,0)}$ e é atribuída ao primeiro componente vibracional da banda Soret $\mathrm{B}_{(1,0)}$.

As Figura 73 e Figura 74 mostram os espectros de excitação e emissão para as díades $\left[\mathrm{M}(4-\mathrm{N}-\mathrm{Py}) \mathrm{TFFPH}_{2}\left\{\mathrm{Ru}_{3} \mathrm{O}(\mathrm{Ac})_{6}\left(\mathrm{py}_{2}\right\}\right] \mathrm{PF}_{6}\right.$ e para a díade [M(4-N-Py)TFFPH $\mathrm{H}_{2}$ $\left\{\mathrm{Ru}(\mathrm{bpy})_{2} \mathrm{Cl}\right\} \mathrm{PF}_{6}$. As duas díades apresentam as duas bandas de emissão típicas, centradas em $649 \mathrm{~nm}$ e em $708 \mathrm{~nm}$, que correspondem aos dois componentes vibracionais da emissão. Há o aparecimento de uma banda de intensidade fraca em $770 \mathrm{~nm}$, esta banda pode ser visualizada nas porfirinas em experimentos realizados a baixa temperatura, pois ela é atribuída a uma banda de fosforescência $T_{(0,0)}$.

A coordenação do cluster $\left[\mathrm{Ru}_{3} \mathrm{O}(\mathrm{Ac})_{6}(\mathrm{py})_{2}\right]^{+}$e do complexo $\mathrm{Ru}(\mathrm{bpy})_{2} \mathrm{Cl}^{+}$suprime parcialmente a fluorescência da porfirina. O mecanismo de supressão pelo cluster pode ser devido à reabsorção de energia, pois o cluster apresenta uma banda de absorção em 690 $\mathrm{nm}$ entre as bandas de emissão da porfirina $(650 / 710 \mathrm{~nm})$, ou ainda pode estar ocorrendo 
uma transferência de elétrons ou energia da porfirina para o cluster. Porém, há exemplos na literatura nos quais o cluster suprime a fluorescência do complexo $\left[\mathrm{Ru}(\mathrm{bpy})_{3}\right]^{2+}$ pelo mecanismo de transferência de energia e para a $\mathrm{Zn}$ porfirina o cluster suprime a fluorescência pelo mecanismo de transferência de elétrons ${ }^{98}$. No caso do cromóforo $\mathrm{Ru}(\mathrm{bpy})_{2} \mathrm{Cl}$ há a possibilidade do estado singleto da porfirina transferir energia para o estado excitado $\mathrm{MLCT}^{3}$ do complexo $\mathrm{Ru}(\mathrm{bpy})_{2} \mathrm{Cl}$, uma vez que é conhecido na literatura que este estado tem uma energia $(\lambda \mathrm{em}=650)^{99}$ similar à emissão das porfirina. No caso particular do estado excitado $\mathrm{MLCT}^{3}$ do complexo $\mathrm{Ru}(\mathrm{bpy})_{2} \mathrm{Cl}$, este pode ser suprimido por um estado d-d de baixa energia, que decai vibracionalmente ${ }^{100}$. Há ainda a possibilidade da diminuição do rendimento quântico de fluorescência (Tabela 15) ocorrer devido à introdução de átomos pesados (complexos periféricos), então, isto favoreceria o cruzamento inter-sistemas e o processo de fosforescência à temperatura ambiente.

$\mathrm{O}$ espectro de excitação das díades é muito semelhante ao da porfirina M(4-NPy) $\mathrm{TFFPH}_{2}$.

As Figura 75 e Figura 76 mostram os espectros de excitação e emissão para as tríades cis- e trans-[B(4-N-Py)BFFPH $\left.2\left\{\mathrm{Ru}_{3} \mathrm{O}(\mathrm{Ac})_{6}(\mathrm{py})_{2}\right\}\left\{\mathrm{Ru}(\mathrm{bpy})_{2} \mathrm{Cl}\right\}\right]\left(\mathrm{PF}_{6}\right)_{2}$. As duas tríades apresentam as duas bandas de emissão típicas, centradas em $\lambda=648 \mathrm{~nm}$ e em 710 $\mathrm{nm}$. Há o aparecimento de uma banda de intensidade fraca em $770 \mathrm{~nm}$, esta banda pode ser visualizada nas porfirinas em experimentos realizados a baixa temperatura, pois ela é atribuída a uma banda de fosforescência $\mathrm{T}_{(0,0)}$.

Os estudos de luminescência mostraram que a introdução de grupos modificadores suprimem a emissão da porfirina. Isto contradiz o sistema proposto em que o complexo $\mathrm{Ru}(\mathrm{bpy})_{2} \mathrm{Cl}^{+}$funcionaria como uma unidade doadora, a porfirina como um cromóforo emissor e o cluster com um aceptor final. Os dados fotofísicos mostram que as duas unidades ligadas às porfirinas $\mathrm{M}(4-\mathrm{N}-\mathrm{Py}) \mathrm{TFPPH}_{2}$, cis- e trans- $\mathrm{B}(4-\mathrm{N}-\mathrm{Py}) \mathrm{BFPPH}_{2}$ estão atuando como aceptores de carga. A separação de carga na tríade assimétrica contendo a porfirina ligada a um complexo $\mathrm{Ru}(\text { bpy })_{2} \mathrm{Cl}^{+}$e ao cluster $\left[\mathrm{Ru}_{3} \mathrm{O}(\mathrm{Ac})_{6}(\text { py })_{2}(\mathrm{~L})\right]^{\mathrm{n}}$ fica impossibilitada. 


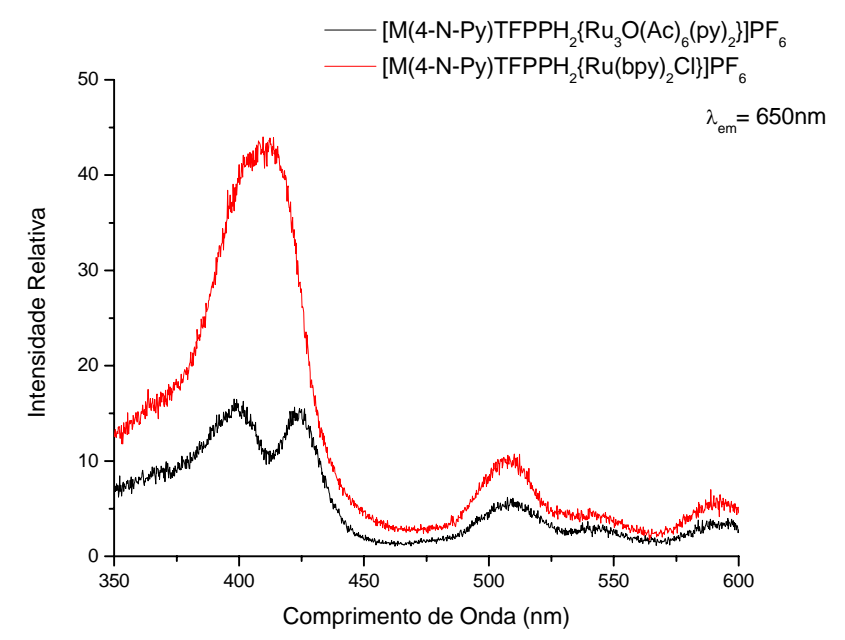

Figura 73: Espectro de excitação das soluções das díades com concentração de aproximadamente $1,0 \times 10^{-6} \mathrm{~mol} . \mathrm{L}^{-1} \mathrm{em}$ DCM.

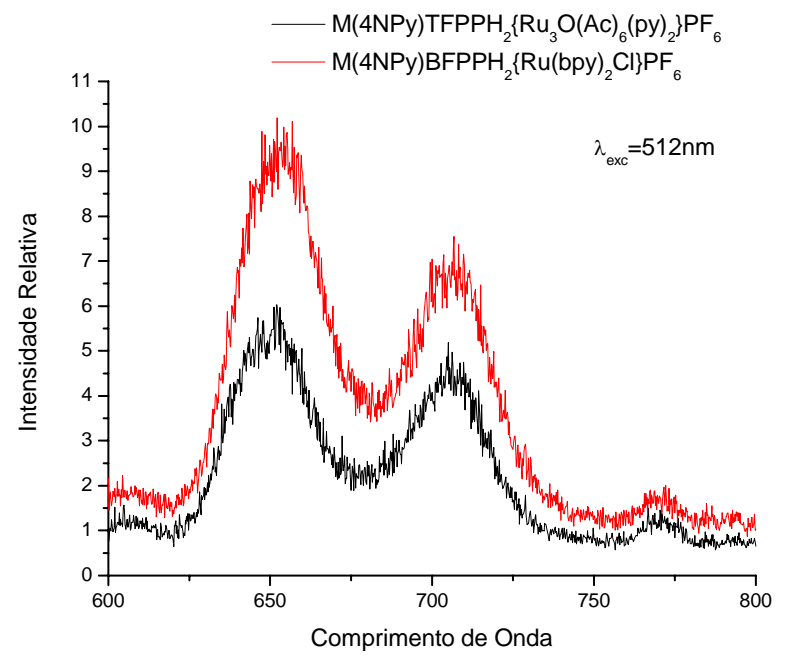

Figura 74: Espectro de emissão das soluções das díades com concentração de aproximadamente $1,0 \times 10^{-6} \mathrm{~mol} . \mathrm{L}^{-1} \mathrm{em}$ DCM.

A supressão da fluorescência pode ser vista nos espectros de emissão das supermoléculas apresentadas nas Figura 74 e Figura 76, para os cálculos de rendimento quântico utilizou-se com padrão a $\mathrm{TPPH}_{2}$, que tem um rendimento quântico de $0,099 \mathrm{em}$ DCM. 


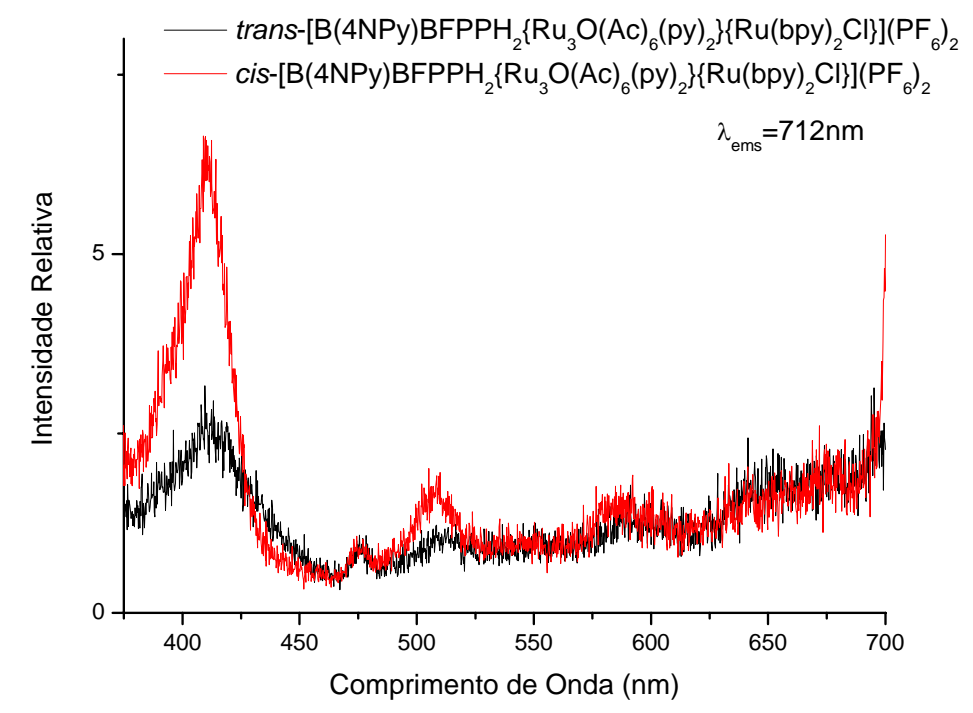

Figura 75: Espectro de excitação das soluções das tríades com concentração de aproximadamente $1,0 \times 10^{-6} \mathrm{~mol} . \mathrm{L}^{-1} \mathrm{em}$ DCM.



Figura 76: Espectro de emissão das das soluções das tríades com concentração de aproximadamente $1,0 \times 10^{-6}$ mol. $\mathrm{L}^{-1} \mathrm{em}$ DCM. 


\section{V - Considerações Finais}

A síntese das porfirinas pentafluorosubstituídas já é de domínio do grupo. Esta síntese é de fácil realização e não exige condições especiais. Com a modificação na proporção dos aldeídos utilizados pode-se observar a formação da porfirina $\mathrm{T}(4-\mathrm{N}$ Py) $\mathrm{MFPPH}_{2}$. A maior dificuldade era com a purificação das porfirinas, pois há a formação de outras espécies que não são de interesse deste projeto. Um grande avanço obtido foi a pré-purificação feita utilizando EtOH. Isto possibilitou a obtenção das porfirinas em um menor tempo e com menores gastos de reagentes. A síntese das tríades propostas foi bem sucedida. A caracterização das supermoléculas e das porfirinas confirmaram as estruturas propostas. Com relação às tríades trans- e cis-[B(4-N-Py) $\mathrm{BFPPH}_{2}\left\{\mathrm{Ru}_{3} \mathrm{O}(\mathrm{Ac})_{6}(\mathrm{py})_{2}\right\}$ $\left.\left\{\mathrm{Ru}(\mathrm{bpy})_{2} \mathrm{Cl}\right\}\right]\left(\mathrm{PF}_{6}\right)_{2}$ não foi possivel realizar experimentos de $\mathrm{RMN}{ }^{1} \mathrm{H},{ }^{19} \mathrm{~F}$ e COSY devido à pequena quantidade obtida na sintese. Mas os experimentos de massa ESI-MS e ESI MSMS comprovam a estrutura das moléculas. Os dados de espectroscopia eletrônica mostram que os espectros, de um modo geral, representam apenas uma somatória do perfil espectral dos componentes, não sugerindo comunicação eletrônica. No entanto, os deslocamentos dos potenciais eletroquímicos dos processos redox das supermoléculas em relação aos componentes isolados indicam que, embora pequena, a comunicação eletrônica existe e não é negligenciável. Além disso, os ensaios de luminescência mostraram que, a introdução de grupos modificadores suprimem a emissão da porfirina. Isto contraria a proposta inicial do projeto em que o complexo $\mathrm{Ru}(\mathrm{bpy})_{2} \mathrm{Cl}^{+}$funcionaria como uma unidade doadora, a porfirina como um cromóforo emissor e o cluster como um aceptor final. Os dados fotofísicos preliminares estão mostrando que as duas unidades ligadas às porfirinas $\mathrm{M}(4-\mathrm{N}-\mathrm{Py}) \mathrm{TFPPH}_{2}$, cis- e trans- $\mathrm{B}(4-\mathrm{N}-\mathrm{Py}) \mathrm{BFPPH}_{2}$ estão atuando como aceptores final de carga. Sendo assim, a separação de carga em uma tríade assimétrica contendo a porfirina ligada a um complexo a $\mathrm{Ru}(\mathrm{bpy})_{2} \mathrm{Cl}^{+}$e ao cluster $\left[\mathrm{Ru}_{3} \mathrm{O}(\mathrm{Ac})_{6}(\mathrm{py})_{2}(\mathrm{~L})\right]^{\mathrm{n}}$ fica comprometida. 


\section{VI - Referências}

1) Little, R.G.; J. Heterocyclic Chem, 1981, 18, 129.

2) Falk, J.E; in "Porphyrins and Metalloporphyrins" ; B.B. Library, London, 1964.

3) Wagner, R.W.; Lindsey.J.S.; J. Am. Chem. Soc., 1994, 261, 897.

4) Gryko, D.T.; Clausen, C.: Roth, K.M.; J. Org. Chem., 2000, 65, 7345.

5) Zhang, X.Q.; Wu,H.M.; Chen,Z.P.; Solid State Commun., 1995, 95(2), 91.

6) Zhang, X.Q.; Wu,H.M.; Wu, X.J.; J. Mater. Chem., 1995, 5(3), 401.

7) Duncan, T.V.; Susumu, K.; Sinks, L.E.; Therien, M.J., J. Am. Chem. Soc., 2006, 128(28), 9000.

8) Vinhado, F.S.; Prado- Manso, C.M.C.; Sacco, H.C.; Iamamoto, Y.; J. Mol. Catal. AChe., 2001, 174 (1-2), 279.

9) Vinhado, F.S.; Martins, P.F.; Iamamoto, Y.; Top. Catal., 2002, 3, 199.

10) Evans, S.; Smith, J. R. L.; J. Chem. Soc., Perkin Trans. 2, 2000, 1541.

11) Evans, S.; Smith, J. R. L.; J. Chem. Soc., Perkin Trans. 2, 2001, 174.

12) Benedito, F. L.; Nakagaki, S.; Saczk, A. A.; Zamora, P. G. P.; Costa, C. M. M.; Appl Catal A, 2003, (1), 1.

13) Smith, K.M; in "Porphyrins and Metalloporphyrins"; ed. K.M. Smith, Elsevier Amsterdam, 1975.

14) Kain, W., Schwederski, B., in "Bioinorganic Chemistry: Inorganic Elements in the Chemistry of Life", John Wiley \& Sons, New York, 1994.

15) Levy, J.G.; Trends Biotechnol, 1995, 13, 14.

16) Rothemund, P. J.; J. Am. Soc., 1939, 61 , 2912.

17) Ball, R. H.; Dorough, G. D.; Calvin, M.; J. Am. Soc.,1946, 68, 2278.

18) Badger, G. M.; Jones, R.A.; Laslett, R. L.; Aust. J. Chem.,1964, 17, 1028.

19) Adler, A. D.; Longo, F. R.; Shergalis, W.; J. Am. Chem. Soc. 1964, 86(15), 3145.

20) Lindsey, J. S.; Schreiman, I. C.; Hsu, H. C.; Kearney, P. C.; J. Org.Chem.,1987, 52, 827.

21) Wijesekera, T.P.; Dolphin, D.; in "Metalloporphyrins in Catalytic Oxidations", Ed.

R.A. Sheldon, Marcel deker Inc., New York, cap.7, 1994.

22 ) Geiger G.R., Litter, B.J.; Lindsey, J.S., J. Chem. Soc. Perkin 2, 2001, 5, 701.

23) Baker, E. W.; Palmer, S. E.; in “The porphyrins”, ed. Dolphin D. 1, Acad. Press New York, 485, 1978.

24) Groves , J. T., McMurray, T. J.; in "Citocrome P-450, Struture, Mechanism and Biochemistry”, Ed. Plenum.Press, New York, 1986.

25) Milgrom, L. R., in "The colours of Life", Oxford, New York, 1997, 85.

26) Adler, A. D.; Longo, F. R.; Finarelli, J.D.; Goldmacher, J.; Assour, J.; Korsakoff, L;. J. Org. Chem.1967, 32, 476.

27) Buchler, J. W.; in "Porphyrins and Metalloporphyrins", ed. Smith, K. M. , Elservier Amsterdam, cap.5, 1965.

28) Schiavon, M. A.; Iamamoto. Y.; Nascimento, O. R.; Assis, M. D.; J. Mol. Catal. A: Chem. 2001,113, 279.

29) Vinhado, F.S.; Martins, P. R.; Masson, A. P.; Abreu, D.G.; Vidoto, E. A.; Nascimento,

O. R; Iamamoto, Y.; J. Mol. Catal. A: Chem. 2002, 188, 141. 
30) Mansuy, D. C.R. Chimie, 2007, 10, 1.

31) Melo, A.J.B.; Iamamoto, Y.; Maestrin, A.P.J.; Smith, J.R.L.; Santos, M. D.; Lopes, N.P.; Bonato, P.S.; J. Mol. Catal. A-Che., 2005, 226 (1), 23.

32) Gotardo, M.C.A.F.; De Moraes,L.A.B.; Assis, M.D.; J. Agric. Food Chem. 2006, 54, 10011.

33) Gouterman, M; in " The Porphyrins" ed. Dolphin D., vol III, part A, 1, New York, Academic Press, 1978.

34) http://www.wuacc.edu/cas/chemistry/sleung/porphyrin/uv-vis.gif

35) Gouterman, M.; J. Mol. Spectrosc. 1961, 6, 138

36) Gouterman, M.; J. Chem. Phys. 1959, 30, 1139.

37) Seybol, P.G.;Goutermann M.; J. Mol. Spec. 1969, 31, 1.

38) Goutermann, M.; Khalil, G.E.; J. Mol. Spec. 1974, 53, 88.

39) Balzani, V.; Scandola, F.; Supramolecular Chemistry, Ellis Horword Limited, cap2, 1991.

40) Kalyanasundaram,K.; J. Chem. Soc., Faraday Trans. 2, 1983,79, 1365.

41) Toma H. E., Araki K., Alexiou A. D. P., Nikolaou S., Dovidauskas S., Coord. Chem. Rev., 2001, 219(21), 187.

42) Toma, H. E.; Araki K., Coord. Chem. Rev, 2000, 196, 307.

43) a) Araki K., Dovidauskas S., Winnischofer H., Alexiou A. D. P., Toma H. E., J. Electroanal. Chem., 2001, 498, 152; b) Dovidauskas S., Araki K., Toma H. E., J. Porphyr Phthalocya, 2000, 4, 727; c) Dovidauskas S., Toma H. E., Araki K., Sacco H. C., Iamamoto Y., Inorg. Chim. Acta, 2000, 305, 206; d) Toma H. E., Araki K., Silva E. O., Monatsh. Chem., 1998, 129, 975; e) Winnischofer, H.; Otake, V.Y.; Dovidauskas, S.; Nakamura, M.; Toma, H.E.; Araki, K.; Electrochim Acta, 2004, 22-23, 3711.

44) Araki, K.; Winnischofer, H.; Viana, H.E.B.; Toyama, M.M.; Engelmann, F.M.; Mayer, I.; Formiga,A.L.B.; Toma,H.E.; J. Electroanal. Chem., 2004, 2,145.

45) Marek, D.; Narra, M.; Schneider, A.; Swavey, S.; Inorg. Chim. Act., 2005, 358,3430.

46) Narra, M.; Elliot, P.; Swavey, S.; Inorg. Chim. Act., 2005, 358,3430.

47) Araki, K.; Araújo, A.L.; Toyama, M.M.; Franco, M.; Azevedo, C.M.N.: Angnes, L.; Toma, H.E.; J. Porphyr Phthalocya, 1998, 2, 467.

48) Engelmann, F.M.; Losco, P.; Winneschofer, H.; Araki, K.; Toma, H.E.; J. Porphyr Phthalocya, 1998, 2, 467.

49) Santos. F.S.; Santos M.L.; Almeida, L.E.; Costa Jr, N.B.; Gimenez, I.F.; Araki,K.; Mayer,I.; Engelmann, F.M.; Toma,H.E.;Barreto, L.S.; J. Colloid. Inter. Sci., 2007, 305, 264.

50) Kon, H.; Tsuge, K.; Imamura, T.; Sasaki, Y.; Ishizaka, S.; Kitamura, N.; Inorg. Chem. 2006, 45, 6875.

51) a) Spyroulias, G. A.; Despotopoulos, A. P.; Raptopoulou, C. P.; Terzis, A.; Montauzon, D.; Poilblanc, R.; Coutsolelos, A. G., Inorg. Chem.,2002, 41, 2648.; b) Sun, H.; Smirnov, V. V.; DiMagno, S. G., Inorg. Chem.,2003, 42, 6032.

52) Kadish, K. M.; Lin, M.; Van Caemlelbexhi, E.; De Stefano, G.; Medforth, C. J.; Nurco, D. J.; Nelson, N. Y.; Krattinger, B.; Muzzi, C. M.; Jaquinod, L.; Xu, Y.; Shyr, D. C.; Smith, K. M.;Shelnutt, J. A., Inorg. Chem., 2002, 41, 6673.

53) Lin, C.-L.; Fang, M.-Y.; Cheng, S.-H., J. Electroanal. Chem.,2002, 531, 155.

54) Kadish, K. M.; Kelly, S., Inorg. Chem., 1982, 21, 3631. 
55) Ozette, K.; Battioni, P.; Leduc, P.; Bartoli, J-F.; Mansuy, D., Inorg. Chim. Acta, 1998, 272, 4.

56) Nango, M.;Takami Hikita, T.; Nakano, T.; Yamada, T.; Nagata, M.; Kurono Y.; Ohtsuka, T., Langmuir, 1998, 14, 407.

57) Dovidauskas S; Araki K; Toma HE; J. Porphyr Phthalocya, 2000, 4 (8), 727.

58) Otake M; Itou M; Araki Y; Ito O; Kido H; Inorg. Chem., 2005, 44 (23), 8581.

59) Itou M; Otake M; Araki Y; Ito O; Kido H; Inorg. Chem., 2005, 44 (5), 1580.

60) a) Bergonzi R., Fabrizzi L., Licchelli M., Mangano C., Coord. Chem. Rev., 1998, 170, 31; b) Belser P., Bernhard S., Blum C., Beyeler A., de Cola L., Balzani V., Coord. Chem. Rev., 1999, 190, 155.

61) Baumann, J. A.; Salmon, D.J.; Wilson, S.T.; Meyer, T.J.; Hatfield, W.E.; Inorg. Chem., 1978, 17(12), 3342.

62) Sullivan, B. P.; Salmon, D. J.; Meyer, T. J.; Inorg. Chem., 1978, 17(12), 3334.

63) Engelmann, F.M.; "Caracterização de Complexos Supramoleculares de Meso(fenilpiridil)porfirinas e suas Propriedades Fotofísicas e Fotoquímicas.", Dissertação de Mestrado, IQ, USP, São Paulo, 2001.

64) SMART V 5.050 (NT) Software for the CCD Detector System; Bruker Analytical Xray Systems, Madison, WI 1998.

65) SAINT V 5.01 (NT) Software for the CCD Detector System Bruker Analytical X-ray Systems, Madison, WI 1998.

66) Sheldrick, G. M.; SHELXS-97, Program for the Solution of Crystal Structure, University of Göttingen, Germany 1997.

67) Sheldrick, G. M.; SHELXL-97, Program for the Refinement of Crystal Structure, University of Göttingen, Germany 1997.

68) SHELXTL 5.10 (PC-Version), Program library for Structure Solution and Molecular Graphics; Bruker Analytical X-ray Systems, Madison, WI 1998.

69) Riul, P.; "Síntese, Caracterização e Atividade Catalítica da Ferroporfirina Metilpiridiltripentafluorofenil Substituída", Dissertação de Mestrado, FFCLRP, USP, Ribeirão Preto, 1998.

70) Ner, M. M.; Adler, A. D.; J. Am. Chem. Soc. 1975, 97, 5107.

71) Subramanian, J.; "Porphyrins and Metalloporphyrins”,, Ed. K.M. Smith, Elservier Scientific Publising Company, Amsterdan , 1975, 571.

72) Araki K.; Dovidauskas S.; Winnischofer H.; Alexiou A. D. P.; Toma H. E.; J. Electroanal. Chem., 2001, 498, 152.

73) Meng, G.Z.G.; James, B.R.; Skov, K.A.; Can. J. Chem., 1994, 72, 1894.

74) Leanord, D.R.; Smith, J.R.L.; J. Chem. Soc., Perkin Trans. 1990, 2, 1917.

75) Birnbaum, E.R.; Hodge, J.A.; Grinstaff, M.W.; Schaefer, W.P.; Henling, L.; Labinger, J.A.; Bercaw, J.E.; Gray, H.B.; Inorg. Chem., 1995, 34, 3625.

76) Nikolaou, S.; "Desenvolvimento de Estruturas Polinucleares Baseadas em Clusters Trinucleares e Complexos Poliimínicos de Rutênio: unidades de montagem em Química Supramolecular.", Tese de Doutorado, IQ, USP, São Paulo, 2002.

77) Bertini, I.; Luchinat, C.; Coord. Chem. Rev., 1996, 150,1.

78) Nikolaou, S.; Uemi, M.; Toma, H. E. Spectrosc. Lett. 2001, 34, 267.

79) Maruyama, M.; Matsuzawa, H.; Kaizu, Y. Inorg. Chim. Acta. 1995, 237, 159. 
80) Silverstein, R. M.; Bassler, G. C.; Morril, T. C.; in "Spectroscopic Identification of Or ganic Compounds”, John Wiley \& Sons, Inc, 5ed, 1991.

81) Baladan, T. S.; Eichöfer; Lehn, J. M. Eur.; J. Org. Chem. 2000, 24, 4047.

82) Nakash, M.; Clyde-Watson, Z.; Feeder, N.; Teat, S. J.; Sanders, J. K. M; Chem. Eur. J. 2000, 6, 2112.

83) Cole, R.B.; in "Electrospray Ionization Mass Spectroscopy"; John Wiley \& Sons Inc.: New York, 1997.

84) (a) Cooks, R.G.; Zhang, D.X.; Koch, K.J.; Gozzo, F.C.; Eberlin, M.N.; Anal. Chem. 2001, 73, 3646. (b) Koch, K.J.; Gozzo, F.C.; Nanita, S.C.; Takats, Z.; Eberlin, M.N.; Cooks, R.G.; Angew. Chem. Int. 2002, 41, 1721.

85) (a) Colton, R.; Dagostino, A.; Traeger, J. C.; Mass Spectrom. Rev. 1995, 14, 79. (b) Johnson, B.F.G.; McIndoe, J.S.; Coord. Chem. Rev. 2000, 200, 901. (c) Fuerstenau, S.D.; Benner, W.H.; Thomas, J.J.; Brugidou, C.; Bothner, B.; Siuzdak, G.; Angew. Chem. 2001, 40, 542. (d) Tomazela, D.M.; Gozzo, F.C.; Ebeling, G.; Dupont, J.; Eberlin, M.N.; Inorg. Chim. Acta 2004, 357, 2349. (e) Pereira, R.M.S.; Paula, V.I.; Buffon, R.; Tomazela, D.M.; Eberlin, M.N.; Inorg. Chim. Acta. 2004, 357, 2100. (f) Demicheli, C.; Ochoa, R.; Lula, I.S.; Gozzo, F.C.; Eberlin, M.N.; Frézard, F.; Appl Organomet Chem. 2003, 17, 226.

86) (a) Hilderling, C.; Adlhart, C.; Chen, P.; Angew. Chem. Int. 1998, 37, 2685. (b) Sabino, A.A.; Machado, A.H.L.; Correia, C.R.D.; Eberlin, M.N.; Angew. Chem. Int. 2004, 43, 2514. (c) Meyer, S.; Koch, R.; Metzger, J.O.; Angew. Chem. Int. 2003, 42, 4700. (d) Gerdes, G.; Chen, P.; Organometallics 2003, 22, 2217.

87) Medeiros, M.A.C.; "Sistemas Supramoleculares para Estudo de Transferência de Elétrons Fotoinduzida". Dissertação de Mestrado, FFCLRP, USP, Ribeirão Preto, 1994.

88 (a) Bottomley, L.A.; Kadish, K.; Inorg. Chem. 1981, 20, 1348. (b) Constant; L.A.; Davis, D.G.; Anal. Chem. 1975, 476, 2253. (c) Chen, F.C.; Cheng, S-H.; YU, C-H.; Liu, M-H.; Su, Y. O.; Journal of Eletroanalytical Chemistry 199, 52, 474 . (d) Ozette, K.; Battioni, P.; Leduc, P.; Bartoli, J.F.; Mansuy, D.; Inorg. Chim. Acta. 1998, 272, 4.

89) Peychal-Heiling, G; Wilson, G.S.; Anal. Chem., 1971,43, 550.

90) Friedermann, G.R.; "Estudo de porfirinas base livre e seus derivados de manganês por eletroquímica e espectro-eletroquímica de RPE e UV-Vis." Tese de doutorado, DQUFPR, 2005.

91) Nikolaou, S.; Toma, H. E.; J. Chem. Soc., Dalton Trans., 2002, 352.

92) Brown, G. M.; Weaver, T. R.; Keene, F.R.; Meyer, T..J.; Inorg. Chem., 1976, 15(1), 190.

93) Dovidauskas, S.; "Química Supramolecular de Porfirino Cluster" Tese de Doutorado, IQ, USP, São Paulo, 2001.

94) Araki K., Toma, H. E.; J.Coord. Chem,1993, 30(1), 9.

95) Hochstrasser, R. M.; Kasha, M. Photochem. Photobiol.1964, 3, 317.

96) Shi, Y.; Zheng, W.; Li Z.; Wang, X.; Wang, D.; Qiu, S.; Li, X.; Opt. Mater, 2006, 28, 1178.

97) Allison, J.B.; Becker, R.S., J. Chem. Phys., 1960, 32, 1410.

98) Wall, M. H.; Akimoto, S. ; Yamazaki, T.; Ohta, N. ; Yamazaki, I. ; Sakuma, T. ; Kido H.;, Bull. Chem. Soc. Jpn., 199, 72, (1), 475.

99) Pinnick, D. V.; Durham, B. ;Inorg. Chem. 1984, 23, 1440. 
100) Juris, A., Balzani, V., Barigelletti, F., Campagna, S., Belser, P.; Vonzelewsky, A.; Coord. Chem. Rev., 1988, 84, 85. 